Portland State University

PDXScholar

$12-16-2021$

\title{
Emotional Intelligence and Resonant Leadership: Investigating School Principals' Preparation and Professional Development in Response to Covid-19 and Other Challenges
}

Ashlie Kaye Miller

Portland State University

Follow this and additional works at: https://pdxscholar.library.pdx.edu/open_access_etds

Part of the Educational Leadership Commons, and the Elementary and Middle and Secondary Education Administration Commons Let us know how access to this document benefits you.

\section{Recommended Citation}

Miller, Ashlie Kaye, "Emotional Intelligence and Resonant Leadership: Investigating School Principals' Preparation and Professional Development in Response to Covid-19 and Other Challenges" (2021). Dissertations and Theses. Paper 5865.

https://doi.org/10.15760/etd.7736

This Dissertation is brought to you for free and open access. It has been accepted for inclusion in Dissertations and Theses by an authorized administrator of PDXScholar. Please contact us if we can make this document more accessible: pdxscholar@pdx.edu. 
Emotional Intelligence and Resonant Leadership:

Investigating School Principals' Preparation and Professional Development

in Response to Covid-19 and Other Challenges

by

Ashlie Kaye Miller

A dissertation submitted in partial fulfillment of the requirements for the degree of

Doctor of Education

in

Educational Leadership: Administration

Dissertation Committee:

Dilafruz Williams, Chair

Christopher Borgmeier

Patrick Burk

Phillip Pearson

Portland State University

2021 
(C) 2021 Ashlie Kaye Miller 


\begin{abstract}
Research has shown that high levels of emotional intelligence and resonant leadership can reduce workplace stress and increase the health, wellness, satisfaction, and performance of employees. Many K-12 principals face a myriad of challenges that tend to produce chronic stress, including the recent Covid-19 pandemic. Yet, it is unclear how the preparation and professional development (PPD) programs available to principals incorporate and encourage resonant leadership practices that are needed to effectively cope with these challenges. This study used an explanatory sequential mixed methods design to examine the perceptions of $\mathrm{K}-12$ principals in Oregon regarding: (a) their needs and challenges, especially during Covid-19; (b) whether and how principal PPD programs incorporate emotional intelligence and resonant leadership practices; and (c) the effectiveness of principal PPD programs in addressing the challenges principals experience. Data were collected in two phases: Phase 1 focused on quantitative data collection with a validated survey; Phase 2 focused on qualitative data collection through interviews of a representative sample of principals, as well as a document review process to explore the PPD opportunities available to the interviewed principals. The results indicated that principals in Oregon need PPD training in all dimensions of emotional intelligence. Furthermore, the PPD that was available to some did not adequately prepare principals to manage the stress and emotions of their positions. Recommendations are made for both preparation programs and the on-going professional development of $\mathrm{K}-12$ principals.
\end{abstract}




\section{Dedication}

This work is dedicated to all the selfless educators and administrators out there who need a bit more balance in their lives. Thank you for being so devoted to always doing your best for your students, your staff, and your communities. I hope you will also devote some time to yourselves so that you can retain your resonance and continue to impact your schools and communities in positive ways! 


\section{Acknowledgements}

First, I would like to acknowledge the sacrifices made by my family — my children, Chayse and Aysha, and my husband, Brandon - to help me finish this dissertation. As a traditional type A, I tend to hyper focus when I have a goal that I am working on, and many things have fallen to the wayside as I hyper focused on my dissertation - things like family celebrations, holidays, college visits, family meals, yard work, and the dishes, to name but a few. I really appreciate everything you have done to step up and take on more in order to support me. Thank you.

I must also acknowledge the somewhat difficult path that led me to and through Portland State University (PSU). I started my doctoral journey at Concordia University Portland with an impressive group of educators and leaders whom I came to know really well during my first two years in the program. Unfortunately, after 115 years as an educational institution, Concordia University closed its doors permanently in the spring of 2020, as my cohort was at the All But Dissertation stage of our program. Several of us transferred to PSU and others scattered to other universities, but we have remained close, and we have supported one another throughout the transition.

I would like to start by acknowledging the work that Dr. Marty Bullis and Dr. Anne Grey did to build an outstanding doctoral program at Concordia University Portland. The program was truly unique in the way that it integrated the dissertation process into the coursework while demonstrating best practices in education by scaffolding learning, supporting an iterative process that focused on proficiency, and providing opportunities to learn in multimodal formats. Furthermore, the program's 
content included a unique focus on transformational learning and ethical practices that I feel are extremely relevant to today's social and political climate, and for which I am very grateful.

I would like to specifically acknowledge the work that Dr. Grey did with me as my previous dissertation advisor. I was ready to defend my dissertation proposal, in no small part due to Dr. Grey's efforts. When Concordia closed, she spent countless hours working with me and really helped me think creatively about my topic, something I sometimes struggled with. She is a kind, compassionate, and caring individual who goes above and beyond to drive her students to success. Thank you so much Anne. You are awesome!

Thanks, also, to my classmates: Wondwesen Tefera, Jarvez Hall, Dominique Austin, Christopher Agudelo, and Ashley Davis (formerly Furlong). I have missed seeing you every Thursday night! Jarvez and Dom brightened our classes with their witty humor, Chris impressed us with his mighty vocabulary, Wonde brought reason to our discussions, and Ashley helped us keep it light. I would like to especially thank Wonde for our many long conversations and Ashley for giving me the opportunity to see a stellar principal in action while learning from her leadership. You are impressive individuals and great friends. Continuing to feel part of a cohort, despite having left Concordia, was critical to finishing this research.

I would also like to acknowledge the teachers and staff at PSU for interrupting their routines and increasing their workload to accept us as students when Concordia abruptly shut down. You could have said no. But you did not. You let your humanity and 
care for others guide the decision and, in doing so, helped us tremendously. Special thanks to Dr. Sybil Kelley and Stefanie Randol, the doctoral program coordinator. You eased my transition to PSU by answering innumerable questions with patience and helping me feel confident that I would be taken care of.

I would also like to thank Dr. Lundell and Dr. Michaud for hiring me as a graduate teaching assistant. When Concordia closed, I lost my Concordia University position at the same time that my GI Bill benefits ended and the Covid-19 pandemic began. Without my graduate teaching assistantship at PSU, I likely would not have been able to finish my degree because of the financial burdens that I was facing. Thank you for giving me a chance and supporting me during my journey. You two are both incredible and inspirational leaders!

Finally, I would like to thank my dissertation committee: Dr. Dilafruz Williams (Chair), Dr. Patrick Burk, Dr. Chris Borgmeier, and Dr. Phillip Pearson, for your expertise, encouragement, and support. I made a lot of changes to this work based on your wise recommendations and appreciate all the time and energy you put into helping me develop as a researcher. I was worried about working with professors I did not know and changing dissertation advisors when I transferred to PSU, but I have been pleasantly surprised. Dr. Williams is truly a gift, and I could not have asked for a better advisor. A million thanks Dilafruz for being so flexible, supportive, and demanding! You were just what I needed to finish this dissertation. I am so grateful to have had the opportunity to benefit from your encouragement, compassion, and wisdom. I wish I could have met you decades ago. Your retirement will leave a void at PSU that will be impossible to fill! 


\section{Table of Contents}

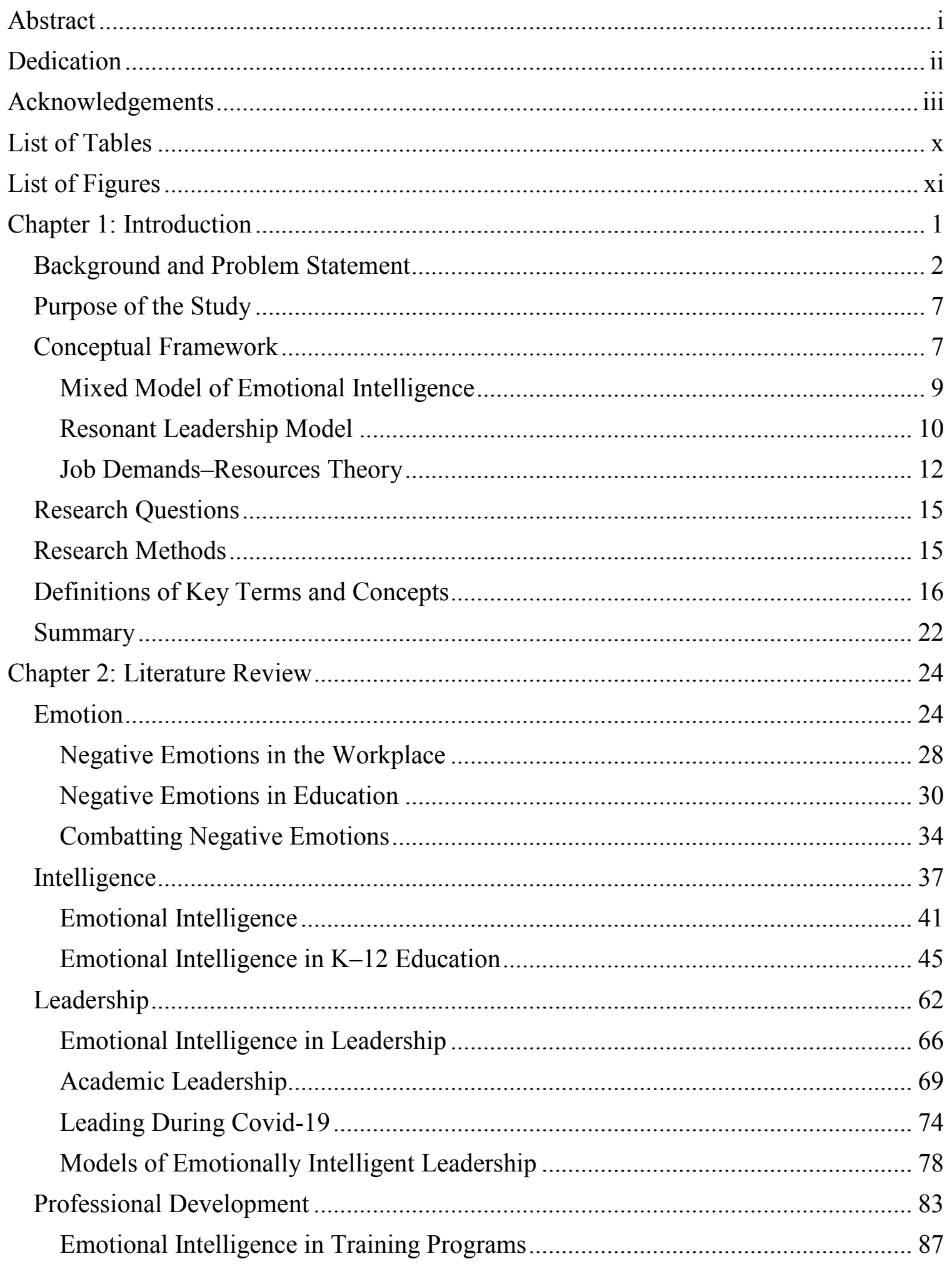


EMOTIONAL INTELLIGENCE AND K12 PRINCIPALS vii

Professional Development Programs for Educational Leaders ............................. 92

Integrating Emotional Intelligence into PPD ...................................................... 98

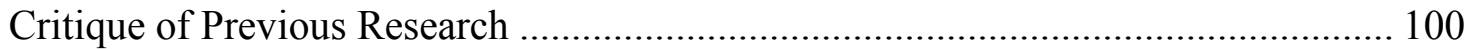

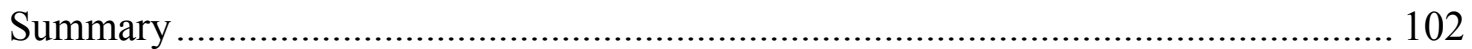

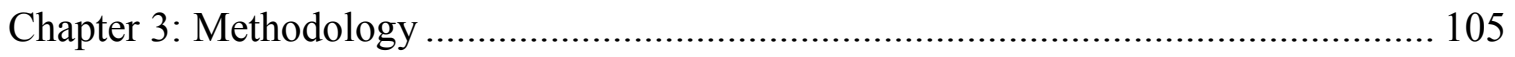

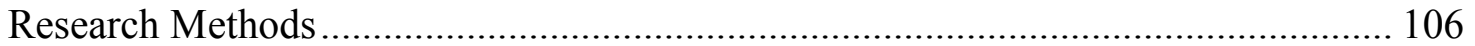

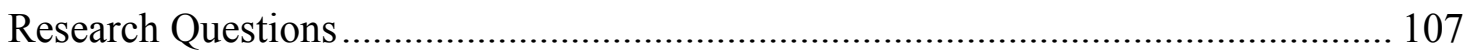

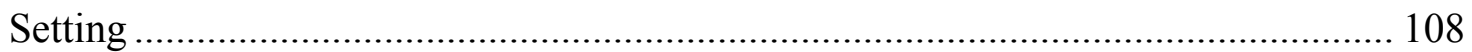

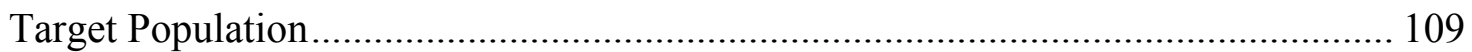

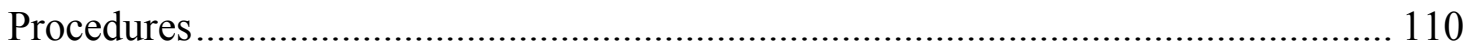

Phase 1: Quantitative Data Collection and Analysis ............................................ 111

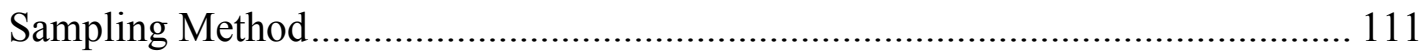

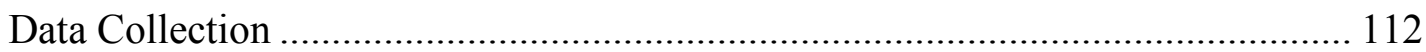

Operationalization of Variables ........................................................................ 115

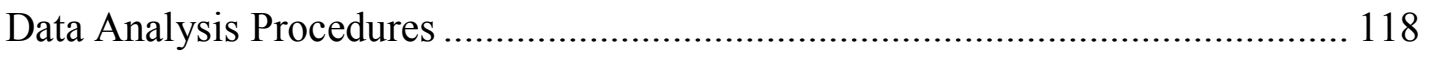

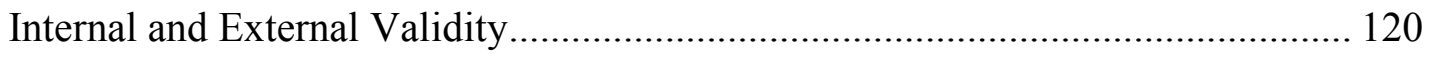

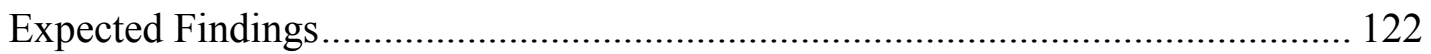

Phase 2: Qualitative Data Collection and Analysis ........................................... 122

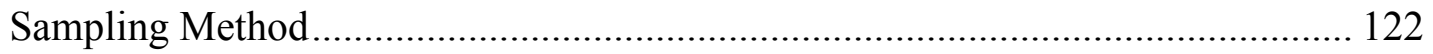

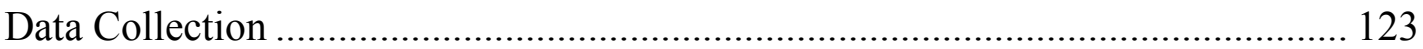

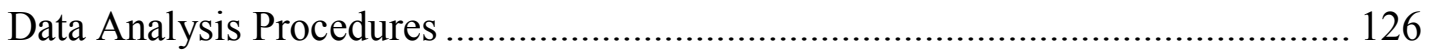

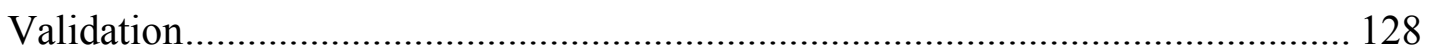

Limitations and Delimitations of the Research Design ........................................ 132

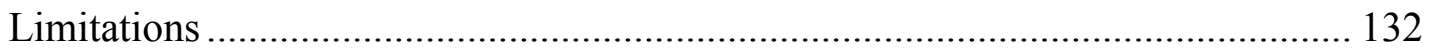

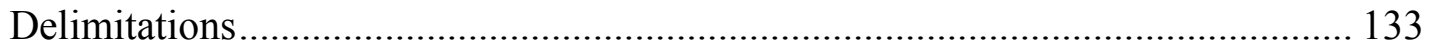

Ethical Issues in the Proposed Study .................................................................. 134

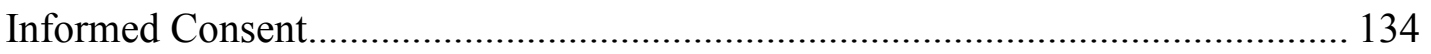

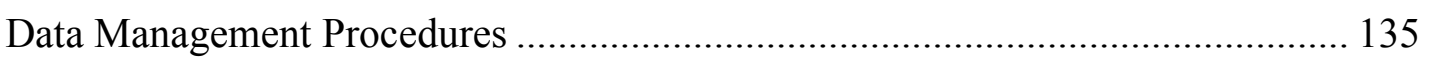

My Positionality as a Researcher ........................................................................ 136

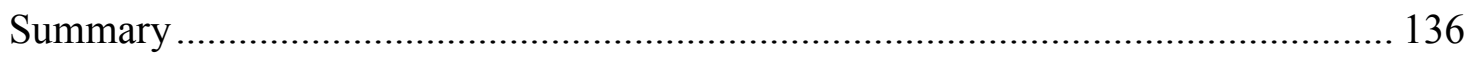

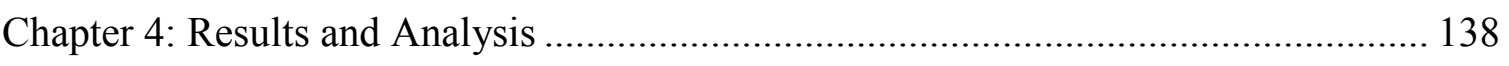

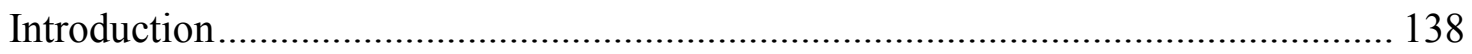

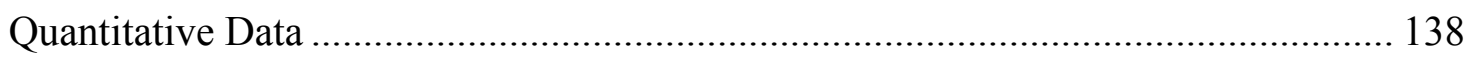


EMOTIONAL INTELLIGENCE AND K12 PRINCIPALS viii

Participant Response Rates and Demographics ............................................... 139

Principal Preparation Programs .............................................................................. 144

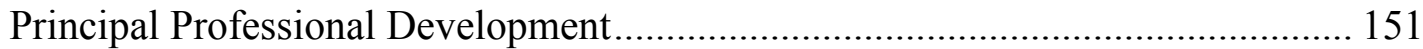

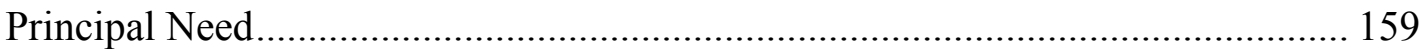

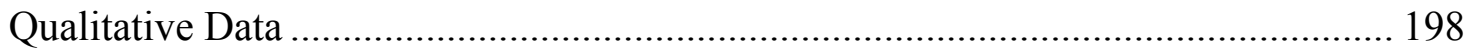

Response Rates and Participant Demographics ................................................... 199

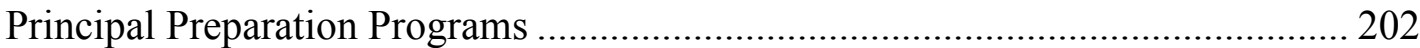

Principal Professional Development............................................................... 208

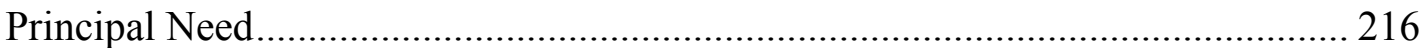

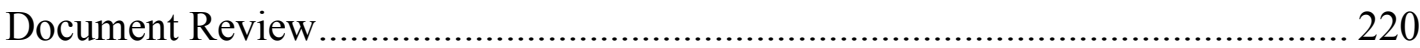

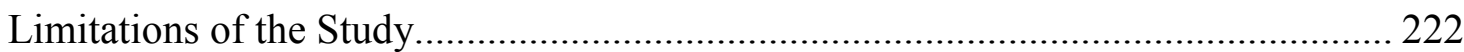

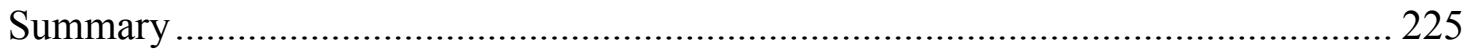

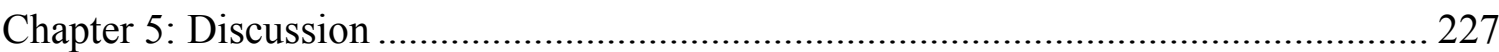

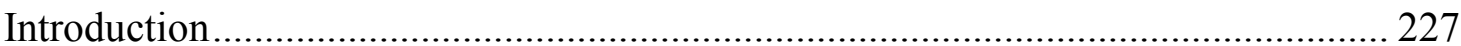

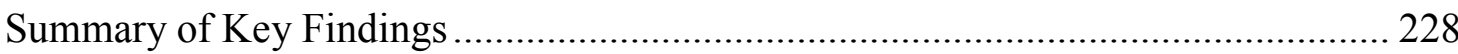

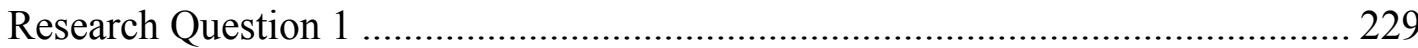

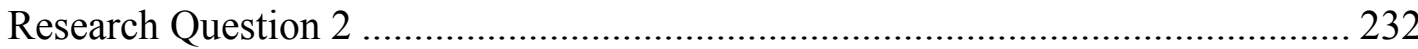

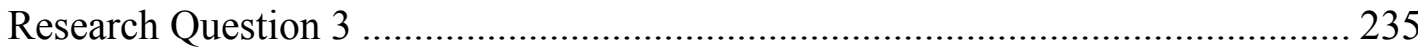

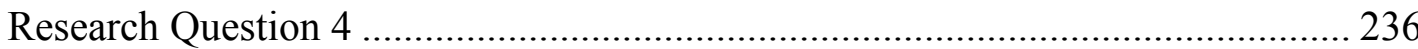

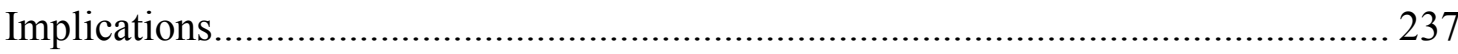

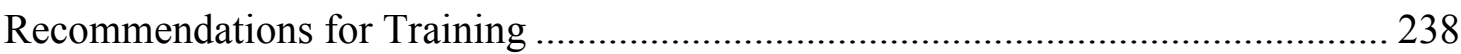

Recommendations for Future Research ............................................................ 238

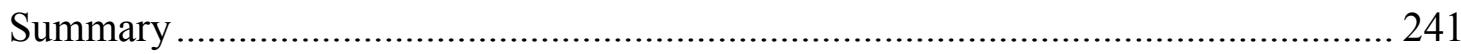

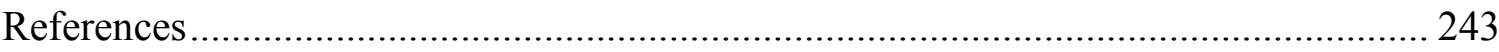

Appendix A: Recruitment Email Templates............................................................ 286

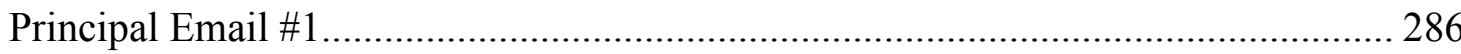

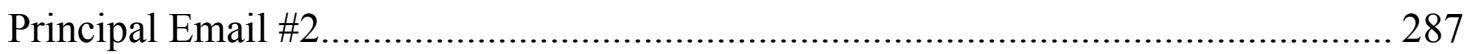

Principal Email \#3 ............................................................................................. 288

Principal Email \#4................................................................................................ 289

Superintendent/District Gatekeeper Email ......................................................... 290

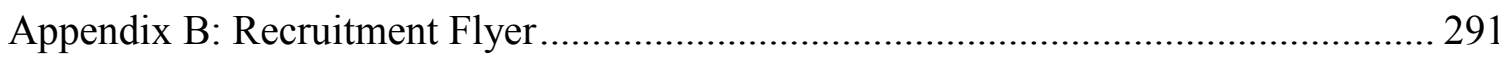

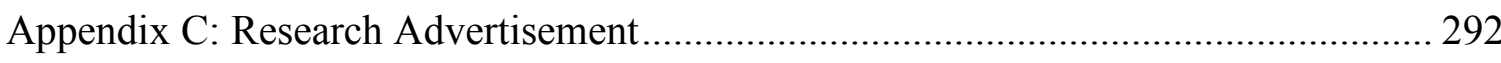

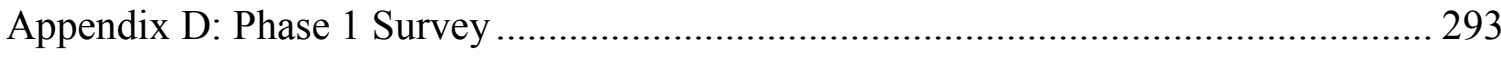


Appendix E: Phase 2 Informed Consent................................................................. 301

Appendix F: Interview Protocol \& Questions ............................................................. 303

Appendix G: Preliminary Statistical Analysis Results .................................................. 304

Appendix H: Ordinal Logistic Regression Results ...................................................... 308 


\section{List of Tables}

Table 3.1: Operationalization of the Variables and Measurement Tools ...................... 114

Table 3.2: Alignment of Research Questions with Data Collection and Analysis...........125

Table 4.1: Emotional Intelligence Skills Included in Preparation Programs.................. 146

Table 4.2: The Helpfulness of EI Training included in Preparation Programs .............. 149

Table 4.3: EI Skills Included in Professional Development for Principals ..................... 153

Table 4.4: Helpfulness of EI Training in Principal Professional Development ............. 156

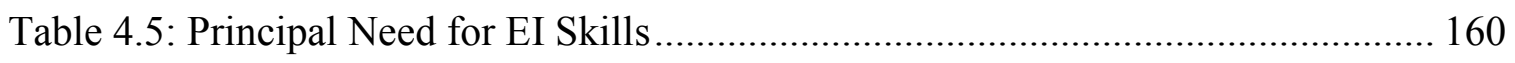

Table 4.6: Principal Need for EI Skills: By Age Group ................................................. 167

Table 4.7: Principal Need for EI Skills: By Gender ....................................................... 171

Table 4.8: Principal Need for EI Skills: By Race/Ethnicity ………………………….... 175

Table 4.9: Principal Need for EI Skills: By Years of Experience Education .................. 179

Table 4.10: Principal Need for EI Skills: By Years of Experience as a Principal.......... 183

Table 4.11: Principal Need for EI Skills: By School Level.......................................... 187

Table 4.12: Principal Need for EI Skills: By School Location.......................................... 191

Table 4.13: Principal Need for EI Skills: By Level of Student Need ............................... 195

Table 4.14: Model Effects of Participant Gender on Perceptions of Need for EI .......... 198

Table 4.15: EI Included in the Programs \& Frameworks That Emerged in Phase 2...... 221 


\section{List of Figures}

Figure 1.1: The Three Legs of School Support.......................................................... 3

Figure 1.2: Change Forces that Lead to the Stress and Burnout of Educators ................... 4

Figure 3.1: Mixed Method Data Collection and Analysis Procedures .......................... 110

Figure 4.1: Individual Characteristics of the Phase 1 Participants ................................. 141

Figure 4.2: School Contexts of the Phase 1 Participants ............................................... 143

Figure 4.3: Inclusion of EI Training in Principal Preparation: By Skill ........................ 147

Figure 4.4: Inclusion of EI Training in Principal Preparation: By Cluster ...................... 148

Figure 4.5: Helpfulness of EI Training in Principal Preparation: By Skill..................... 150

Figure 4.6: Helpfulness of EI Training in Principal Preparation: By Cluster.................. 151

Figure 4.7: Inclusion of EI Training in Professional Development: By Skill ................ 154

Figure 4.8: Inclusion of EI Training in Professional Development: By Cluster ............ 155

Figure 4.9: Helpfulness of EI in Professional Development: By Skill .......................... 157

Figure 4.10: Helpfulness of EI in Professional Development: By Cluster ..................... 158

Figure 4.11: Perceptions of Need for EI Training: By Skill ........................................... 161

Figure 4.12: Perceptions of Need for EI Training: By Cluster ....................................... 162

Figure 4.13: Perceptions of Need for EI Clusters: By Age.......................................... 164

Figure 4.14: Perceptions of Need for EI Skills: By Age............................................. 165

Figure 4.15: Perceptions of Need for EI Clusters: By Gender ..................................... 168

Figure 4.16: Perceptions of Need for EI Skills: By Gender ......................................... 169

Figure 4.17: Perceptions of Need for EI Clusters: By Race/Ethnicity ........................... 173

Figure 4.18: Perceptions of Need for EI Skills: By Race/Ethnicity ............................... 174

Figure 4.19: Perceptions of Need for EI Clusters: By Years of Experience: Education 176

Figure 4.20: Perceptions of Need for EI Skills: By Years of Experience: Education .... 177

Figure 4.21: Perceptions of Need for EI Clusters: By Years of Experience: Principal .. 180

Figure 4.22: Perceptions of Need for EI Skills: By Years of Experience: Principal ...... 181

Figure 4.23: Perceptions of Need for EI Clusters: By School Level ............................. 184

Figure 4.24: Perceptions of Need for EI Skills: By School Level................................. 185

Figure 4.25: Perceptions of Need for EI Clusters: By School Location .......................... 188

Figure 4.26: Perceptions of Need for EI Skills: By School Location............................. 189

Figure 4.27: Perceptions of Need for EI Clusters: By Level of Need ............................. 193

Figure 4.28: Perceptions of Need for EI Skills: By Level of Need ................................. 194 
Figure 4.29: Individual Characteristics and Contexts of the Phase 2 Participants ......... 201 


\section{Chapter 1: Introduction}

As Boyatzis and McKee (2005) so eloquently stated, "for those bold enough to lead in this age of uncertainty, the challenges are immense" (p. 1). Their observation now seems uncannily prophetic as I think about how Americans held on by a thread while 2020 blew through our lives like a tornado. The turbulence and chaos caused by Covid19 has been a new American reality now for eighteen months, and there seems to be no end in sight. It is difficult to grasp the immensity of the changes we have faced. We have had to cover our faces with masks while in public, maintain social distancing, forsake our holiday traditions, and postpone our graduation celebrations, weddings, and funerals, all while enduring a turbulent social and political climate that has divided many families and social groups.

The Covid-19 pandemic has affected all aspects of our American society, but it has been especially damaging to the $\mathrm{K}-12$ education system. Educators spent the majority of the last year and a half working from home with limited social interactions, overwhelming amounts of screen time, and constant preoccupation for their students. They have been under extreme pressure to keep up with, and adapt to, a constantly changing and completely transformed instructional environment. And while most schools have now, in the fall of 2021, returned to in-person learning, educators continue to face challenges, such as limited staffing, public criticism, increasing Covid-19 case rates, and gubernatorial mandates that continue to make it difficult to provide students with equitable opportunities for success. 
As a result of these added pressures, many educators have found themselves failing to manage escalating amounts of stress, but this problem is not new. Researchers have been highlighting the need to address educator stress and burnout for many years in response to the high turnover rates of $\mathrm{K}-12$ educators. Some even claim that educator stress levels are comparable to the levels endured by individuals working in the health care industry (Bottiani et al., 2019). Unfortunately, the Covid-19 pandemic has increased the amount of stress that educators are being forced to manage, which has implications for their health and wellness, as well as their ability to meet the needs of students (Ford et al., 2019; Laybourn et al., 2019). Although the stress that administrators are experiencing is atypical, this has provided an opportunity to generalize about educator responses to stress. This chapter provides a broad overview of the existing body of research on this topic, which has informed the questions explored and the methods used in this study.

\section{Background and Problem Statement}

Much like photographers, educators are both artists and scientists. Photographers must learn to adjust their aperture, shutter speed, and camera lenses based on a variety of technical factors; however, they must do so with an eye for capturing the magnificent and the unique, something that requires both technical expertise and creativity. Likewise, educators must constantly balance and fine tune the use of the technical and creative tools at their disposal, to inspire and transform their students. Although photographers often carry their cameras, they regularly use a tripod for support and stability. The same is true for $\mathrm{K}-12$ schools in the United States (Figure 1.1). Without the support of the instructional staff, the administrators who lead them, and the communities that make up 
the school systems, schools have the potential to become unstable and unable to meet the needs of their students.

\section{Figure 1.1}

The Three Legs of School Support

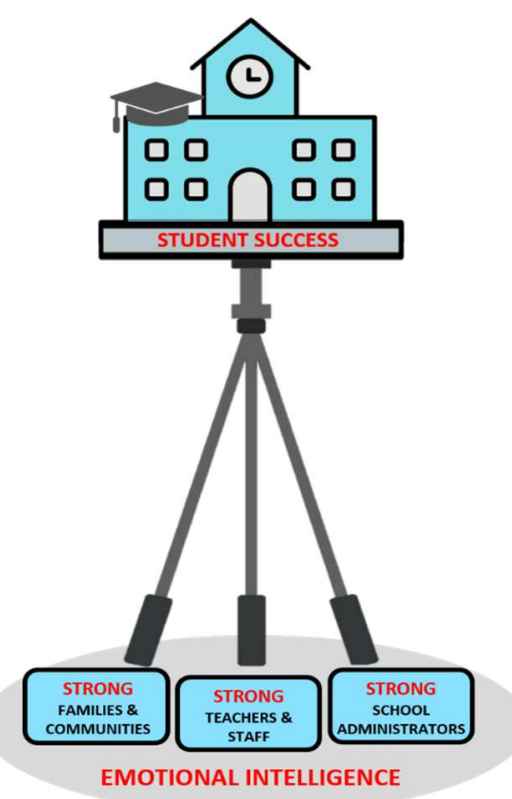

Note: Akin to a photographer's tripod, there are three primary support structures for students in a school system: (a) the community; (b) the teachers and staff members; and (c) the school administrators. Each support structure must be strong to reinforce student success. The development of emotional intelligence can help strengthen these structures. The clipart images used to design this image were obtained from Carterart (n.d.) and Iyi Kon (n.d.-a, n.d.-b). 
Research suggests that the classroom teacher is a primary factor in the success of students (Leonard \& Maulding Green, 2018; Quinlan et al., 2018), but it also suggests that teacher success depends largely on the climate of the school and the support of the school's principal (Loewenberg, 2016; Mehdinezhad \& Mansouri, 2016; Tripses, 2019). Therefore, it is likely that student outcomes are indirectly affected by the leadership at the school, reinforcing the need to recruit, support, and retain high-quality principals (MeyerLooze et al., 2019; Sánchez-Núñez et al., 2015).

Figure 1.2

Change Forces that Lead to the Stress and Burnout of Educators

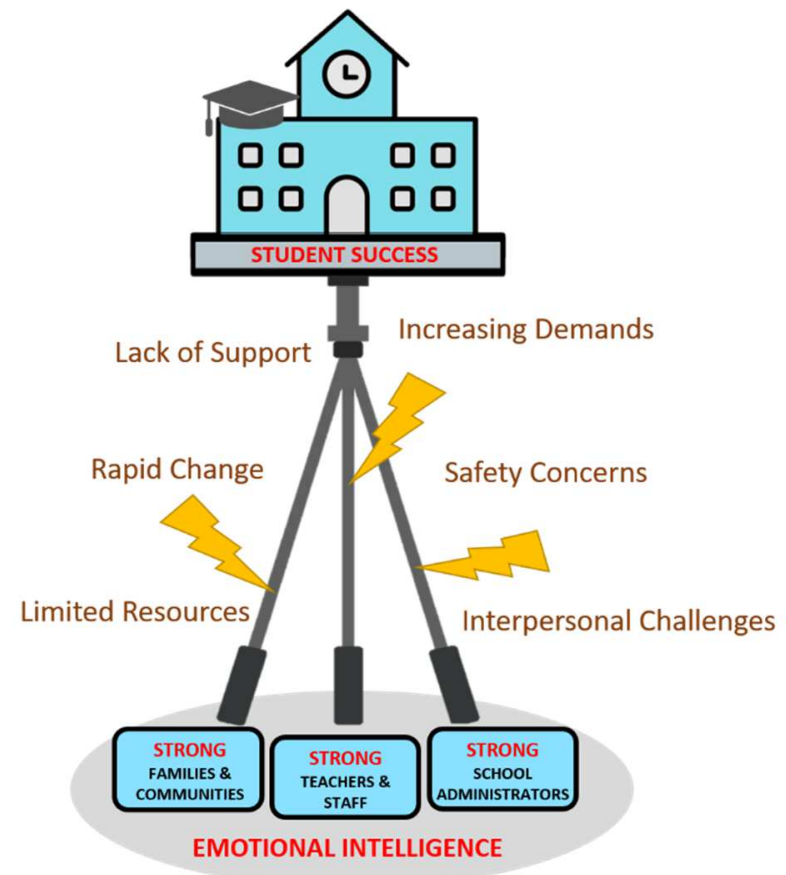

Note: Decreasing resources and increasing demands weaken the support structures that provide a foundation for student success. The development of emotional intelligence can help strengthen these support structures and provide resilience against stress and burnout. The clipart images used to design this image were obtained from Carterart (n.d.) and Iyi Kon (n.d.-a, n.d.-b). 
Unfortunately, the impact of societal trends and change forces—-such as globalization, competition, budget cuts, calls for accountability, increasing diversity, technology, interpersonal and intrapersonal challenges, school safety concerns, political division, racial injustice, and diseases, such as Covid-19 (Figure 1.2) - have increased the stress felt by all educators, including administrators. This increased stress has led to impaired health and wellness, decreases in performance, and high rates of burnout and turnover of both teachers and administrators, which have weakened two critical legs of the K-12 support system (Bottiani et al., 2019; Levin \& Bradley, 2019; Ouellette et al., 2018).

Fortunately, research from many different fields indicates that the development of emotional intelligence skills can help strengthen resilience against stress and burnout (Anthony-McMann et al., 2017; Haghighi \& Gerber, 2019; Schutte \& Loi, 2014), which may indirectly strengthen the support structures that reinforce student success (Joseph \& George, 2018; Sánchez-Núñez et al., 2015; Turk \& Wolfe, 2019). However, very little attention has been devoted to helping educators develop these skills (Herman et al., 2020a, 2020b). Student-based Social-Emotional Learning (SEL) programs have been implemented in most $\mathrm{K}-12$ schools (Yettick, 2018), and recently, programs that target the emotional health of teachers, such as the Cultivating Awareness and Resilience in Education (CARE) for teachers program, have emerged (Jennings et al., 2011; SchonertReichl, 2017); however, the needs of educational leaders, such as K-12 principals, have been largely ignored despite the extreme pressure and chronic stress they often endure (Sanchez et al., 2019; Wallace Foundation, 2016). Furthermore, there is very little 
research on the effectiveness of programs that do focus on improving the emotional skills of principals (Sánchez-Núñez et al., 2015; Wallace Foundation, 2016). Despite the compelling evidence in support of the need for emotional intelligence training for principals, it is unclear which factors determine principals' needs for training and which dimensions of emotional intelligence should be included in professional learning opportunities to properly support them.

This study contributes to the body of knowledge required to address the needs of educational leaders in response to occupational stress and burnout by investigating how the preparation and professional development programs and activities designed for $\mathrm{K}-12$ principals in the state of Oregon support the emotional needs of principals, especially during times of stress and uncertainty such as many principals are currently experiencing because of Covid-19. The results of this study include recommendations for preparation programs and the on-going professional development of $\mathrm{K}-12$ principals. These recommendations have the potential to benefit the $\mathrm{K}-12$ educational system at multiple levels and inform a variety of decision-makers, including district-level policy makers interested in improving the quality of professional development programs for school leaders; individuals, organizations, and post-secondary institutions involved in the preparation of principals; researchers interested in the topics of emotional intelligence, leadership, stress, and burnout in $\mathrm{K}-12$ education; as well as $\mathrm{K}-12$ administrators, teachers, students, and communities interested in improving school climate, decreasing turnover, and increasing student achievement. 


\section{Purpose of the Study}

The purpose of this study is to explore whether and to what degree the preparation and professional development opportunities available to $\mathrm{K}-12$ principals in Oregon support their emotional needs. Specifically, this study focuses on the emotional skills principals need to cope with, manage, and bounce back from occupational stress, such as the stress that has been caused by the challenges and uncertainties related to the Covid-19 pandemic. This study also seeks to understand the ways in which the individual characteristics of principals and the contexts in which they lead (e.g., school level, location, level of need) influence their need for the development of emotional skills.

\section{Conceptual Framework}

Imenda (2014) states that "the conceptual or theoretical framework is the soul of every research project" (p. 185). It is important to define the type of framework used to guide one's research to determine the literature review process, develop the

methodological approaches, and answer the research questions. The problems explored in this study cannot be easily explained by one theoretical perspective and require an inductive synthesis of a variety of existing views and concepts to explore the phenomena in an integrated way.

This research, therefore, is guided by a framework based on three conceptual and theoretical perspectives that shape the understanding of the data: (a) Goleman's mixed model of emotional intelligence (Goleman, 1997; Goleman et al., 2013); (b) Boyatzis and McKee's (2005) resonant leadership model; and (c) Bakker and Demerouti's (2014, 2017) job demands-resources theory. Goleman's mixed model of emotional intelligence 
(Goleman, 1997; Goleman et al., 2013) is used to explore the role that emotional intelligence plays in the preparation and professional development activities that have been designed for $\mathrm{K}-12$ principals in Oregon and helps identify the dimensions included and/or needed. Boyatzis and McKee's (2005) resonant leadership model is used to understand how the participants use emotional skills in their leadership practices to engage in self-care and to increase resilience and resonance. Lastly, Bakker and Demerouti's $(2014,2017)$ job demands-resources (JD-R) theory is used to understand the elements in the $\mathrm{K}-12$ work environment that affect stress and burnout in relation to emotional intelligence and resonant leadership.

Combined, these frameworks support four main assumptions:

1. Emotions affect performance (Behera \& Pani, 2014; George \& Dane, 2016; Lerner et al., 2015; Lings et al., 2014; Schutte \& Loi, 2014; Williams, 2015).

2. Emotional intelligence is an essential skill for high-quality leadership (Boyatzis \& McKee, 2005; Goleman et al., 2013; Sanchez et al., 2019; Wallace Foundation, 2016).

3. Emotional intelligence is a skill that can be developed (Boyatzis \& McKee, 2005; Dolev \& Leshem, 2017; Embregts et al., 2019; Gilar-Corbi et al., 2019; Goleman et al., 2013; Nafukho et al., 2016; Parrish, 2015; Pearson \& Weinberg, 2017; Zeidner, 2017).

4. Emotional responses to stress and change can be managed with the development of emotional skills (Bassal et al., 2016; Behera \& Pani, 2014; Ford et al., 2019; 
Hord \& Roussin, 2013; Kunze \& Menges, 2017; Schutte \& Loi, 2014; Stephens \& Carmeli, 2016; Ugoani et al., 2015; Williams, 2015; Yip \& Côté, 2013).

These assumptions may limit my ability as a researcher to fully understand the problem by underestimating the role of other factors that may influence the stress, burnout, performance, and leadership needs of $\mathrm{K}-12$ principals in Oregon. For example, there may be additional aptitude-based, trait-based, or context-based factors, or combinations thereof, that affect principals' emotional intelligence levels, leadership practices, and stress-management skills. Furthermore, these assumptions may limit my ability to recognize additional skill-building opportunities that may be missing from the $\mathrm{K}-12$ professional learning opportunities available to principals that could play a larger role in principal success than the development of emotional intelligence.

\section{Mixed Model of Emotional Intelligence}

There are many models of emotional intelligence, and new theories continue to shape the field, spurring disagreement and controversy among experts (Antonakis \& Dietz, 2010; McCleskey, 2012). Ability-based theories support the idea that emotional intelligence is an ability that is highly correlated with general intelligence (' $\mathrm{g}$ '), can be tested using objective criteria, and can develop over time via the cognitive changes of the brain as one ages but, like IQ, cannot be directly developed with training (Antonakis \& Dietz, 2010; Clarke, 2010; Côté et al., 2011; McCleskey, 2012; Nagler et al., 2014; Ugoani et al., 2015; Williams, 2015). Alternatively, mixed-model theories support the idea that one's emotional intelligence is based in part on ability, acknowledging that some people are naturally more emotionally intelligent than others, while recognizing 
that emotional intelligence can be developed through awareness and training (Goleman, 1997; Goleman et al., 2013; McCleskey, 2012; Nafukho et al., 2016; Ugoani et al., 2015).

While evidence suggests that emotional intelligence is in part based on natural ability (Antonakis \& Dietz, 2010; Clarke, 2010; Côté et al., 2011; McCleskey, 2012; Nagler et al., 2014; Ugoani et al., 2015; Williams, 2015), research also supports the idea of emotional intelligence as a skill that can be developed to improve organizational success (Dolev \& Leshem, 2017; Embregts et al., 2019; Gilar-Corbi et al., 2019; Nafukho et al., 2016; Parrish, 2015; Pearson \& Weinberg, 2017; Zeidner, 2017). Consequently, the research conducted in this study is viewed using a mixed model framework, specifically Goleman's (1997) theory of emotional intelligence.

Goleman $(2001,2013)$ saw the utility of emotional intelligence for its practical application in the workplace. His model involves four constructs - self-awareness, selfmanagement, social awareness, and relationship management—which include emotional skills and competencies that comprise one's emotional intelligence. Goleman, among others, posits that the development of these skills improves interpersonal relationships and success in the workplace (Dadehbeigi \& Shirmohammadi, 2010; Dolev \& Leshem, 2017; Embregts et al., 2019; Goleman et al., 2001, 2013; McCleskey, 2012; Nafukho et al., 2016; Ugoani et al., 2015; Zijlmans et al., 2011, 2015).

\section{Resonant Leadership Model}

There are many positive leadership models discussed in the leadership literature. For example, many researchers have explored the positive benefits associated with servant leadership, in which leaders view their role as one of service to others (Crippen, 
2010; Hays, 2008; Sendjaya \& Sarros, 2002). Although most researchers agree that service is essential for quality leadership, some researchers argue that effective leaders must also motivate and inspire those with whom they work, advocating for a leadership model that promotes transformation (Hofmeyer et al., 2015; Martin et al., 2003). Ultimately, both servant leaders and transformational leaders care deeply about the personal development of others and build positive interpersonal relationships that promote learning and success. However, while both models acknowledge the importance of connecting with others, and the ways in which service and inspiration help build and maintain relationships and success, neither model explicitly acknowledges the role that emotional intelligence plays in a leader's capacity to form productive and positive relationships with those with whom they work while managing negative emotions, such as those resulting from stress.

There are two leadership models described in the literature that explicitly include emotional intelligence: Bradberry and Greaves' (2012) framework, as described in their book Leadership 2.0, and Boyatzis and McKee's (2005) resonant leadership model. Bradberry and Greaves' (2012) framework includes two types of leadership: core leadership and adaptive leadership. Core leadership skills include the skills that leaders tend to learn in leadership programs, such as planning and data-based decision-making skills, while adaptive leadership skills include the skills that tend to make leaders stand out, such as emotional intelligence. The framework explicitly includes emotional intelligence as a necessary component of exceptional leadership and uses the four emotional intelligence competencies (Goleman et al., 2013) to outline suggestions to help 
leaders develop emotional intelligence; however, the authors do not explicitly address stress and burnout in Leadership 2.0.

In contrast, Boyatzis and McKee's (2005) resonant leadership model directly links emotional intelligence to the ability to handle stress and is, therefore, more applicable to this research. Resonant leadership emphasizes the importance of using emotional skills to care for oneself and others. Boyatzis and McKee (2005) explain that even resonant leaders-leaders who are "awake, aware, and attuned to themselves, to others, and to the world around them" (p. 9) and who use this awareness to form positive relationships, inspire others, and get results — can fall out of resonance and into dissonance when they do not take steps to counter the negative effects of power stress-a unique type of stress caused by the pressures of leadership. They claim that for leaders to maintain their resonance, they must build their emotional resilience, which fuels their ability to maintain resonant leadership practices. These concepts are extremely relevant to this study.

\section{Job Demands-Resources Theory}

There are several models and theories in the literature related to job stress and burnout. Some take a broader stance to examine stress by considering an individual's demands and resources, regardless of the industry, while others examine stress and burnout related to specific fields. There are several models that focus on $\mathrm{K}-12$ education. For example, the prosocial classroom model (Jennings \& Greenberg, 2009) focuses specifically on teacher stress, emphasizing the importance of emotional intelligence and the use of emotional skills, such as mindfulness, to reduce the harmful effects of stress in 
the classroom. Similarly, the coping, competence, and context theory of teacher stress extends the prosocial classroom model to examine the role that the three components of coping, competence, and context have on teacher stress, the management of teacher stress, and the development of management skills (Herman et al., 2020b). While these models provide some insight into how emotional intelligence affects stress and burnout in education, they provide a somewhat shallow view, focusing mainly on elements that reduce stress, rather than the complex relationship between protective and destructive occupational factors as they are related to stress.

Conversely, Bakker and Demerouti's $(2014,2017)$ JD-R theory examines the complex relationships between protective and destructive occupational factors. This theory builds on predecessors such as Herzberg's (1966) two-factor theory, which explored how motivating factors and dissatisfiers affected job satisfaction; Karasek's (1979) demand-control model, which examined how the relationship between job demands and job control affect job strain; and Siegrist's (1996) effort-reward imbalance model, which examined how the relationship between an individual's efforts, and the rewards they receive for those efforts, affect stress. Bakker and Demerouti (2014) point out that, much like the models that focus specifically on education, these previous models have several weaknesses, one of which is one-sided attention to either job stress or work motivation. Conversely, the JD-R theory explores the complex relationship between job demands—-workload, negative climate, conflict, student behavior, and so on—and job resources - positive climate, empowerment, efficacy, sense of accomplishment, sense of purpose, recognition, and so on — as they are related to job satisfaction and stress. The 
JD-R theory argues that high job resources can reduce the negative effects of high job demands and that burnout is most likely to occur when resources are low and demands are high.

Further justifying its use in this study, the JD-R theory has been used recently to study the effects of Covid-19 on teacher exhaustion and principal leadership. Collie (2021) examined the role of autonomy-supportive and autonomy-thwarting leadership on workplace buoyancy and the somatic burden, stress, and emotional exhaustion felt by Australian teachers during the first wave of school closures due to Covid-19. The researcher used the JD-R theory as a conceptual framework that allowed them to understand how autonomy had the potential to function as both a resource and a demand. This research explores a similar topic: how emotional intelligence can be used to buffer the negative effects of stress. When coupled with Goleman's mixed model of emotional intelligence and Boyatzis and McKee's (2005) resonant leadership model, Bakker and Demerouti's $(2014,2017)$ JD-R theory provides a comprehensive conceptual framework through which the research in this study can be viewed, allowing understanding of how emotional intelligence can be a job resource that improves the contexts in which principals work, improving their ability to cope with, and bounce back from, stress and burnout. 


\section{Research Questions}

I asked the following research questions:

- RQ1: How do the perceptions of $\mathrm{K}-12$ principals in Oregon, regarding their needs for the development of emotional intelligence skills, vary based on their individual characteristics and the contexts in which they lead?

- RQ2: How do K-12 principals in Oregon perceive that their preparation and professional development programs have supported the development of emotional intelligence skills?

- RQ3: How do K-12 principals in Oregon perceive that their preparation and professional development programs have prepared them to manage the stress and emotions caused by Covid-19 and other challenges?

- RQ4: How do the principal preparation and professional development themes exposed in the principal interviews and document review process explain the results from the initial quantitative phase of the study?

\section{Research Methods}

This study used an explanatory sequential mixed methods design (Creswell \& Creswell, 2018; Creswell \& Plano Clark, 2018) to explore the role that emotional intelligence plays in the principal preparation and professional development programs available in Oregon. A mixed methods methodology allowed me to take a pragmatic approach to developing a well-rounded, deep understanding of the topic that honored both the collective voice of principals in Oregon and the individual voices of a select group of principals. I recruited a variety of participants from all levels of $\mathrm{K}-12$ education 
in Oregon, serving in different contexts with different experiences and needs. I used a document review process, survey, and interviews to develop a holistic view of the topic.

I collected data in two phases: a quantitative phase and a qualitative phase. During the quantitative phase, I used a survey to gather information about the types of preparation and professional development activities available to principals and their perceptions regarding the need for training that includes emotional-intelligence skill development. I also used the survey to preliminarily classify candidates based on their individual characteristics and the contexts in which they led. During the qualitative phase, I interviewed a representative sample to develop greater insight into the themes that emerged from the survey results. I explored principal stress and preparation in response to the Covid-19 pandemic in more depth and collected documents related to the training opportunities that principals mentioned. I used differential and inferential statistics to analyze the quantitative data gathered from the survey and a priori coding to analyze the qualitative data, including the data gathered from the reviewed documents and the interviews.

\section{Definitions of Key Terms and Concepts}

The main topics explored in this study include emotion, intelligence, emotional intelligence, stress, burnout, leadership, and professional development as they apply to the $\mathrm{K}-12$ educational context in the state of Oregon. There are many interpretations and definitions of these concepts; therefore, they have been defined here as they apply to this study to ensure clarity and consistency. 
- Ability-Based Emotional Intelligence. An ability-based model of emotional intelligence is grounded in the idea that emotional intelligence is an ability similar to IQ. It can be tested and can develop as one ages but cannot be improved with training.

- Burnout. High levels of all three of Leiter and Maslach's (2016) dimensions of burnout, including emotional exhaustion, depersonalization, and reduced personal accomplishment.

- Depersonalization. One of the three dimensions of burnout, which can be recognized by detachment from work, often resulting in irritation, a negative attitude, and inappropriate behavior (Leiter \& Maslach, 2016).

- Emotional Exhaustion. One of the three dimensions of burnout, which can be recognized by a sense of fatigue and loss of energy, often leading to debilitation (Leiter \& Maslach, 2016).

- Emotional Intelligence. A form of intelligence that involves "the ability to monitor one's own and others' feelings and emotions, to discriminate among them, and to use this information to guide one's thinking and actions" (Salovey \& Mayer, 1990, p. 189).

- Emotional Intelligence Skills. Refers to 18 specific competencies grouped into the four clusters included in the mixed model of emotional intelligence: selfawareness, self-management, social awareness, and relationship management (Goleman et al., 2013). 
- Emotions. Defined by Lerner et al. (2015) as "multifaceted, biologically mediated, concomitant reactions (experiential, cognitive, behavioral, expressive) regarding survival-relevant events" (p. 2), which emphasizes the biological quality of emotions.

- Emotional Quotient (EQ). Defined by some researchers as one's emotional intelligence level. Alternatively, EQ is defined as the measurement of one's emotional intelligence to mirror the use of the term IQ with general intelligence. In this study, both definitions are used within the context of the research that is cited.

- General Intelligence (' $\mathbf{g}$ '). A construct that includes different cognitive abilities, including processing efficiency and capacity, which can be measured by an IQ assessment (Fletcher \& Hattie, 2011).

- In-Service Professional Development. Professional development opportunities that are designed to develop a working educator's (in this study, specifically, a working principal's) skills, in contrast to the professional learning opportunities that are designed to prepare individuals to become principals.

- Intelligence. In contrast with emotion, which is generally classified as a mental reaction, intelligence is classified as a mental ability. For the purpose of this study, Gottfredson's (1997) definition of intelligence is used. Gottfredson defines intelligence as:

a very general mental capability that, among other things, involves the ability to reason, plan, solve problems, think abstractly, comprehend 
complex ideas, learn quickly and learn from experience. It is not merely book learning, a narrow academic skill, or test-taking smarts. Rather it reflects a broader and deeper capability for comprehending our surroundings- - catching on," "making sense" of things, or "figuring out" what to do. (p. 13)

- Intelligence Quotient (IQ). An assessment developed in the $20^{\text {th }}$ century to measure intelligence (Sundem, 2014; Ugoani et al., 2015).

- Job Demands. This study uses West's (2018) definition of job demands as "the social, physical, psychological, or organizational aspects of the job that require sustained psychological or physical effort and therefore cost" (p. 26). In a school environment, this can include workload, policies, leadership, climate, conflict, student behavior, and all other student, administrative, and interpersonal-related activities that explicitly or implicitly fall within the scope of the educator's duties.

- Job Resources. This study uses West's (2018) definition of job resources as "the physical, social, psychological, or organizational aspects of the job that reduce job demands and stimulate personal learning, growth, and development" (p. 26). In a school environment, this can include shared leadership, empowerment, efficacy, sense of accomplishment, sense of purpose, and recognition, as well as other internal and external rewards that inspire individuals to seek education as a vocation. 
- Mixed Models of Emotional Intelligence. A model that supports the idea that an individual's emotional intelligence level is determined both by natural ability and skills that can be developed and improved with training.

- Preparation and Professional Development (PPD). Includes pre-service and inservice professional development.

- Pre-Service Professional Development. Professional development opportunities offered as part of a principal preparation program that lead to state licensure as a principal.

- Professional Development. Training and professional learning opportunities that lead to the development of professional knowledge, competencies, and skills that are needed to be successful in one's occupation.

- Reduced Personal Accomplishment. Refers to a sense of professional inefficacy and a lack of productivity because of one's inability to cope, which is one of the three dimensions of burnout (Leiter \& Maslach, 2016).

- Relationship Management. One of the emotional intelligence clusters (Goleman et al., 2013). Includes the following competencies/skills: inspiration, influence, developing others, change catalyst, conflict management, and teamwork/collaboration.

- Resonance. The ability to stay in tune with others and calibrate the impact of one's moods and behaviors while remaining present and emotionally available (Boyatzis \& McKee, 2005; Goleman et al., 2001). 
- Resonant Leadership. Boyatzis and McKee's (2005) definition of resonant leadership is used in this study. A model in which leaders use the emotional skills of mindfulness, hope, and compassion to produce resonant relationships that help leaders counter the negative effects of power stress - "a vicious cycle of stress, pressure, sacrifice, and dissonance" (p. 9)—-so that they can maintain their resonance.

- Self-Awareness. One of the emotional intelligence clusters (Goleman et al., 2013). Includes the following competencies/skills: emotional self-awareness, accurate self-assessment, and self-confidence.

- Self-Management. One of the emotional intelligence clusters (Goleman et al., 2013). Includes the following competencies/skills: self-control, transparency, adaptability, achievement, initiative, and optimism.

- Social Awareness. One the emotional intelligence clusters (Goleman et al., 2013). Includes the following competencies/skills: empathy, organizational awareness, and service.

- Social-Emotional Intelligence. Often used interchangeably with the term emotional intelligence. Emotional intelligence is used more commonly in both the business world and post-secondary education, whereas social-emotional intelligence is used more commonly within $\mathrm{K}-12$ education and is often associated with SEL programs used at the primary level (see definition below). For the purposes of this study, social-emotional intelligence, social-emotional competency, and emotional intelligence refer to the same construct. 
- Social-Emotional Learning (SEL). Refers specifically to K-12 programs designed to help children develop the social and emotional skills they need to interact successfully with their peers and teachers in the educational environment.

- Stress. The body's reaction to a challenge or demand. Often experienced as a negative emotion when the stimuli tax an individual's coping resources.

- Trait-Based Emotional Intelligence. Trait-based models of emotional intelligence refer to models that support the idea that an individual's emotional intelligence can be developed but include personality traits that lie outside the cognitive sphere of influence and reflect one's perception of one's emotional world (Petrides et al., 2018; Ugoani et al., 2015).

\section{Summary}

Student success is directly and indirectly affected by the teachers, administrators, and communities that support schools (Leonard \& Maulding Green, 2018; Meyer-Looze et al., 2019; Sánchez-Núñez et al., 2015). Unfortunately, changes to the educational environment have resulted in increasing responsibilities and expectations that have led to high levels of stress among educators and administrators, which has affected their ability to meet the needs of their students. Research has shown that the development of emotional intelligence can provide resilience against stress and burnout; however, this prospect is often overlooked in the development of professional learning opportunities for educational leaders. Efforts have been made to teach students and teachers how to use emotional skills to combat negative emotions and stress, but very little attention has been devoted to this at the leadership level. Therefore, it is not clear how principal preparation 
and professional development programs provide opportunities for developing emotional intelligence, nor which dimensions of emotional intelligence should be included to effectively support principals.

This study sought to discover how the preparation and professional development programs and activities designed for $\mathrm{K}-12$ principals in the state of Oregon incorporated emotional intelligence and how these efforts relate to the success of such programs in supporting the needs of principals. I used an explanatory sequential mixed methods study design to explore the preparation and professional development opportunities available to $\mathrm{K}-12$ principals in Oregon, the perceptions of principals regarding their training needs, and some of the factors that may influence these perceptions, especially during the heightened context of Covid-19. By exploring the links between emotional intelligence and stress during a period of extreme, heightened stress, this study identifies factors that will also be relevant to $\mathrm{K}-12$ educator preparation and development in the presence of stressors and challenges during non-pandemic times. It is my hope that this research will result in recommendations that can be applied to the preparation and professional development opportunities currently available to $\mathrm{K}-12$ principals in Oregon. 


\section{Chapter 2: Literature Review}

The purpose of this study is twofold: to understand how the preparation and professional development opportunities available to $\mathrm{K}-12$ principals in Oregon have supported their needs and prepared them to manage and cope with occupational stress; and to understand the ways in which the individual characteristics of principals and the contexts in which they lead might influence their needs. This literature review examines the existing research regarding how emotions affect behaviors and the performance of leaders, particularly in the $\mathrm{K}-12$ environment, how emotional intelligence can be developed, and the best practices for the development of professional learning programs for educators and administrators. To examine these topics holistically, I have structured this literature review around three broad areas of related research: (a) research related to emotions and how emotions affect decision making processes, stress, burnout, and workplace performance; (b) research related to intelligence, including the theories of emotional intelligence and practical applications of emotional intelligence in the workplace; and (c) research regarding leadership, how emotional intelligence can be developed in leaders, and the best practices for including emotional intelligence in preparation and professional development programs and activities.

\section{Emotion}

Emotions are an incredibly important part of the human existence. They motivate parents to care for their children and soldiers to defend their communities. They make life worth living for some and worth ending for others. Lerner et al. (2015) define emotion as "multifaceted, biologically mediated, concomitant reactions (experiential, cognitive, 
behavioral, expressive) regarding survival-relevant events" (p. 2), emphasizing the biological quality of emotions. Because emotions are reactions caused by the normal biological functioning of the body, they are often difficult to control (Asma \& Gabriel, 2019; Lerner et al., 2015; Volynets et al., 2019). People may learn to control the evidence of their emotions, such as crying, or they may become desensitized to events that previously resulted in emotion, such as is often the case with soldiers in combat; however, most individuals continue to have emotions that guide their behaviors, actions, and decisions (Drouvelis \& Grosskopf, 2016; Enachescu et al., 2019).

Research suggests that emotions powerfully influence decision making in conscious and unconscious ways that result in both beneficial and harmful consequences for decision makers (Barnum \& Solomon, 2019; Drouvelis \& Grosskopf, 2016; Enachescu et al., 2019). Researchers have found that integral emotions-emotional responses that arise when considering the consequences of decisions—can be beneficial when they motivate a person to respond to injustice or avoid excessive risk taking but can also cause individuals to act irrationally, even when they have cognitive information that suggests that their reasoning is flawed (Barnum \& Solomon, 2019; Enachescu et al., 2019). For example, a fear of losing money prevents many people from gambling. This is a rational fear, as gambling is a high-risk activity, and it will most likely have beneficial outcomes by preventing excessive risk. However, when a fear of flying prevents people from travelling by aircraft, decision making becomes based on emotion, rather than information, resulting in an irrational decision because the chance of dying in a car crash is statistically higher than the chance of dying in a plane crash (Barnum \& Solomon, 
2019; Enachescu et al., 2019; Lerner et al., 2015). Cognitively speaking, the fear of losing money due to gambling is rational, but a fear of flying due to the chance of a plane crash is irrational.

Like integral emotions, research indicates that incidental emotions can have both positive and negative outcomes on actions and decision making (Barnum \& Solomon, 2019; Fochmann et al., 2019). Researchers have found that mood affects an individual's judgment and decision making, causing incidental emotions to be transferred unconsciously and irrationally to decisions that are not related to the source of the emotions (Barnum \& Solomon, 2019; Enachescu et al., 2019; Lerner et al., 2015). For example, someone in a good mood may be more inclined to donate money to a charity in the checkout line at the grocery store, but if they were to have an argument with a significant other before going to the store, they may be less inclined to donate money. Likewise, they may drive more aggressively and be less courteous to fellow customers and workers at the grocery store, ignoring the fact that these individuals were not involved in the argument. The positive interactions and deeds of a person can inspire those with whom they come in contact to pass on positivity, whereas the negative interactions and deeds of a person can inspire others to pass on negativity, essentially paying one's mood forward.

Equally important to the understanding of how integral and incidental emotions affect decision-making is how these emotions influence interpersonal negotiations. Researchers have found that there is a reciprocal influence of emotion on negotiation partners that affects their behaviors and decisions (Enachescu et al., 2019; Lerner et al., 
2015). For example, research indicates that an expression of gratitude by one person can trigger generosity in another (Gulliford et al., 2019), whereas the expression of disappointment by one person can trigger feelings of guilt that may lead to reparative action by the other (Wubben et al., 2009). Additionally, it appears that the powerdifferential between negotiators affects the emotions, behaviors, and decisions of the individuals involved. Van Dijk et al. (2008) and Van Kleef (2016) found that in a negotiation between two people with a low power-differential (i.e., where both parties have similar power), an expression of anger by one person can trigger concession and cooperation in the other. On the other hand, Lelieveld et al. (2012) found that in a negotiation between two people with a high-power differential, an expression of anger by the person with more perceived power can lead to fear and a desire for retaliation in the person with less perceived power. Overall, research suggests that, at a minimum, emotion serves the following functions in decision-making:

- helping individuals understand one another's emotions, beliefs, and intentions;

- incentivizing or imposing a cost on others' behavior; and

- evoking complementary, reciprocal, or shared emotions in others. (Keltner \& Haidt, 1999, as cited in Lerner et al., 2015, p. 12)

Furthermore, research indicates that emotions influence the personal and professional performance of individuals (Behera \& Pani, 2014; George \& Dane, 2016). Positive emotions have been shown to increase collaboration, creativity, engagement, and, perhaps most importantly, the personal resources that allow one to cope and remain resilient (Bassal et al., 2016; Fredrickson, 2004; Gloria \& Steinhardt, 2016; Meneghel et 
al., 2016). In contrast, negative emotions have been shown to decrease an individual's health and wellbeing by causing mental health issues, such as stress, anxiety, and depression, which often lead to physical health issues, as well as a decrease in engagement and performance (Anthony-McMann et al., 2017; Haghighi \& Gerber, 2019; Laybourn et al., 2019).

\section{Negative Emotions in the Workplace}

The workplace environment can be very demanding of an individual's physical, intellectual, and psychological resources, and when demands exceed resources, negative emotions often surface. There are many causes for negative emotions in the workplace. Pérez-Rodríguez et al. (2019) found that when employees perceived they were being treated unfairly, it caused negative emotions that increased work stress. Ozcelik and Barsade (2018) found that feelings of loneliness in the workplace resulted in negative emotions that led to antisocial behavior and a cycle of negative social interactions that lowered employee affiliation and job performance. Similarly, Cho et al. (2016) found that incivility, in the form of rude, discourteous, or condescending behavior — suffered by $98 \%$ of the employees in their study - significantly increased emotional exhaustion and led to lower levels of performance on the job.

Furthermore, researchers have found that negative emotions experienced at work are often carried over to affect an employee's future performance. Rispens and Demerouti (2016) asked 62 professionals working in a variety of professions to complete daily reports about their emotions and performance. They found that negative emotions caused by workplace conflict were carried over to the following day. Similarly, Chadi et 
al. (2017) monitored the work of 102 temporary workers at a German research institute after they were told that the project they had worked on previously had been canceled. They found that employees began exerting less effort, resulting in a decrease in performance, when they perceived that their previous work had been meaningless. These two studies illustrate the dampening effect of negative emotions on job performance that continues past the time when the emotions were experienced

Research also indicates that negative emotions can lead to burnout from taskrelated role demands (Lings et al., 2014; Rispens \& Demerouti, 2016; Wassif et al., 2019) and that overload is often the cause of negative workplace emotions, frequently leading to stress and burnout (Bassal et al., 2016; Cho et al., 2016; Lings et al., 2014). When worklife balance is compromised and personal resources become depleted, most aspects of an individual's life suffer (Lings et al., 2014; Meneghel et al., 2016; Moqbel \& Nah, 2017). Furthermore, there is evidence that heavy workloads significantly increase emotional exhaustion and that an employee's workload is a significant determinant of stress and burnout (Bottiani et al., 2019; Lings et al., 2014; Ryan et al., 2017).

This link between workload and burnout is especially concerning because stress can have a harmful effect on an individual's health. Stress increases one's risk of psychological disorders, such as anxiety and depression, as well as physical diseases, such as cardiovascular disease, diabetes, and obesity. Stressful situations cause the body to shift into a fight-or-flight mode for survival, which increases an individual's heart rate, blood pressure, and respiration (Gloria \& Steinhardt, 2016). This process is beneficial when an individual is in danger or needs to focus on a short-term event but can be 
extremely harmful when stress becomes chronic, eventually effecting an individual's quality of life, interpersonal relationships, and productivity in the workplace (Gloria \& Steinhardt, 2016).

\section{Negative Emotions in Education}

In the education field, researchers agree that stress has become chronic for many educators. The levels of stress, burnout, and turnover experienced by educators is higher than the levels experienced in many other industries (McIntyre et al., 2017), and some researchers claim that it is matched only by the levels experienced by healthcare providers, such as doctors and nurses (Bottiani et al., 2019). Studies indicate that $46 \%$ of teachers nationwide report high daily amounts of stress, with up to $50 \%$ of teachers leaving the profession within their first five years of employment, and nearly $30 \%$ of teachers experiencing clinically significant anxiety due to accountability policies related to standardized testing (Bottiani et al., 2019; von der Embse et al., 2016a). Additionally, some studies have found that the conditions in urban schools increase teacher stress to an even greater degree, with some researchers finding that $93 \%$ of urban teachers experience high levels of stress (Bottiani et al., 2019; Herman et al., 2020b). Other researchers have found that $75 \%$ of teachers working with trauma-affected students report plans to leave their schools (Christian-Brandt et al., 2020). Thus, chronic stress appears to be a key factor in the attrition of many educators.

As school districts struggle to address widespread teacher attrition, while continuing to improve student outcomes, researchers have focused on identifying the causes of teacher stress, burnout, and turnover. Some researchers blame outcomes-related 
factors, such as the test-based accountability policies enacted to meet the No Child Left Behind legislation (Ryan et al., 2017; von der Embse et al., 2016a, 2016b), whereas others blame changing work conditions and issues, such as the compassion fatigue experienced by teachers working with students who have been affected by trauma (Christian-Brandt et al., 2020). However, many researchers emphasize the multidimensional character of educator stress (Bottiani et al., 2019; Eddy et al., 2019; Ouellette et al., 2018). Eddy et al. (2019) argue that stress likely results from a complex combination of factors that is dependent on the context of the school. That is, the stress experienced by educators at a high-performing school with ample resources and high expectations would be different from that experienced by those at a low-performing school with limited resources where students may struggle more.

Teacher stress in the context of the availability of resources has been further explored in terms of a teacher's personal, institutional, and classroom resources (Bottiani et al., 2019; Ouellette et al., 2018). Bottiani et al. (2019) explain that a teacher's personal resources include their self-efficacy and resilience; their institutional resources refer to the working conditions of their school, including issues such as class sizes, the number of classes teachers must prepare for, additional duties, professional recognition, teacher collegiality, and their satisfaction with school leadership. Classroom resources refer to their personal capacity — in terms of content knowledge, emotional intelligence, and personality traits - to meet their students' academic, behavioral, social, and emotional needs. Other researchers classify these multidimensional factors as internal and external factors (Martínez-Monteagudo et al., 2019). However, regardless of the way researchers 
frame these resources, there is consensus that when workplace demands are high and personal resources are low, teachers experience stress. When stress becomes chronic, teachers often experience burnout and sometimes choose to leave the profession (Bottiani et al., 2019; Christian-Brandt et al., 2020).

Furthermore, evidence suggests that when teachers experience stress, the quality of their teaching decreases and their interactions with administrators, colleagues, parents, and students deteriorate, leading to negative student outcomes (Bottiani et al., 2019; Eddy et al., 2019; Ouellette et al., 2018). Studies have shown that teacher stress decreases their ability to manage difficult behavior, increasing the use of ineffective classroom management procedures — such as harsh forms of behavior management that, in turn, increase the disruptive behaviors of students - making it difficult for teachers to teach effectively (Bottiani et al., 2019; Eddy et al., 2019). Additionally, some studies have found that teacher stress directly increases student stress (Eddy et al., 2019; Herman et al., 2020b). In fact, research indicates that stress and burnout in teachers leads to negative outcomes for students, affecting both their academic performance and their development of emotional skills (Bottiani et al., 2019; Eddy et al., 2019; Herman et al., 2020a, 2020b). Although there are several reasons for teacher stress, some evidence suggests that organizational health is the strongest predictor of teacher stress and satisfaction (Ouellette et al., 2018), indicating that teacher success depends largely on the climate of the school and the social support systems that are in place (Eddy et al., 2019; Hargreaves \& Fullan, 2013; Ouellette et al., 2018). School leadership, then, likely plays a powerful role in ensuring teacher success and helping teachers combat stress and burnout. In fact, research 
indicates that teacher retention is determined more by school leadership than by other variables related to the individual characteristics of the teacher and the school (Player et al., 2017). Some studies further indicate that even in school contexts typically considered likely to have high turnover rates (e.g., schools with high need student populations), teacher retention has been maintained with a quality leadership team in place (Player et al., 2017). This finding corresponds with a growing body of literature that suggests that principals play a fundamental role in retaining teachers and ensuring their success (Leonard \& Maulding Green, 2018; Loewenberg, 2016; Mehdinezhad \& Mansouri, 2016; Sánchez-Núñez et al., 2015; Tripses, 2019).

Teacher success affects student success; therefore, the effect principals have on teacher retention and success indirectly, but critically, influences student learning (Grissom \& Bartanen, 2019; Leonard \& Maulding Green, 2018; Levin \& Bradley, 2019; Meyer-Looze et al., 2019; Sánchez-Núñez et al., 2015; Yan, 2020). In fact, several researchers claim that principals are one of the most important factors in student success, second only to teachers (Grissom \& Bartanen, 2019; Levin \& Bradley, 2019; Yan, 2020). But much like teachers, principals experience tremendous amounts of stress. Research suggests that, on average, $18 \%$ of principals nationwide leave their schools after serving only one year (Bartanen et al., 2019; Grissom \& Bartanen, 2019; Levin \& Bradley, 2019), and $35 \%$ of principals leave before the end of their second year (Levin \& Bradley, 2019). These numbers surpass teacher turnover rates (Bartanen et al., 2019; Grissom \& Bartanen, 2019) and indicate an alarming trend, as school improvement initiatives take time, and school districts need to retain effective principals to ensure teacher and student 
success (Bartanen et al., 2019; Levin \& Bradley, 2019; Levin et al., 2019; Pietsch et al., 2020).

\section{Combatting Negative Emotions}

Fortunately, research indicates that there are promising ways to combat negative emotions that lead to stress, burnout, and turnover. One such way is with the development of emotional intelligence. Many researchers have found that emotional intelligence can buffer the stress caused by negative emotions, increasing the health, wellness, satisfaction, and performance of employees (Bassal et al., 2016; Behera \& Pani, 2014; Ford et al., 2019; Kunze \& Menges, 2017; Schutte \& Loi, 2014; Stephens \& Carmeli, 2016; Ugoani et al., 2015; Williams, 2015; Yip \& Côté, 2013). Most of the research reviewed separates emotional intelligence into two categories of skills: the skills that help individuals understand emotions and the skills that help individuals regulate emotions.

Research indicates that the emotional intelligence skills that help individuals understand emotions also permit individuals to rationalize their emotions, which reduces the negative emotions experienced and allows individuals to make better decisions (Pérez-Rodríguez et al., 2019; Yip \& Côté, 2013). Pérez-Rodríguez et al. (2019) found that emotional understanding allows employees to reassess instances in which they felt they were being treated unfairly to minimize the emotional impact of the incident. Yip and Côté (2013) found that emotional understanding can improve decision-making by allowing one to make decisions that are unbiased by incidental anxiety levels caused by unrelated events. Furthermore, emotional understanding has been found to help 
individuals reduce the negative emotions of others. For example, Whiteside and Barclay (2016) demonstrated the effects of self-reflection on empathy and interactional justice. They found that the effects of low empathy and unfair treatment can be overcome by increasing an individual's self-awareness.

Similarly, research has shown that emotional skills that help with regulating emotions allow individuals to change the way they think in order to experience more positive emotions. These skills help employees manage the suppression or constructive expression of negative emotions to maintain harmonious work relationships. Cho et al. (2016) and Bassal et al. (2016) both found that cognitive reappraisal skills reduce negative emotions. Cho et al. (2016) found that these skills help decrease the amount of emotional exhaustion employees feel when faced with incivility. Bassal et al. (2016) similarly found that these skills allow individuals to experience more positive emotions, less negative emotions, and less symptoms associated with poor physical and mental health. Likewise, Kunze and Menges (2017) and Stephens and Carmeli (2016) both found that managing negative emotions allows individuals to maintain harmonious work relationships. Kunze and Menges (2017) found that the ability to regulate and suppress negative emotions allowed for older employees to work with younger supervisors amicably, despite their negative emotions. On the other hand, Stephens and Carmeli (2016) found that a team's capacity to constructively express negative emotions allowed team members to enhance performance while maintaining positive working relationships.

Furthermore, skills in emotional regulation appear to contribute to the ability for employees to work effectively in team environments and to remain in employment 
positions, despite challenges. Proponents of the broaden-and-build theory of positive emotions (Fredrickson, 2004) believe that positive emotions broaden mindsets, allowing an individual to build personal resources that help them remain resilient, whereas negative emotions narrow mindsets, limiting an individual's personal resources and resilience (Fredrickson, 2004; Gloria \& Steinhardt, 2016). This contrast suggests that positive emotions may be able to buffer the effects of negative emotions to increase an individual's resources and prevent burnout (Fredrickson, 2004; Gloria \& Steinhardt, 2016; Meneghel et al., 2016; Moqbel \& Nah, 2017).

Several studies have employed this theory explore the effects of positive emotions in real-life workplaces. Gloria and Steinhardt (2016) tested the theory on 200 postdoctoral students employed at a large research institution in Texas and found that positive emotions increased their resilience, that coping strategies partially mediated the link between positive emotions and resilience, and that resilience moderated the impact of stress on mental health issues, such as anxiety and depressive symptoms. Likewise, Meneghel et al. (2016) tested the theory on 1076 employees belonging to 216 teams at 40 service companies to explore the effects of positive emotions on teamwork. They found that the collective positive emotions of teams helped them cope with stress and develop resilience. Finally, Moqbel and Nah (2017) explored the relationship between enterprise social media (ESM) and employee performance at a large information technology firm that had been using ESM for over six years. They surveyed 276 employees regarding workplace integration, positive emotions, and performance and found that the use of ESM platforms increased workplace integration and positive emotions, which led to 
increases in performance. Collectively, these studies show a clear link between positive emotions and workplace success.

Although the literature suggests that positive emotions improve coping mechanisms, which enhance resilience, not all coping mechanisms are positive. In fact, maladaptive coping methods, such as contriving positive emotions and suppressing emotions, often have negative outcomes (Bassal et al., 2016; Gloria \& Steinhardt, 2016). Research suggests that contriving positive emotions is emotionally draining and can damage the well-being of employees (Lennard et al., 2019; Lings et al., 2014, 2016; Sanz-Vergel et al., 2012); however, the evidence regarding the benefits and risks of emotional suppression is less conclusive. Bassal et al. (2016) claim that the suppression of emotions is associated with low levels of well-being and emotional exhaustion. However, Lings et al. (2014) report that suppressing negative emotions does not have a significant impact on emotional exhaustion. Kunze and Menges (2017) go further, arguing that the suppression of negative emotions can have positive effects in the workplace. They indicate that the expression of negative emotions has the potential to cascade into a cycle of negative emotions, which can harm the workplace environment. Therefore, it seems that emotional suppression can be damaging in some circumstances and beneficial in others.

\section{Intelligence}

Although research indicates that emotions play an important role in decisionmaking, performance, and wellbeing, research has also shown that intelligence can affect these factors. The most popular definition of intelligence appears to be Gottfredson's 
(1997) definition, which continues to be cited regularly in the literature. Gottfredson defines intelligence as

a very general mental capability that, among other things, involves the ability to reason, plan, solve problems, think abstractly, comprehend complex ideas, learn quickly and learn from experience. It is not merely book learning, a narrow academic skill, or test-taking smarts. Rather it reflects a broader and deeper capability for comprehending our surroundings_- "catching on," "making sense" of things, or "figuring out" what to do... [intelligence does not capture] creativity, character, personality, or other important differences among individuals. (p. 13) Emotion is generally classified as a mental reaction, whereas intelligence is classified as a mental ability. Although views on intelligence differ, Fletcher and Hattie (2011) argue that there are three different types of intelligence: problem-solving, verbal, and social intelligence. They contend that what it means to be intelligent varies based on the age of the individual being assessed and the culture of the individual making the assessment. For example, adults tend to see social skills as a measurement of the intelligence of elementary-school students, verbal skills as a measurement of the intelligence of high-school students, and problem-solving abilities as a measurement of the intelligence of college students. There is a progression of expectations that changes based on the age of the individual. An intelligent five-year-old may be able to sit still and stay quiet while their teacher is giving instructions, but this ability may no longer be viewed as intelligent in high school. 
Likewise, different cultures have different values that affect their views on intelligence. Collective cultures value social harmony over personal development and achievement; therefore, they are more likely to see social intelligence as hallmarks of intelligence. In contrast, individualistic cultures, which tend to value personal development and achievement over social harmony, are more likely to see problem solving and verbal ability as hallmarks of intelligence (Fletcher \& Hattie, 2011). Because collective cultures value slow contemplative thought, silence is often a hallmark of intelligence, whereas in individualistic cultures, such as that of the United States, silence is often seen as a lack of intelligence (Fletcher \& Hattie, 2011).

Though there are many different perspectives regarding what it means to be intelligent, most experts agree that intelligence can be measured and that the ability to measure it is a key component (Fletcher \& Hattie, 2011; Nisbett et al., 2012; Sundem, 2014; Ugoani et al., 2015). Consequently, when most people think about intelligence, they think about IQ, an assessment developed in the 20th century to measure intelligence (Sundem, 2014; Ugoani et al., 2015). The Intelligence Quotient (IQ), also known as the Standford-Binet scale, was created by Alfred Binet and Théodore Simon in 1916 to identify school children who were not benefiting from regular instruction (Fletcher \& Hattie, 2011; Twomey et al., 2018). It was later adapted for use with adults by the American psychologist and Stanford University professor Lewis Terman, and it is now in its fifth revision (Fletcher \& Hattie, 2011; Twomey et al., 2018).

Researchers claim that IQ is a measure of one's general intelligence (' $\mathrm{g}$ ') and that it can change over time because of the cognitive transformation of the brain as one ages, 
but that it cannot be developed with training. It has been widely accepted as a main factor in determining success, and this concept has been mass-marketed in the United States; however, the validity of the measure has been challenged by many researchers over the last 40 years (Fletcher \& Hattie, 2011; Nafukho et al., 2016; Nisbett et al., 2012; Sundem, 2014; Ugoani et al., 2015). Nisbett et al. (2012) state that IQ “is one of psychology's greatest achievements and one of its most controversial" (p. 131), noting that debates continue in several areas, such as the validity of the scale, its reliability in different cultural contexts, and its potential for misuse. Similarly, Ugoani et al. (2015) argue that IQ is controversial because it relies on situational factors to predict achievement.

Although historically the study of intelligence centered on analytic processes, "theorists [soon] began to hypothesize that perhaps cognitive intelligence, as measured by IQ tests, does not encompass intelligence in its entirety" (Ugoani et al., 2015, p. 564), and that perhaps there are multiple types of intelligence that have a larger impact on success than previously thought. It has, however, taken many years for this idea to take root. Thorndike (1920) "hypothesized that intelligence had academic as well as emotional and social components" (as cited in Nafukho et al., 2016, pp. 72-73) and Wechsler (1940) argued that intelligence was composed of "intellective and non-intellective factors that determine intelligent behavior" (pp. 444-445, as cited in Nafukho et al., 2016, p. 73). More recently, Sundem (2014) claimed that the practical intelligence that allows individuals to complete "grocery store math," which many intellectually gifted individuals lack, is a type of intelligence largely distinct from general intelligence. He reasoned that "the intelligence we measure has little to do with the intelligence we 
express in our lives" (p. 15). He also posited that there is a disconnect between intelligence and success, which he claimed explains the existence of "gifted idiots" (p. 16) who experience much less success than their IQ predicts, as well as individuals who excel in narrow areas who experience more success than their IQ predicts.

Gardner (1983) took the idea of multiple intelligences further, when he popularized the concept of eight distinct types of intelligences: linguistic, musical, logical-mathematical, spatial, bodily-kinesthetic, interpersonal, intrapersonal, and naturalistic. He proposed that these intelligences are just as important as the analytic type of intelligence measured by IQ tests. Gardner's research paved the way for theories of emotional intelligence, which are similar to Gardner's interpersonal intelligence- the ability to understand and appreciate other people's feelings, fears, and motives - and intrapersonal intelligence - the ability to understand and appreciate one's own feelings, fears, and motives (Dolev \& Leshem, 2017; McCleskey, 2012).

\section{Emotional Intelligence}

Many researchers credit Salovey and Mayer (1990) with originating the term emotional intelligence as we know it today (McCleskey, 2012; Ugoani et al., 2015). Salovey and Mayer's (1990) definition is used to describe emotional intelligence as involving "the ability to monitor one's own and others' feelings and emotions, to discriminate among them and to use this information to guide one's thinking and actions" (p. 189). Although this definition is widely considered by scholars to be the most accepted theory on emotional intelligence, Goleman's (1997) theory is likely the most well-known outside of the scientific community. Goleman saw the utility of emotional 
intelligence for its practical application in the workplace, and his theory was well received by corporate America after the publishing of his bestselling book Emotional Intelligence: Why It Can Matter More Than IQ. There are key elements that differentiate Goleman's (1997) theory from that of Salovey and Mayer, and as interest in the study of emotional intelligence has grown, many other researchers have developed alternate theories and definitions (Bar-On, 2004, 2006; Gignac, 2010; Kaplan et al., 2010; Law et al., 2004; Petrides, 2010; Schutte et al., 1998). These theories continue to shape the field and spur disagreement and controversy among experts. However, for the purpose of this review, I have grouped the research on emotional intelligence into three categories: ability-based models, mixed models, and trait-based models.

Ability-based models center on the belief that emotional intelligence is an ability that is highly correlated with general intelligence, can be tested using objective criteria, and can develop over time because of the cognitive changes of the brain as one ages but, like IQ, cannot be directly developed with training (Antonakis \& Dietz, 2010; Gignac, 2010; Salovey \& Mayer, 1990). Therefore, researchers who support ability-based theories are mainly interested in researching how emotional intelligence affects success and performance as part of one's general intelligence but not in how to use this knowledge to improve performance. As with IQ, the main purpose of ability-based models is to classify people so that researchers can understand them but not necessarily to help them.

Mixed models of emotional intelligence are based on the belief that one's emotional intelligence level is dependent, in part, on ability and that some people are naturally more emotionally intelligent than others; however, proponents of the mixed 
model also believe that emotional intelligence is a skill or competency that can be developed through awareness and training (Boyatzis, 2009, 2018; Bradberry \& Greaves, 2009; Goleman, 1997). Therefore, unlike the ability-based models, the main purpose of the mixed model is to highlight the importance of emotional intelligence in life and to help people improve their emotional intelligence to achieve more success.

Trait-based emotional intelligence is used by some researchers to refer to mixed models of emotional intelligence because the mixed models generally include both ability and trait-based aspects (Tang et al., 2010). However, for the purpose of this examination, trait-based emotional intelligence refers to models that are based on the assumption that personality traits lie outside the cognitive sphere of influence, thus distinguishing the trait-based models from mixed models and changing the operationalization of the construct (Ugoani et al., 2015).

Although several ability-based models exist, the Mayer ability model, developed by Salovey and Mayer (1990), is the best known and commonly accepted ability-based model within the field (McCleskey, 2012). This model evaluates four basic emotionbased abilities: perception of emotions, facilitation of thought based on emotions, understanding of emotions, and regulation of emotions (Salovey \& Mayer, 1990). The Mayer-Salovey-Caruso Emotional Intelligence Test (MSCEIT) was developed to measure each of the emotion-based abilities considered by the Mayer ability model and includes 141 “emotion-based-problem-solving items" (Ugoani et al., 2015, p. 567) that objectively assess an individual's emotional intelligence. 
Like the Mayer ability model, the Goleman et al. $(2001,2013)$ mixed model involves four constructs that make up emotional intelligence; however, unlike the Mayer ability model, its constructs are linked to effective performance in the workplace and include the following four clusters of emotional-intelligence competencies: selfawareness, self-management, social awareness, and relationship management (Goleman et al., 2001, 2013). The model was built on the premise that individuals are born either with or without an aptitude for emotional intelligence but that each emotionalintelligence construct includes emotional skills and competencies that can be developed to improve emotional intelligence, thereby improving interpersonal relationships and success in the workplace. Based on his original theory, developed in 1995, and the resulting model, Goleman developed the Emotional Competency Inventory (ECI) in 2001 to measure emotional intelligence (Ugoani et al., 2015). The ECI is comprised of 72 items and allows for self-reporting, direct reporting, and peer rating, providing 360degree feedback (McCleskey, 2012).

Another relevant mixed model based on the premise that emotional intelligence can be developed and improved is the model developed by Bar-On (Ugoani et al., 2015). Several researchers claim that Bar-On's ideas on emotional intelligence predate those of Salovey and Mayer (1990), as he purportedly used the term emotional intelligence in the unpublished version of his doctoral dissertation in 1985; however, Bar-On did not formally publish his ideas until 1997 (Ugoani et al., 2015). Bar-On (1997) defines emotional intelligence as "a cross-section of interrelated emotional and social competencies, skills and facilitators that determine how effectively we understand and 
express ourselves, understand others and relate with them, and cope with daily demands" (p. 14, as cited in Nafukho et al., 2016, p. 73). His model consists of five dimensions that encompass the following social skills and personality traits: intrapersonal, interpersonal, adaptability, stress management, and general mood (Nafukho et al., 2016). Bar-On developed an emotional quotient inventory (EQ-i) to measure these five dimensions. It was originally designed as a self-report measure (Ugoani et al., 2015) but, like the ECI, it now allows for 360-degree feedback (McCleskey, 2012). The EQ-i consists of 133 items scored on a 5-point Likert scale (Ugoani et al., 2015).

Petrides' (2010) trait-based emotional intelligence model does not see emotional intelligence as an ability, as Salovey and Mayer (1990) argue, or as a set of skills and competencies, as Goleman (1997) contends, but instead as a personality trait "that lies outside the taxonomy of human cognitive ability" (Ugoani, et al., 2015, p. 568). Petrides (2010) states that emotional intelligence is a "constellation of emotional self-perceptions located at the lower levels of personality hierarchies" (p. 137). His model of emotional intelligence includes four components: well-being, sociability, self-control, and emotionality. These components can be measured with Petrides' Trait Emotional Intelligence Questionnaire (TEIQue), a self-report instrument that is available in two versions: a short version, consisting of 30 items, and a long version, consisting of 153 items (McCleskey, 2012).

\section{Emotional Intelligence in K-12 Education}

History of Emotional Intelligence Integration in K-12 Education. Emotional intelligence has become a popular concept in $\mathrm{K}-12$ education but was not widely 
implemented until the later part of the 21st century. Researchers began studying the importance of emotional intelligence in K-12 education in the 1960s, when Dr. James Comer developed the Comer School Development Program at Yale University to focus on the impacts of psychosocial development on student achievement (Comer, 2020; Effrem \& Robbins, 2019). Comer's work continued and eventually contributed to the development of the K-12 New Haven Social Development Program—created by Yale psychology and education professor Dr. Roger Weissberg and disability rights activist Mr. Timothy Shriver, to promote concepts, such as self-awareness and self-management among students - as well as the creation of the William T. Grant Consortium for SchoolBased Promotion of Social Competence, which was co-chaired by Dr. Weissberg (Effrem \& Robbins, 2019; Weissberg, 2019).

In 1994, the Fetzer Institute hosted a conference to discuss school-based efforts to address the psychological and developmental needs of children. According to Elbertson et al. (2010), this event led to the establishment of the Collaborative to Advance Social and Emotional Learning — now the Collaborative for Academic, Social, and Emotional Learning (CASEL) — which adopted five core competencies: self-awareness, selfmanagement, social awareness, relationship skills, and responsible decision-making. It was also at this conference that the term social-emotional learning (SEL) was first introduced. As a result, educators and organizations involved in PK-12 education often refer to emotional intelligence as social-emotional intelligence/competence and refer to the development of emotional intelligence in children as SEL. 
Both Weissberg and Shriver continue to be heavily involved in CASEL, and their work continues to play a large role in promoting the importance of teaching social and emotional skills to PK-12 students (Effrem \& Robbins, 2019; Weissberg, 2019). In collaboration with other researchers, they have produced several influential works that have helped grow the SEL field, including Promoting Social and Emotional Learning: Guidelines for Educators (Elias et al., 1997), Safe and Sound: An Educational Leaders' Guide to Evidence-Based Social and Emotional Learning Programs (Collaborative for Academic, Social, and Emotional Learning, 2005), and Handbook of Social and Emotional Learning: Research and Practice (Durlak et al., 2015), among others (Weissberg, 2019).

Federal legislation has also had an impact on the integration of emotional intelligence into education initiatives in PK-12 schools (Effrem \& Robbins, 2019). In 1994, President Bill Clinton signed the Goals 2000: Educate America Act, which promoted "partnerships that will increase parental involvement and participation in promoting the social, emotional, and academic growth of children" (Goals 2000: Educate America Act, 1994). This work was continued in 2002 with the creation of the No Child Left Behind Act, which resulted in the establishment of mental-health grants that were designed to improve social and emotional development and promote school readiness, as well as more recently, with the Every Student Succeeds Act (ESSA). The ESSA continues to encourage social-emotional learning with programs, such as Head Start; Title I, Title II, and Title IV funding for mental-health services; tiered programs that target behavioral interventions and support; and training for school personnel, as well as 
accountability provisions that include measurement of the emotional climate of schools (Effrem \& Robbins, 2019; Eklund et al., 2018; Grant et al., 2017).

As a result of these legislative efforts, most public-school districts in the United States recognize the need for emotional intelligence and have plans in place to support students in developing social and emotional skills (Eklund et al., 2018; Weissberg, 2019; Yettick, 2018). Eklund et al. (2018) comprehensively reviewed the emotional learning standards in place in the United States using CASEL's core competencies as a framework. They found that all states had freestanding SEL standards for preschool and that 49 states had SEL standards embedded in their health and/or physical education standards at the $\mathrm{K}-12$ level; however, the terminology used to describe the standards varied, and some states did not include all of the core competencies. Ohio was the only state that did not include any of CASEL's competencies within the state's health or PE standards, but they were included in the state's counseling standards. Like many other states, Oregon's state standards include all five core competencies at both the preschool and $\mathrm{K}-12$ levels, and the $\mathrm{K}-12$ standards were embedded in the state's health, $\mathrm{PE}$, and counseling standards.

Effects of K-12 Emotional-Intelligence Standards. Most researchers, educational agencies, and educators seem to agree that SEL programs can lead to positive effects for students, including increasing positive outcomes, such as school attachment (Jennings et al., 2020; Yang et al., 2018), protective factors for at-risk students (Tan et al., 2018), academic engagement (Yang et al., 2018), academic achievement (Bierman et al., 2010; Rutledge et al., 2015), and lifelong effectiveness (Taylor et al., 2017), while 
decreasing negative behaviors, such as aggression (Bierman et al., 2010; Raimundo et al., 2013) and bullying (Espelage et al., 2015; Smith \& Low, 2013), among others (Rutledge et al., 2015). Durlak et al. (2011) comprehensively reviewed 213 studies conducted over a 50-year period ending in 2007 that assessed the development of social-emotional skills in over $270,000 \mathrm{~K}-12$ students participating in whole-school SEL intervention programs. They examined how each intervention used sequenced activities, active learning, a focus on personal or social skills, and explicit SEL targets to develop student skills. They also examined student outcomes, and the types of outcome measures used, in six areassocial and emotional skills, attitudes, behaviors, conduct, emotional distress, and academics - to evaluate the results of each study. They found that SEL programs produced positive student outcomes in a variety of behavioral, attitudinal, and skillsbased areas, as well as an $11 \%$ average gain in academic achievement.

Taylor et al. (2017) sought to extend Durlak et al.'s (2011) work by evaluating how SEL interventions that targeted emotional intelligence in childhood affected wellbeing later in life for diverse populations. They reviewed the follow-up effects of 820 studies that occurred from 1981 to 2014 and that used school-based universal SEL interventions intended to improve the emotional intelligence of over 97,400 K-12 students. They concluded that SEL interventions were beneficial to diverse demographic groups, that students became more resilient and continued on a positive developmental trajectory as a result of SEL intervention, and that students continued to demonstrate benefits for one to 3.75 years on average following the intervention, showing higher levels of wellbeing at follow-up. They also found that some positive effects, such as 
improved social relationships and higher graduation and college attendance rates, and fewer negative outcomes, such as arrests and clinical disorders, were seen up to 18 years post-intervention.

Many researchers believe that these studies, and others like them, indicate that well-designed and implemented SEL programs have the potential to positively impact student outcomes, but some researchers continue to question the strength of this evidence. For example, Effrem and Robbins (2019) claim that the evidence presented by Durlak et al. (2011) is weak because many of the studies did not include post-interventions, the measurement of SEL was not standardized, only a few studies tested the relationship between skill development and positive outcomes, and the majority of the studies $(56 \%)$ focused on elementary-school students. Additionally, they argue that two of the studies included in the meta-analysis did not show positive outcomes. For instance, a study conducted by Duncan (2007) found that measures of social-emotional intelligence did not predict academic performance. Lastly, they claim that there is little conclusive research on the effects of SEL programs because most of the research that has been conducted is outdated and biased. Despite these critiques of SEL research, there is a great deal of evidence indicating that SEL programs have positive effects on outcomes in $\mathrm{K}-12$ students.

Emotional Intelligence in Teachers. Although substantial research has focused on positive outcomes of emotional intelligence programs for students, little attention has been given to the promotion of outcomes in the educators and administrators responsible for supporting students (Herman et al., 2020a, 2020b). Therefore, most of the research 
involving teachers and administrators focuses on how their emotional intelligence can be used to improve student outcomes (Grant et al., 2017; Merritt et al., 2012; Quinlan et al., 2018; Stevenson \& Markowitz, 2019), rather than on how emotional intelligence can be used to improve their ability to manage their own stress and reduce burnout.

Some progress has, however, been made toward understanding the relationship between teachers' emotional intelligence and stress. Researchers have begun to recognize that although a high level of emotional intelligence in teachers can lead to improved student outcomes by fostering positive school relationships (Jennings et al., 2020; Yang et al., 2018), teachers with seemingly high levels of emotional intelligence may still be ill-equipped to deal with negative emotions, such as stress and emotional exhaustion. Joseph and George (2018) reviewed several studies that had contradictory findings regarding the emotional intelligence levels of teachers. Some studies showed that higher levels of emotional intelligence helped teachers reduce stress by creating stronger professional relationships that led to a greater sense of job satisfaction. In contrast, other studies found that teachers with higher emotional intelligence levels often experienced more stress as a result of their emotional intelligence. These seemingly opposite findings indicate that although skill in relationship management can increase resilience by allowing teachers to create stronger relationships, these skills may not help teachers practice the self-care needed to effectively manage their stress levels. These contradictions illustrate the complexity of emotional intelligence and may provide evidence supporting the importance of developing a variety of emotional skills, especially skills that help teachers and administrators manage stress and develop resilience. 
Although the needs of administrators are often neglected, several researchers have developed frameworks aimed at developing mindfulness in teachers. The relationship between mindfulness and emotional intelligence remains unclear; however, many researchers believe that training in mindfulness techniques helps individuals develop selfawareness, an emotional intelligence cluster that forms the foundation for all other emotional intelligence skills (Mager, 2019; Rodríguez-Ledo et al., 2018; Thakrar, 2019; Walters, 2019). Therefore, throughout this literature review, mindfulness will be referred to in conjunction with emotional intelligence. Schonert-Reichl (2017) explored mindfulness-based interventions used to improve teachers' self-awareness and selfmanagement skills to help them manage stress and improve their own health and wellness while fostering positive relationships with their students to improve student outcomes. She found that two programs - the Cultivating Awareness and Resilience in Education (CARE) program and the Stress Management and Relaxation Techniques (SMART) in Education program — were especially effective at decreasing the distress felt by teachers, improving their health and wellbeing, and increasing their compassion for students.

The CARE for Teachers program was developed in 2007 by researchers at Penn State University and the Garrison Institute, and several studies have been conducted to explore the effects of the program on teachers' wellbeing (CREATE for Education, 2021a, 2021c; Jennings et al., 2011). Jennings et al. (2011) conducted two pilot studies with 71 educators to examine the effects in two settings: an urban setting with highpoverty and a suburban/rural setting. Pre- and post-intervention questionnaires were used to assess changes in educator stress and wellbeing, changes in motivational orientation 
and efficacy, and changes in six dimensions of mindfulness. The researchers found that CARE was more effective in the urban setting, indicating that it may be more useful in high-risk school districts.

Schussler et al. (2016) conducted four focus groups with 50 teachers who had participated in CARE to further explore the quantitative results gathered from previous data. They found that as a result of the CARE program, participants developed greater self-care, self-awareness, and self-management skills. Similarly, Sharp and Jennings (2016) used semi-structured interviews to explore previous findings regarding how eight teachers who reported positive changes on five self-report instruments-a time urgency scale, a burnout inventory, an emotion regulation questionnaire, a mindfulness questionnaire, and a daily physical symptoms inventory—applied the mindfulness strategies they learned in the CARE program to their work as educators. The researchers found that the participants integrated mindfulness through the use of CARE metaphors, a present-centered awareness of their emotions, and emotional reappraisal techniques that allowed them to reevaluate situations and shift their perspectives. The participants reported that these practices allowed them to manage their emotional reactions and generate more compassion for their students, which improved their interactions with students.

In another study to examine outcomes of the CARE program, Jennings et al. (2017) assessed its efficacy within 36 urban elementary schools in a high-poverty region of New York City. Two hundred and twenty-four teachers received 30 hours of in-person training from November to February, in addition to completing self-directed activities in 
a workbook, listening to self-directed audio recordings of mindfulness and awareness practices, and participating in three one-on-one phone coaching sessions. The teachers completed self-report measures to assess their adaptive emotion regulation, teaching efficacy, mindfulness, psychological distress, time urgency, and physical distress pre- and post-intervention. Classroom observations were also conducted to assess the interactions between teachers and students in the classroom. The researchers found that the CARE program had positive effects on all elements except teaching efficacy and physical distress, indicating that $\mathrm{CARE}$ is an effective tool for increasing the emotional intelligence of teachers to increase mindfulness, reduce stress, and build a positive classroom environment.

Doyle et al. (2018) extended this research by evaluating three additional components of the CARE program with the same 224 participants: (a) how the program was implemented by trainers; (b) how the participants responded and adhered to the program; and (c) how the participants integrated the CARE techniques into their practices nine months after the training concluded. They found that teacher perceptions of program usefulness were significantly related to how often they practiced and engaged in follow up, as well as to how the program affected their stress levels. They also found that participant responsiveness played a role in the relationship between the facilitation of the program and continued practice and that the quality of the facilitation only affected the outcomes of the training after the participants had a basic level of understanding of the concepts presented. In other words, teacher buy-in was more important than the quality of the facilitation in producing positive results. 
Several researchers argue that mindfulness training programs, such as the CARE program, start with teacher outcomes but that these outcomes eventually lead to student outcomes. Roeser et al. (2012) reviewed popular mindfulness training programs, including CARE; SMART in Education; Inner Resilience; Mindfulness, Courage, and Reflection for Educators; Mindful Schools; and the Passageworks Soul of Education Course for Teachers, and created a logic model to outline the relationship between teacher outcomes and student outcomes. They argue that increasing the health and wellbeing of teachers leads to increased engagement and performance, which then lead to positive school outcomes, such as improved interpersonal relationships and climate, as well as positive student outcomes, such as belonging, engagement, motivation to learn, and academic performance.

Conversely, it follows that failing to address the stress that teachers experience may result in negative student outcomes. Roeser et al. (2012) explain that "teaching is uncertain, emotional, and attentionally demanding work" (p. 168) that requires emotion regulation and relationship-management skills. Without these skills, stress can quickly become distress, leaving teachers without the ability to cope with and recover from stress and diverting their resources toward survival and self-preservation, rather than engaging in the practices that support positive student outcomes (Roeser et al., 2013). Therefore, Roeser et al. (2013) argue that professional learning opportunities for teachers must help them effectively cope with and develop the ability to recover from stress.

Consequently, Roeser et al. (2013) engaged 113 teachers in Canada and the western United States in a study of the effects of the SMART mindfulness training 
program on teacher stress. Like the CARE program, the SMART program uses mindfulness training experientially to focus on stress reduction and resiliency in educators. The researchers used self-report measures and physiological indicators of stress, such as blood pressure and resting heart rate, to determine the stress levels of participants pre-intervention, post-intervention, and three months following the intervention. Additionally, the Canadian participants provided salivary cortisol samples and engaged in additional assessments that measured their working memory and attentional abilities. The participants were divided into experimental and control groups. The experimental group participants completed 36 hours of SMART training, divided into 11 sessions over an eight-week period, during which time they engaged in activities designed to encourage mindfulness and self-compassion as resources for coping with stress and manifesting emotional resilience. The researchers found that the experimental groups experienced a higher level of mindfulness and self-compassion and a lower level of stress and burnout than the control groups, and the Canadian experimental group also showed improvements in their attentional abilities and working memory. However, the researchers did not find evidence of statistically significant effects in the physiological indicators.

Other researchers have had similar findings. Ragoonaden (2017) studied the effects of the Canadian version of the SMART in Education program on 60 preservice elementary teachers using the Five Factor Mindfulness Questionnaire, practice logs, and an assignment that was part of their educational program. They found that the participants' mindfulness scores increased post-intervention, and they became less 
reactive with modest decreases in stress. Additionally, Crain et al. (2017) found that the SMART program improved mood and sleep at post-intervention and at the 3-month follow up. Chesak et al. (2019) also found significant improvements on participant stress, anxiety, gratitude, happiness, life satisfaction, and quality of life after they participated in a condensed version of SMART that included a 90-minute session to go over the core components, followed by eight 1-hour teleconferences over a year's time, during which participants were encouraged to read the Mayo Clinic Guide to Stress-Free Living book and complete 12 SMART modules, while practicing the mindfulness activities included.

Although some professional development programs for teachers, such as the SMART program, include training that acknowledges the importance of improving the ability of teachers to cope with and recover from stress, several researchers point out that this element is largely absent from teacher preparation programs and argue that this leaves new teachers unprepared for the challenges they will face (Roeser et al., 2012; Schonert-Reichl et al., 2015). Schonert-Reichl et al. (2015) explored the preservice standards for state-approved teacher preparation programs in all 50 states to determine whether they conveyed the need for emotional intelligence. They analyzed the degree to which the standards indicated that teachers were required to be taught to develop emotional intelligence, including (a) developing their own emotional intelligence using CASEL's five core competencies; (b) developing the emotional intelligence of their students; and (c) developing an educational environment that promotes emotional intelligence. The researchers found that teacher emotional intelligence was given very little attention in the state standards and that the competencies of self-awareness and self- 
management were largely neglected. They also found that there were few state-level standards focused on promoting the emotional intelligence of students in a comprehensive way, with only $33 \%$ of the states addressing all of CASEL's core competencies. However, they did find that most states included standards related to the educational environment, such as standards that encourage school-wide coordination and school-family partnerships that support student success.

Other researchers have explored the value of preservice courses that include emotional intelligence. Joseph and George (2018) reviewed the literature and found that previous research indicates that emotional intelligence training has positive effects on increasing the emotional skills of preservice teachers. Similarly, Waajid et al. (2013) sought to determine how courses that include emotional intelligence influence preservice teachers' views of emotion in the classroom, as well as how teacher preparation programs can prepare future teachers to focus on SEL. They examined the reflective assignments of twelve students in their senior year of a teacher preparation program and found that a focus on emotional intelligence was necessary to shift to student-centered pedagogy, help students develop a greater appreciation of SEL, and develop a desire to learn more.

Therefore, research indicates that it is very likely that emotional intelligence training is beneficial for increasing both student outcomes and teacher outcomes. The use of SEL programs to develop the emotional intelligence skills of students is widespread; however, the use of similar programs to develop the emotional intelligence skills of teachers is limited. However, although researchers have begun to recognize the need for professional learning opportunities that focus on increasing the health, wellbeing, and 
resilience of $\mathrm{K}-12$ teachers, there are very few studies that focus on the emotional needs of principals.

Emotional Intelligence of Principals. Researchers have explored how the emotional intelligence of $\mathrm{K}-12$ principals relates to transformational leadership (Wang et al., 2016), the management of change efforts (Tai \& Kareem, 2018), teacher job satisfaction (Swift, 2018), teacher efficacy (Leonard \& Maulding Green, 2018), teacher attitudes (Simms, 2016), the improvement of instructional strategies (Chen \& Guo, 2020), school climate (Allred et al., 2016; Mason, 2018; Noe, 2012), and school outcomes (Kline, 2011; Noe, 2012; Pervez et al., 2016). However, very little attention has been placed on how emotional intelligence can be used to increase the health, wellbeing, and resilience of principals, despite evidence that, like teachers, most principals are under incredible amounts of stress that often leads to burnout and turnover (Bartanen et al., 2019; Grissom \& Bartanen, 2019; Levin \& Bradley, 2019).

Recently, as mindfulness training has become a more popular intervention used to increase a teacher's ability to manage and bounce back from stress, some researchers have begun exploring the use of mindfulness training with principals. Wells (2013) conducted a conceptual review of over 30 years of research on principal stress and the interventions used to respond to principal stress. Wells (2015) expanded this review to include emotional intelligence, neuroscience findings, and resonant leadership, concluding that mindfulness practices may be a viable option to counteract principal stress. Klocko and Wells (2015) continued this exploration by studying the stress levels of $708 \mathrm{~K}-12$ principals in a midwestern U.S. state to measure trends in stress and 
principal attitudes over time in response to state accountability pressure. They found that the principals experienced chronic levels of stress that increased significantly from 2009 to 2012. They inferred that because it was unlikely that job expectations for principals would decrease under the current educational framework, principals needed to find ways to manage their stress and proposed mindfulness practices as a practical solution. Wells and Klocko (2018) expanded on these findings by reviewing the literature regarding physician stress and burnout, uncovering several parallels between the work that physicians do and the work that principals do, such as working long hours, dealing with a variety of complex issues in relative isolation, being subject to public scrutiny and legal threats, and difficulty setting boundaries to protect their personal life. Therefore, they argued that because mindfulness practices have been used successfully with physicians to reduce stress and burnout, these practices may also have positive implications for principals.

Although this research indicates that principals experience a great deal of stress and that mindfulness practices may help principals manage and recover from stress better, very little research has been conducted regarding how principals respond to mindfulness training. Some insight has been gained from several whole-school SEL programs, which have been developed to recognize the importance of all stakeholders and strengthen the emotional intelligence of all community members, including administrators. For example, Elbertson et al. (2010) and Stillman et al. (2018) have researched the effects of such programs on positive outcomes for participants; however, the research focus remained on the effects experienced by teachers and students. 
CREATE for Education, a non-profit organization that serves educators with the goal "to nurture healthy, caring, equitable school communities that support social and emotional learning and teacher and principal wellness" (CREATE for Education, 2021b, para. 1) has recently adapted the CARE for Education program to meet the needs of principals. With several years of data now available, researchers have begun to study the effects of the program. One such researcher has followed the experiences of 13 principals at six public schools in a mid-sized school district who were engaging in the CARE program (Mahfouz, 2017, 2018a, 2018b). She interviewed the principals before and after their participation, observed their CARE training sessions, shadowed them in their schools, and conducted a survey of their perceptions to explore how mindfulness practices affected their leadership. She found that the principals reported experiencing chronic stress, and although some of them were somewhat resistant to the CARE program, the practices they learned generally led to positive outcomes. These outcomes included an increase in emotional intelligence skills, such as self-awareness, selfmanagement, and self-compassion, all of which helped them manage their stress levels. Mahfouz and Gordon (2020) suggests seven action steps that can be taken to help principals develop their emotional intelligence:

- formalizing self-care in the leadership standards;

- creating an environment where self-care is valued and supported for all staff, including leaders;

- implementing professional development programs for school leaders that include emotional intelligence training and mindfulness practices; 
- promoting coaching and mentoring as sources of support;

- embedding SEL in all aspects of district and state policies, including strategic plans, curricula, standards, and budgets;

- committing to long-term principal assignments; and

- prioritizing SEL by tying it to measurements of student performance.

These action items present a framework for the integration of emotional intelligence into all elements of the K-12 school structure, including leadership practices. Although there is a limited amount of research on how emotional intelligence helps principals manage and recover from occupational stress, there is evidence to suggest that it is an important component of effective leadership practices (Doe et al., 2015; Ugoani et al., 2015).

\section{Leadership}

Although research indicates that skillful and effective leadership is critical for the success of both employers and employees across fields, leadership is inherently complex. This complexity has driven researchers to search for leadership practices and models that have a large impact on outcomes while seeking to develop programs that help leaders acquire the skills they need to be successful and meet the needs of the U.S. companies, institutions, and organizations that spend nearly $\$ 14$ billion annually on leadership development programs (Gurdjian et al., 2014). As a result, the concept of effective leadership has continued to evolve over time.

Transactional Leadership. Beginning in the 1940s, transactional leadership, which is characterized by "the establishment of fair and stable exchange relationships" (Zacher \& Johnson, 2015, p. 1212), was a common style of leadership. Transactional 
leaders clarify responsibilities and expectations, help their followers set goals, monitor follower progress, and provide rewards for high levels of performance (McCleskey, 2014; Zacher \& Johnson, 2015). Researchers have found that these practices are effective in some settings and generally have positive effects; however, over time, research has shown that the rewards-based system used by transactional leaders may not provide enough intrinsic motivation to inspire the creativity needed to stimulate innovation and organizational success (McCleskey, 2014; Zacher \& Johnson, 2015). Further, some researchers have found that transactional leaders may develop dissonant behaviors, such as micromanagement, as well as coercive or authoritarian practices that have negative effects on an organization (Hofmeyer et al., 2015; Martin et al., 2003).

Servant Leadership. In the 1970s, Robert Greenleaf popularized the idea of servant leadership (Boyum, 2008). Servant leadership interweaves the concepts of serving and leading to such an extent that neither concept outweighs the importance of the other. According to Boyum (2008) and Sendjaya and Sarros (2002), a servant leader is an individual whose dedication to community and the common good inspires others. They list 10 practices of servant leaders: listening, which conveys a desire to understand others' points of view; empathy, which shows dedication to interpersonal relationships; healing, which represents a dedication to wellness; persuasion, which increases understanding and promotes knowledge; awareness, which promotes authenticity and trust; foresight, which helps one predict what will happen in the near future; conceptualization, which reveals the importance of the big picture as well as its parts; commitment to growth, which demonstrates a commitment to knowledge; stewardship, 
which conveys a responsibility to benevolence and nonmaleficence; and commitment to community, which acknowledges the importance of relationships. Crippen (2010) argues that there should be 11 traits and adds calling to his list (p. 33), as he claims that calling allows one to serve without ambition.

Furthermore, intention is a critical piece of servant leadership. Boyum (2008) and Sendjaya and Sarros (2002) both discuss the responsibility of servant leaders to put the needs of others above their own needs. This seems to imply the need for a lack of selfcare in leaders. However, when evaluating a leader's practices, one must consider the leader's intentions. Is the leader's intention to take care of themself so that they can serve others, rather than to put their needs above the needs of others? Is the leader's intention to gain recognition for themself or their team, rather than to help others within their community grow and improve? In servant leadership, the intentions behind a leader's actions and practices, must always be in the service of others.

Transformational Leadership. Transformational leadership, is a leadership approach that helps transform individuals and organizations, sharing some characteristics with servant leadership but with differences in conceptualization. Transformational leaders are described as leaders who care deeply about the personal development of their followers and build interpersonal relationships that promote learning, motivate development, and inspire high levels of performance (Hofmeyer et al., 2015; Martin et al., 2003; Zacher \& Johnson, 2015). In other words, transformational leaders have high levels of emotional intelligence. Boyum (2008) claimed that servant leadership and transformational leadership have the same philosophical foundations; however, 
transformational leadership is distinct in that its leaders and followers both seek actions that improve one another's lives, thereby benefiting from a reciprocal relationship. Stone et al. (2003), on the other hand, differentiated transformational leadership from servant leadership based on the leader's focus, claiming that transformational leaders focus on the organization's needs, rather than an individual's needs. Other researchers have identified the fact that transformational leaders are better equipped to motivate and inspire followers as a key element that elevates the transformational style above other models (Hofmeyer et al., 2015; Martin et al., 2003). Transformational leadership includes all the positive traits that are often cited in other models of high-quality leadership, such as collaboration, emotional intelligence, and the ability to drive positive change, while avoiding the potentially negative effects of transactional leadership, such as a tendency towards micromanagement and authoritarian practices (Hofmeyer et al., 2015; Martin et al., 2003; Zacher \& Johnson, 2015).

Research indicates that transformational leadership is likely the most accepted and widely tested leadership model. Leithwood and Sun (2012) explored the results of 79 unpublished theses and dissertations that used quantitative methods to study transformational school leadership and found that transformational leadership positively affected teachers' behaviors and influenced the whole-school environment. Zacher and Johnson (2015) explored how the transformational leadership of teachers affected student creativity and found that transformational leadership positively predicted creativity. Similarly, Leithwood and Jantzi (1999) explored the effects of the transformational leadership of principals and teachers on 9,941 students attending 110 schools in a large 
Canadian school district that was facing several important change initiatives. Survey results indicated that teacher leadership had a statistically significant effect on student engagement, but the effect was weak. In contrast, principal leadership had a greater effect than teacher leadership and explained $27 \%$ of the variation in the school conditions measured, which is a large effect when compared with other studies on educational factors that relate to school effectiveness.

\section{Emotional Intelligence in Leadership}

Regardless of the leadership style in use, emotional intelligence is an integral component of effective leadership. Ugoani et al. (2015) found that leaders need emotional intelligence to develop healthy relationships and manage conflict. They used the emotional intelligence scale developed by Schutte et al. (1998) to survey 47 working adults engaged in different industries in Nigeria and investigate the relationship between emotional intelligence and transformational leadership. They found that emotional intelligence was strongly correlated with transformational leadership metrics and concluded that " 90 percent of leadership success is accounted for by emotional intelligence" (p. 564).

Similarly, Tang et al. (2010) sought to understand how emotional intelligence is related to transformational leadership practices and whether cross-cultural differences exist in the emotional intelligence of leaders. They asked 100 academic leaders -50 from the U.S. and 50 from Taiwan — to self-report on leadership practices and emotional intelligence. They found that some cultural differences existed between U.S. and Taiwanese leaders but that there were also many similarities. For example, they found 
positive relationships between the emotional intelligence of the participants and several relationship-oriented leadership practices, and they found that as overall emotional intelligence increased, the overall leadership effectiveness of leaders in both cultures increased. They concluded that emotional intelligence is an "underlying competency for effective academic leadership in both cultures" (p. 918).

Although research indicates that there is a likely relationship between emotional intelligence and transformational leadership, some researchers have not found a link between emotional intelligence and transformational leadership. Føllesdal and Hagtvet (2013) investigated the extent to which an individual's ability-based emotional intelligence scores on the MSCEIT predicted transformational leadership when controlling for age, personality factors, and general mental ability. One hundred and eleven leaders took the MSCEIT to determine their emotional intelligence levels, while 459 of their subordinates, approximately five per leader, completed a transformational leadership assessment that measured four components: idealized influence, inspirational motivation, intellectual stimulation, and individualized consideration. The researchers found that the leaders' MSCEIT scores did not predict transformational leadership as reported by their subordinates.

Whereas some researchers have studied the relationship between emotional intelligence and specific leadership models, other researchers have used brain science to explain the importance of emotional intelligence in leadership. Doe et al. (2015) discussed the disparity between IQ and success and cited examples, such as the bankruptcy of Enron, the fallout from the British Petroleum Deepwater Horizon oil spill, 
and the mishandling of Hurricane Katrina, which they claimed highlight the failures of highly intelligent leaders who were unable to effectively manage their own emotions, understand other's emotions, and manage relationships with their stakeholders. They argued that although one's general intelligence and emotional intelligence work together, emotional intelligence is a greater predictor of success. They used brain science to describe the complex interplay between the cortex, the rational center of the brain, and the amygdala, the emotional center of the brain, and explained that the amygdala reacts more quickly than the cortex and can override the cortex during challenging moments to protect one from danger. They concluded that this protective feature can result in nonemotionally intelligent decision-making unless leaders are trained to modify their behavior to make emotionally intelligent decisions.

Similarly, Goleman and Boyatzis (2008) described examples of leaders who were hired because of their general intelligence and were later fired because of their social intelligence. They further discussed discoveries in neuroscience that explain how mirror neurons, spindle cells, and oscillators allow a leader's brain to sync up with the brains of their followers as a measure of emotional intelligence. They claim that neural circuits, which provide a foundation for interpersonal relationships, have a physical effect on both the leader's brain and the follower's brain and that this effect has practical implications in the workplace. For example, they cited research that shows that people who received positive feedback with negative emotional signals felt worse about their performance than people who received negative feedback with positive emotional signals. This indicates that positive emotional signals, including smiles and laughter, can buffer the 
effects of negative information. Therefore, Goleman and Boyatzis (2008) claim that just as stress and tension can spread throughout an organization to affect others, so can joy and positivity.

\section{Academic Leadership}

There are myriad factors that contribute to effective leadership in an academic environment, and it is evident that quality leadership affects student and teacher outcomes at both the K-12 and post-secondary levels. Research indicates that leadership style has the potential to affect student creativity (Zacher \& Johnson, 2015), student achievement (Marzano et al., 2005; Noe, 2012), the instructional methods used by teachers (Hofmeyer et al., 2015; Martin et al., 2003), teacher burnout and turnover (Ford et al., 2019), and school climate (Ford et al., 2019; Leithwood \& Sun, 2012; Noe, 2012), among other elements.

Zacher and Johnson (2015) surveyed 71 pairs of graduate advisors and PhD students and found that advisors who were perceived as having transformational leadership styles inspired more creativity in their students. According to the researchers, transformational leadership increases motivation and inspiration by stimulating "independent and creative thinking, and [providing] a psychologically safe, personcentered, and caring working environment" (p. 1214). This indicates that advisors who are transformational leaders help their students develop creative thinking skills and motivate them through providing a positive, healthy environment.

Furthermore, in the same way that a student's approach to learning is guided by the educational context of that learning, a teacher's approach to teaching is guided by the 
administrative context in which the teacher teaches (Hofmeyer et al., 2015; Martin et al., 2003). In a study of how teachers' perceptions of departmental leadership affected their approaches to teaching, Martin et al. (2003) found that teachers' experiences of academic leadership affected the methods they used with their students. According to the researchers,

the more collaborative approaches to the leadership of teaching at the individual subject level are associated with more conceptual change-oriented and studentfocused approaches to teaching... [which] are associated with deeper approaches to learning... [suggesting] that the way in which teachers experience the leadership of their department is an important precursor to the quality of student learning processes and outcomes in their departments. (pp. 257-258)

Therefore, teachers who perceive their supervisors as transformational leaders tend not to adopt an information-transmission/teacher-focused approach to teaching and are more likely to adopt a student-centered approach (Martin et al., 2003).

Similarly, Hofmeyer et al. (2015) found that the system used by academic leadership to recognize and reward teachers in higher education had negative effects on student outcomes because the system rewarded research over the leadership of teaching. According to Hofmeyer et al. (2015), "this message that research is the top priority in higher education undermines and disenfranchises individuals committed to leadership in learning and teaching for students" (p. 188). They argue that collaborative models of leadership promote learning and teaching and that student outcomes will be improved when teachers are consistently rewarded for focusing on teaching, rather than research. 
Although the context of research versus teaching may not apply at the K-12 level, the same concepts are relevant, as academic leaders' actions have widespread consequences on the instructional techniques used by teachers, as well as on student achievement and school climate.

Marzano et al. (2005) conducted a meta-analysis that reviewed over 30 years of research and 5,000 studies on the effects of K-12 school leadership. They identified 69 studies - which included 2,802 schools and an estimate of 14,000 teachers and 1,400,000 students - that explored the relationship between principal leadership and the academic achievement of students, as measured by a standardized achievement test. Each of the studies included either reported effect sizes in correlation form or included enough information for the researchers to compute the effect sizes themselves. Based on this review, they found that 21 leader responsibilities have a statistically significant association with student achievement.

Marzano et al. (2005) did not identify emotional intelligence as one of the leadership responsibilities that affect student achievement, although several of the responsibilities identified in their list involve emotional intelligence-specifically the responsibilities of communication, culture, relationships, and situational awarenessindicating that emotional intelligence may play a role in improving student outcomes. However, the relationship between the emotional intelligence of principals and student outcomes is indirect at best and remains unclear. This lack of clarity is evidenced by a study by Noe (2012), which explored the relationship between secondary-level principals' emotional intelligence, school culture, and student achievement. Using data 
from standardized tests and two instruments that measured principal emotional intelligence and school culture, he found that neither principal emotional intelligence nor school culture predicted student achievement.

Although it may be difficult to tie student outcomes directly to the emotional intelligence of academic leaders, several researchers have reported that emotional intelligence is a key component of effective school leadership (Blaik Hourani et al., 2020; Ford et al., 2019; Mason, 2018). Ford et al. (2019) claim that school leaders can reduce turnover and affect the attitudes and emotions of teachers by supporting their psychological needs. Through a multilevel path analysis and a sample of over 1,500 teachers at 73 schools in an urban school district in the midwestern U.S., they found that working conditions were a key predictor of teacher turnover and that administrative support was a key factor affecting working conditions. They argue that school leaders must work with teachers one-on-one to support their psychological needs. They recommend engaging in intentional conversations with individual teachers to improve both their personal and professional relationships and engaging in schoolwide efforts to build trust, increase autonomy, and increase relatedness to improve the overall climate and social conditions of the school. In addition, they claim that these activities lead to positive emotional and behavioral outcomes, including decreased stress and burnout, decreased turnover, increased organizational commitment, and an improvement in job satisfaction.

Other researchers have found that emotional intelligence leads to innovative leadership practices. Blaik Hourani et al. (2020) interviewed 27 school leaders and 
managers in Abu Dhabi using Boyatzis and Goleman's mixed model of emotional intelligence and Van der Vyver et al.'s human capital theory to examine how they used emotional intelligence professionally. They found that the school leaders used emotional intelligence to support motivation, self-reflection, anger management, stress management, and social skills that led to trust, collaboration, teamwork, and innovation.

Similarly, Mason (2018) examined the role that emotional intelligence plays in establishing a school culture and sought to understand how a principal's daily leadership practices include emotional intelligence. She interviewed four high-school principals with more than five years of experience who were working in the southeastern U.S., conducted focus groups with each of them and four to five of the teachers who worked for them, collected short surveys from each that included four open-ended questions about emotional intelligence and leadership, and conducted a document review process that included a card-sorting activity using the 21 leadership responsibilities from Marzano et al. (2005). She found that school leaders use emotional intelligence skills to build positive relationships, set the emotional tone of the school, and manage conflict and resistance to change.

While many researchers have recognized that emotionally intelligent leadership may be necessary to build trust, inspire excellence, and improve student achievement in academic environments, several researchers also emphasize the importance of change management (Fullan, 2011; Fullan \& Scott, 2009; Marx, 2006). Fullan and Scott (2009) argue that turnaround leadership is needed to respond to an increase in change forces that are affecting the educational landscape. They claim that turnaround leaders must listen, 
link, lead, model, teach, and learn to manage change effectively. They must listen to stakeholders in order to diagnose the situation, link together what is learned, and lead in partnership with others by doing and learning while modeling a culture that supports change, teaching their staff how to implement change, and experimenting to learn what works. Transformational leaders and turnaround leaders have several things in common: they build trust and confidence by investing in interpersonal relationships, supporting people, and inspiring creative problem-solving to respond to problems (Boyum, 2008; Fullan \& Scott, 2009; Sendjaya \& Sarros, 2002).

\section{Leading During Covid-19}

The ability to inspire trust and confidence, while creatively responding to problems, is especially important in today's social and political climate as educators face constant changes, turbulence, and uncertainty due to the Covid-19 pandemic. Cavins (2021) discusses the concept of wicked problems, problems that are unprecedented in history and that are incredibly complex because of their relationships with other existing problems and the high-stakes risks and impacts of their possible solutions. Covid-19 is such a problem, which makes its role in educational leadership inherently difficult to define and solve.

Several researchers have conducted literature reviews to understand how Covid19 may be affecting occupational stress and how leaders can support the needs of their employees. Extremera (2020) reviewed the literature to explore how emotional intelligence can support stress management in response to Covid-19. He found that there are intrapersonal and interpersonal psychosocial processes of emotional intelligence that 
can provide a framework for understanding how Covid-19 is affecting people. According to his synthesis of the literature, individuals with high intrapersonal emotional intelligence generally have a lower emotional intensity, have more effective coping strategies, have the ability to process negative emotions better, and tend to engage in healthier lifestyle habits than those with low levels of emotional intelligence. These skills may affect how they manage the uncertainty and stress caused by Covid-19. Furthermore, Extremera (2020) suggests that interpersonal psychosocial processes related to how selfisolation is affecting social relationships, how people are prioritizing altruistic and socially cohesive behaviors, as well as how negative emotions caused by the pandemic might affect one's level of tolerance and empathy, provide avenues for future research.

Cavins (2021) reviewed the literature to develop a conceptual framework to help leaders manage the effects of Covid-19 by integrating emotional intelligence into their leadership practices. He found that there are four elements needed to resolve wicked problems: self-actualization to remain confident under the pressures of uncertainty; social responsibility to create a foundation of caring, concern, and collective support within the organization; optimism to support resilience and motivate their followers; and stress tolerance to control their own reactions while modeling resilience.

Some researchers have extended this line of research by exploring how the responses of academic leaders to the Covid-19 pandemic have affected teacher stress and student success. Chaseling et al. (2020) interviewed five secondary-level principals in New South Wales, Australia regarding the transition to remote learning during the pandemic. They found that the pandemic caused several problems that interfered with 
remote learning, such as students having to work in response to their parents' unemployment, limited access to technology and the internet, interpersonal issues like domestic violence, and increased feelings of stress and anxiety. Despite these challenges, they claim that some good has come from the pandemic, as it highlighted the equity gap in Australia and made the disparity between schools difficult to ignore. Additionally, the authors emphasize that the interviews that were conducted demonstrated that the principals were hyper-focused on the welfare of both students and families during the pandemic.

Other researchers have explored the effects of Covid-19 on teacher outcomes. Collie (2021) recruited 325 teachers in eight Australian states to complete an online questionnaire that examined the role of autonomy-supportive and autonomy-thwarting leadership on workplace buoyancy and the stress, emotional exhaustion, and somatic burden felt by Australian teachers during the Covid-19-related school closures. She found that autonomy-supportive leadership was related to higher levels of workplace buoyancy and lower levels of stress, emotional exhaustion, and somatic burden, while autonomythwarting leadership was related to higher levels of emotional exhaustion. She found that teaching in a completely remote capacity was less stressful for teachers than teaching in a hybrid environment, although emotional exhaustion was not yet evident in teachers working in a hybrid format. Unexpectedly, she also found that reduced work due to Covid-19 was related both to greater workplace buoyancy and a greater somatic burden. The author speculates that the increased somatic burden may have been in response to increased financial concerns, which have been shown to be associated with health 
complaints in other lines of research. Her research indicates that transitioning to a fully remote teaching environment resulted in the best outcomes for teachers.

Lastly, Fernandez and Shaw (2020) examined the academic systems that supported the rapid transition to remote learning due to Covid-19, which they claim emphasize the importance of a leader's capacity to learn and evolve in a crisis. They promote servant leadership, shared leadership, and quality communication as best practices for navigating the unpredictable adaptive challenges that Covid-19 caused. First, they claim that servant leadership is necessary to build the trust, collaboration, connection, and empowerment needed to manage transformative change, arguing that academic leaders must make the welfare and safety of teachers, staff, and students their top priority, which requires both emotional intelligence and emotional stability. Second, they emphasize the importance of all stakeholders working together through a shared leadership model, which encourages collaboration and inclusivity, increases peer-support, and makes the institution more agile and innovative. They claim that shared leadership is especially effective in a crisis because it improves the quality of the decisions made. Lastly, they warn that leaders must balance communication carefully and deliver messages through a variety of channels for accessibility. They explain that leaders must avoid delivering too much or too little information and must communicate in a way that "balance[s] reality with hope and empathy, while looking for silver linings in the crisis" (p. 43). One such silver lining may be the opportunity for academic leaders to "create a spiral of success" (p. 41) by eliminating inefficient practices and rejuvenating veteran faculty. 


\section{Models of Emotionally Intelligent Leadership}

Research indicates that leaders with high levels of emotional intelligence are better at building trust, garnering support for a shared vision, mediating disagreements, ensuring cooperation, and managing change (Fullan \& Scott, 2009; Nafukho et al., 2016; Ugoani et al., 2015). Researchers have also found that when leaders have high emotional intelligence levels, it has a positive influence on the health, wellness, and performance of those who work with them (Doe et al., 2015; Ford et al., 2019; Schutte \& Loi, 2014). Consequently, the evidence indicates that in most situations, emotional intelligence is an important component of effective leadership in a variety of organizations and institutions (Boyatzis \& McKee, 2005; Goleman et al., 2001, 2013; Parrish, 2015).

Recently, several new models of emotionally intelligent leadership have emerged, including the leadership framework published in the book Leadership 2.0 (Bradberry \& Greaves, 2012) and a leadership framework that includes the idea of resonance, as described in the book Primal Leadership (Goleman et al., 2001, 2013) and later developed into the resonant leadership model created by Boyatzis and McKee (2005). Unlike other leadership models, these models explicitly include emotional intelligence; however, each model frames the practical applications of emotionally intelligent leadership in different ways.

Like many leadership models, the framework developed by Bradberry and Greaves (2012) in Leadership 2.0 seeks to highlight the leadership skills used by the world's most effective leaders. They discuss leadership in terms of two types of leadership: core leadership and adaptive leadership. They claim that core leadership 
includes foundational skills that every leader must possess, such as creating a vision, planning, communication, and decision-making skills. In contrast, adaptive leadership includes "a unique combination of skills, perspective, and guided effort that enable true excellence" (p. 7). According to the authors, adaptive leadership skills include integrity, credibility, a focus on organizational justice and transparency, an appreciation for diversity, devotion to lifelong learning, the desire to encourage others to grow and develop, and the most important skill: emotional intelligence. Bradberry and Greaves claim that "people with the highest IQs outperform those with average IQs just $20 \%$ of the time, while people with average IQs outperform those with the highest IQs $70 \%$ of the time" (p. 132), describing emotional intelligence as the missing link that can explain this finding. They recommend that leaders develop skills in four main areas: selfawareness, self-management, social awareness, and relationship management. They claim that self-awareness is a foundational skill that makes the development of all the adaptive leadership skills easier.

Although Bradberry and Greaves' (2012) framework highlights the importance of adaptive leadership skills that include emotional intelligence, the focus remains on how the development of emotional skills in leaders affects those around them, ignoring the importance of self-care as an aspect of emotional intelligence. Research suggests that self-care is necessary to cope with, and recover from, the stress and emotional exhaustion that leaders, such as K-12 principals, regularly face (Klocko \& Wells, 2015; Wells, 2015; Wells \& Klocko, 2018). However, this element is largely missing from most leadership 
models. Self-care is, however, included in Boyatzis and McKee’s (2005) resonant leadership model.

The concept of resonant leadership (Boyatzis \& McKee, 2005) stems from Goleman et al.'s $(2001,2013)$ work in Primal Leadership, which advanced the notion of emotionally intelligent leadership. Resonant leadership emphasizes the importance of using emotional intelligence to create resonance - the ability to stay in tune with others and calibrate the impact of one's moods and behaviors while remaining present and emotionally available (Boyatzis \& McKee, 2005; Goleman et al., 2001)—by caring for oneself and others. Goleman et al. (2001) found that a leader's emotional style was contagious, affecting the mood and behaviors of everyone else in the organization, which had a direct effect on meeting an organization's goals. They claim that resonance can help people find meaning in the face of chaos and turbulence, a topic that is increasingly relevant in the face of the Covid-19 pandemic.

Boyatzis and McKee (2005) describe resonant leaders as leaders who are "awake, aware, and attuned to themselves, to others, and to the world around them" (p. 3) and resonant leadership as a model that gives leaders the tools to develop and retain their resonance. According to the authors, the resonant leadership model acknowledges that leaders face a unique type of stress and emotional exhaustion that is an inherent part of leadership and that when this stress becomes chronic, leaders can fall into dissonance. Unfortunately, reducing the source of stress is not always possible for leaders; therefore, they must find ways to manage and bounce back from stress. The authors recommend 
using mindfulness, hope, and compassion to counteract the effects of power stress so that leaders can nourish and maintain their resonance.

There has been very little research on resonant leadership; however, the research that exists is positive. Marques (2015) synthesized the results of 10 years of research, including three phenomenological studies, 72 interviews, and a comprehensive review of the literature, to evaluate the most effective leadership styles given the changing work and leadership requirements of the 21 st century. She found that the resonant leadership model is promising because it is flexible, focuses on relationships, and encourages deep engagement. Similarly, Taner and Aysen (2013) claim that resonant leadership appears to help leaders face the financial, psychological, and social costs of pain and grief that many of those with whom they interact are experiencing. They describe resonance as "the intensification and prolongation of sound by vibration" (p. 595) and explain that when leaders are in harmony with their followers, it resonates throughout an organization.

Similarly, research conducted on resonant leadership specifically in K-12 education has also been positive. In response to several earlier studies conducted on principal stress, Klocko and Wells (2015) presented resonant leadership as a conceptual framework that can be used to help $\mathrm{K}-12$ principals cope with chronic stress, which they argue is likely to intensify because of the increasingly complex educational climate in the U.S. Additionally, Turk and Wolfe (2019) found substantial overlap between Boyatzis and McKee's (2005) model of resonant leadership, Goleman's (1997) mixed model of emotional intelligence, and Reivich and Shatté's (2002) model of resilience, which has implications for supporting the needs of $\mathrm{K}-12$ principals. Turk and Wolfe (2019) 
interviewed $26 \mathrm{~K}-12$ principals in Pennsylvania to explore the ways in which $\mathrm{K}-12$ principals were already using resonant leadership practices to manage stress. They found that principals with fewer than six years of experience showed higher amounts of selfawareness, whereas principals with more than six years of experience were able to identify more definitive and independent mindfulness practices, indicating that a principal's years of experience affects how they manage stress and engage in emotionally intelligent leadership.

Combined, these results indicate that emotional intelligence is an important component of leadership that may need to be developed to ensure leadership success and that resonant leadership provides a framework for the acquisition of emotionally intelligent leadership skills that include self-care. Evidence suggests that emotional intelligence is important, not only for supporting a leader's followers and ensuring the organizational environment is positive and productive, but also for supporting leaders' ability to cope with stress and develop resilience. Although there is limited research on how emotional intelligence helps principals manage and recover from occupational stress, it is clear that emotional intelligence is an important component of effective leadership. Likewise, although there is limited research on resonant leadership, the resonant leadership model provides a much-needed framework for the operationalization of emotionally intelligent leadership, which may be useful for supporting the professional development of principals. 


\section{Professional Development}

As stress and uncertainty in $\mathrm{K}-12$ education increase, the need for professional development programs that support the emotional intelligence of $\mathrm{K}-12$ principals also increases. However, several questions remain regarding whether emotional intelligence can be developed, how the emotional intelligence of leaders should be developed, the variables that may influence professional development programs, and the professional development models that show the most promise.

Current findings in the literature suggest that regardless of an individual's inherent abilities, emotional intelligence can be improved through awareness and training. Despite substantial differences in design, interventions ranging in length from four weeks to several years showed significant gains in the emotional intelligence levels of the participants who received training. These interventions were aimed at developing the emotional intelligence of a variety of students, including $\mathrm{K}-12$ students (Durlak et al., 2011; Taylor et al., 2017; Zeidner, 2017) and postsecondary students enrolled in human services (Castillo \& Fischer, 2017), business (Clarke, 2010), tourism (Fernández-Gámez et al., 2018), music (McGinnis, 2018), the social sciences (Gilar-Corbi et al., 2019), and counseling programs (Pearson \& Weinberg, 2017). Researchers in all of these studies found that gains in emotional intelligence levels were directly related to the training interventions, suggesting that a variety of training protocols are effective at increasing emotional intelligence levels.

Empirical studies conducted with employees in a variety of fields show similar findings. Research on emotional intelligence training programs, ranging in length from 
eight weeks (Dadehbeigi \& Shirmohammadi, 2010) to two years (Dolev \& Leshem, 2017), found that teachers (Chesak et al., 2019; Dolev \& Leshem, 2017; Doyle et al., 2018; Quinlan et al., 2018; Stevenson \& Markowitz, 2019), bank employees (Dadehbeigi \& Shirmohammadi, 2010), and residential facility staff (Embregts et al., 2019; Zijlmans et al., 2011, 2015) had increased emotional intelligence levels as a result of training. Dolev and Leshem (2017) studied the results of a two-year emotional intelligence training program on teachers and found that the training promoted the development of emotional intelligence skills, including self-awareness, an increased awareness of the emotional intelligence of others, and a desire to develop these skills in their students. Similarly, researchers studying the effects of emotional intelligence training on employees who worked with clients with intellectual disabilities found that the training protocols used in the studies had positive effects on the interpersonal relationships between staff members and their clients, as well as the staff's ability to support the needs of their clients (Embregts et al., 2019; Zijlmans et al., 2011, 2015). These findings indicate that emotional intelligence can be developed in employees within the context of their work.

Although research involving the effectiveness of training on emotional intelligence in leaders is limited, the evidence indicates that, much like research conducted on students and employees, emotional intelligence training initiatives can increase their emotional intelligence as well. In a study of 71 non-governmental organization (NGO) leaders, Nafukho et al. (2016) found that emotional intelligence training methods resulted in emotional intelligence growth. They also found that a well- 
designed training program can increase emotional intelligence scores. Further, leaders with high levels of emotional intelligence were better at creating alternative options to settle disagreements, ensuring cooperation and trust among colleagues, inspiring high levels of performance, communicating a shared vision, managing their emotions, and gaining the emotional support of their employees. Like Bradberry and Greaves (2012), they argue that emotional intelligence is better than IQ at predicting performance.

Although this evidence suggests that emotional intelligence can be developed in students, employees, and leaders, several studies have had less conclusive findings. Clarke (2010) studied the effects of emotional intelligence training on two groups of business students to determine the importance of team-based learning. He found that the group that received emotional intelligence training followed by 14 weeks of team-based practice statistically significantly improved their emotional intelligence levels, while the group that received emotional intelligence training without team-based practice did not. Clarke concluded that it is not possible to develop emotional intelligence without teambased learning opportunities. While this may be a factor in the success of emotional intelligence training protocols, Clarke's (2010) argument is somewhat controversial because other variables that differed between groups, such as the length of the training, coaching received after training, or opportunities to reflect on behaviors and practice emotional intelligence skills, may have affected the results as much as, or more than, the cooperative learning component itself.

Like Clarke (2010), Opengart (2005) and Dadehbeigi and Shirmohammadi (2010) support the notion that emotional intelligence can be developed; however, they believe 
there are limitations. Opengart (2005) found that emotional intelligence can only be developed with an understanding of the emotion work rules, which consider the context in which an emotion occurs. Dadehbeigi and Shirmohammadi (2010) found that the emotional intelligence training protocols used in their study only resulted in statistically significant improvement in the relationship management cluster of emotional intelligence. They hypothesized that this singular result was related to the participants' work environment because participants were bank employees with a high need for relationship management competencies in their daily interactions with customers. They argue that the work environment gave the training context, thus affecting which emotional intelligence skills were developed.

In summary, most studies conducted on students, employees, and leaders suggest that emotional intelligence can be developed in these populations. Researchers report many positive effects as a result of emotional intelligence training, suggesting that emotional intelligence training programs have the ability to help participants manage their emotions (Castillo \& Fischer, 2017; Nafukho et al., 2016; Parrish, 2015), cope with stress (Jennings et al., 2011; Schonert-Reichl, 2017; Schussler et al., 2016), respond better to other's feelings and emotions (Castillo \& Fischer, 2017; Embregts et al., 2019; Zijlmans et al., 2011, 2015), find more meaning in their work (Thory, 2016), increase productivity (Farnia \& Nafukho, 2016), increase career competency (Embregts et al., 2019; Fernández-Gámez et al., 2018; Zijlmans et al., 2011, 2015), and improve their leadership skills (Nafukho et al., 2016; Parrish, 2015). Furthermore, several researchers argue that careful consideration in the design of professional development opportunities 
will create the optimal learning environment for skill development (Daugherty et al., 2017; Herman et al., 2017).

\section{Emotional Intelligence in Training Programs}

Although researchers have yet to define concrete guidelines for development of training protocols aimed at increasing emotional intelligence, several themes have emerged from the literature. These patterns suggest that the positive effects of emotional intelligence training programs are influenced by specific elements of the training programs, such as activities that inspire self-awareness and mindfulness (Castillo \& Fischer, 2017; Embregts et al., 2019; Fernández-Gámez et al., 2018; Jennings et al., 2011, 2017; Schonert-Reichl, 2017); activities that are designed around experiential learning (Fernández-Gámez et al., 2018; Jennings et al., 2011, 2017; Pearson \& Weinberg, 2017; Schonert-Reichl, 2017; Zeidner, 2017); activities that involve team-based learning (Clarke, 2010; Gilar-Corbi et al., 2019; Pearson \& Weinberg, 2017); and activities that provide goal-setting opportunities, as well as coaching or feedback from trainers (Embregts et al., 2019; Farnia \& Nafukho, 2016; McGinnis, 2018; Nafukho et al., 2016; Zijlmans et al., 2011, 2015).

Self-Awareness and Mindfulness. Self-awareness and mindfulness activities have been successfully included in emotional intelligence training in a variety of ways. Zijlmans et al. $(2011,2015)$ and Embregts et al. (2019) used video feedback and coaching to deliver emotional intelligence training to residential facility staff working with clients with intellectual disabilities. They found that video feedback allowed staff members to reflect on how their behavior affected their clients' behavior, prompting more awareness 
and mindfulness. The training led to both an increase in the emotional intelligence levels of the staff members and a reduction in their clients' challenging behaviors. In another study, Dolev and Leshem (2017) used individual coaching sessions in a two-year training program to promote self-awareness in teachers and found that these practices increased the emotional intelligence levels of participants.

Debriefing activities also appear to raise self-awareness and mindfulness. Fernández-Gámez et al. (2018) used debriefing activities to encourage participants to analyze and reflect on their behavior; Clarke (2010) instructed participants to debrief how well their teams engaged in team-based learning activities; Pearson and Weinberg (2017) had participants use a diary to reflect on their personal development and "evaluate relevant theory in relation to their own life situations" (p. 615); and Castillo and Fischer (2017) had participants use expressive writing and deep breathing activities to reflect on their experiences. Researchers found that these practices, all of which include selfreflection and mindfulness, played a role in improving the emotional intelligence levels of participants.

Similarly, self-awareness and mindfulness training programs have been used to help participants manage stress. Several researchers have found both the CARE and SMART programs to be effective in increasing self-management and lowering stress with the use of short periods of silent reflection, writing reflections, reappraisal techniques, breathing exercises, body scans, and meditation. Research conducted by Jennings et al. (2011, 2017), Roeser et al. (2012), Schonert-Reichl (2017), Schussler et al. (2016, 2019), and Sharp and Jennings (2016) found that CARE is an effective tool for increasing 
mindfulness, reducing stress, and building a positive classroom environment. Similarly, research conducted by Crain et al. (2017), Chesak et al. (2019), Ragoonaden (2017), and Roeser et al. (2013) found that the SMART in Education program resulted in an increase in the mindfulness of educators and a decrease in their stress and burnout levels.

Experiential Learning. Some researchers argue that to acquire emotional skills, one must engage in experiential learning by practicing what is learned both inside and outside the training environment. Several studies have found that when experiential learning activities are integrated into emotional intelligence training, it allows participants to practice the learned skills in practical situations, which improves the results of the training initiatives.

Mindfulness training, such as that used in the CARE and SMART in Education programs, is inherently experiential in nature, as participants actively practice mindfulness techniques, such as breathing exercises. Furthermore, other programs have successfully used skills-based role play to practice the skills needed for emotionally intelligent activities, including communication, teamwork, conflict resolution, selfcontrol, and self-confidence. Pearson and Weinberg (2017) found that the emotional intelligence levels of participants increased significantly when experiential learning activities were added to training. Fernández-Gámez et al. (2018) noted that experiential learning helps break down participants' resistance to training by allowing them to connect the training to the context in which they live, learn, and work. Lastly, Zeidner (2017) studied emotional intelligence in relation to the needs of gifted $\mathrm{K}-12$ students. He developed 10 guidelines for emotional intelligence training programs, one of which 
included the need for experiential learning. The positive growth of emotional intelligence found by these researchers may be at least partially related to the use of experiential learning activities.

Team-Based Learning. Collaborative team-based learning and group work is often successfully incorporated into emotional intelligence training programs to facilitate role-play exercises, practice communication skills, and reflect on behavior. Gilar-Corbi et al. (2019) successfully trained participants in emotional intelligence using the Programa de Capacitación Avanzada en Competencia Emocional (Advanced Training Program in Emotional Intelligence), which combines group work with independent tutorials and online learning activities. They found that the training significantly improved all of the emotional skills that were assessed. Similarly, Pearson and Weinberg (2017) used group work, combined with lectures, seminars, on-the-job learning, and skills-based role play practice, to train counseling students and found that the participants' emotional intelligence levels increased significantly over the course of the program. As mentioned above, Clarke (2010) had similar findings and, therefore, argues that emotional intelligence training must be combined with team-based learning to be effective.

Several researchers, however, have shown improvement in emotional intelligence without using team-based learning activities. Castillo and Fischer's (2017) training protocol was based entirely on independent expressive writing and deep breathing exercises, and they found that these self-reflective methods increased the emotional intelligence of participants, despite a lack of team-based learning opportunities. Likewise, the training protocol used by Embregts et al. (2019) did not use team-based learning and 
relied largely on independent activities, such as individual feedback on emotional intelligence assessment results, the formulation of individual goals and development plans, and individual feedback on recorded interactions between staff members and clients. Still, the researchers found that these activities had positive effects on the emotional intelligence levels of staff members. Therefore, it appears that team-based learning may enhance emotional intelligence training but is not always necessary for training to have positive outcomes, and context may be important in determining the need for team-based exercises.

Goal Setting. Several researchers have used goal-setting activities to set the stage for the development of emotional intelligence skills. Zeidner (2017) argues that goals and objectives should always be specified before any type of training activity. McGinnis (2018) required participants to create an action plan, choose one specific emotional intelligence skill to work on, and select development strategies to help them meet their goals. She found that emotional intelligence levels were statistically significantly improved through the use of these strategies. Similarly, Embregts et al. (2019) and Zijlmans et al. $(2011,2015)$ had participants use the results of their pre-intervention emotional intelligence tests to formulate individual goals and development plans that were monitored throughout each program. They found that the training had positive effects on the emotional intelligence levels of the participants, and these goal-setting activities may have played a role in the success of the interventions.

Coaching and Feedback. Goleman and Boyatzis (2008) claim that "spending time with a living, breathing model of effective behavior provides the perfect stimulation 
for our mirror neurons, which allow us to directly experience, internalize, and ultimately emulate what we observe" (p. 6). Research indicates that their observation, which is based on brain science, may have merit, and several researchers emphasize the importance of including coaching and feedback in emotional intelligence training. Embregts et al. (2019), Farnia and Nafukho (2016), Nafukho et al. (2016), and Zijlmans et al. $(2011,2015)$ all included coaching, feedback, or both in the training interventions they used. Embregts et al. (2019) and Zijlmans et al. (2011, 2015) provided extensive feedback to participants on their pre-intervention emotional intelligence tests, goals, and interactions with clients. Likewise, Nafukho et al. (2016) included individual coaching sessions to help participants interpret emotional intelligence test results, review the coach's observations during the training, and help participants use the skills they learned during a one-year period following the training. All of these training initiatives resulted in statistically significant improvements in the emotional intelligence levels of the participants, indicating that coaching and feedback may play a role in the success of training programs.

\section{Professional Development Programs for Educational Leaders}

Thus far, this literature review has established that emotional intelligence is an important aspect of leadership, that emotional intelligence can be developed in students, employees, and leaders, and that the development of emotional intelligence may be influenced by specific elements of the training programs used. However, the question remains: how should the emotional intelligence of principals be developed? To answer 
this question, we must first explore the professional development models that are currently used to train $\mathrm{K}-12$ leaders.

Professional development programs for educational leaders generally include preservice preparation programs and clinical experiences hosted by universities. They also often include in-service training opportunities, which are generally hosted by school district personnel, provided by school district personnel in collaboration with outside consultants, or provided by independent agencies and universities (Herrmann et al., 2019; Wallace Foundation, 2016). The quality of these programs varies substantially from state to state, and many researchers are concerned at indications of a nationwide trend that suggests that both the available pre-service and in-service opportunities fail to meet the needs of principals (Sanchez et al., 2019; Wallace Foundation, 2016).

In an effort to obtain a balanced view of the state of nationwide university-based pre-service programs, the Wallace Foundation (2016) commissioned reports from four national agencies: the American Association of Colleges for Teacher Education, the School Superintendents Association, and the American Institutes for Research, and the University Council for Educational Administration. They found five themes in the data that they gathered:

1. The course of study required by pre-service professional development programs often does not align well with a principal's daily work.

2. Most superintendents believe that improvement is needed, and, for the most part, university personnel agree.

3. Some university policies and practices block change. 
4. Strong partnerships between the university and the district are essential for improvement.

5. States are not using their power to improve pre-service principal preparation effectively.

Based on these findings, the authors suggest that pre-service programs be redesigned to reflect the job of the principal, including intensive clinical experiences and mentorship programs; that school districts and universities build stronger relationships to allow for the continuous improvement of programs; and that state policymakers create structures to support and encourage the growth of high-quality programs.

Since the Wallace Foundation's report was published, several states have begun overhauling their pre-service principal preparation programs. An example is the creation of Nevada Leads, a university-district partnership, which was designed to improve the preparation of $\mathrm{K}-12$ principals in Nevada in response to Nevada's dismal ranking in the 2017 Quality Counts report as the state with the worst education in the nation (Sanchez et al., 2019). The Nevada Leads program encompasses many of the best practices recommended in the literature. It uses a cohort model, it includes an internship, the courses are taught by a university faculty member in collaboration with one to two practicing principals, and principal candidates are mentored by practicing principals who receive training aligned with the course content and learning objectives for each of their mentee's classes. Additionally, instruction is delivered in a flipped, hybrid-course format, and the principal candidates must participate in a culminating project that consists of a comprehensive exam and seven activities that they will likely have to participate in as 
future principals (e.g., writing formal evaluation feedback for teachers). Although many of the elements included were based on best practices from the research, Sanchez et al. (2019), do not present evidence that this program has been effective.

Most researchers agree that there are several elements that are essential when designing quality pre-service and in-service professional development opportunities for $\mathrm{K}-12$ principals. These include strong partnerships between school districts and the organizations that offer the training (Campanotta et al., 2018; Sanchez et al., 2019; Sutcher et al., 2017; Wallace Foundation, 2016); the use of professional learning communities (Campanotta et al., 2018; Goode, 2019; Hipp \& Weber, 2008; Sutcher et al., 2017); opportunities for experiential learning (Campanotta et al., 2018; Goode, 2019; Sutcher et al., 2017); instruction in the use of collaborative data-based decision-making (Sutcher et al., 2017); and continuous improvement as a means for enhancing instruction (Sutcher et al., 2017). Sutcher et al. (2017) explored the elements of two decades of highquality principal preparation and professional development programs that led to increased retention of principals and teachers, improved teacher effectiveness, increased student achievement, or a combination thereof. They identified four building blocks needed for high-quality programs, which apply to both pre-service and in-service professional development programs: (a) authentic applied learning opportunities, such as field-based internships for pre-service principals, coaching and mentorship programs for both preservice and in-service principals, and activities with context-specific scenarios; (b) professional learning communities, including cohorts for pre-service programs and professional networks for in-service programs; (c) partnerships between school districts 
and professional development programs that inform the blending of research and practice; and (d) a focus on improving instruction via teacher professional learning communities, data, collaborative decision-making, and strategies for continuous improvement.

Other researchers have discussed the importance of additional components in preservice and in-service professional development opportunities, such as a well-defined purpose for all professional learning activities, the relevance of the learning objectives to a principal's job, and elements such as the comfort and convenience of the training for busy professionals. Goode (2019) used semi-structured interviews and focus groups to explore the professional development experiences of nine urban, $\mathrm{K}-8$ principals in New Jersey. She found that the professional development opportunities available to principals were dissatisfying and deficient because of a lack of differentiation for the audience, a lack of meaningful activities with context-driven real-world scenarios, and a lack of opportunity to collaborate and learn from colleagues working in similar contexts. Furthermore, because principals are inherently busy, she also found it important that professional development opportunities occur in a comfortable place with access to technology and that they include web-based access to both the training materials and the training sessions.

It seems that professional learning models are often classified based on either the characteristics of the training methods employed or the objectives of the training offered. For example, models can be based on the following training methods:

- collaborative-learning principles 
- coaching and mentoring philosophies

- experiential learning

or the following training objectives:

- proficiency in specific standards

- the ability to respond to specific situations appropriately

- the ability to meet the needs of specific populations

- the attainment of rewards, such as certificates and degrees (Metcalf, 2019;

Meyer-Looze et al., 2019; Sanchez et al., 2019)

These classifications, however, do not address some of the dimensions that affect the success of professional learning activities, and a more comprehensive framework may be needed to understand how diverse elements of professional development programs affect the success of the activities.

The RAND Corporation addressed this gap through a comprehensive search, synthesis, and analysis of the professional development literature to inform $\mathrm{K}-12$ decision-makers about the use of research-based leadership interventions to improve student outcomes (Daugherty et al., 2017; Herman et al., 2017). They developed the professional learning logic model, a comprehensive logic model that uses an objectivesbased approach to focus on meeting the individual needs of $\mathrm{K}-12$ principals. Their model emphasizes the importance of aligning program content and structure with both the needs of individual principals - depending on experience level and the context in which they lead - and evidence-based practice. Additionally, the model emphasizes the importance of ensuring that principals are trained by qualified trainers and that they receive high- 
quality training through formal training sessions and ongoing support. Lastly, the model recommends that principals are given opportunities to give feedback on how they use the skills they have learned and on how well the training meets their needs.

\section{Integrating Emotional Intelligence into Preparation and Professional Development}

The wide range in quality and efficacy of principal preparation and professional development programs points to the need to incorporate explicit emotional intelligence training, but research is limited on how best to do this. Some studies contribute valuable information regarding this need for pre-service professional development programs. Researchers recommend that preparation programs educate principals to focus on the future and to manage change in response to increasing turbulence in the educational environment, which requires emotional intelligence. Tripses (2019) points out that a focus on the future requires global competence and "leadership qualities of the heart" (p. 27). Similarly, Meyer-Looze et al. (2019) argue that for principals to implement and sustain change, they must understand how to make team members feel valued and respected, as well as how to ensure that their needs and concerns are understood. Other researchers have additionally advocated for the need for additional self-awareness, selfmanagement, social-awareness, and relationship management skills (Doe et al., 2015; Ugoani et al., 2015).

Researchers have pointed out that preparation and professional development programs for school leaders rarely incorporate the development of emotional intelligence (Sanchez et al., 2019). Even for those programs that do include some degree of emotional intelligence-related content, very few focus on all four emotional intelligence clusters 
defined by Goleman et al. (2001, 2013). Hesbol (2019) stated that in principal preparation and professional development programs "much emphasis and attention is placed on what principals need to do with, in, and for schools, yet little attention is placed on how schools and districts affect the ways in which principals perform" (Hesbol, 2019, p. 46). She argues that principals need networks of support and communication to build selfefficacy.

Research by Sánchez-Núñez et al. (2015) may provide a direction for future research. They examined the effects of a two-year pre-service licensure program in New York-which explicitly included emotional intelligence in the courses by using the Goleman et al. (2001) mixed model of emotional intelligence- on the emotional intelligence of 32 principal candidates. They found that at the end of the program, the participants reported increases in several social awareness and relationship management competencies, including the ability to inspire and guide others, take an active interest in the development needs of others, engage in productive teamwork, and have a positive influence on others. However, the perceptions of observers who were tasked with observing and independently scoring the principal candidates' competencies - members of community organizations who regularly worked with leaders seeking licensure and were selected by the researchers - did not change, which was unexpected. The researchers explain that one likely reason for these findings may be that the observers recognized the candidates' potential from the beginning, which could have skewed the scores. They also hypothesize that because the principal candidates had not yet had the opportunity to practice their newfound skills in a real-world context, their behaviors may 
not have aligned with their perceptions. As a result, Sánchez-Núñez et al. (2015) suggest that future research should explore how to identify and measure the constructs of emotional intelligence within school leadership preparation and professional development activities so that they can focus deliberately and intentionally on developing skills in all the emotional intelligence competencies.

\section{Critique of Previous Research}

Most emotional intelligence researchers agree that the ability to understand, appreciate, and regulate emotions is important; however, there are considerable differences in the field concerning the acceptance of a single valid model, the use of consistent terminology, the availability of valid and reliable tools to assess and measure emotional intelligence, and the importance of emotional intelligence research in the workplace. These differences in perspective have led to much disagreement among researchers.

Pertaining to intelligence, Fletcher and Hattie (2011) argue that theories of multiple intelligences deny the well-supported notion of a general intelligence (' $\mathrm{g}$ ') that involves processing efficiency and capacity. They contend that although some critics of the notion of ' $\mathrm{g}$ ' see reasoning processes as more segmental than the single underlying dimension suggested by ' $\mathrm{g}$ ', evidence for these theories is limited.

In terms of emotional intelligence in relation to intelligence research, Antonakis and Dietz (2010) argue that future research must be committed to the ability-based model because it is the only emotional intelligence model that is grounded in the existing frameworks of intelligence. They claim that all other emotional intelligence models 
overlap with personality research too much to offer anything new to the intelligence field; therefore, they suggest using neuroscience to determine if there are areas of the brain, not linked to IQ, that can predict performance. They also maintain that all emotional intelligence tests, regardless of the model, "do not reliably predict incremental variance in performance outcomes" (p. 166); therefore, they advocate for designing tests that measure emotions biologically or physiologically to ensure that the instruments have objectively correct answers.

Like Antonakis and Dietz (2010), Lindebaum and Cartwright (2010) criticize emotional intelligence scholars for failing to address issues concerning the measurement of emotional intelligence; however, they also focus their criticism on gaps in the research that fail to investigate the idea that in certain circumstances emotional intelligence may have negative consequences. They contend that emotionally intelligent leaders could use manipulation to achieve personal and organizational gain and, in doing so, both ignore their responsibility to society and neglect the needs of those they supervise. Additionally, they argue that emotional intelligence can have a negative impact on the health and wellbeing of individuals with high emotional intelligence when they work in emotional fields, driving them to overwork and neglect their own self-care when not given proper support. Lastly, they suggest that further research is needed to address whether low emotional intelligence ever leads to high performance outcomes; whether specific branches of emotional intelligence may be tied to beneficial outcomes in certain tasks, while others may not; and whether there are limits to the amount of emotional intelligence that is beneficial (Antonakis \& Dietz, 2010, p. 282). 
These critiques and disagreements uncover important issues regarding the study and measurement of emotional intelligence, but they do not directly affect the outcomes of this research, as my goal is not to try to understand how reasoning processes function nor to understand which parts of the brain predict performance. Similarly, the purpose of this study is not to understand how leaders may use emotional intelligence to manipulate others or to examine how emotional intelligence affects performance outcomes. The goal of this research is to understand how emotional intelligence may be used to support the needs of $\mathrm{K}-12$ principals to manage stress and prevent burnout. Antonakis and Dietz (2010) make an interesting point that emotional intelligence can have a negative impact on individuals with high emotional intelligence levels because of their tendency to put others ahead of themselves. Education is an emotional field, and many teachers, presumably with high emotional intelligence levels, often overwork and neglect their own self-care in the interest of their students. This research indirectly explores the effects of occupational demands and lack of self-care on burnout and turnover, which supports Antonakis and Dietz's (2010) argument about the potential negative impact of emotional intelligence. However, this research does not explore how emotional intelligence causes overwork and stress; rather its focus is on how emotional intelligence can help principals manage and cope with overwork and stress.

\section{Summary}

This literature review demonstrates that emotions are an important part of the human experience that affect an individual's health, wellness, and decision-making (Barnum \& Solomon, 2019; Enachescu et al., 2019); emotional intelligence includes 
important emotional skills that may affect an individual's workplace performance more than their general intelligence (Bradberry \& Greaves, 2012; Nafukho et al., 2016); and high levels of emotional intelligence in the workplace have been shown to have a positive effect on an organization's climate (Allred et al., 2016; Mason, 2018). Additionally, evidence indicates that emotional intelligence training can be used to help individuals manage stress and prevent burnout (Ford et al., 2019; Kunze \& Menges, 2017), which may be very helpful to teachers and principals who are facing extreme levels of stress due to Covid-19 and other challenges within the K-12 educational system (Collie, 2021; McIntyre et al., 2017). Programs that promote the development of emotional intelligence have been used successfully in $\mathrm{K}-12$ education to help teachers cope with stress (Jennings et al., 2017; Schonert-Reichl, 2017); however, the stress-management needs of principals have been largely ignored (Sánchez-Núñez et al., 2015; Wallace Foundation, 2016).

Evidence indicates that in most situations, emotional intelligence is an important component of effective leadership (Boyatzis \& McKee, 2005; Goleman et al., 2001, 2013; Parrish, 2015). Some leadership models have started incorporating emotional intelligence (Bradberry \& Greaves, 2012; Goleman et al., 2001, 2013); however, Boyatzis and McKee's (2005) resonant leadership model is the only model that specifically and explicitly includes mindfulness practices that address self-care for the purpose of managing stress, and there is little indication that their suggestions for selfcare have been integrated into principal preparation and professional development programs. Consequently, there is sufficient evidence to support that an investigation 
examining the role of emotional intelligence and resonant leadership practices in principal preparation and professional development would yield socially important findings. This literature review has provided strong support for pursuing a research project to investigate the following: (a) how the perceptions of $\mathrm{K}-12$ principals in Oregon, regarding their needs for the development of emotional intelligence, vary based on their individual characteristics and the contexts in which they lead; (b) how the preparation and professional development opportunities available to $\mathrm{K}-12$ principals in Oregon have supported their emotional needs; and (c) how the preparation and professional development opportunities available to $\mathrm{K}-12$ principals in Oregon have prepared them to manage the stress and emotions caused by Covid- 19 . 


\section{Chapter 3: Methodology}

This study used an explanatory sequential mixed methods design to examine the role of emotional intelligence in preparing $\mathrm{K}-12$ principals in Oregon to manage and recover from stress and to explore to what degree the preparation and professional development opportunities available to $\mathrm{K}-12$ principals in Oregon have supported their emotional needs. Specifically, the research questions explored how principal perceptions varied regarding the need for the development of emotional intelligence, how principals perceived that their preparation and professional development programs had supported the development of emotional intelligence, and how prepared principals in Oregon felt to manage the stress and emotions they experienced in their positions as educational leaders, as well as the stress and emotions they experienced because of the turbulence and chaos caused by the Covid-19 pandemic and the heightened social and political turmoil of the 2020-2021 school year.

The research design included two phases: a quantitative phase and a qualitative phase. This chapter outlines each phase of the study, the sampling methods that were used to select participants for each phase, and the instruments and procedures that were used to collect and analyze the data. Lastly, this chapter identifies the limitations and delimitations that applied to this study, as well as the measures that were taken to ensure that the research was conducted in an ethical manner and aligned with Institutional Review Board regulations and recommendations for research with human subjects. 


\section{Research Methods}

Quantitative research allows the exploration of attitudes and opinions of large groups of individuals; however, the results of such research are often limited, lacking the voice of the participants and the depth of their perspectives (Creswell \& Creswell, 2018). Qualitative research allows honoring the uniqueness and diversity of individual voices by seeking to understand each participant's perspective; however, the validity of such research can be difficult to establish, and the results are often highly subjective (Creswell \& Poth, 2018; Stake, 2010). Mixed methods research combines the strengths of both methods to develop a deep, well-rounded understanding of the issue of interest, while honoring individual voices and often producing results that can be generalized to a larger population (Creswell \& Plano Clark, 2018). This research used an explanatory sequential mixed methods design to explore the collective voice of $\mathrm{K}-12$ principals in Oregon, while honoring the individual voices of a representative sample of principals working in diverse contexts.

This study does not seek to build a theory or understand an abstract concept; therefore, a grounded theory design was inappropriate. It did not manipulate variables to examine causation; therefore, an experimental or quasi-experimental design was not used. Furthermore, the research cannot be limited to a single descriptive, correlation, or causalcomparative design, as it sought to describe the emotional intelligence needs of principals while exploring the relationships between variables and examining the differences between subgroups. Consequently, multiple sources of data were needed to provide an in- 
depth analysis of the phenomenon being studied within a real-world context, with the ability to adapt the study design as needed to gain a deeper understanding of the issue.

The use of an explanatory sequential mixed methods study provided the data needed to address the research questions. It also facilitated understanding both the perceptions of $\mathrm{K}-12$ principals in Oregon regarding their needs for professional development opportunities that focus on emotional intelligence and the factors that influence their perceptions. Mixed method studies are often used to explore perceptions. For example, McGill et al. (2020) used a two-phase explanatory sequential mixed method study design to examine the perceptions of 57 academic advisors regarding the conceptual, informational, and relational components of a professional development program. Soleas (2015) used similar methods to explore the perceptions of 44 new teachers regarding the inclusive practices they learned in their teacher preparation program and their intentions to use the practices in their classrooms. And Zumbrunn et al. (2016) used the approach to investigate the perceptions of 598 middle school and high school students regarding writing feedback and to search for relationships between the feedback they received, their writing self-efficacy, and their writing self-regulation aptitude. Therefore, it seems that explanatory sequential mixed methods studies have often been used to explore the perspectives of participants, making this design the optimal choice for this research.

\section{Research Questions}

There is little research indicating how the preparation and professional development opportunities available to $\mathrm{K}-12$ principals in Oregon support their 
emotional needs; therefore, the following research questions were used to explore this phenomenon:

- RQ1: How do the perceptions of $\mathrm{K}-12$ principals in Oregon, regarding their needs for the development of emotional intelligence skills, vary based on their individual characteristics and the contexts in which they lead?

- RQ2: How do K-12 principals in Oregon perceive that their preparation and professional development programs have supported the development of emotional intelligence skills?

- RQ3: How do K-12 principals in Oregon perceive that their preparation and professional development programs have prepared them to manage the stress and emotions caused by Covid-19 and other challenges?

- RQ4: How do the principal preparation and professional development themes exposed in the principal interviews and document review process explain the results from the initial quantitative phase of the study?

\section{Setting}

This research was conducted in the state of Oregon, U.S.A. The population in Oregon is predominately White. At the time of this research, $75.3 \%$ of the population was White and not Hispanic or Latino, whereas $13.3 \%$ was Hispanic or Latino, $4.8 \%$ was Asian, $3.9 \%$ was two or more races, $2.2 \%$ was Black or African American, $1.8 \%$ was American Indian or Alaska Native, and $0.5 \%$ was Native Hawaiian or other Pacific Islander (United States Census Bureau, n.d.). On average, there were approximately 40 individuals per square mile (United States Census Bureau, n.d.), 38\% of the state's 
students attended rural schools (Chalk Board Project, n.d.), and 12.6\% of the population was living in poverty (United States Census Bureau, n.d.). According to the Educator Advancement Council (2019), 38.1\% of Oregon students were ethnically/racially diverse, whereas only $10.4 \%$ of public-school teachers and $11.4 \%$ of public-school administrators were ethnically/racially diverse.

\section{Target Population}

The target population for this study was $\mathrm{K}-12$ principals serving in public-school districts across the state of Oregon, including principals from rural, urban, and suburban schools; principals serving at the elementary, middle/junior-high-school, and high-school levels; principals serving at low-need, average-need, and high-need schools; and principals with a variety of individual characteristics and experiences in education. Principals working under a reciprocal administrator license and principals prepared outside of Oregon were excluded from the study based on their lack of experience with Oregon preparation and professional development programs.

Although the job duties of assistant principals and vice principals vary considerably from school district to school district and school to school, they were included in the study because of their rich perspectives regarding their principal preparation programs. Principals, assistant principals, and vice principals with less than one year of experience were also included in the study because research indicates that a principal's first year is generally very stressful and that new principals often do not have time to engage in self-care (Lovely, 2004). 


\section{Procedures}

\section{Figure 3.1}

Mixed Method Data Collection and Analysis Procedures

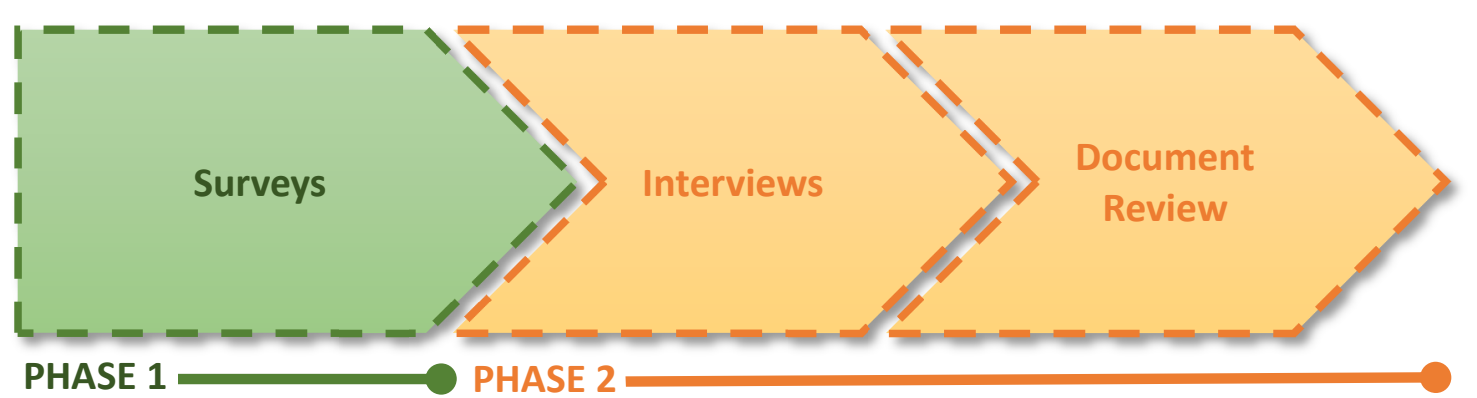

As seen in Figure 3.1, data collection occurred in two phases. Phase 1 focused on quantitative data collection and analysis in the form of a survey. The survey preliminarily classified candidates based on their individual characteristics and the contexts in which they led, gathered information regarding the types of preparation and professional development activities that had been available to the participants, and recruited participants for Phase 2 of the study.

Phase 2 focused on qualitative data collection and analysis. The leads generated by the survey were used to recruit participants for the interviews. The interviews explored the data gathered in Phase 1 of the study and expanded on the participants' perspectives in response to Covid-19. A document review process was also used during Phase 2 to explore the activities and training programs mentioned in the interviews, ensuring triangulation of the data (Baxter \& Jack, 2008). 


\section{Phase 1: Quantitative Data Collection and Analysis}

\section{Sampling Method}

In Phase 1 of the study, I used volunteer and snowball-sampling methods. All 1,259 principals in Oregon who had their contact information up to date with the Oregon Department of Education were invited to participate in the study. I carried out this broad recruitment in an effort to recruit $\mathrm{K}-12$ principals with a variety of experiences in education, as well as principals serving in a variety of contexts across the state, including principals from rural, urban, and suburban schools; principals serving at low-need, average-need, and high-need schools; and principals serving at the elementary, middle/junior-high-school, and high-school levels.

I contacted each potential participant directly with a series of emails (Appendix A). The first email was sent directly from Qualtrics to all principals on April 28, 2021. It explained the purpose of the study and its importance. This email included a flyer explaining the study (Appendix B), a link to a research website with more information about the study (https://sites.google.com/pdx.edu/ashliekmiller-research/home), and a direct link to take the survey, as well as a small incentive - a free Maslach Burnout Inventory (Maslach et al., 2018)_for the first 50 principals to respond. The second email was sent on May 17, 2021 to principals who had not yet completed the survey. This email included a reminder about the survey with a direct link to the survey. On the same day, an email was sent out to all superintendents in the state to request assistance in encouraging principals to participate. Two additional emails were sent to principals on May 24, 2021: one giving those who had not yet responded one last chance to respond and another 
thanking those who had already responded for participating and encouraging them to reach out to other principals who may not have completed the survey yet.

I set an original goal to recruit a minimum of 300 principals. I based this goal on procedures for determining sample sizes in survey research developed by Bartlett et al. (2001). They contend that continuous sample-size formulas can be used with continuous data, but categorical formulas should be used when a categorical variable will play a primary role in data analysis. This study included both continuous and categorical data that played primary roles in data analysis; therefore, I used Cochran's sample size formula for categorical data (Bartlett et al., 2001). According to Bartlett et al. (2001), for a population size of 1500 , with a margin of error of .05 (i.e., a confidence level of $95 \%$ ), and a predicted variability of .5 , leading to a $t$-value of 1.96 , a sample size of 306 principals would be needed. Therefore, assuming a 10\% attrition rate, a sample size of approximately 300 principals would have been ideal for this study's population size of 1,259 principals in the state of Oregon.

\section{Data Collection}

A 26-item survey (Appendix D) was the primary data-collection instrument. The survey included questions designed to collect information regarding the individual characteristics of the principals and the contexts in which they led, information regarding the types of preparation and professional development activities to which they had been exposed, and their perceptions regarding their needs for professional learning that focused on developing emotional intelligence competencies. The first section of the survey included a consent form. The second section of the survey included seven items 
that were used to screen participants and generate a confidentiality code used as a key to deidentify the survey responses. The third section of the survey included eight items that were used to gather information regarding each participant's demographics, experiences, and the contexts in which they were leading (e.g., school level, location, and need). The fourth section of the survey consisted of four multi-part items that were used to gather information regarding the principal preparation programs in which the respondents had participated. The fifth section of the survey consisted of six items, including 4 multi-part items that were used to gather information regarding the professional development programs and training in which the respondents had participated after they had become licensed as principals, as well as information on their perceptions of need for the development of self-awareness, self-management, social awareness, and relationship management skills. And, finally, the last four questions were used to generate leads for Phase 2 of the study. Table 3.1 outlines the variables involved in the study and the measurement tools that were used to gather information on the variables. 
Table 3.1

Operationalization of the Variables and Measurement Tools

\begin{tabular}{|c|c|c|c|c|}
\hline $\begin{array}{l}\text { Variable } \\
\text { Name }\end{array}$ & Variable Type & Construct Definition & $\begin{array}{c}\text { Measurement } \\
\text { Tool } \\
\end{array}$ & $\begin{array}{c}\text { Level of } \\
\text { Measuremen }\end{array}$ \\
\hline Gender & $\begin{array}{l}\text { Predictor / } \\
\text { Moderating }\end{array}$ & $\begin{array}{l}\text { Female } \\
\text { Male } \\
\text { Other: (Specify) }\end{array}$ & $\begin{array}{l}\text { Multiple } \\
\text { Choice (one } \\
\text { answer) }\end{array}$ & Nominal \\
\hline $\begin{array}{l}\text { Ethnicity / } \\
\text { Race }\end{array}$ & $\begin{array}{l}\text { Predictor / } \\
\text { Moderating }\end{array}$ & $\begin{array}{l}\text { Asian } \\
\text { Black or African American } \\
\text { Hispanic or Latinx } \\
\text { Native American or Alaskan } \\
\text { Native } \\
\text { Native Hawaiian or Pacific } \\
\text { Islander } \\
\text { White or Caucasian } \\
\text { Other: (Specify) }\end{array}$ & $\begin{array}{l}\text { Multiple } \\
\text { Choice } \\
\text { (multiple } \\
\text { answers) }\end{array}$ & Nominal \\
\hline Age & $\begin{array}{l}\text { Predictor / } \\
\text { Moderating }\end{array}$ & Specify & Text & Continuous \\
\hline $\begin{array}{l}\text { Years of } \\
\text { Experience in } \\
\text { Education }\end{array}$ & $\begin{array}{l}\text { Predictor / } \\
\text { Moderating }\end{array}$ & Specify & Text & Continuous \\
\hline $\begin{array}{l}\text { Years of } \\
\text { Experience as } \\
\text { a Principal }\end{array}$ & $\begin{array}{l}\text { Predictor / } \\
\text { Moderating }\end{array}$ & Specify & Text & Continuous \\
\hline School Level & $\begin{array}{l}\text { Predictor / } \\
\text { Moderating }\end{array}$ & $\begin{array}{l}\text { Elementary School } \\
\text { Middle/Junior High School } \\
\text { High School }\end{array}$ & $\begin{array}{l}\text { Multiple } \\
\text { Choice } \\
\text { (multiple } \\
\text { answers) }\end{array}$ & Nominal \\
\hline $\begin{array}{l}\text { School } \\
\text { Location }\end{array}$ & $\begin{array}{l}\text { Predictor / } \\
\text { Moderating }\end{array}$ & $\begin{array}{l}\text { Urban } \\
\text { Suburban } \\
\text { Rural }\end{array}$ & $\begin{array}{l}\text { Multiple } \\
\text { Choice (one } \\
\text { answer) }\end{array}$ & Nominal \\
\hline School Need & $\begin{array}{l}\text { Predictor / } \\
\text { Moderating }\end{array}$ & $\begin{array}{l}\text { Low Need } \\
\text { Average Need } \\
\text { High Need }\end{array}$ & $\begin{array}{l}\text { 3-Point Likert } \\
\text { Scale }\end{array}$ & Ordinal \\
\hline $\begin{array}{l}\text { Number of } \\
\text { Learning } \\
\text { Opportunities }\end{array}$ & Predictor & Specify & Text & Continuous \\
\hline $\begin{array}{l}\text { Availability } \\
\text { of PPD } \\
\text { Activities }\end{array}$ & Predictor & $\begin{array}{l}\text { Yes } \\
\text { Unsure } \\
\text { No }\end{array}$ & $\begin{array}{l}\text { 3-Point Likert } \\
\text { Scale }\end{array}$ & Ordinal \\
\hline
\end{tabular}




\begin{tabular}{|c|c|c|c|c|}
\hline $\begin{array}{l}\text { Variable } \\
\text { Name }\end{array}$ & Variable Type & Construct Definition & $\begin{array}{c}\text { Measurement } \\
\text { Tool } \\
\end{array}$ & $\begin{array}{c}\text { Level of } \\
\text { Measurement }\end{array}$ \\
\hline $\begin{array}{l}\text { Helpfulness } \\
\text { of PPD } \\
\text { Activities }\end{array}$ & Outcome & $\begin{array}{l}\text { Helpful } \\
\text { Unsure } \\
\text { Not Helpful }\end{array}$ & $\begin{array}{l}\text { 3-Point Likert } \\
\text { Scale }\end{array}$ & Ordinal \\
\hline $\begin{array}{l}\text { Perceptions } \\
\text { of Need for } \\
\text { Training }\end{array}$ & Outcome & $\begin{array}{l}\text { Yes } \\
\text { Unsure } \\
\text { No }\end{array}$ & $\begin{array}{l}\text { 3-Point Likert } \\
\text { Scale }\end{array}$ & Ordinal \\
\hline
\end{tabular}

Note. $\mathrm{PPD}=$ Preparation and Professional Development

\section{Operationalization of Variables}

This study sought to explore the perceptions of $\mathrm{K}-12$ principals in Oregon regarding their needs for preparation and professional development opportunities aimed at strengthening emotional intelligence, specifically the emotional skills needed to cope with, manage, and bounce back from stress. This study also sought to understand the ways in which the individual characteristics of principals and the contexts in which they worked influenced these needs. According to Martinez (2018), to test hypotheses and draw meaningful conclusions, all the concepts included in a study's research questions must be defined and expressed concretely by means of conceptualization and operationalization. The concepts in this study have been operationalized in Table 3.1 and are discussed below in terms of each research question.

The first research question asked how the perceptions of $\mathrm{K}-12$ principals in Oregon, regarding their needs for the development of emotional intelligence skills, varied based on their individual characteristics and the contexts in which they led. Individual characteristics refer to the personal differences among principals, such as years of experience, age, gender, and ethnicity/race. Individual contexts refer to the different 
contexts in which principals worked, such as the level of school they worked atelementary, middle/junior high school, or high school — the location of the school— urban, suburban, or rural — and the level of need of the students at the school-low need, average need, or high need. These concepts were operationalized as predictor variables that may influence principal need, as an outcome variable. Principal need was determined by the degree to which principals agreed with the need for training in the four emotional intelligence clusters (Goleman et al., 2013), which were separated into 15 specific emotional intelligence skills.

The second research question asked how the preparation and professional development opportunities available to $\mathrm{K}-12$ principals in Oregon had supported their emotional needs. The preparation and professional development opportunities were divided into two sections in the survey: a section on principal preparation programs that they attended in pursuit of licensure (i.e., pre-service) and a section on principal professional development that was available to principals after they became licensed (i.e., in-service). Each section included four multi-part questions that asked participants if they had attended trainings that helped them develop the 15 specific emotional intelligence skills and, if so, how helpful they found the trainings. Additional questions explored the number of professional development opportunities that principals had the opportunity to participate in each year and the number of opportunities in which they participated. The number of these professional development opportunities and the types of activities that were available were operationalized as predictor variables that may influence the 
outcome variables: the degree to which the activities they participated in helped them and their perception of their current need for training.

The third research question asked how the preparation and professional development opportunities available to $\mathrm{K}-12$ principals in Oregon prepared them to manage the stress and emotions caused by Covid-19 and other challenges. Again, the number of professional development opportunities and the types of activities they participated in were operationalized as predictor variables that may have influenced how prepared principals felt to manage the stress and emotions caused by Covid-19, which in this question, is the outcome variable. Item numbers 17, 19,23, and 25 on the survey (Appendix D) each include two prompts that relate specifically to how the activities included in the principal preparation programs (items 17 and 19) and professional development programs (items 23 and 25) helped principals manage their emotional responses and the emotional responses of their staff to the rapid changes and uncertainty associated with Covid-19. Although these questions seek to answer this research question to some degree, most of the insight for this question was gathered from the interviews conducted in Phase 2 of the study.

The last research question is a mixed method question that asked how the themes discovered in the principal interviews and document review process explained the results from the initial quantitative phase of the study. Neither predictor nor outcome variables were used to answer this question. 


\section{Data Analysis Procedures}

The data collected from the survey were used to explore the perceptions of $\mathrm{K}-12$ principals in Oregon regarding their needs for the development of emotional intelligence, to identify factors that may have influenced their needs, and to understand how the preparation and professional development opportunities they participated in supported their emotional needs and prepared them to manage the stress and emotions caused by Covid-19. I collected the raw data with a Qualtrics survey, downloaded it into a password-protected Microsoft Excel spreadsheet for preliminary descriptive analysis, and then prepared the data for exportation to IBM SPSS Statistics (Version 28) for statistical analysis. Because the outcome data were ordinal in nature, with a combination of continuous, nominal, and ordinal predictor variables, I selected ordinal logistic regression analysis to determine if any of the independent variables - gender, ethnicity/race, age, experience, school level, school location, need level at school-had a statistically significant effect on the 13 main emotional intelligence skills included on the survey. According to Laerd Statistics (2021), "logistic regression models do not allow the direct entry of categorical variables into the equation" (p. 4); therefore, new dichotomous variables, or dummy variables, must be created to represent all the information from each categorical variable. Furthermore, dichotomous cumulative categories must be created for each level of the dependent variable, so that separate binomial logistic regressions can be run. Therefore, in preparing the data in SPSS, I created dummy variables for the categorical independent variables (gender, race, school level, school location, and need) and dichotomous cumulative categories for the levels of my dependent variables (yes, 
unsure, and no; or helpful, unsure, and not helpful). I then used a combination of linear, PLUM, and GENLIN procedures to ensure that the data met the assumptions required for an ordinal logistic regression and to analyze the data (Laerd Statistics, 2021, p. 12). The GENLIN procedures produce an omnibus statistical test, which tests the significance of two or more parameters in a model simultaneously (Salkind, 2010). I ran the GENLIN procedures for each categorical variable, allowing me to understand the effects of each group (e.g., males vs. females) on each dependent variable. Additionally, the GENLIN procedures included odds ratios and confidence intervals in the parameter estimates, allowing me to avoid misleading results that remove the effect of sample size (Salkind, 2007).

I first used the results from the linear procedure to test for multicollinearity (i.e., to ensure that the independent variables were not highly correlated with one another) so that it would be clear which variables were affecting the dependent variables (Table G1). I then used PLUM and GENLIN procedures to analyze the results of the full likelihood ratio tests (Table G2) for each of the dependent variables, which compared the fit of the proportional odds model to a model with varying location parameters to ensure that there were proportional odds. Next, I assessed the cell size of my data to discover how many covariate patterns there were and analyzed the results of the deviance goodness-of-fit tests for each dependent variable (Table G3) to investigate the overall fit of the ordinal logistic regression model. Then, I analyzed the model-fitting information (Table G4) to determine if the final model statistically significantly predicted each dependent variable over and above the intercept-only model and reviewed the results of the ordinal logistic 
regression equations (Appendix $\mathrm{H}$ ) to determine if the independent variables had a statistically significant effect on the dependent variables. When assessing the results of the regression analysis, I determined statistical significance at a risk of less than .05 for type 1 error (i.e., $\alpha=0.05$ ).

Lastly, I used descriptive statistics within Excel to explore the data in more depth. I created individual worksheets for different aspects of the data. For example, I created sheets to explore survey answers regarding the availability, helpfulness, and need for emotional intelligence in principal preparation and professional development. I also rearranged the data into groups (e.g., male vs. female, urban vs. suburban vs. rural, etc.) so that I could compare the similarities and differences between groups. I used formulas to calculate the frequency of each response type, as well as to calculate basic descriptive statistics, such as mean, range, and standard deviations. I then formatted the data so that it could be graphed, and I explored the data using a variety of pie charts, line charts, clustered bar charts, and clustered column charts.

\section{Internal and External Validity}

Internal validity refers to the degree to which a study's claims regarding the relationships between the independent and dependent variables are accurate. Leighton (2012) explains that establishing cause and effect between the independent and dependent variables can be difficult when additional variables affect the relationship, potentially leading to false positive or negative findings that threaten the internal validity of the study. She suggests using randomly assigned experimental and control groups to eliminate this possibility. Unfortunately, although this study sought to determine if a 
relationship existed between the ratings of need for emotional intelligence training and the independent variables studied, the study was not experimental in nature; therefore, the use of a control group was not possible.

Instead, I controlled threats to internal validity by identifying a variety of variables that may affect the relationships studied. It is possible that variables - such as age, experience, or the context of the school that the principal works in—may affect a principal's perceived need for emotional intelligence training. Additionally, variables, such as exposure to situations requiring emotional intelligence, may affect perceptions of need more than the school level principals work at; therefore, principals who work in schools that have more parent involvement may report higher levels of need for emotional intelligence training. I attempted to control these variables by choosing an omnibus statistical test that allowed me to test for the effect of all variables, increasing the internal validity of the study.

External validity refers to the degree to which the results of a study can be generalized to a larger population. This study used a volunteer sampling strategy to increase the external validity of the study; however, the results can only be generalized to principals serving in the state of Oregon. The professional development opportunities available to principals in the broader United States depend largely on the requirements stipulated by the governing bodies of each state's educational system. Therefore, the opportunities available to principals likely vary from state to state, changing the factors that influence their perceptions and reducing the applicability of the findings of this study. 


\section{Expected Findings}

I expected to find that principal perceptions of need for training would be influenced by their years of experience and age, as well as the context of their schools. For example, I expected to find that principals serving in an elementary school context were more sensitive to the emotional needs of both their students and their students' parents because of the context and, therefore, might have a higher need for emotional intelligence than principals serving at the secondary level. Similarly, I expected to find that new principals and principals serving at the secondary level who may have had less experience interacting with adults, might need to develop their emotional intelligence skills more to improve their interactions with both their teaching staff and their students' parents, potentially influencing their perceptions.

\section{Phase 2: Qualitative Data Collection and Analysis}

\section{Sampling Method}

At the end of the Phase 1 survey, participants were asked if they were willing to participate in interviews, and a small incentive — a free book on leadership — was offered for participation. Those who expressed a willingness to participate were screened using purposeful sampling and recruited based on the degree to which they likely represented different perspectives in terms of experience, age, gender, burnout level, and the contexts of the school environments in which they worked. Several researchers argue that the sample size needed for data saturation for interviews cannot be predicted (Fusch \& Ness, 2015; Malterud et al., 2016). However, other researchers disagree, and several offer guidance regarding sample sizes (Guest et al., 2006; Hennink et al., 2017). Guest et al. 
(2006) argue that a minimum of nine to 12 interviews are needed for data saturation, whereas Hennink et al. (2017) recommend a minimum of 16 interviews. The latter found that although nine interviews were needed to reach code saturation, 16 to 24 interviews were needed to fully understand the information and reach meaning saturation.

The interviews conducted in this study were used to expand on the impact of Covid-19 and explain the differences and anomalies noted in the survey data. I hoped to conduct at least 10 interviews; however, I sought to recruit as many participants as needed to provide a deep understanding of the quantitative data. The surveys conducted in Phase 1 produced an abundant number of leads for Phase 2; therefore, to achieve a holistic view, I gave preference to the participants who represented diverse backgrounds, had diverse experiences, and who served diverse populations. I compared the data collected during the interviews with the data collected from the surveys in Phase 1 to triangulate the data and increase the likelihood of data saturation. As recommended by Malterud et al. (2016), I evaluated data saturation by tracking the number of new and repeated themes discussed by the participants to determine if I needed to conduct more interviews. In the end, I conducted 12 interviews.

\section{Data Collection}

In Phase 2 of the study, I used interviews and a document review process to develop a holistic view of how the preparation and professional development opportunities available to $\mathrm{K}-12$ principals in Oregon supported their emotional needs, as well as how their needs varied based on their individual characteristics and the contexts in which they led. 
Interviews. As seen in Table 3.2, I used the interviews as a primary data source to collect information regarding how the preparation and professional development opportunities available to $\mathrm{K}-12$ principals in Oregon supported their emotional needs, particularly in relation to the stress and emotions caused by Covid-19. I developed a 30minute semi-structured interview protocol (Appendix F) using nine open-ended questions, which were aligned with the study's research questions. I used a pilot testing process to finalize and refine the questions after completing Phase 1 analysis. The interviews were conducted and recorded using Zoom video conferencing software.

Documents. I conducted a document review based on information shared in the interviews, which was tied to information reported in the surveys, regarding the types of preparation and professional development programs and activities to which the participants were exposed. As seen in Table 3.2, I collected data from preparation and professional development websites, as well as books mentioned by the principals. I reviewed these artifacts for evidence that supported the inclusion or exclusion of activities that encouraged the development of emotional intelligence.

Field Notes. I used field notes to record my observations and contextualize the data collection process. I organized notes in a dedicated Microsoft OneNote Notebook that was password protected to ensure confidentiality. The notebook included a section for each data collection instrument, and I created a new page for each observation and note-taking event. 
EMOTIONAL INTELLIGENCE AND K12 PRINCIPALS

Table 3.2

Alignment of Research Questions with Data Collection and Analysis

\begin{tabular}{|c|c|c|c|c|}
\hline Research Questions & $\begin{array}{c}\text { Primary Data } \\
\text { Collection } \\
\text { Tools }\end{array}$ & $\begin{array}{c}\text { Data } \\
\text { Sources }\end{array}$ & Datapoints & $\begin{array}{c}\text { Data } \\
\text { Analysis }\end{array}$ \\
\hline
\end{tabular}

RQ1: How do the perceptions of $\mathrm{K}-12$ principals in Oregon, regarding their needs for the development of emotional intelligence skills, vary based on their individual characteristics and the contexts in which they lead?
- Need for EI training

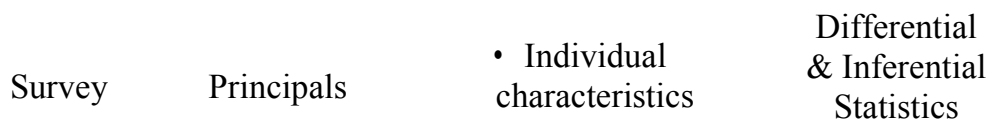

RQ2: How do K-12 principals in Oregon perceive that their preparation and professional development programs have supported the development of emotional intelligence skills?
Survey Principals

Interviews Principals

- School contexts

- Preparation \& professional development opportunities

- Helpfulness of EI training

- Perceptions of EI training

A Priori Coding
Differential \& Inferential Statistics
RQ3: How have the preparation and professional development opportunities available to $\mathrm{K}-12$ principals in Oregon prepared them to manage the stress and emotions caused by Covid-19?
- Professional preparation \& development opportunities Interviews Principals

- Management of stress \& emotions caused by COVID

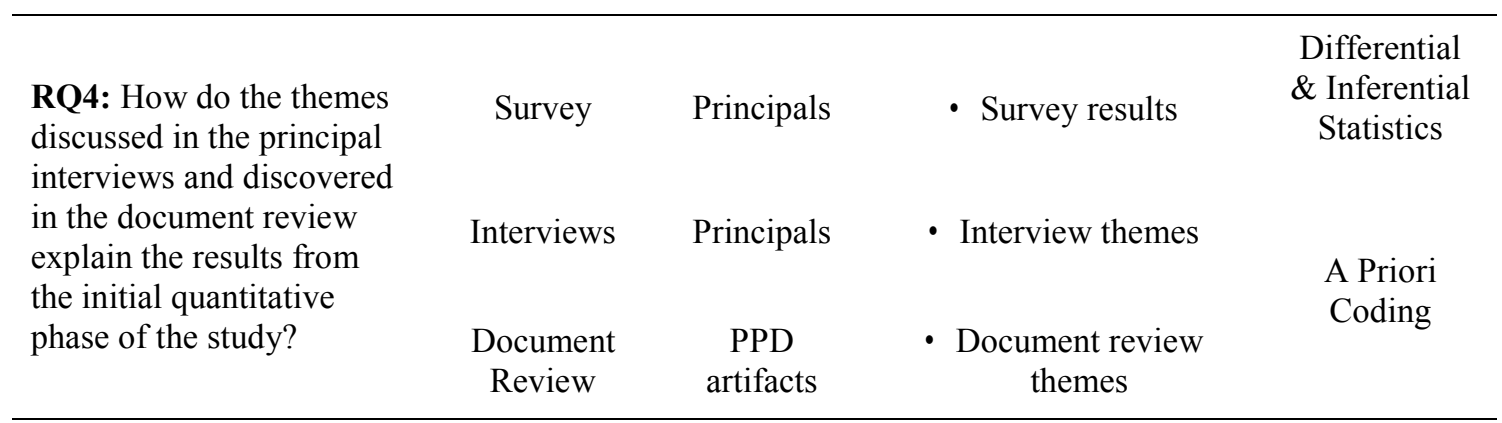

Note. $\mathrm{EI}=$ emotional intelligence, $\mathrm{PPD}=$ Preparation and Professional Development 


\section{Data Analysis Procedures}

Interviews. Using the data collected from the interviews, I examined how the preparation and professional development programs in Oregon prepared the participants to manage the widespread political and social changes caused by the Covid-19 pandemic, including the stress and emotional exhaustion experienced by members of the participants' communities. I modified my Zoom settings to record video and audio files for each interview, as well as to produce a transcription that I downloaded into a password-protected folder on my computer. The transcriptions contained substantial inaccuracies; therefore, I hired a research assistant to review the videos and edit the transcriptions as needed. I then member-checked the interview transcriptions for accuracy by adding each transcription to an individual encrypted folder that was secured with a password consisting of the confidentiality codes that participants had originally created for the surveys. I shared the link to the individual folders with each corresponding interview participant by email and gave them instructions for accessing the folders with their confidentiality codes (i.e., I reminded them that the code was created using the first three letters of their birth months, plus the number of cousins they have, plus the number of children they have, etc.). I also gave them my cell phone number in case they needed me to send them a text message with the password. I then completed any edits and redactions that were requested by the participant and deleted the recordings after the participants were satisfied with the transcriptions.

Next, I used the ATLAS.ti Qualitative Data Analysis (Version 9) software to code the transcriptions. I conducted a priori coding using descriptive, evaluation, and theming 
data-coding techniques as described by Saldaña (2013). I used descriptive coding guided by the conceptual frameworks in this study to assign topics to aspects of the transcriptions. I used the mixed model of emotional intelligence (Goleman et al., 2013) to classify the emotional needs described by the participants, the resonant leadership model (Boyatzis \& McKee, 2005) to classify the stress management skills and self-care described by the participants, and the job demands-resources (JD-R) theory (Bakker \& Demerouti, 2014) to provide additional insight into the stress and burnout levels of the participants. I used evaluation coding to assign judgment to the participants' perceptions about the utility of the preparation and professional development opportunities that have been available to them. I used theming data to create memos describing overall meaning of aspects of the data using phrases and/or sentences, such as the ability of the principals to perform specific aspects of their jobs. Lastly, I used anchor codes to identify information related to each research question. I ended up with 42 codes that I used to code the data.

I grouped the codes into eight categories-emotional intelligence, leadership, burnout, current climate, preparation programs, professional development programs, interview questions, and research questions - and then exported the information for each code or group of codes into an Excel spreadsheet based on the theme that I was exploring and analyzing at the time. The Excel spreadsheet included the information that was coded (i.e., quoted material that I selected, ranging from single words to paragraph-length discourse), the codes that were applied to that information, the code groups that the codes belonged to, and any memos or comments that I wrote as I was coding. Additionally, I 
often added extra columns to allow me to compute frequencies and add additional notes and observations. I started by creating an Excel spreadsheet for each interview question and any interesting themes that emerged, such as burnout and self-care. Lastly, I created Excel spreadsheets for each research question and compared my analysis of the interview data with my analysis of the information reported in the surveys to search for parallels and dissimilarities, as well as to triangulate the data.

Documents. I used the information reported in the interviews to identify specific programs and activities that were helpful to the participants. I recorded information concerning each program and framework in my field notes. I then researched the programs online, looking for evidence that supported the inclusion or exclusion of activities designed to encourage the development of emotional intelligence and reduce burnout. I used a priori coding to assign topics to aspects of the data as described in the interview section above. I then compared the document review data with the interview and survey data to analyze how the emergent themes affected my preliminary answers to the research questions, further triangulating the data and substantiating my conclusions.

\section{Validation}

In quantitative research, inferential statistics can be used to validate data and support the credibility of research findings. Although the process is less clear with qualitative research, the validation of data collection and analysis must still be addressed. Most researchers agree that triangulating the data is important (Creswell \& Creswell, 2018; McGinn, 2012; Pope, 2017; Yin, 2018); however, there are diverse approaches to validation. Morgan and Ravitch (2018) take a streamlined approach in recommending 
only two methods to validate qualitative research: the use of triangulation and participant validation. Yin (2018), on the other hand, recommends additional methods to ensure validation, such as the use of multiple sources of evidence, researcher training, case study protocols, pilot studies, databases, and documentation of the chain of evidence. This study used a variety of approaches to ensure the credibility, dependability, confirmability, and transferability of the qualitative data.

Credibility. Credibility refers to the degree to which the data that is collected and analyzed can be trusted to answer the research questions. In this study I used triangulation, maximum variation sampling, negative case sampling, pilot studies, and member checking to increase the credibility of the data.

I used methodological, environmental, and theory triangulation to cross-verify the data. To accomplish methodological triangulation, I gathered evidence from multiple sources, such as surveys, interviews, and documents. According to McGinn (2012), this strategy allows the strengths of one method to cancel out the weaknesses of another. Additionally, I accomplished environmental triangulation by gathering evidence from multiple locations across the state of Oregon and theory triangulation by using peer debriefing to recruit unbiased views of the study from individuals who were not directly involved in the study.

To obtain a holistic view of the needs of principals, I used a maximum variation sampling strategy. I recruited $\mathrm{K}-12$ principals serving in school districts across the state, including principals from rural, urban, and suburban schools; principals serving at the elementary, middle/junior-high-school, and high-school levels; principals serving in low- 
need, average-need, and high-need schools; and principals from a variety of backgrounds and with a variety of experiences in education. According to McGinn (2012), maximum variation sampling can be helpful in uncovering negative evidence that allows the researcher to develop a more complete picture of the phenomenon.

I used pilot testing to ensure that the data collection instruments could collect the desired information in an efficient and comfortable manner for the participants. I conducted pilot studies with a small number of individuals who were not involved in the research to test out the survey and interview questions. Additionally, I practiced interviewing individuals to develop my interview protocols and become comfortable with the process. Lastly, I used member checking to assess how well my interpretations agreed with my participants' interpretations (McGinn, 2012). After the transcriptions of the interviews were completed, the transcripts were sent to the participants for validation and then redacted and edited as needed.

Dependability. Dependability refers to the degree to which the results of the study are consistent and repeatable. I used data saturation and code audits to increase the dependability of this study, to ensure the development of a complete understanding of the data, and to reduce the likelihood of the discovery of additional themes should the study be repeated. I audited the codes that were applied to the interview transcripts by calculating the number of new and repeated themes to ensure that appropriate sample sizes were achieved. My goal was to find at least two examples of each code that helped answer each research question, indicating that new themes were no longer being discovered. It was my intention that the codes that were developed to describe the data 
present an honest representation of the data; however, my experience as an educator may have shaped my understanding of the data, which may have skewed the results (McGinn, 2012; Pope, 2017).

Confirmability. Confirmability refers to the degree to which the results of the study can be externally confirmed. I used audit trails and reflexivity to increase the confirmability of the study. Yin (2018) and McGinn (2012) recommend maintaining a chain of evidence to document data analysis steps and trace the development of themes and categories. This record provides justification for the decisions made and allows external auditors to confirm the results of the study. I recorded chains of evidence, otherwise referred to as audit trails, in my field notes to provide full disclosure regarding how and why I interpreted the data the way I did. I also provided thick descriptions of the data and used a reflexive approach to document how my perspectives influenced the collection and interpretation of the data, as recommended by McGinn (2012).

Transferability. Transferability refers to the degree to which the methods used in the study, or the results of the study, can be applied to other contexts. It is unlikely that the results of this study can be applied to other contexts because principals in different states may have different experiences and perceptions regarding their professional development needs. However, the methods used to determine how emotional intelligence can be incorporated into professional learning activities to support principals can be transferred to other contexts. Therefore, I provided thick descriptions of the data collection and analysis procedures as a framework for potential future research in other contexts. 


\section{Limitations and Delimitations of the Research Design}

This section will describe the limitations and delimitations that apply to this study.

\section{Limitations}

There are several limitations that restrict the conclusions that can be drawn from this study. First, the sample used in this research was limited to principals working in public school districts in the state of Oregon; therefore, the findings are not generalizable to private schools or school districts located in other states and countries. Second, although efforts were made to obtain a sample that included the perceptions of all principals in the state of Oregon, the sample obtained was smaller than needed to reliably represent all desired variations, and principals who have experience with or who have strong feelings about emotional intelligence training or stress and burnout in education may have been more likely to self-select to participate in the study; therefore, the findings may not represent the perspectives of all the $\mathrm{K}-12$ public school principals employed in Oregon.

Third, limitations to the data-collection method are present for both quantitative and qualitative portions of the study. The data gathered from the surveys included demographic and professional development items that I designed, and although these questions were validated by peer review and a pilot study, the inclusion of such questions limits the validity and reliability of the instrument because they have not been formally tested. Additionally, the number of items on the survey were reduced to encourage 
maximum participation, which may have limited my understanding of the possible variations and aspects of the phenomenon.

Lastly, researcher bias is a limitation present in all qualitative research (McGinn, 2012; Yin, 2018). I am an assistant principal who has worked in different capacities and roles in six different school districts in the state of Oregon. My experiences have shaped my understanding of the leadership challenges present in $\mathrm{K}-12$ education and my interpretation of the data gathered in this study. I made efforts to reduce my bias by including member checking and code audits in the design of this study; however, the elimination of all bias is not possible.

\section{Delimitations}

Delimitations to this research study are defined by the context of the research questions and study population of interest. This research did not include the perspectives of students, teachers, or staff members who were not serving as principals when the survey was administrated, nor did it include principals who were working under a reciprocal license. Although the purpose of this study was ultimately to help school districts support principals so that they can adequately support teachers and students, the immediate focus is on supporting the principals' needs, rather than the needs of their instructional staff or students. Although the perceptions of the principals' supervisors, colleagues, and subordinates would provide interesting data regarding the need for the development of emotional intelligence in principals, this type of data collection was not feasible given the site access that would be needed to gather this data, and the procedures and manpower that would be required to analyze it. 
In addition, based on the conceptual framework used, this research did not identify dimensions of emotional intelligence that were based entirely on ability-based or trait-based emotional intelligence models, nor did it examine professional learning skills that were unrelated to emotional intelligence.

\section{Ethical Issues in the Proposed Study}

The human subject protection measures used in this study design sought to maximize the benefits of the research and minimize its potential harms in alignment with the ethical principles of respect for persons, beneficence, and justice. Prior to administering surveys or conducting interviews, I obtained reviews and approvals of all study instruments by the Institutional Review Board at Portland State University. This section will discuss the ethical considerations for the research design.

\section{Informed Consent}

Separate consent forms were used for each phase of the study. A consent form describing Phase 1 of the study and explaining the benefits and risks of participation was included as the first section of the Phase 1 survey (Appendix D). It was also made available on the website describing the research, and participants were not able to access the remaining sections of the survey without giving consent. The participants for Phase 2 of the study were selected based on the leads generated by the survey, and a link to the second consent form (Appendix E) was sent via email to the individuals who were invited to participate in Phase 2 of the study. This Phase 2 consent form was also available on the website describing the research. 


\section{Data Management Procedures}

The data collected in this study consisted entirely of Type 1 and Type 2 data. This type of data is not normally expected to result in harm; however, disclosure could breech a promise of confidentiality. Although personally identifying information must be maintained to classify and recruit participants, all information that could be used directly or indirectly to identify participants was modified with study codes that identified participants in a separate document. Participants were asked to generate their own identification codes using a series of prompts included on the survey. A key was created that linked the identification codes to the participants' identities. As the investigator, I am the only individual who has had access to the key and, pending exigent circumstances, I will delete all personally identifying information 3 years after the research has been completed.

In accordance with federal regulations, Institutional Review Board policies, and best practices for data management, all data gathered in this study are stored on my computers and/or computer drives, which are encrypted, protected with strong passwords and firewalls, and locked when not in use. All documents, spreadsheets, and databases that contain information that could identify the participants in the study are kept in password-protected folders and all passwords are kept secure. I only conducted data analysis on data sets that were de-identified and identifying information will not be revealed in publications or reports, whether written or oral.

Recordings of interviews were uploaded for transcription using a secure connection. These recordings were deleted after they were member checked, and all 
necessary redactions and edits were made to the transcripts. Data that included personally identifying information were not transferred by email, and I used password-protected, encrypted individual folders to transfer files to participants for member checking.

\section{My Positionality as a Researcher}

There are no conflicts of interest in this study. I have not supervised any of the participants, nor do I have any financial stake in or connection with providers of preparation and professional development training programs for educators. The small incentive offered to the first 50 respondents to encourage participation in the surveys and interviews was within acceptable limits to avoid any appearance of coercion. I acknowledge a personal interest in ensuring the completion of this study as quickly as possible to minimize the financial hardship involved in obtaining a doctorate degree. I also acknowledge that the subject matter is of high interest to me because of my experience in education and leadership. However, although these interests may cause unintentional bias in my interpretation of results, I worked to safeguard against that bias in the study design and implementation of data collection, analysis, and interpretation.

\section{Summary}

The purpose of this explanatory sequential mixed methods study was to discover how the professional development programs and activities designed for $\mathrm{K}-12$ principals in the state of Oregon supported their emotional needs. As a researcher, I have taken efforts to develop a strong research design that aligns the data collection and data analysis procedures with the research questions posed. I have also used a variety of strategies to obtain valid and reliable findings while protecting the study's participants from harm. 
The research design included two phases. Phase 1 focused on quantitative data collection and analysis in the form of a validated survey, and Phase 2 focused on qualitative data collection through interviews of a representative sample of principals and a document review process used to explore the preparation and professional development opportunities available to the principals who were interviewed. This chapter outlined each phase of the study, the sampling methods that were used to select participants for each phase, and the instruments and procedures that were used to collect and analyze the data, as well as the limitations and delimitations that applied to this study and the measures that were taken to ensure that the research was conducted in an ethical manner. 


\section{Chapter 4: Results and Analysis}

\section{Introduction}

This study was designed to explore how the preparation and professional development opportunities available to $\mathrm{K}-12$ principals in Oregon have supported their needs for the development of emotional intelligence skills. This chapter provides a detailed analysis of the data collected to answer the following research questions: (RQ1) How do the perceptions of $\mathrm{K}-12$ principals in Oregon, regarding their needs for the development of emotional intelligence skills, vary based on their individual characteristics and the contexts in which they lead? (RQ2) How do K-12 principals in Oregon perceive that their preparation and professional development programs have supported the development of emotional intelligence skills? (RQ3) How do K-12 principals in Oregon perceive their preparation and professional development programs to have prepared them to manage the stress and emotions caused by Covid-19 and other challenges? and (RQ4) How do the principal preparation and professional development themes exposed in the principal interviews and document review process explain the results from the initial quantitative phase of the study? The findings presented in this chapter are based on the research methodology described in Chapter 3 and divided into quantitative and qualitative sections.

\section{Quantitative Data}

I collected quantitative data with a 26-item survey (Appendix D) that was administered at the end of the 2021 school year. The survey consisted of five sections: a screening section, a demographics section, a section that focused on principal preparation 
programs, a section that focused on professional development programs that were available to principals after they had received their licensure, and a section that was designed to develop leads for the qualitative phase of the study. The questions examined the extent to which principal preparation and professional development programs and activities available to principals in Oregon included the development of emotional intelligence skills, the degree to which the programs and activities were helpful in developing these skills, and the degree to which the participants felt that principals in Oregon needed training to develop emotional intelligence skills.

\section{Participant Response Rates and Demographics}

One hundred and seventeen principals responded to the survey; however, 23 participants did not respond to enough questions to be included in the study (respondents needed to complete all of the principal preparation questions, a minimum of $45 \%$ of the total questions, to be included), 13 participants who were working under a reciprocal license and four participants who had attended their principal preparation programs out of state were excluded because of their lack of experience with Oregon preparation and professional development programs, and nine participants only responded to enough questions to be included in the principal preparation section of the study (respondents needed to complete all of the professional development questions, a minimum of $84 \%$ of the total questions, for their answers to be included in the professional development section). Therefore, the data from 77 of the participants were included in the analysis of the principal preparation questions, and the data from 69 of the participants were included in the analysis of the professional development questions. These sample sizes did not 
meet recommended survey sample sizes (Bartlett et al., 2001); therefore, the findings presented in this chapter may not be generalizable to the entire population of principals in Oregon.

The demographics section of the survey collected a variety of individual characteristics and experiences, such as gender, race/ethnicity, age, and years of experience (Figure 4.1). Participants were 53\% female and 47\% male. Eighty-seven percent were White/Caucasian, $6 \%$ were Hispanic/Latinx, $4 \%$ were two or more races, and 3\% were Black/African American, reflecting that 13\% of the participants were ethnically diverse, which exceeded the state average of 11.4\% (Educator Advancement Council, 2019). The oldest principal was 70 years old and the youngest was 36 , with an average age of 50. On average, the principals who responded to the survey had 26 years of experience in education and 13 years of experience as a principal; however, there were principals with as little as 6 years of experience in education and 2 years of experience as a principal, as well as principals with up to 40 years of experience in education and 29 years of experience as a principal. Additionally, 60 of the 77 principals (78\%) who participated had obtained both their preliminary/principal and professional/district-level administrator's licenses. 


\section{Figure 4.1}

\section{Individual Characteristics of the Phase 1 Participants}
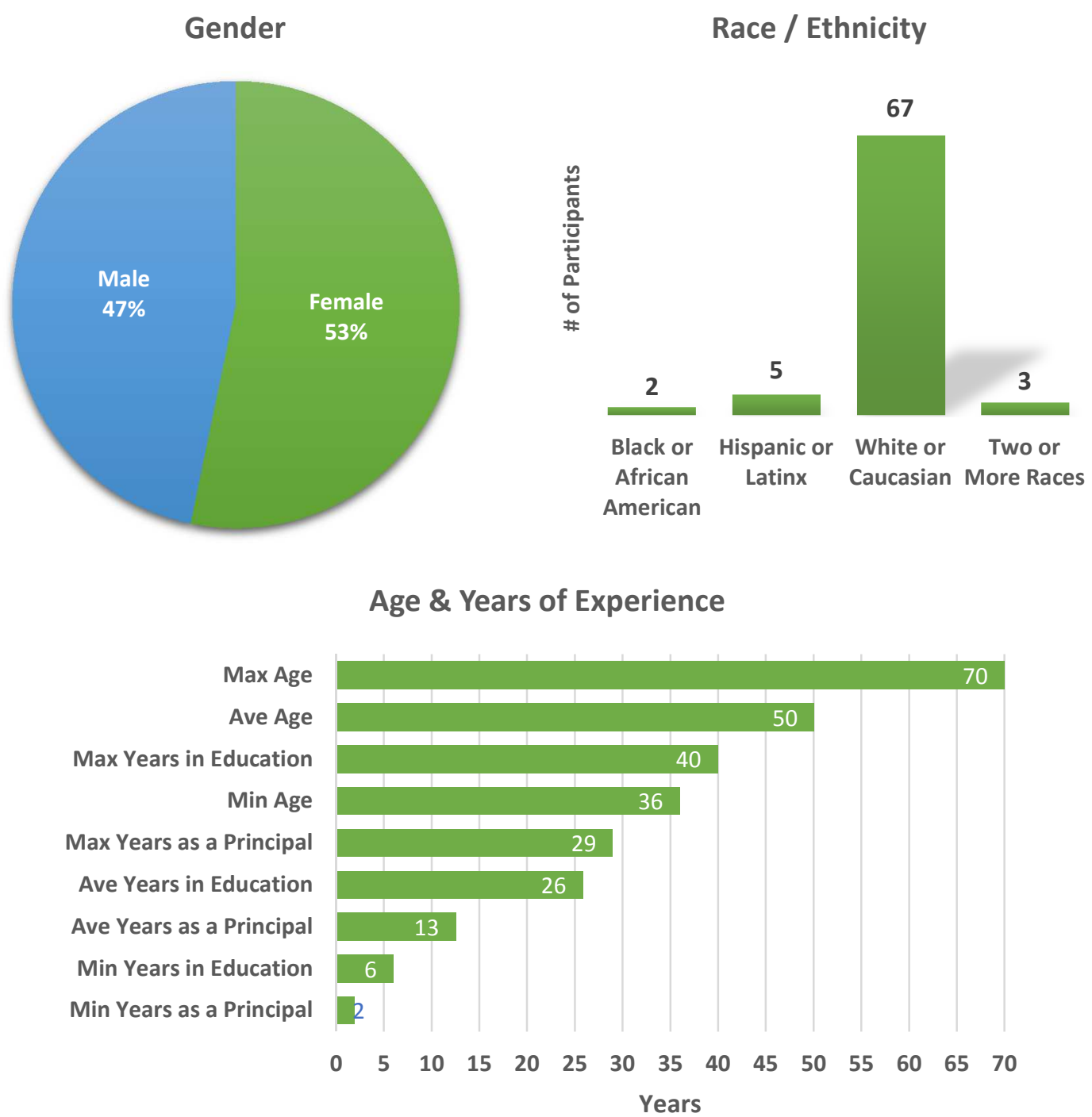

Note. The participants had a variety of individual characteristics and experiences that were collected with the survey, such as gender, race/ethnicity, age, years of experience in education, and years of experience as a principal. 
The participants worked in a variety of school contexts (Figure 4.2). Most worked in traditional public schools, but $5 \%$ of respondents worked in public charter schools. About half of the participants worked in elementary schools with the remaining split fairly evenly between middle/junior high and high schools. The majority of the principals worked at rural schools, with approximately one third of the participants working at urban schools and another third at suburban schools. These numbers align closely with state averages, as there are 555 elementary (49\%), 240 middle/junior high (21\%), and 342 high schools (30\%) in Oregon (Oregon Department of Education, 2021) and 38\% of Oregon's students attend rural schools (Chalk Board Project, n.d.). Lastly, $60 \%$ of the participants worked at high-need schools, while $21 \%$ worked at average-need schools, and only $10 \%$ worked at low-need schools. Principals provided their own insights on needs in the survey. The State School Fund considers student needs to be generally higher in communities with higher levels of poverty and for students who are in foster care, who are pregnant or parenting, who are neglected, and who require special education or English language development programs. 


\section{Figure 4.2}

\section{School Contexts of the Phase 1 Participants}
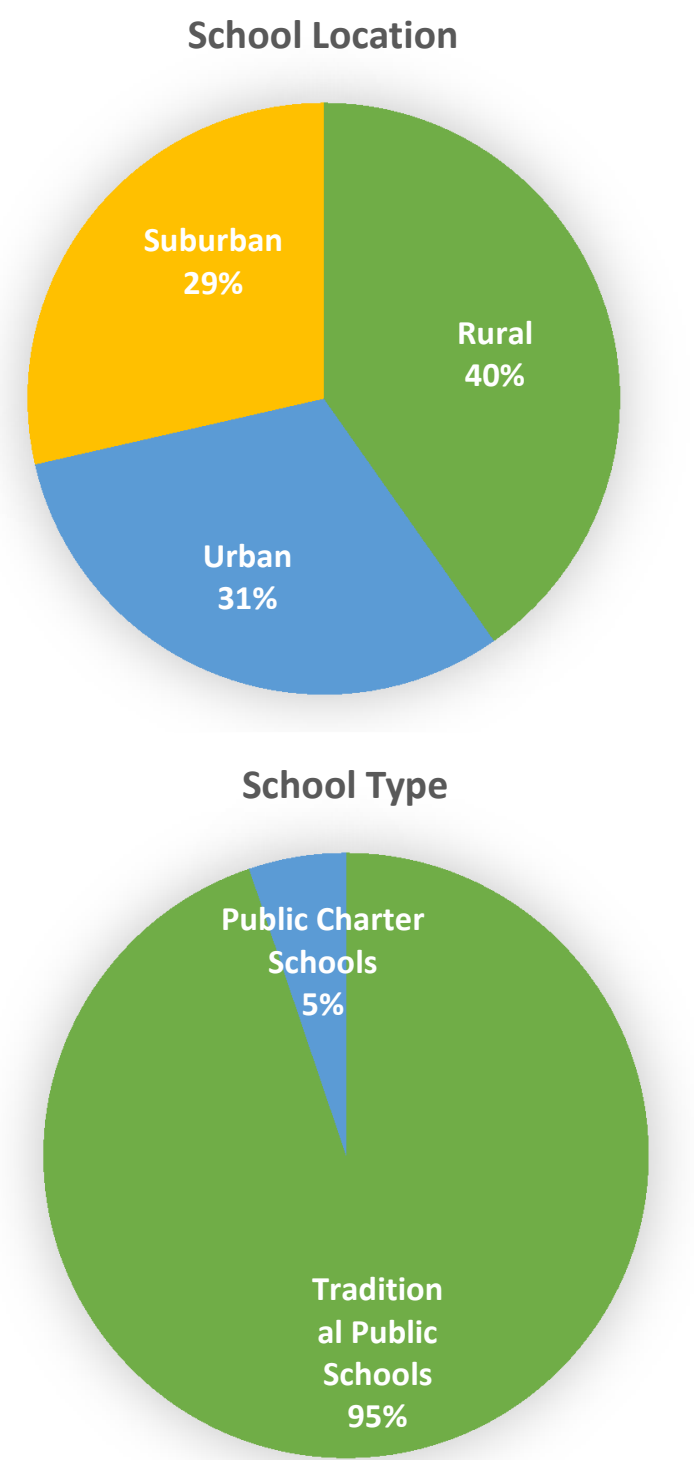

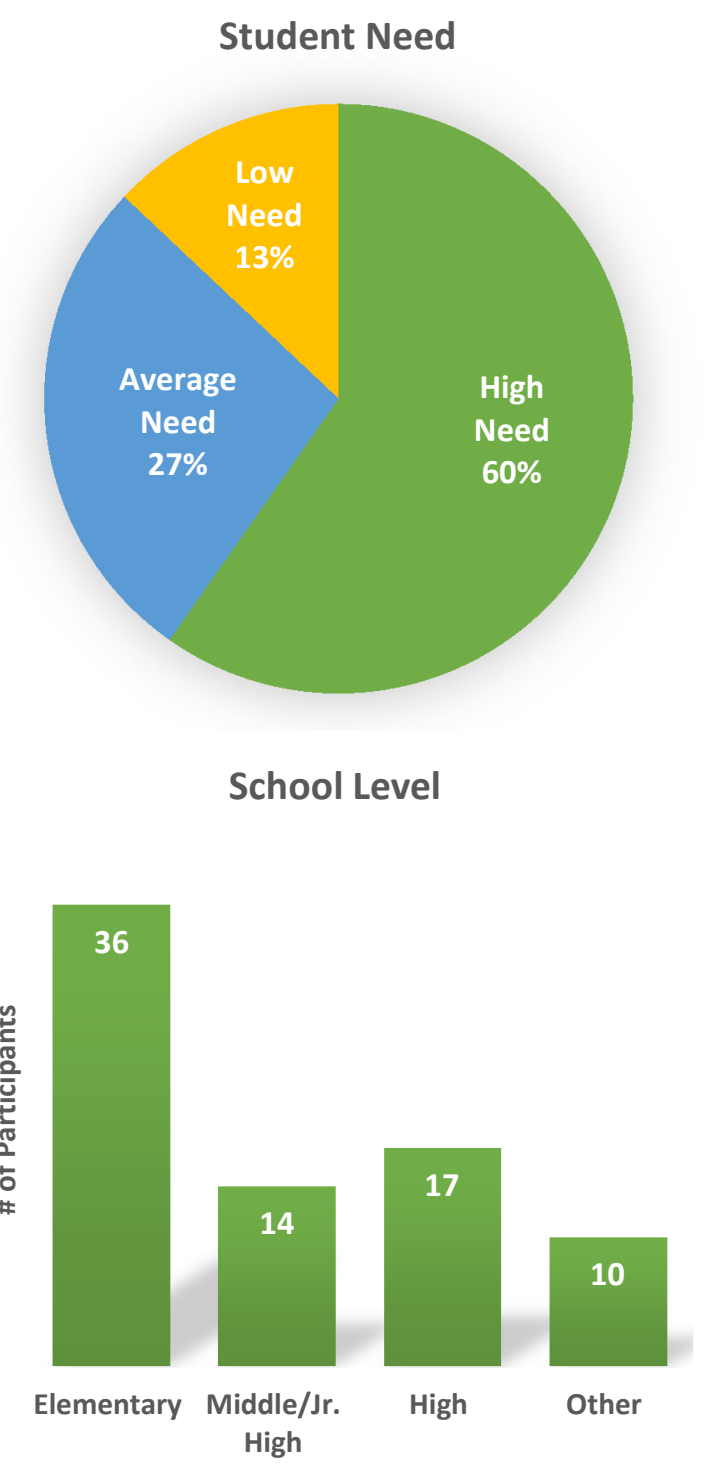

Note. The participants worked in a variety of school contexts, including at different types of schools, at different school levels, at schools with different levels of student need, and at schools in a variety of locations across the state. 


\section{Principal Preparation Programs}

The survey (Appendix D) included four multi-part questions regarding the participants' perceptions of their principal preparation programs in relation to the development of 13 distinct and two Covid-19-specific skills. These skills were grouped into the emotional intelligence clusters of self-awareness, self-management, social awareness, and relationship management (Goleman et al., 2001, 2013). The first part of each question asked if the development of each skill was included in the principal preparation programs that the participant had attended. The second part of the question asked how helpful principals found the training that they had experienced. Participants responded using 3-point Likert scales with the options of yes, unsure, and no for the first part of the question and the options of helpful, unsure, and unhelpful for the second part of the question. Descriptive statistics were used to summarize the data and inform the answers to the second and third research questions.

Table 4.1 displays a comparison of the percentage of the participants who responded with yes, unsure, or no to each of the emotional intelligence skills, Figure 4.3 graphs the percentage of the participants who responded yes to each of the emotional skills, and Figure 4.4 groups the emotional intelligence skills explored into selfawareness, self-management, social awareness, and relationship management clusters (Goleman et al., 2001, 2013). When participants were asked if their principal preparation program(s) included training that helped them develop emotional intelligence skills, most participants indicated that their principal preparation programs included training on skills designed to help manage interpersonal relationships, such as encouraging trust and 
collaboration $(75 \%, n=58)$, managing conflict effectively $(75 \%, n=58)$, and managing change effectively $(79 \%, n=61)$. However, less than $50 \%$ of the participants indicated that they had received training in the remaining 10 skills included on the survey, with only $2(2.6 \%)$ participants indicating that they received training that would have helped them manage the effects of the pandemic on themselves, and only $1(0.8 \%)$ participant indicating that they received training that would have helped them manage the effects of Covid-19 on others, such as their staff, students, and their students' families $(1.3 \%, n=$ 1). As seen in Figure 4.4, on average, $51 \%( \pm 36 \% S D)$ of the participants indicated that they had received training in the relationship management cluster, $26 \%( \pm 17 \%)$ in the social awareness cluster, $23 \%( \pm 28 \%)$ in the self-management cluster, and $13 \%( \pm 5 \%)$ in the self-awareness cluster. 


\section{Table 4.1}

\section{Emotional Intelligence Skills Included in Principal Preparation Programs}

\begin{tabular}{|c|c|c|c|c|}
\hline \multirow[t]{2}{*}{ Cluster } & \multirow[t]{2}{*}{ Skill } & \multicolumn{3}{|c|}{ Participant Responses } \\
\hline & & $\begin{array}{c}\text { Yes } \\
\%(n)\end{array}$ & $\begin{array}{c}\text { Unsure } \\
\%(n)\end{array}$ & $\begin{array}{c}\text { No } \\
\%(n)\end{array}$ \\
\hline \multirow[t]{3}{*}{ Self-Awareness } & $\begin{array}{l}\text { Understanding how one reacts to } \\
\text { emotions }\end{array}$ & $11.7(9)$ & $0.0(0)$ & $88.3(68)$ \\
\hline & $\begin{array}{l}\text { Understanding how others influence } \\
\text { emotions }\end{array}$ & $9.1(7)$ & $1.3(1)$ & $89.6(69)$ \\
\hline & Understanding how emotions affect others & $19.5(15)$ & $1.3(1)$ & $79.2(61)$ \\
\hline \multirow[t]{4}{*}{ Self-Management } & Adapting to change & $63.6(49)$ & $2.6(2)$ & $33.8(26)$ \\
\hline & Preventing emotions from affecting others & $10.4(8)$ & $1.3(1)$ & $88.3(68)$ \\
\hline & Managing and coping with stress & $15.6(12)$ & $0.0(0)$ & $84.4(65)$ \\
\hline & $\begin{array}{l}\text { Managing emotional responses to Covid- } \\
19\end{array}$ & $2.6(2)$ & $0.0(0)$ & $97.4(75)$ \\
\hline \multirow[t]{3}{*}{ Social Awareness } & $\begin{array}{l}\text { Recognizing the unstated emotions of } \\
\text { others }\end{array}$ & $14.3(11)$ & $3.9(3)$ & $81.8(63)$ \\
\hline & Recognizing the collective mood in a room & $19.5(15)$ & $1.3(1)$ & $79.2(61)$ \\
\hline & Understanding the political forces at work & $45.5(35)$ & $2.6(2)$ & $51.9(40)$ \\
\hline Relationship & Supporting the emotional needs of others & $23.4(18)$ & $2.6(2)$ & $74.0(57)$ \\
\hline \multirow[t]{4}{*}{ Management } & Encouraging trust and collaboration & $75.3(58)$ & $3.9(3)$ & $20.8(16)$ \\
\hline & Managing conflict effectively & $75.3(58)$ & $1.3(1)$ & $23.4(18)$ \\
\hline & Managing change effectively & $79.2(61)$ & $0.0(0)$ & $20.8(16)$ \\
\hline & $\begin{array}{l}\text { Managing the effects of Covid-19 on } \\
\text { others }\end{array}$ & $1.3(1)$ & $1.3(1)$ & $97.4(75)$ \\
\hline
\end{tabular}

Note. Participants were asked if their principal preparation program(s) included training that helped them develop the emotional intelligence skills listed. The percentage (number) of the participants who responded with each answer is presented in the columns above. 


\section{Figure 4.3}

\section{Inclusion of EI Training in Principal Preparation: By Skill}

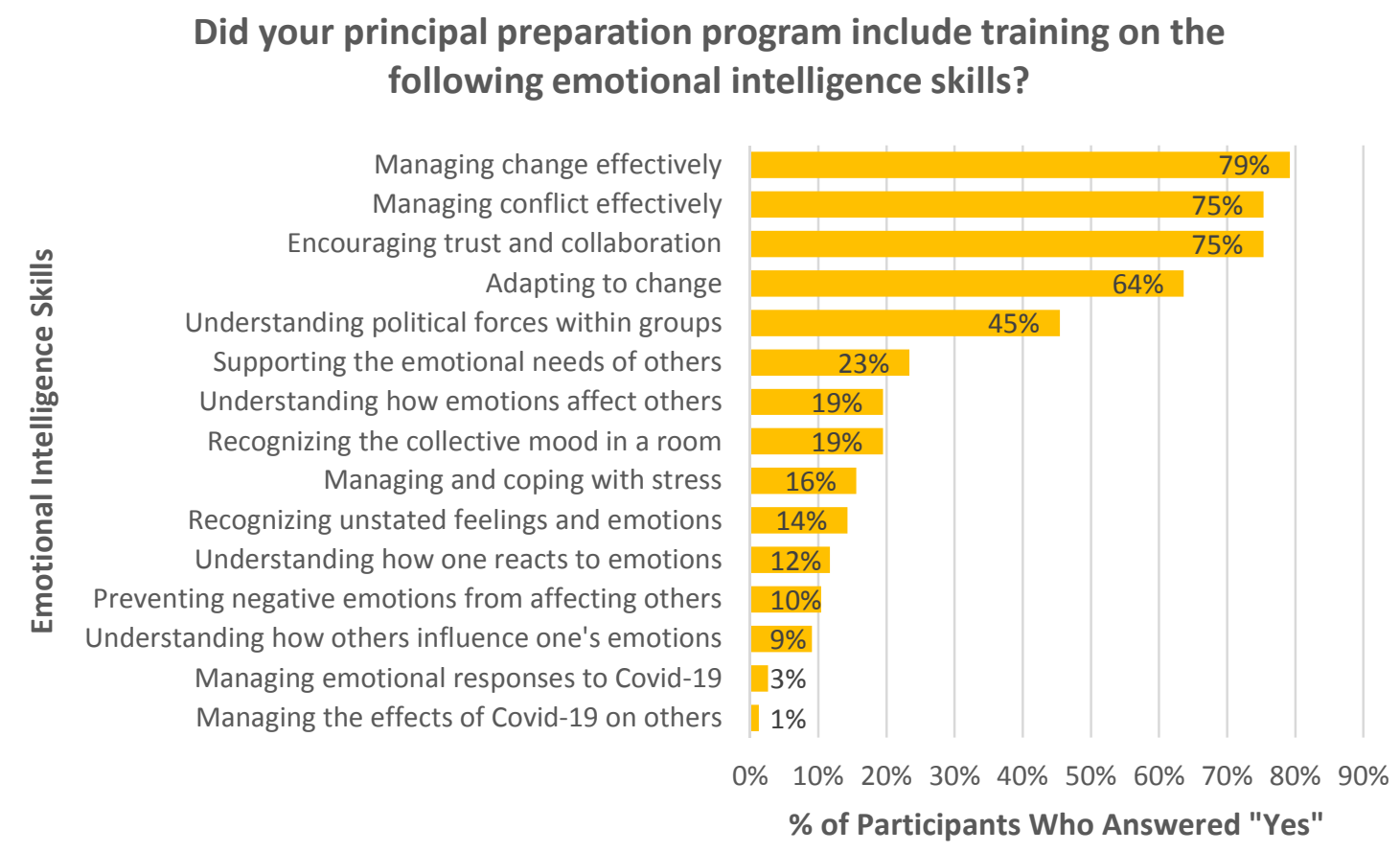

Note. This chart displays the percentage of the participants who responded yes to the question "Did your principal preparation program include training on the following emotional intelligence skills?" for each of the 15 emotional skills listed. 
Figure 4.4

Inclusion of EI Training in Principal Preparation: By Cluster

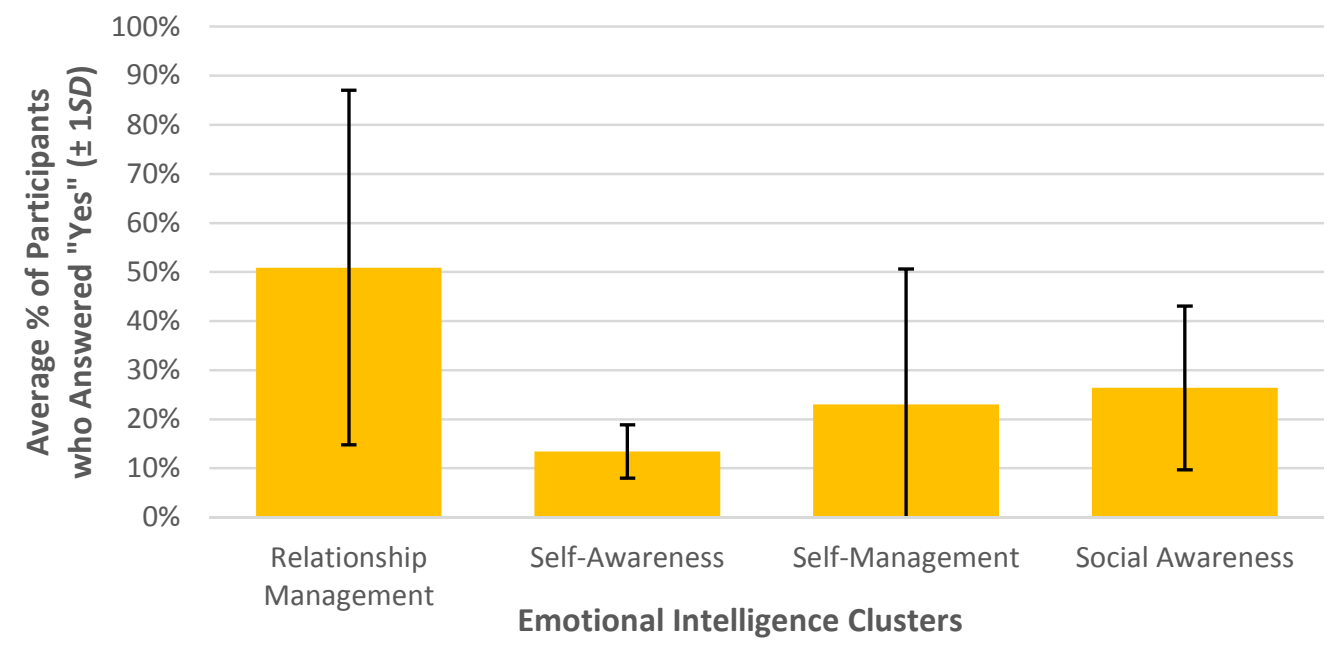

Note. This chart groups the 15 emotional intelligence skills into self-awareness, self-management, social awareness, and relationship management clusters (Goleman et al., 2001, 2013). The number of yes answers is averaged across all questions within each cluster.

When participants indicated that an emotional intelligence skill was included in their principal preparation programs, they were asked to answer a follow-up question regarding how helpful they perceived the training to be. Most of the participants who received training found it to be helpful (Table 4.2 and Figure 4.5). For example. $100 \%$ of the participants who received training on recognizing the collective mood in a room $(n=$ 17), the one participant who received training on managing the effects of Covid-19 on others $(100 \%, n=1)$, and $88 \%$ of the participants who received training on managing change effectively $(n=59)$ found the training to be helpful. However, only slightly more than half of the participants who received training on managing and coping with stress 
$(57 \%, n=14)$ found it to be helpful, and neither of the participants who received training on managing their own emotional responses to Covid-19 $(0 \%, n=2)$ found the training they received to be helpful.

Table 4.2

Helpfulness of EI Training in Principal Preparation: By Skill

\begin{tabular}{llccc}
\hline Cluster & \multicolumn{1}{c}{ Skill } & \multicolumn{3}{c}{ Participant Responses } \\
\cline { 3 - 5 } & & Helpful & Unsure & Not \\
& & $\%(n)$ & $\%(n)$ & $\begin{array}{c}\text { Helpful } \\
\%(n)\end{array}$ \\
\hline \multirow{2}{*}{ Self-Awareness } & Understanding how one reacts to emotions & $66.7(8)$ & $25.0(3)$ & $8.3(1)$ \\
& Understanding how others influence & $63.6(7)$ & $27.3(3)$ & $9.1(1)$ \\
& emotions & & & \\
& Understanding how emotions affect others & $77.8(14)$ & $16.7(3)$ & $5.6(1)$ \\
\hline Self-Management & Adapting to change & $85.7(42)$ & $10.2(5)$ & $4.1(2)$ \\
& Preventing emotions from affecting others & $77.8(7)$ & $11.1(1)$ & $11.1(1)$ \\
& Managing and coping with stress & $57.1(8)$ & $35.7(5)$ & $7.1(1)$ \\
& Managing emotional responses to Covid-19 & $0.0(0)$ & $50(1)$ & $50(1)$ \\
\hline Social Awareness & Recognizing the unstated emotions of others & $81.3(13)$ & $12.5(2)$ & $6.3(1)$ \\
& Recognizing the collective mood in a room & $100.0(17)$ & $0.0(0)$ & $0.0(0)$ \\
& Understanding the political forces at work & $86.5(32)$ & $10.8(4)$ & $2.7(1)$ \\
\hline Relationship & Supporting the emotional needs of others & $59.1(13)$ & $31.8(7)$ & $9.1(2)$ \\
& Encouraging trust and collaboration & $87.5(49)$ & $3.6(2)$ & $8.9(5)$ \\
& Managing conflict effectively & $82.1(46)$ & $8.9(5)$ & $8.9(5)$ \\
& Managing change effectively & $88.1(52)$ & $3.4(2)$ & $8.5(5)$ \\
& Managing the effects of Covid-19 on others & $50.0(1)$ & $50.0(1)$ & $0.0(0)$ \\
\hline
\end{tabular}

Note. Participants were asked how helpful the training that they had received in their principal preparation program(s), if any, was in helping them develop the emotional intelligence skills listed.

Participants responded with helpful, unsure, or not helpful. The percentage (number) of the participants who responded with each answer is presented in the columns above. 


\section{Figure 4.5}

\section{The Helpfulness of Emotional Intelligence Training in Principal Preparation: By Skill}

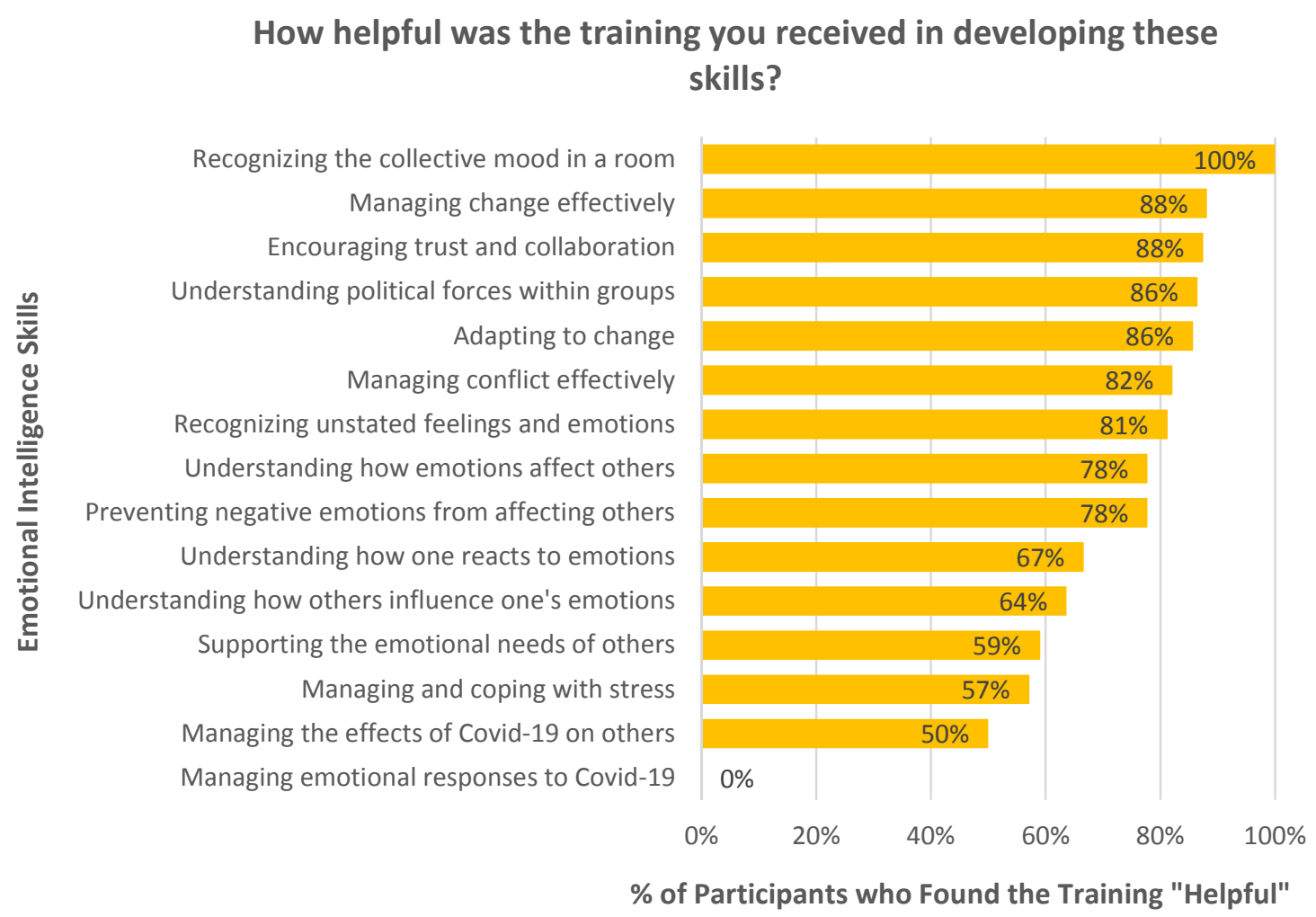

Note. This chart displays the percentage of the participants who received emotional intelligence training and who indicated that they found the training helpful.

Figure 4.6 groups the 15 emotional intelligence skills into the self-awareness, self-management, social awareness, and relationship management clusters (Goleman et al., 2001, 2013). On average, $89 \%( \pm 10 \%)$ of the participants indicated that they felt that the training that they received in the social awareness cluster was helpful, $83 \%( \pm 13 \%)$ indicated their training in the relationship management cluster was helpful, $69 \%( \pm 7 \%)$ indicated their training in the self-awareness cluster was helpful, and 55\% $( \pm 39 \%)$ indicated that their training in the self-management cluster was helpful. 


\section{Figure 4.6}

Helpfulness of EI Training in Principal Preparation: By Cluster

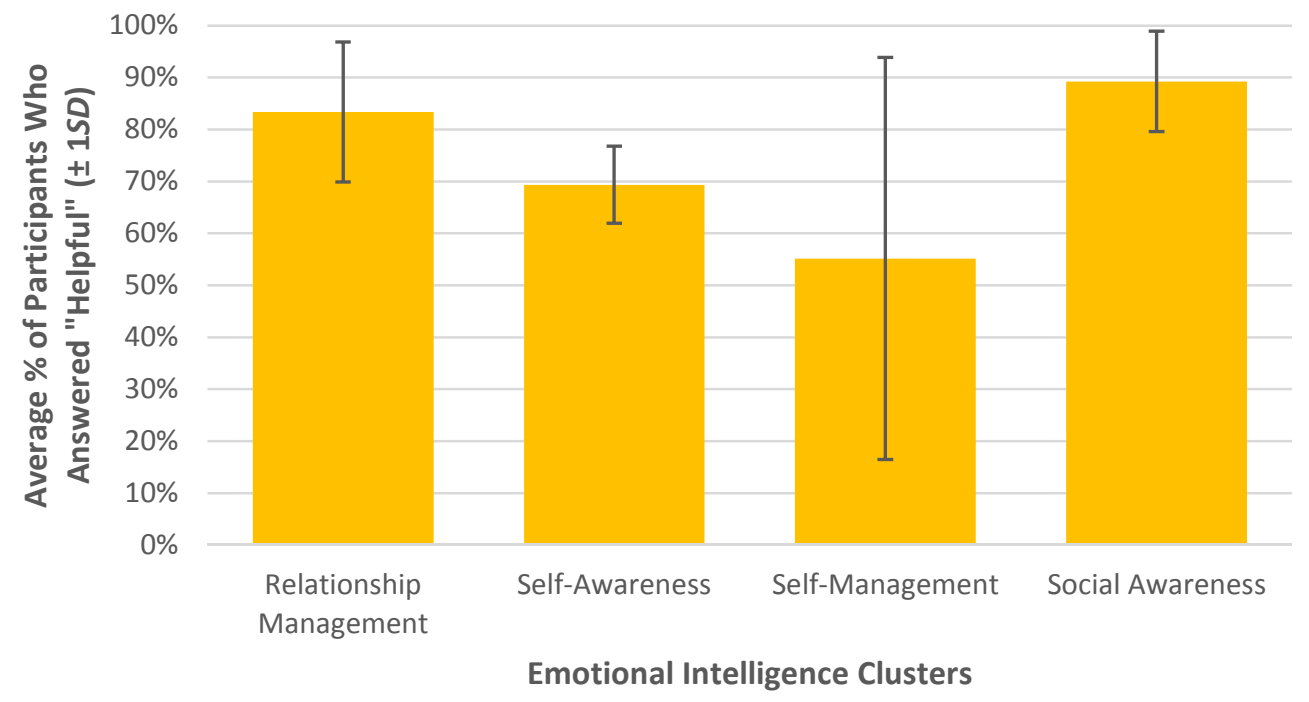

Note. This chart groups the 15 emotional intelligence skills into self-awareness, self-management, social awareness, and relationship management clusters (Goleman et al., 2001, 2013). The number of helpful answers is averaged across all questions within each cluster.

\section{Principal Professional Development}

The survey (Appendix D) included six questions regarding the principals' perceptions of the professional development opportunities that have been available to them in Oregon. Like the principal preparation opportunity section of the survey, these questions asked about principals' development of 13 distinct and two Covid-19-specific skills that were grouped into the emotional intelligence clusters of self-awareness, selfmanagement, social awareness, and relationship management (Goleman et al., 2001, 2013). The first question asked the participants how many leadership-focused professional development activities they had the opportunity to participate in each year. 
The second question asked how many professional development activities they participated in each year on average. The remaining four questions asked the degree to which each emotional intelligence skill was included in the professional development programs and activities in which the participant had participated, as well as how helpful principals found the training that they had received. Participants responded using 3-point Likert scales with the options of yes, unsure, and no for the first parts of the question and the options of helpful, unsure, and unhelpful for the second part of the question. Descriptive statistics were used to summarize the data and inform the answers to the second and third research questions:

RQ2. How do $\mathrm{K}-12$ principals in Oregon perceive that their preparation and professional development programs have supported the development of emotional intelligence skills?

RQ3. How do $\mathrm{K}-12$ principals in Oregon perceive their preparation and professional development programs to have prepared them to manage the stress and emotions caused by Covid-19 and other challenges?

Overall, the participants indicated that on average they had the opportunity to participate in 9.07 ( \pm 7.05) leadership-focused professional development activities each year; however, they were generally only capable of participating in an average of 6.21 ( \pm 5.79) of the opportunities available. Table 4.3 and Figure 4.7 display the percentage of the participants who indicated that they had participated in professional development activities that included emotional intelligence skills. Over $50 \%$ of the participants indicated that they had participated in 7 of the professional development activities, but 
less than $40 \%$ had participated in the remaining 8 . The greatest percentage of participants were trained in encouraging trust and collaboration $(66 \%, n=45)$ and the fewest participants were trained in managing the effects of Covid-19 on others $(19 \%, n=13)$.

\section{Table 4.3}

\section{EI Skills Included in Professional Development for Principals}

\begin{tabular}{|c|c|c|c|c|}
\hline \multirow[t]{2}{*}{ Cluster } & \multirow[t]{2}{*}{ Skill } & \multicolumn{3}{|c|}{ Participant Responses } \\
\hline & & $\begin{array}{l}\text { Yes } \\
\%(n)\end{array}$ & $\begin{array}{l}\text { Unsure } \\
\%(n)\end{array}$ & $\begin{array}{l}\text { No } \\
\%(n)\end{array}$ \\
\hline \multirow[t]{3}{*}{ Self-Awareness } & Understanding how one reacts to emotions & $54.4(37)$ & $0.0(0)$ & $45.6(31)$ \\
\hline & $\begin{array}{l}\text { Understanding how others influence } \\
\text { emotions }\end{array}$ & $39.7(27)$ & $1.5(1)$ & $58.8(40)$ \\
\hline & Understanding how emotions affect others & $38.2(26)$ & $0.0(0)$ & $61.8(42)$ \\
\hline \multirow[t]{4}{*}{ Self-Management } & Adapting to change & $55.9(38)$ & $2.9(2)$ & $41.2(28)$ \\
\hline & Preventing emotions from affecting others & $25.0(17)$ & $2.9(2)$ & $72.1(49)$ \\
\hline & Managing and coping with stress & $52.9(36)$ & $0.0(0)$ & $47.1(32)$ \\
\hline & $\begin{array}{l}\text { Managing emotional responses to Covid- } \\
19\end{array}$ & $25.0(17)$ & $1.5(1)$ & $73.5(50)$ \\
\hline \multirow[t]{3}{*}{ Social Awareness } & $\begin{array}{l}\text { Recognizing the unstated emotions of } \\
\text { others }\end{array}$ & $27.9(19)$ & $2.9(2)$ & $69.1(47)$ \\
\hline & Recognizing the collective mood in a room & $25.0(17)$ & $2.9(2)$ & $72.1(49)$ \\
\hline & Understanding the political forces at work & $38.2(26)$ & $2.9(2)$ & $58.8(40)$ \\
\hline Relationship & Supporting the emotional needs of others & $54.4(37)$ & $2.9(2)$ & $42.6(29)$ \\
\hline \multirow[t]{4}{*}{ Management } & Encouraging trust and collaboration & $66.2(45)$ & $0.0(0)$ & $33.8(23)$ \\
\hline & Managing conflict effectively & $61.8(42)$ & $0.0(0)$ & $38.2(26)$ \\
\hline & Managing change effectively & $57.4(39)$ & $2.9(2)$ & $39.7(27)$ \\
\hline & $\begin{array}{l}\text { Managing the effects of Covid-19 on } \\
\text { others }\end{array}$ & $19.1(13)$ & $1.5(1)$ & $79.4(54)$ \\
\hline
\end{tabular}

Note. Participants were asked if the professional development programs they had attended since becoming a principal included training that helped them develop the emotional intelligence skills listed. Participants responded with yes, unsure, or no. The percentage (number) of the participants who responded with each answer is presented in the columns above. 


\section{Figure 4.7}

Inclusion of EI Training in Professional Development: By Skill

\section{Have you attended any professional development trainings that helped you develop the following skills?}

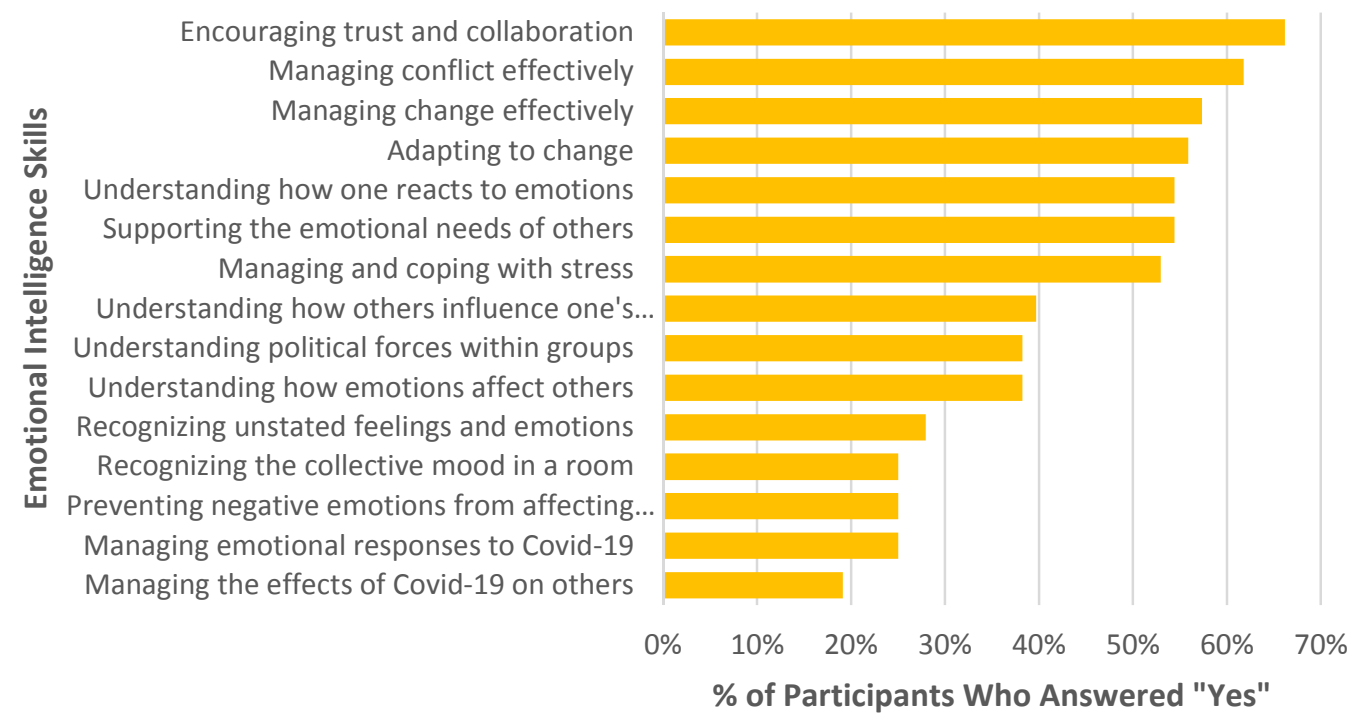

Note. This chart displays the percentage of the participants who responded yes to the question "Have you attended any professional development trainings that helped you develop the following skills?" for each of the 15 emotional skills listed.

Figure 4.8 groups the emotional intelligence skills in Figure 4.7 into the selfawareness, self-management, social awareness, and relationship management clusters (Goleman et al., 2001, 2013). On average, 52\% ( $\pm 18 \%)$ of the participants indicated that they had received training in the relationship management cluster, $44 \%( \pm 9 \%)$ in the social awareness cluster, $40 \%( \pm 17 \%)$ in the self-management cluster, and $30 \%( \pm 7 \%)$ in the self-awareness cluster. 


\section{Figure 4.8}

Inclusion of EI Training in Professional Development: By Cluster

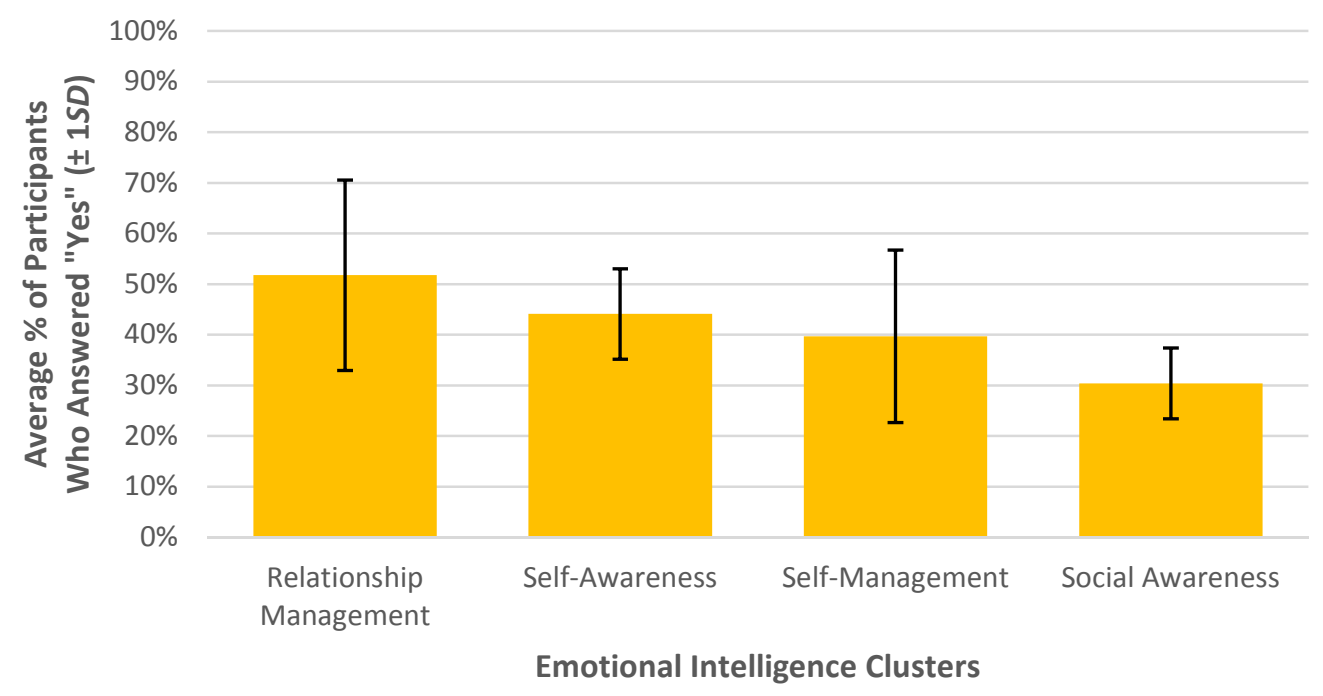

Note. This chart groups the 15 emotional intelligence skills into self-awareness, self-management, social awareness, and relationship management clusters (Goleman et al., 2001, 2013). The number of yes answers is averaged across all questions within each cluster.

When participants indicated that an emotional intelligence skill was included in their principal professional development programs, they were asked to answer a followup question regarding how helpful they perceived the training to be. As seen in Table 4.4 and Figure 4.9, most of the participants who received training found it to be helpful. The percentage of participants who found training to be helpful ranged from $89 \%(n=28)$ for training on understanding how emotions affect others up to $100 \%(n=17)$ for training on recognizing the collective mood in a room. 


\section{Table 4.4}

\section{Helpfulness of EI Training in Principal Professional Development}

\begin{tabular}{llccc}
\hline Cluster & Skill & \multicolumn{3}{c}{ Participant Responses } \\
\cline { 3 - 5 } & & $\begin{array}{c}\text { Helpful } \\
\%(n)\end{array}$ & $\begin{array}{c}\text { Unsure } \\
\%(n)\end{array}$ & $\begin{array}{c}\text { Not Helpful } \\
\%(n)\end{array}$ \\
\hline Self-Awareness & Understanding how one reacts to emotions & $94.6(35)$ & $5.4(2)$ & $0.0(0)$ \\
& $\begin{array}{l}\text { Understanding how others influence } \\
\text { emotions }\end{array}$ & $90.0(27)$ & $6.7(2)$ & $3.3(1)$ \\
& Understanding how emotions affect others & $89.3(25)$ & $3.6(1)$ & $7.1(2)$ \\
\hline Self-Management & Adapting to change & $90.2(37)$ & $7.3(3)$ & $2.4(1)$ \\
& Preventing emotions from affecting others & $94.7(18)$ & $5.3(1)$ & $0.0(0)$ \\
& Managing and coping with stress & $93.9(31)$ & $3.0(1)$ & $3.0(1)$ \\
& Managing emotional responses to Covid- & & & \\
& 19 & $94.7(18)$ & $5.3(1)$ & $0.0(0)$ \\
\hline Social Awareness & Recognizing the unstated emotions of & & & \\
& others & $94.7(18)$ & $0.0(0)$ & $5.3(1)$ \\
& Recognizing the collective mood in a room & $100.0(17)$ & $0.0(0)$ & $0.0(0)$ \\
& Understanding the political forces at work & $92.6(25)$ & $7.4(2)$ & $0.0(0)$ \\
\hline Management & Supporting the emotional needs of others & $91.9(34)$ & $5.4(2)$ & $2.7(1)$ \\
& Encouraging trust and collaboration & $93.0(40)$ & $2.3(1)$ & $4.7(2)$ \\
& Managing conflict effectively & $90.0(36)$ & $7.5(3)$ & $2.5(1)$ \\
& Managing change effectively & $92.3(36)$ & $5.1(2)$ & $2.6(1)$ \\
& Managing the effects of Covid-19 on & & & \\
& others & $92.9(13)$ & $0.0(0)$ & $7.1(1)$ \\
\hline
\end{tabular}

Note. Participants were asked how helpful the training that they had received in professional development program programs and activities designed for principals, if any, was in helping them develop the emotional intelligence skills listed. Participants responded with helpful, unsure, or not helpful. The percentage of the participants who responded with each answer is presented in the columns above. 


\section{Figure 4.9}

Helpfulness of EI in Professional Development: By Skill

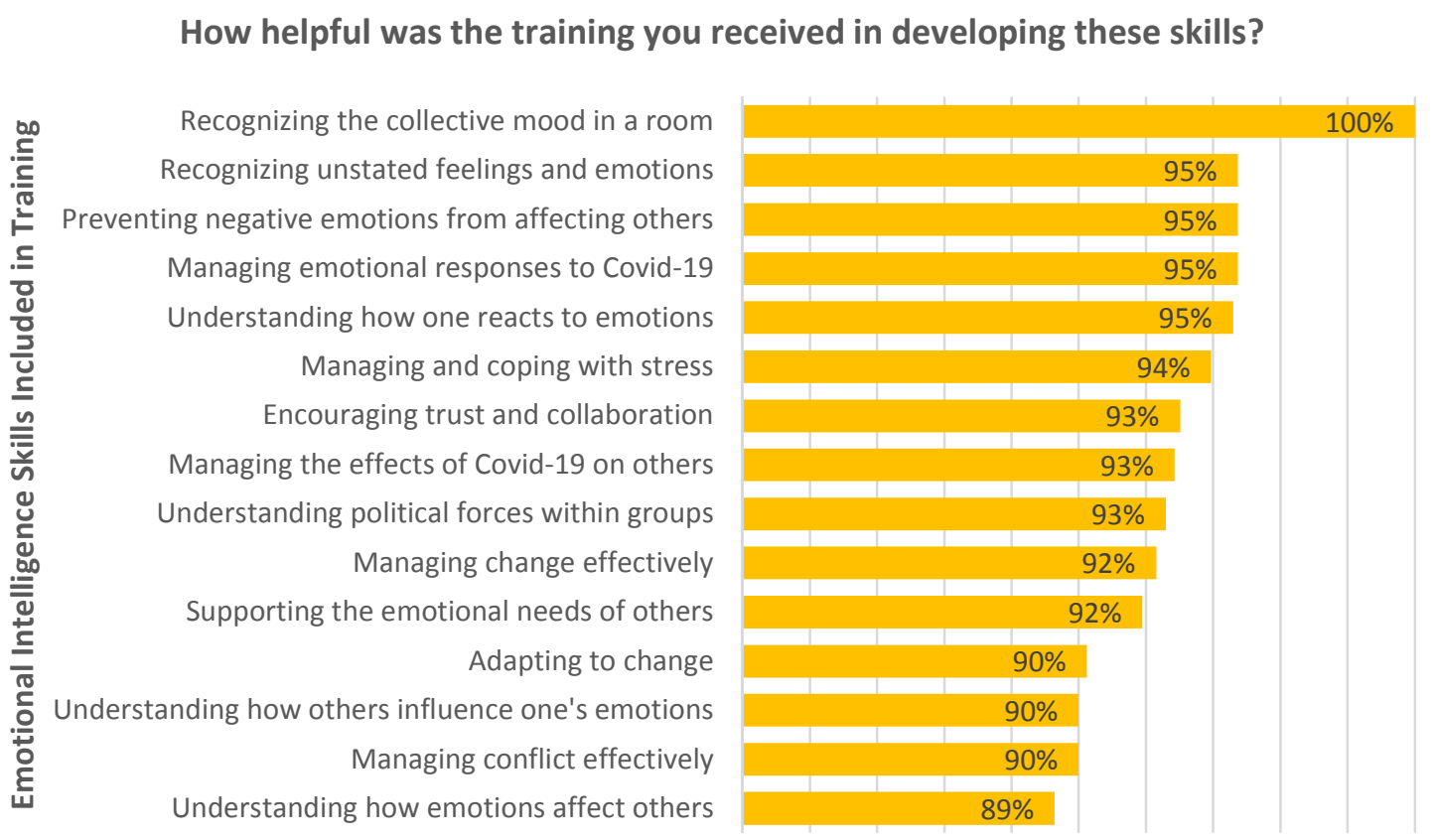

$80 \%$ 82\% 84\% 86\% 88\% 90\% 92\% 94\% 96\% 98\% 100\% $\%$ of Participants who Found the Training "Helpful"

Note. This chart displays the percentage of the participants who received emotional intelligence training and indicated that they found the training helpful when responding to the question "How helpful was the training you received in developing these skills?"

Figure 4.10 groups the emotional intelligence skills in Figure 4.9 into the selfawareness, self-management, social awareness, and relationship management clusters (Goleman et al., 2001, 2013). On average, 96\% ( $\pm 4 \%)$ of the participants indicated that they felt that the training that they received in the social awareness cluster was helpful, $93 \%( \pm 2 \%)$ felt that their training in the self-management cluster was helpful, $92 \%$ 
$( \pm 1 \%)$ indicated that their training in the relationship management cluster was helpful, and $91 \%( \pm 3 \%)$ felt their training in the self-awareness cluster was helpful.

\section{Figure 4.10}

Helpfulness of EI in Professional Development: By Cluster

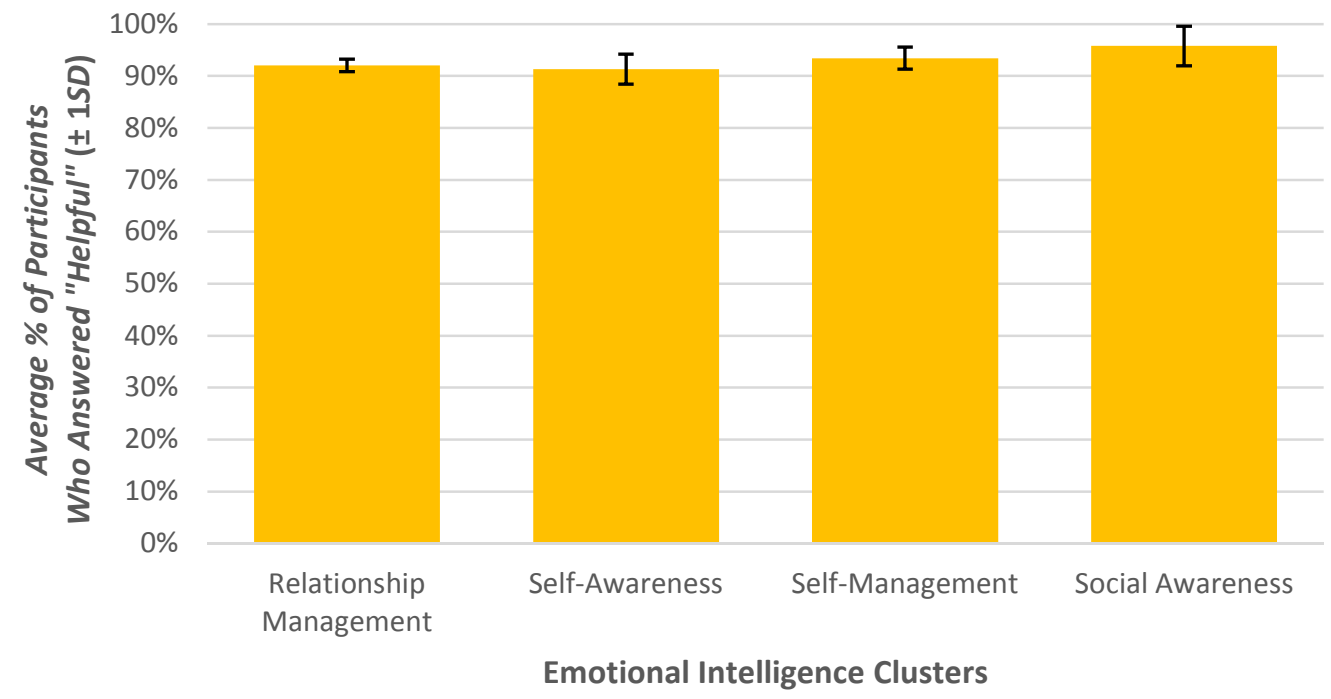

Note. This chart groups the 15 emotional intelligence skills explored into self-awareness, selfmanagement, social awareness, and relationship management clusters (Goleman et al., 2001, 2013). The number of helpful answers is averaged across all questions within each cluster. 


\section{Principal Need}

Twelve questions in the demographics and principal professional development sections of the survey (Appendix D) were used to inform the answer to the first research question: how do the perceptions of $\mathrm{K}-12$ principals in Oregon, regarding their needs for the development of emotional intelligence skills, vary based on their individual characteristics and the contexts in which they lead? The questions in the demographics section were used to define the individual characteristics of the principals and the contexts in which the principals led so that they could be grouped and compared. The questions in the principal professional development section were used to collect information on the participants' perceptions of need for the inclusion of emotional intelligence training in the opportunities available to principals. Participants responded using a 3-point Likert scale with the options of yes, unsure, and no. Descriptive and inferential statistics were used to summarize the data and determine if principal perceptions of need for emotional intelligence training varied based on their individual characteristics and the contexts in which they led.

Table 4.5 and Figure 4.11 display the percentage of the participants who indicated that they felt that principals in Oregon need training in emotional intelligence skills. Most of the participants felt that training was needed in all the emotional intelligence skills listed, with a range from $75.4 \%$ (managing emotional responses to Covid-19) to $95.7 \%$ (managing change effectively). 


\section{Table 4.5}

Principal Need for EI Skills

\begin{tabular}{llccc}
\hline Cluster & Skill & \multicolumn{3}{c}{ Participant Responses } \\
\cline { 3 - 5 } & & Yes & Unsure & No \\
& & $\%(n)$ & $\%(n)$ & $\%(n)$ \\
\hline Self-Awareness & Understanding how one reacts to emotions & $92.8(64)$ & $5.8(4)$ & $1.4(1)$ \\
& Understanding how others influence & $87.0(60)$ & $11.6(8)$ & $1.4(1)$ \\
& emotions & & \\
& Understanding how emotions affect others & $89.9(62)$ & $8.7(6)$ & $1.4(1)$ \\
\hline Self-Management & Adapting to change & $94.2(65)$ & $4.3(3)$ & $1.4(1)$ \\
& Preventing emotions from affecting others & $87.0(60)$ & $10.1(7)$ & $2.9(2)$ \\
& Managing and coping with stress & $92.8(64)$ & $5.8(4)$ & $1.4(1)$ \\
& Managing emotional responses to Covid- & $75.4(52)$ & $17.4(12)$ & $7.2(5)$ \\
& 19 & & & \\
\hline Social Awareness & Recognizing the unstated emotions of & $79.7(55)$ & $15.9(11)$ & $4.3(3)$ \\
& others & & & \\
& Recognizing the collective mood in a room & $78.3(54)$ & $15.9(11)$ & $5.8(4)$ \\
& Understanding the political forces at work & $88.4(61)$ & $8.7(6)$ & $2.9(2)$ \\
\hline Relationship & Supporting the emotional needs of others & $89.9(62)$ & $7.2(5)$ & $2.9(2)$ \\
Management & Encouraging trust and collaboration & $94.2(65)$ & $2.9(2)$ & $2.9(2)$ \\
& Managing conflict effectively & $94.2(65)$ & $4.3(3)$ & $1.4(1)$ \\
& Managing change effectively & $95.7(65)$ & $4.3(3)$ & $0.0(0)$ \\
& Managing the effects of Covid-19 on & $79.7(55)$ & $15.9(11)$ & $4.3(3)$ \\
& others & & \\
\hline
\end{tabular}

Note. Participants were asked if they felt principals needed training in the emotional intelligence skills listed. Participants responded with yes, unsure, or no. The percentage of the participants who responded with each answer is presented in the columns above. 
Figure 4.11

Perceptions of Need for EI Training: By Skill

Do you feel that principals in Oregon need training on these skills?

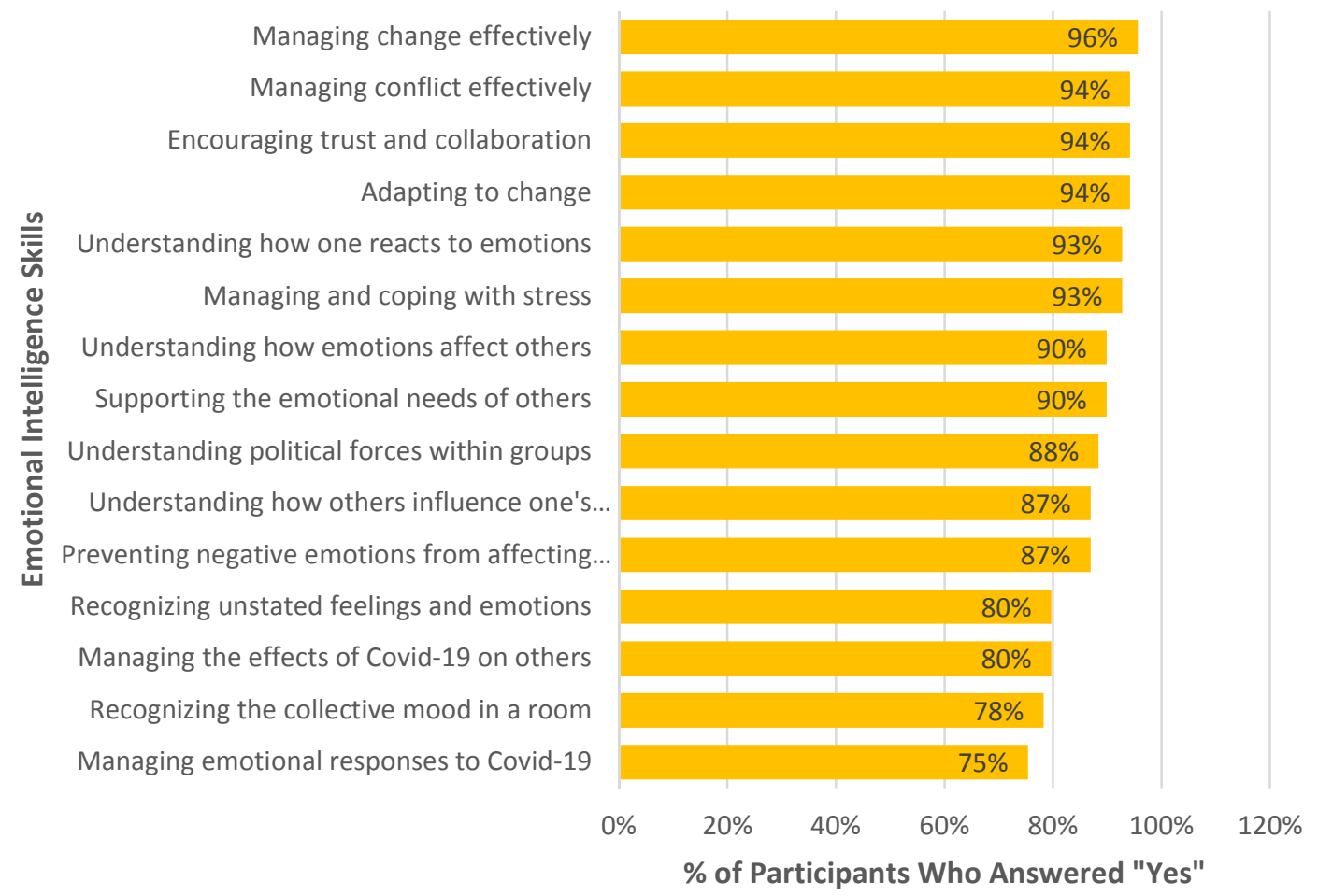

Note. This chart displays the percentage of the participants who indicated that they feel that principals need training in each of the 15 emotional intelligence skills listed.

Figure 4.12 groups the emotional intelligence skills in Figure 4.11 into the selfawareness, self-management, social awareness, and relationship management clusters (Goleman et al., 2001, 2013). On average, $91 \%( \pm 7 \%)$ of the participants indicated that they think Oregon principals need training in the relationship management cluster, $90 \%$ $( \pm 3 \%)$ think Oregon principals need training in the self-awareness cluster, $87 \%( \pm 9 \%)$ 
think Oregon principals need training in the self-management cluster, and $82 \%( \pm 5 \%)$ think Oregon principals need training in the social awareness cluster.

\section{Figure 4.12}

Perceptions of Need for EI Training: By Cluster

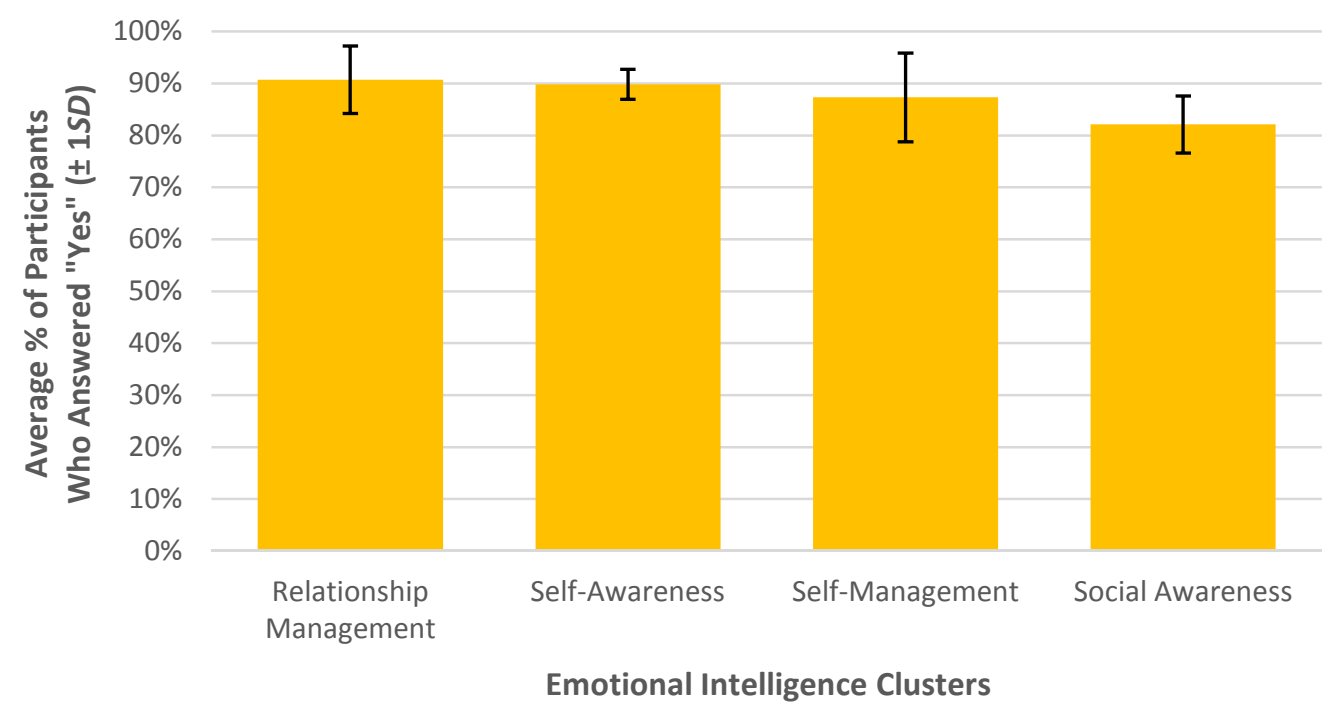

Note. This chart groups the 15 emotional intelligence skills explored into self-awareness, selfmanagement, social awareness, and relationship management clusters (Goleman et al., 2001, 2013). The number of yes answers is averaged across all questions within each cluster. 
To answer the research question fully about how Oregon principals' perceptions of the need for emotional intelligence training vary based on their individual characteristics and the contexts in which they led, it was necessary to explore the participants' demographics in greater depth. I first grouped the responses by the independent variables - principal age, gender, race/ethnicity, years of experience in education, years of experience as a principal, school level, school location, and student need at the school— to determine the effects of individual characteristics and contexts on principals' perceived need for emotional intelligence training. I then ran a cumulative odds ordinal logistic regression with proportional odds to determine if the independent variables explained a statistically significant proportion of the variation in participants' perceptions of need.

Principal Age. The participants' ages ranged from 36 to 70 years, with an average age of 50. I grouped participants' responses into four age groups: $<40(n=7), 40$ to $49(n=29), 50$ to $59(n=24)$, and $>59(n=9)$. I calculated the percentage of participants who indicated that principals in Oregon need training in emotional intelligence — those who answered yes to the survey questions regarding need-for each group and visually assessed plots to explore how age was related to the principals' perceptions (Figures 4.13 and 4.14). All the principals under 40 years old indicated that principals in Oregon need training in all the skills that were explored, demonstrating a higher perception of need than nearly all the other age groups. 


\section{Figure 4.13}

Perceptions of Need for EI Clusters: By Age

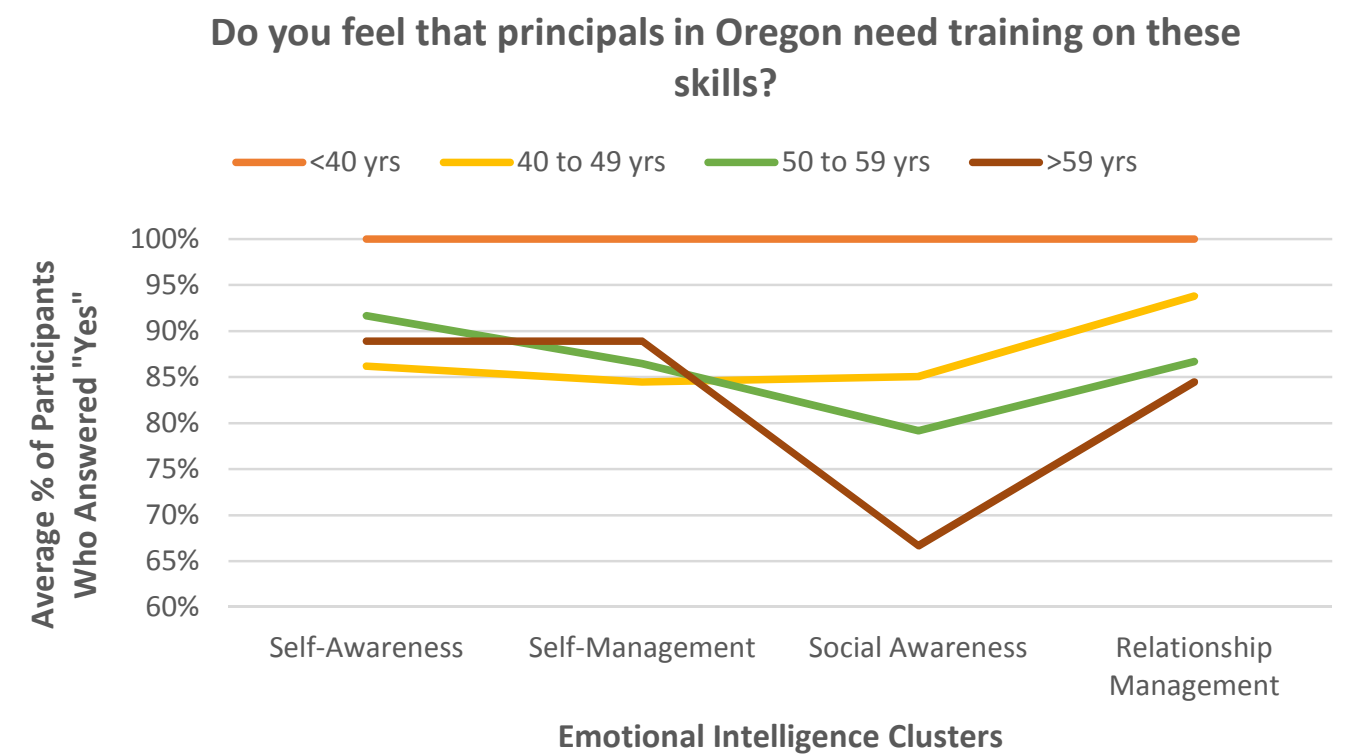

Note. This chart displays principal perceptions of need for emotional intelligence skill training in the self-awareness, self-management, social awareness, and relationship management clusters (Goleman et al., 2001, 2013) when grouped by principal age. Percentages are averaged across all questions for each cluster. 


\section{Figure 4.14}

Perceptions of Need for EI Skills: By Age

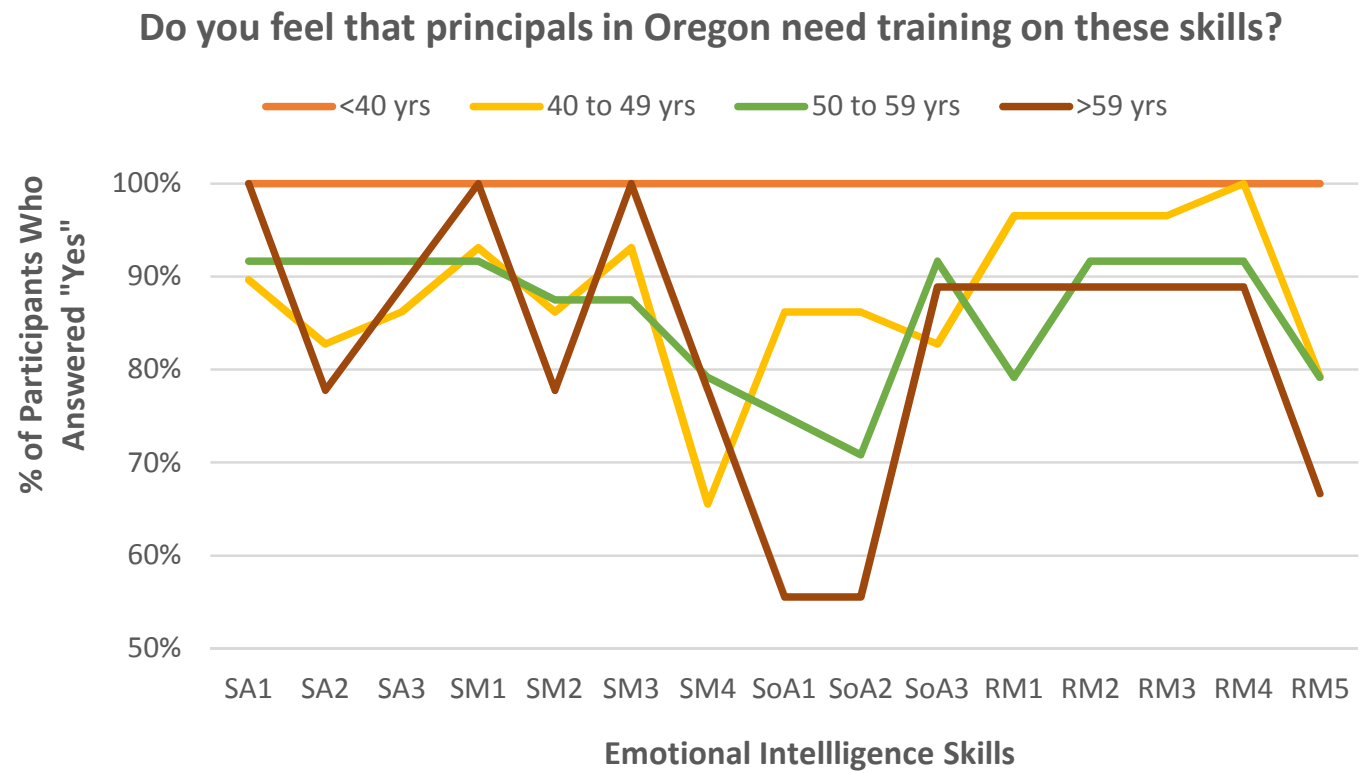

Note. This chart displays principal perceptions of need for training in the 15 emotional intelligence skills when grouped by principal age. The emotional intelligence skills include: SA1— Understanding how one reacts to emotions, such as stress; SA2-Understanding how others influence one's emotional state; SA3 — Understanding how emotions affect others; SM1—Adapting to change; SM2 — Preventing negative emotions and moods from affecting others; SM3Managing and coping with stress; SM4-Managing emotional responses to Covid-19; SoA1— Recognizing the unstated feelings and emotions of others; SoA2-Recognizing the collective mood in a room; SoA3-Understanding the political forces at work within groups (social networks, power relationships, etc...); RM1—Supporting the emotional needs of others; RM2Encouraging trust and collaboration; RM3 — Managing conflict effectively; RM4-Managing change effectively; and RM5-Managing the effects of Covid-19 on staff, students, and families. 
Although there was much more variability in the perceptions of need reported by the other age groups, there appears to be a relationship between participant age and perceptions of need for training in some areas. For example, there was a negative relationship between age and perceived need for training for both the social awareness and relationship management clusters. Specifically, need for training decreased as age increased in these 5 of the 15 emotional intelligence skills: recognizing the unstated feelings and emotions of others, recognizing the collective mood in a room, encouraging trust and collaboration, managing conflict effectively, and managing change effectively (Table 4.6). 
Table 4.6

Principal Need for EI Skills: By Age Group

\begin{tabular}{|c|c|c|c|c|c|}
\hline \multirow[t]{3}{*}{ Cluster } & \multirow[t]{3}{*}{ Skill } & \multicolumn{4}{|c|}{ Participant Responses by Age Group } \\
\hline & & $<40$ & $40-49$ & $50-59$ & $>59$ \\
\hline & & $\%(n)$ & $\%(n)$ & $\%(n)$ & $\%(n)$ \\
\hline \multirow[t]{3}{*}{ Self-Awareness } & $\begin{array}{l}\text { Understanding how one reacts to } \\
\text { emotions }\end{array}$ & $100(7)$ & $90(26)$ & $92(22)$ & $100(9)$ \\
\hline & $\begin{array}{l}\text { Understanding how others influence } \\
\text { emotions }\end{array}$ & $100(7)$ & $83(24)$ & $92(22)$ & $78(7)$ \\
\hline & $\begin{array}{l}\text { Understanding how emotions affect } \\
\text { others }\end{array}$ & $100(7)$ & $86(25)$ & $92(22)$ & $89(8)$ \\
\hline \multirow[t]{4}{*}{ Self-Management } & Adapting to change & $100(7)$ & $93(27)$ & $92(22)$ & $100(9)$ \\
\hline & $\begin{array}{l}\text { Preventing emotions from affecting } \\
\text { others }\end{array}$ & $100(7)$ & $86(25)$ & $88(21)$ & $78(7)$ \\
\hline & Managing and coping with stress & $100(7)$ & $93(27)$ & $88(21)$ & $100(9)$ \\
\hline & $\begin{array}{l}\text { Managing emotional responses to Covid- } \\
19\end{array}$ & $100(7)$ & $66(19)$ & $79(19)$ & $78(7)$ \\
\hline \multirow[t]{3}{*}{ Social Awareness } & $\begin{array}{l}\text { Recognizing the unstated emotions of } \\
\text { others }\end{array}$ & $100(7)$ & $86(25)$ & $75(18)$ & $56(5)$ \\
\hline & $\begin{array}{l}\text { Recognizing the collective mood in a } \\
\text { room }\end{array}$ & $100(7)$ & $86(25)$ & $71(17)$ & $56(5)$ \\
\hline & Understanding the political forces at work & $100(7)$ & $83(24)$ & $92(22)$ & $89(8)$ \\
\hline Relationship & Supporting the emotional needs of others & $100(7)$ & $97(28)$ & $79(19)$ & $89(8)$ \\
\hline \multirow[t]{4}{*}{ Management } & Encouraging trust and collaboration & $100(7)$ & $97(28)$ & $92(22)$ & $89(8)$ \\
\hline & Managing conflict effectively & $100(7)$ & $97(28)$ & $92(22)$ & $89(8)$ \\
\hline & Managing change effectively & $100(7)$ & $100(29)$ & $92(22)$ & $89(8)$ \\
\hline & $\begin{array}{l}\text { Managing the effects of Covid-19 on } \\
\text { others }\end{array}$ & $100(7)$ & $79(23)$ & $79(19)$ & $67(6)$ \\
\hline
\end{tabular}

Note. Participants were asked if they felt principals needed training in the emotional intelligence skills listed. The percentage of the participants who responded with yes in each age category is presented in the columns above.

Principal Gender. All participants identified as either male or female. I compared the percentage of male $(n=31)$ and female $(n=38)$ participants who indicated that principals in Oregon need training in emotional intelligence and visually assessed a plot of percentages to explore how gender was related to principal perceptions of need for 
emotional intelligence training (Figures 4.15 and 4.16). The participants who identified as female saw a greater need than the participants who identified as male for training in every emotional intelligence skill that was explored.

\section{Figure 4.15}

Perceptions of Need for EI Clusters: By Gender

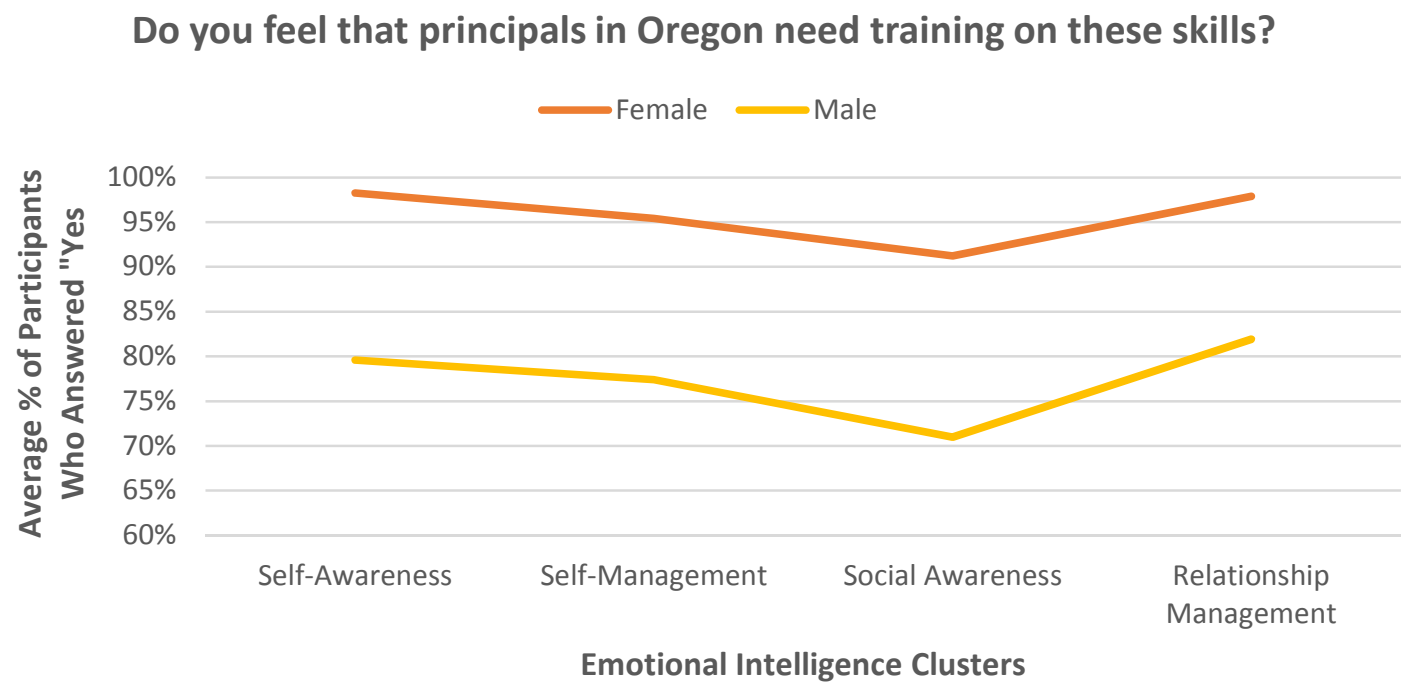

Note. This chart displays principal perceptions of need for emotional intelligence skill training in the selfawareness, self-management, social awareness, and relationship management clusters (Goleman et al., 2001, 2013) when grouped by principal gender. Percentages are averaged across all questions for each cluster. 


\section{Figure 4.16}

Perceptions of Need for EI Skills: By Gender

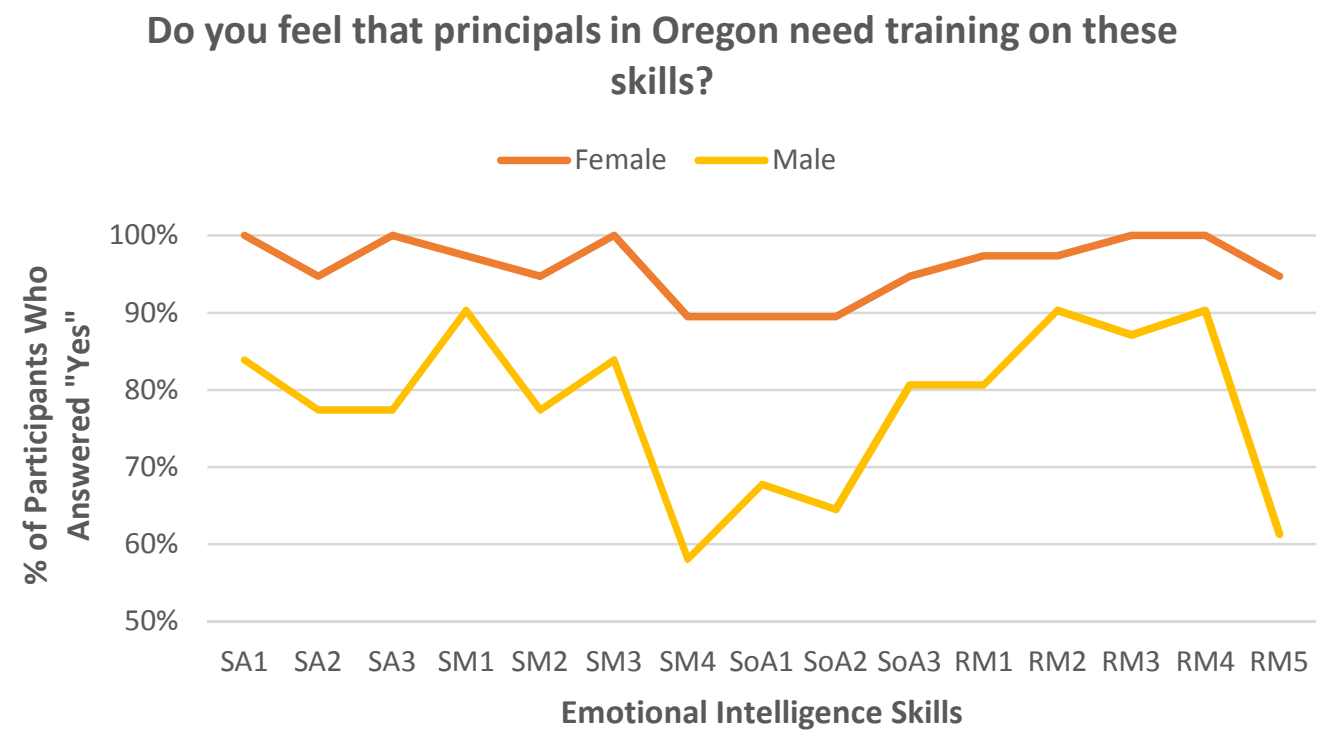

Note. This chart displays principal perceptions of need for training in the 15 emotional intelligence skills when grouped by principal gender. The Emotional Intelligence skills include: The emotional intelligence skills include: SA1—Understanding how one reacts to emotions, such as stress; SA2 Understanding how others influence one's emotional state; SA3-Understanding how emotions affect others; SM1—Adapting to change; SM2—Preventing negative emotions and moods from affecting others; SM3-Managing and coping with stress; SM4-Managing emotional responses to Covid-19; SoA1-Recognizing the unstated feelings and emotions of others; SoA2Recognizing the collective mood in a room; SoA3-Understanding the political forces at work within groups (social networks, power relationships, etc...); RM1—Supporting the emotional needs of others; RM2 - Encouraging trust and collaboration; RM3-Managing conflict effectively; RM4-Managing change effectively; and RM5-Managing the effects of Covid-19 on staff, students, and families. 
The biggest differences were seen in the need to understand how emotions affect others, manage emotional responses to Covid-19, recognize the collective mood in a room, and manage the effects of Covid-19 on staff, students, and families (Table 4.7). Whereas $100 \%$ of females felt that principals needed training to understand how emotions affect others, only $77 \%$ of males agreed. Similarly, $89 \%$ of females felt that training was needed to help manage one's emotional responses to Covid-19, and 95\% felt that it was needed to help manage the effects of Covid-19 on others, whereas only $58 \%$ and $61 \%$ of males, respectively, agreed. Lastly, $89 \%$ of females felt that training was needed to recognize the collective mood in a room, but only $65 \%$ of males agreed. The smallest differences were seen in adapting to change (females $=97 \%$, males $=90 \%)$, supporting the emotional needs of others (females $=97 \%$, males $=81 \%$ ), and managing change effectively $($ females $=100 \%$, males $=90 \%)$. 
Table 4.7

Principal Need for EI Skills: By Gender

\begin{tabular}{|c|c|c|c|}
\hline \multirow[t]{2}{*}{$\overline{\text { Cluster }}$} & \multirow[t]{2}{*}{ Skill } & \multicolumn{2}{|c|}{ Participant Responses by Gender } \\
\hline & & Female & Male \\
\hline \multirow[t]{3}{*}{ Self-Awareness } & $\begin{array}{l}\text { Understanding how one reacts to } \\
\text { emotions }\end{array}$ & $100(38)$ & $84(26)$ \\
\hline & $\begin{array}{l}\text { Understanding how others influence } \\
\text { emotions }\end{array}$ & $95(36)$ & $77(24)$ \\
\hline & $\begin{array}{l}\text { Understanding how emotions affect } \\
\text { others }\end{array}$ & $100(38)$ & $77(24)$ \\
\hline \multirow[t]{4}{*}{ Self-Management } & Adapting to change & $97(37)$ & $90(28)$ \\
\hline & $\begin{array}{l}\text { Preventing emotions from affecting } \\
\text { others }\end{array}$ & $95(36)$ & $77(24)$ \\
\hline & Managing and coping with stress & $100(38)$ & $84(26)$ \\
\hline & $\begin{array}{l}\text { Managing emotional responses to Covid- } \\
19\end{array}$ & $89(34)$ & $58(18)$ \\
\hline \multirow[t]{3}{*}{ Social Awareness } & $\begin{array}{l}\text { Recognizing the unstated emotions of } \\
\text { others }\end{array}$ & $89(34)$ & $68(21)$ \\
\hline & $\begin{array}{l}\text { Recognizing the collective mood in a } \\
\text { room }\end{array}$ & $89(34)$ & $65(20)$ \\
\hline & Understanding the political forces at work & $95(36)$ & $81(25)$ \\
\hline Relationship & Supporting the emotional needs of others & $97(37)$ & $81(25)$ \\
\hline \multirow[t]{4}{*}{ Management } & Encouraging trust and collaboration & $97(37)$ & $90(28)$ \\
\hline & Managing conflict effectively & $100(38)$ & $87(27)$ \\
\hline & Managing change effectively & $100(38)$ & $90(28)$ \\
\hline & $\begin{array}{l}\text { Managing the effects of Covid-19 on } \\
\text { others }\end{array}$ & $95(36)$ & $61(19)$ \\
\hline
\end{tabular}

Note. Participants were asked if they felt principals needed training in the emotional intelligence skills listed. The percentage of the participants who responded with yes in each gender category is presented in the columns above.

Principal Race and Ethnicity. Participants indicated that they belonged to four race/ethnicity groups: Black or African American $(n=2)$, Hispanic or Latinx $(n=5)$, Two or More Races $(n=3)$, and White or Caucasian $(n=59)$. I calculated the percentage of participants who indicated that principals in Oregon need training in emotional 
intelligence for each group and visually assessed plots to explore how race and ethnicity was related to principal perceptions of need for emotional intelligence training (Figures 4.17 and 4.18). The participants who identified as Black/African American and Hispanic/Latinx saw a greater need for training than participants who identified as White/Caucasian. Whereas 100\% of Black/African American and Hispanic/Latinx participants felt that principals needed training in all the emotional intelligence skills listed, on average only $86 \%$ ( $\pm 7 \%$ ) of White/Caucasian participants agreed (Table 4.8$)$. The biggest differences were seen in White/Caucasian participants' perceptions of need for training that helps manage emotional responses to Covid- $19($ White $/$ Caucasian $=$ $73 \%$ ), recognize the unstated feelings and emotions of others (White/Caucasian $=76 \%$ ), recognize the collective mood in a room (White/Caucasian $=75 \%$ ), and manage the effects of Covid-19 on staff, students, and families (White/Caucasian $=78 \%$ ). 


\section{Figure 4.17}

Perceptions of Need for EI Clusters: By Race/Ethnicity

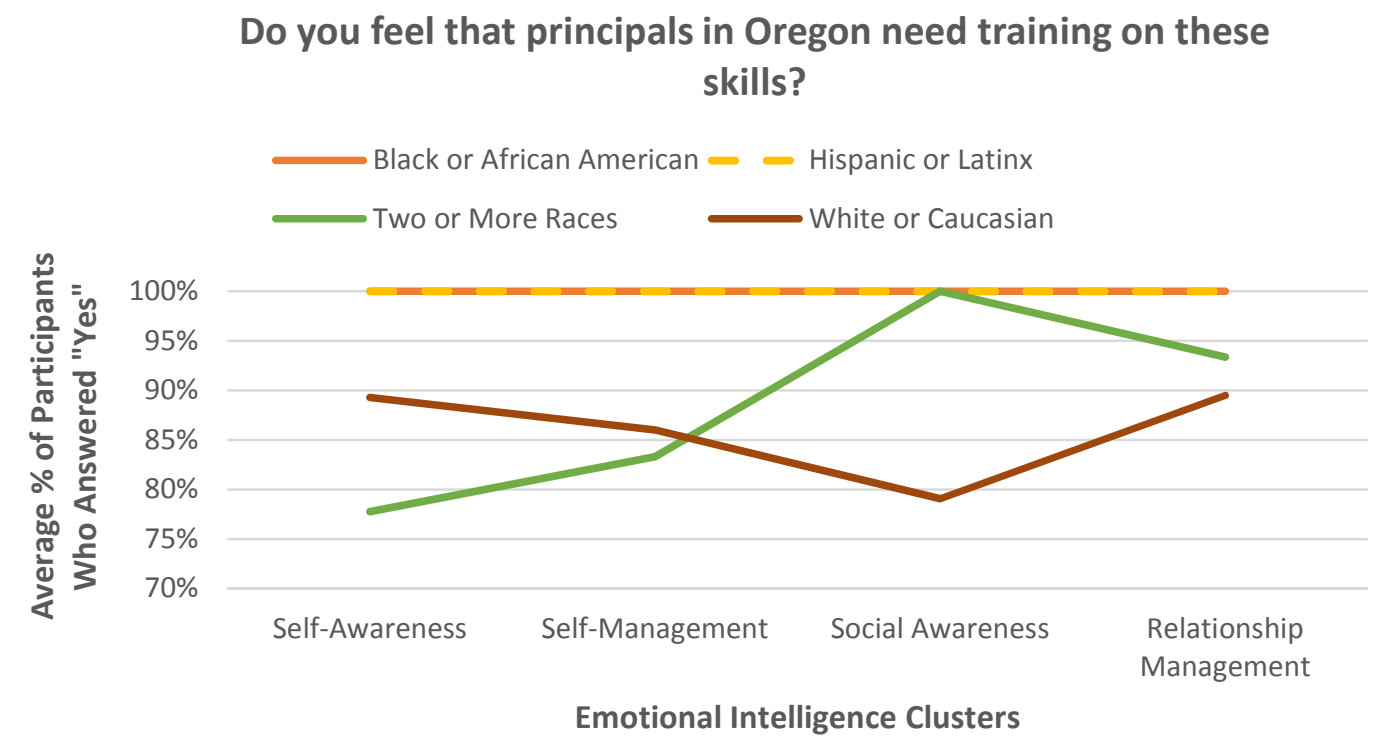

Note. This chart displays principal perceptions of need for self-awareness, self-management, social awareness, and relationship management clusters (Goleman et al., 2001, 2013) grouped by principal race and ethnicity. Percentages are averaged across all questions for each cluster. 


\section{Figure 4.18}

\section{Perceptions of Need for EI Skills: By Race/Ethnicity}

\section{Do you feel that principals in Oregon need training on these skills?}

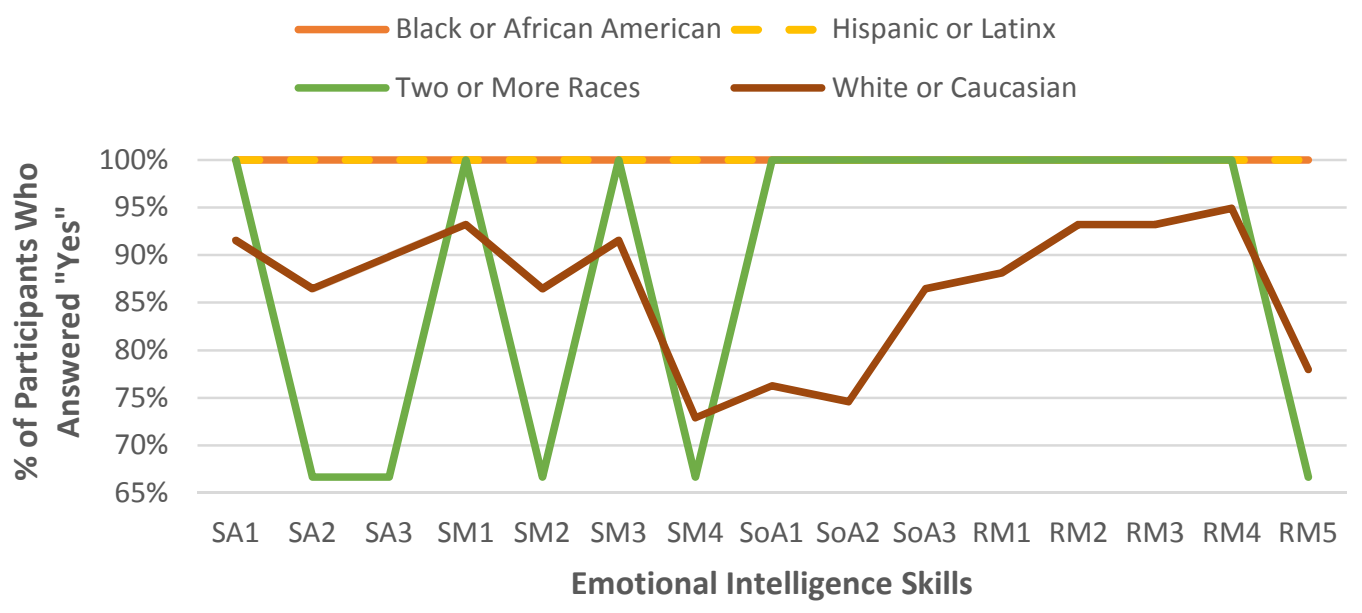

Note. This chart displays principal perceptions of need for training in the 15 emotional intelligence skills when grouped by principal race and ethnicity. The Emotional Intelligence skills include: The emotional intelligence skills include: SA1—Understanding how one reacts to emotions, such as stress; SA2-Understanding how others influence one's emotional state; SA3-Understanding how emotions affect others; SM1—Adapting to change; SM2—Preventing negative emotions and moods from affecting others; SM3 —-Managing and coping with stress; SM4-Managing emotional responses to Covid-19; SoA1—Recognizing the unstated feelings and emotions of others; SoA2 Recognizing the collective mood in a room; SoA3-Understanding the political forces at work within groups (social networks, power relationships, etc...); RM1—Supporting the emotional needs of others; RM2 - Encouraging trust and collaboration; RM3-Managing conflict effectively; RM4-Managing change effectively; and RM5-Managing the effects of Covid-19 on staff, students, and families. 
Table 4.8

Principal Need for EI Skills: By Race/Ethnicity

\begin{tabular}{llcccc}
\hline Cluster & Skill & \multicolumn{3}{l}{ Participant Responses by Race/Ethnicity } \\
\cline { 3 - 6 } & & Black & Hispanic & 2+ Races & White \\
& & $\%(n)$ & $\%(n)$ & $\%(n)$ & $\%(n)$ \\
\hline Self- & Understanding how one reacts to emotions & $100(2)$ & $100(5)$ & $100(3)$ & $92(54)$ \\
Awareness & Understanding how others influence emotions & $100(2)$ & $100(5)$ & $67(2)$ & $86(51)$ \\
& Understanding how emotions affect others & $100(2)$ & $100(5)$ & $67(2)$ & $90(53)$ \\
\hline Self- & Adapting to change & $100(2)$ & $100(5)$ & $100(3)$ & $93(55)$ \\
Management & Preventing emotions from affecting others & $100(2)$ & $100(5)$ & $67(2)$ & $86(51)$ \\
& Managing and coping with stress & $100(2)$ & $100(5)$ & $100(3)$ & $92(54)$ \\
& Managing emotional responses to Covid-19 & $100(2)$ & $100(5)$ & $67(2)$ & $73(43)$ \\
\hline Social & Recognizing the unstated emotions of others & $100(2)$ & $100(5)$ & $100(3)$ & $76(45)$ \\
Awareness & Recognizing the collective mood in a room & $100(2)$ & $100(5)$ & $100(3)$ & $75(44)$ \\
& Understanding the political forces at work & $100(2)$ & $100(5)$ & $100(3)$ & $86(51)$ \\
\hline Relationship & Supporting the emotional needs of others & $100(2)$ & $100(5)$ & $100(3)$ & $88(52)$ \\
Management & Encouraging trust and collaboration & $100(2)$ & $100(5)$ & $100(3)$ & $93(55)$ \\
& Managing conflict effectively & $100(2)$ & $100(5)$ & $100(3)$ & $93(55)$ \\
& Managing change effectively & $100(2)$ & $100(5)$ & $100(3)$ & $95(56)$ \\
& Managing the effects of Covid-19 on others & $100(2)$ & $100(5)$ & $67(2)$ & $78(46)$ \\
\hline
\end{tabular}

Note. Participants were asked if they felt principals needed training in the emotional intelligence skills listed. The percentage of the participants who responded with yes in each gender category is presented in the columns above.

Years of Experience in Education. The participants' years of experience in education ranged from 6 to 40 years with an average of 25.87 ( \pm 5.89 ) years. The participants' responses were grouped into four experience groups: less than $10(n=3), 10$ to $19(n=17), 20$ to $29(n=36)$, and greater than $30(n=13)$. I calculated the percentage of participants who indicated that principals in Oregon need training in emotional intelligence for each group and visually assessed plots to explore how years of experience 
in education was related to principal perceptions of need for emotional intelligence training (Figures 4.19 and 4.20).

\section{Figure 4.19}

Perceptions of Need for EI Clusters: By Years of Experience: Education

Do you feel that principals in Oregon need training on these skills?

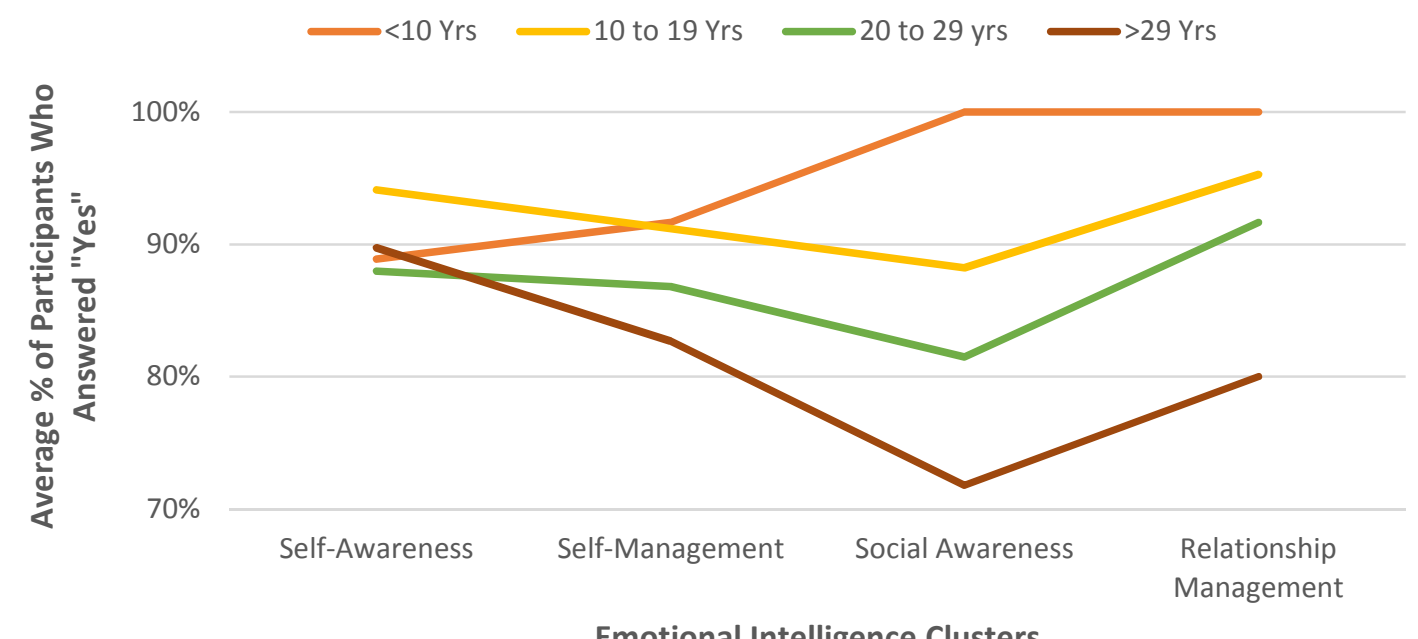

Note. This chart displays principal perceptions of need for self-awareness, self-management, social awareness, and relationship management clusters (Goleman et al., 2001, 2013) when grouped by years of experience in education. Percentages are averaged across all questions for each cluster. 


\section{Figure 4.20}

Perceptions of Need for EI Skills: By Years of Experience: Education

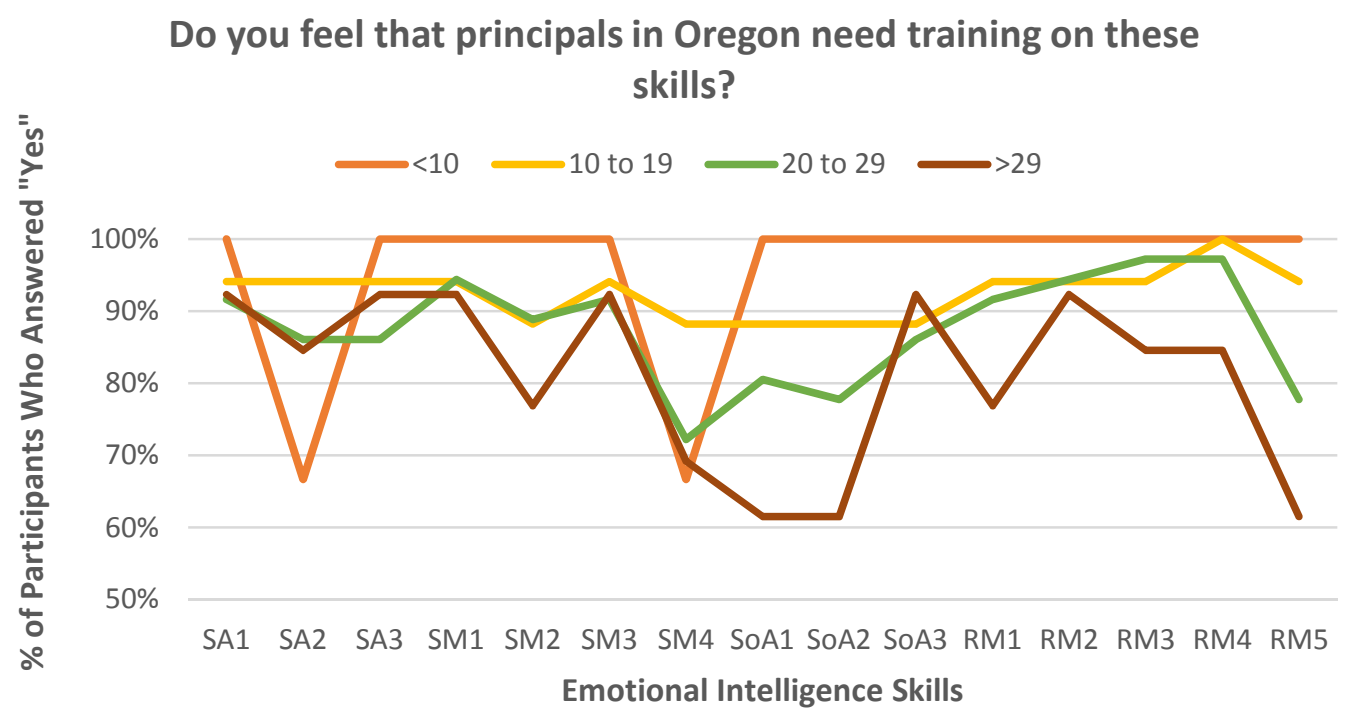

Note. This chart displays principal perceptions of need for training in the 15 emotional intelligence skills when grouped by years of experience in education. The Emotional Intelligence skills include: The emotional intelligence skills include: SA1—Understanding how one reacts to emotions, such as stress; SA2—Understanding how others influence one's emotional state; SA3—Understanding how emotions affect others; SM1—Adapting to change; SM2—Preventing negative emotions and moods from affecting others; SM3 — Managing and coping with stress; SM4—Managing emotional responses to Covid-19; SoA1—Recognizing the unstated feelings and emotions of others; SoA2 Recognizing the collective mood in a room; SoA3 - Understanding the political forces at work within groups (social networks, power relationships, etc...); RM1—Supporting the emotional needs of others; RM2-Encouraging trust and collaboration; RM3-Managing conflict effectively; RM4 - Managing change effectively; and RM5-Managing the effects of Covid-19 on staff, students, and families. 
As was seen for age, there appears to be a relationship between years of experience in education and perceptions of need for training in some of the emotional intelligence skills, specifically those in the social awareness and relationship management clusters. The need for training decreased as years of experienced increased in the 5 following emotional intelligence skills: preventing negative emotions and moods from affecting others, recognizing the unstated feelings and emotions of others, recognizing the collective mood in a room, supporting the emotional needs of others, and managing the effects of Covid-19 on staff, students, and families (Table 4.9). This trend suggests that there may be a negative relationship between years of experience in education and perceptions of need for training in these emotional intelligence skills. 


\section{Table 4.9}

Principal Need for EI Skills: By Years of Experience Education

\begin{tabular}{|c|c|c|c|c|c|}
\hline \multirow[t]{3}{*}{ Cluster } & \multirow[t]{3}{*}{ Skill } & \multicolumn{4}{|c|}{$\begin{array}{c}\text { Participant Responses by Years of } \\
\text { Experience }\end{array}$} \\
\hline & & $<10$ & $10-19$ & $20-29$ & $>30$ \\
\hline & & $\%(n)$ & $\%(n)$ & $\%(n)$ & $\%(n)$ \\
\hline \multirow{3}{*}{$\begin{array}{l}\text { Self- } \\
\text { Awareness }\end{array}$} & Understanding how one reacts to emotions & $100(3)$ & $94(16)$ & $92(33)$ & $92(12)$ \\
\hline & $\begin{array}{l}\text { Understanding how others influence } \\
\text { emotions }\end{array}$ & $67(2)$ & $94(16)$ & $86(31)$ & $85(11)$ \\
\hline & Understanding how emotions affect others & $100(3)$ & $94(16)$ & $86(31)$ & $92(12)$ \\
\hline \multirow{4}{*}{$\begin{array}{l}\text { Self- } \\
\text { Management }\end{array}$} & Adapting to change & $100(3)$ & $94(16)$ & $94(34)$ & $92(12)$ \\
\hline & Preventing emotions from affecting others & $100(3)$ & $88(15)$ & $89(32)$ & $77(10)$ \\
\hline & Managing and coping with stress & $100(3)$ & $94(16)$ & $92(33)$ & $92(12)$ \\
\hline & $\begin{array}{l}\text { Managing emotional responses to Covid- } \\
19\end{array}$ & $67(2)$ & $88(15)$ & $72(26)$ & $69(9)$ \\
\hline \multirow[t]{3}{*}{$\begin{array}{l}\text { Social } \\
\text { Awareness }\end{array}$} & $\begin{array}{l}\text { Recognizing the unstated emotions of } \\
\text { others }\end{array}$ & $100(3)$ & $88(15)$ & $81(29)$ & $62(8)$ \\
\hline & $\begin{array}{l}\text { Recognizing the collective mood in a } \\
\text { room }\end{array}$ & $100(3)$ & $88(15)$ & $78(29)$ & $62(8)$ \\
\hline & Understanding the political forces at work & $100(3)$ & $88(15)$ & $86(31)$ & $92(12)$ \\
\hline Relationship & Supporting the emotional needs of others & $100(3)$ & $94(16)$ & $92(33)$ & $77(10)$ \\
\hline \multirow[t]{4}{*}{ Management } & Encouraging trust and collaboration & $100(3)$ & $94(16)$ & $94(34)$ & $92(12)$ \\
\hline & Managing conflict effectively & $100(3)$ & $94(16)$ & $97(35)$ & $85(11)$ \\
\hline & Managing change effectively & $100(3)$ & $100(17)$ & $97(35)$ & $85(11)$ \\
\hline & $\begin{array}{l}\text { Managing the effects of Covid-19 on } \\
\text { others }\end{array}$ & $100(3)$ & $94(16)$ & $78(28)$ & $62(8)$ \\
\hline
\end{tabular}

Note. Participants were asked if they felt principals needed training in the emotional intelligence skills listed. The percentage of the participants who responded with yes in each category of years of experience in education is presented in the columns above.

Years of Experience as a Principal. The participants' years of experience as a principal ranged from 2 to 29 years, with an average of $12.56( \pm 9.52)$ years. The participants' responses were grouped into four experience groups: $<5(n=22), 5$ to $9(n=$ 20), 10 to $14(n=18)$, and over $14(n=9)$. I calculated the percentage of participants who indicated that principals in Oregon need training in emotional intelligence for each group 
and visually assessed plots to explore how years of experience as a principal was related to principal perceptions of need for emotional intelligence training (Figures 4.21 and 4.22).

Figure 4.21

Perceptions of Need for EI Clusters: By Years of Experience: Principal

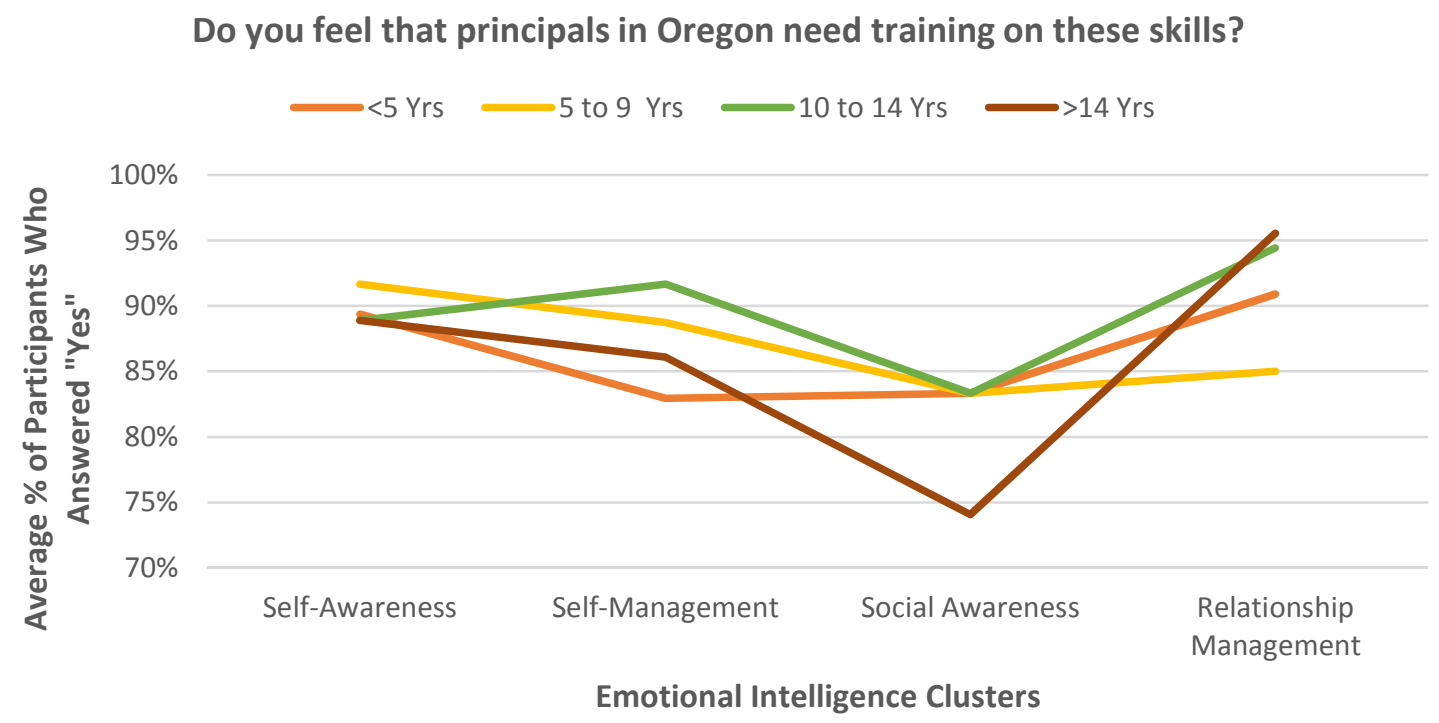

Note. This chart displays principal perceptions of need for self-awareness, self-management, social awareness, and relationship management clusters (Goleman et al., 2001, 2013) when grouped by years of experience as a principal. Percentages are averaged across all questions for each cluster. 


\section{Figure 4.22}

Perceptions of Need for EI Skills: By Years of Experience: Principal

\section{Do you feel that principals in Oregon need training on these skills?}

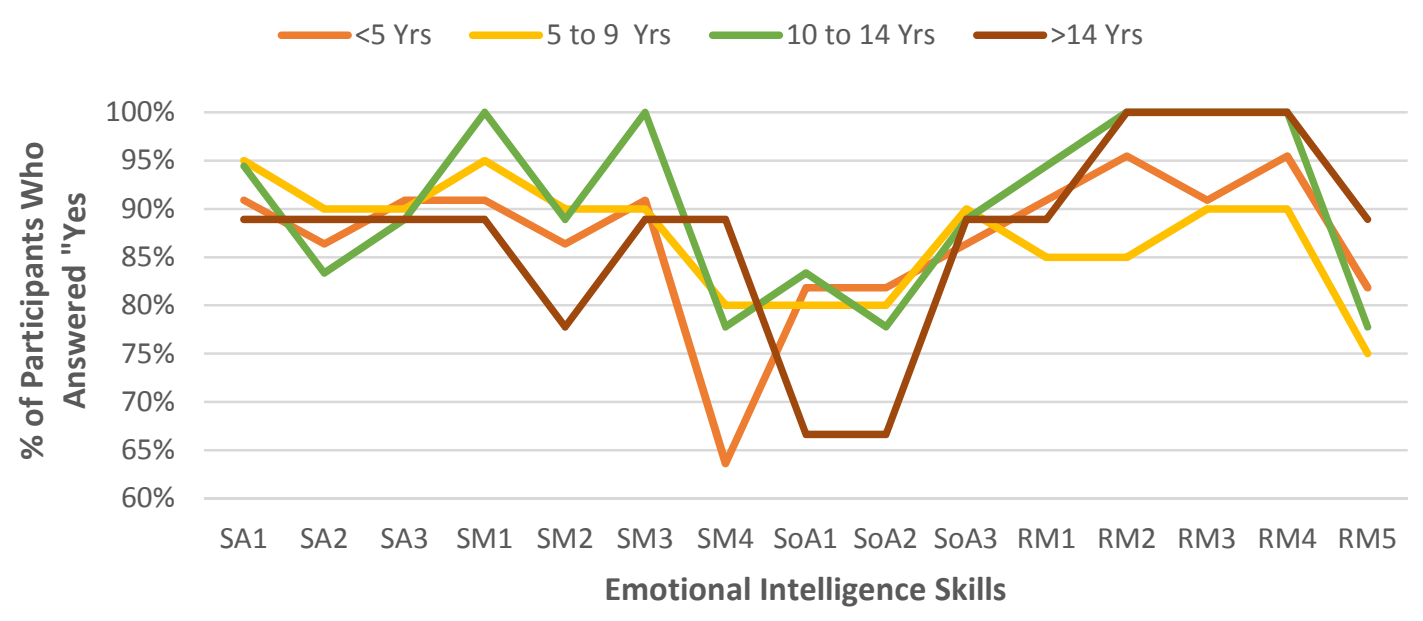

Note. This chart displays principal perceptions of need for training in the 15 emotional intelligence skills when grouped by years of experience as a principal. The Emotional Intelligence skills include: The emotional intelligence skills include: SA1 - Understanding how one reacts to emotions, such as stress; SA2-Understanding how others influence one's emotional state; SA3-Understanding how emotions affect others; SM1—Adapting to change; SM2—Preventing negative emotions and moods from affecting others; SM3 - Managing and coping with stress; SM4-Managing emotional responses to Covid-19; SoA1-Recognizing the unstated feelings and emotions of others; SoA2-Recognizing the collective mood in a room; SoA3 - Understanding the political forces at work within groups (social networks, power relationships, etc...); RM1—Supporting the emotional needs of others; RM2—Encouraging trust and collaboration; RM3 - Managing conflict effectively; RM4-Managing change effectively; and RM5— Managing the effects of Covid-19 on staff, students, and families. 
As seen in Figures 4.21 and 4.22, there appears to be a pattern in the participants' perceptions of need for training in some of the emotional intelligence skills. In general, all participants expressed a lower level of need for several self-awareness and social awareness skills and a higher level of need for relationship management skills (Table 4.10). In some skill areas, principals with more years of experience indicated that training was needed more than principals with less experience. Interestingly, $100 \%$ of principals with 10 to 14 years of experience $(n=18)$ felt that training was needed in adapting to change, managing and coping with stress, encouraging trust and collaboration, managing conflict effectively, and managing change effectively. Similarly, 100\% of principals with over 14 years of experience $(n=9)$ agreed that training was needed in the three latter skills. On the other hand, principals with less than 10 years of experience reported much lower levels of need for these skills, with principals with 5 to 9 years of experience reporting the lowest levels of need. 


\section{Table 4.10}

Principal Need for EI Skills: By Years of Experience as a Principal

\begin{tabular}{|c|c|c|c|c|c|}
\hline \multirow[t]{3}{*}{ Cluster } & \multirow[t]{3}{*}{ Skill } & \multicolumn{4}{|c|}{ Participant Responses by Years of Experience } \\
\hline & & $<5$ & $5-9$ & $10-14$ & $>14$ \\
\hline & & $\%(n)$ & $\%(n)$ & $\%(n)$ & $\%(n)$ \\
\hline \multirow[t]{3}{*}{$\begin{array}{l}\text { Self- } \\
\text { Awareness }\end{array}$} & $\begin{array}{l}\text { Understanding how one reacts to } \\
\text { emotions }\end{array}$ & $91(20)$ & $95(19)$ & $94(17)$ & $89(8)$ \\
\hline & $\begin{array}{l}\text { Understanding how others influence } \\
\text { emotions }\end{array}$ & $86(19)$ & $90(18)$ & $83(15)$ & $89(8)$ \\
\hline & $\begin{array}{l}\text { Understanding how emotions affect } \\
\text { others }\end{array}$ & $91(20)$ & $90(18)$ & $89(16)$ & $89(8)$ \\
\hline$\overline{\text { Self- }}$ & Adapting to change & $91(20)$ & $95(19)$ & $100(18)$ & $89(8)$ \\
\hline \multirow[t]{3}{*}{ Management } & $\begin{array}{l}\text { Preventing emotions from affecting } \\
\text { others }\end{array}$ & $86(19)$ & $90(18)$ & $89(16)$ & $78(7)$ \\
\hline & Managing and coping with stress & $91(20)$ & $90(18)$ & $100(18)$ & $89(8)$ \\
\hline & $\begin{array}{l}\text { Managing emotional responses to Covid- } \\
19\end{array}$ & $64(14)$ & $80(16)$ & $78(14)$ & $89(8)$ \\
\hline \multirow[t]{3}{*}{$\begin{array}{l}\text { Social } \\
\text { Awareness }\end{array}$} & $\begin{array}{l}\text { Recognizing the unstated emotions of } \\
\text { others }\end{array}$ & $82(18)$ & $80(16)$ & $83(15)$ & $67(6)$ \\
\hline & $\begin{array}{l}\text { Recognizing the collective mood in a } \\
\text { room }\end{array}$ & $82(18)$ & $80(16)$ & $78(14)$ & $67(6)$ \\
\hline & Understanding the political forces at work & $86(19)$ & $90(18)$ & $89(16)$ & $89(8)$ \\
\hline Relationship & Supporting the emotional needs of others & $91(20)$ & $85(17)$ & $94(17)$ & $89(8)$ \\
\hline \multirow[t]{4}{*}{ Management } & Encouraging trust and collaboration & $95(21)$ & $85(17)$ & $100(18)$ & $100(9)$ \\
\hline & Managing conflict effectively & $91(20)$ & $90(18)$ & $100(18)$ & $100(9)$ \\
\hline & Managing change effectively & $95(21)$ & $90(18)$ & $100(18)$ & $100(9)$ \\
\hline & $\begin{array}{l}\text { Managing the effects of Covid-19 on } \\
\text { others }\end{array}$ & $82(18)$ & $75(15)$ & $78(14)$ & $89(8)$ \\
\hline
\end{tabular}

Note. Participants were asked if they felt principals needed training in the emotional intelligence skills listed. The percentage of the participants who responded with yes in each category of years of experience as a principal is presented in the columns above. $\mathrm{EI}=$ Emotional Intelligence.

Principal Context: School Level. Each participant identified the level of the school in which they most recently led as either elementary $(n=31)$, middle/junior high $(n=13)$, high $(n=15)$, or a combination of the above $(n=10)$. I excluded principals who worked at schools that served more than one level $(\mathrm{K}-8[(n=4], 6-12[n=1]$, and $\mathrm{K}-12$ 
$[n=5])$ from the school-level data because I believed that it would obscure the results. I calculated the percentage of participants who indicated that principals in Oregon need training in emotional intelligence for each group (Table 4.11) and visually assessed plots to explore how school level is related to principal perceptions of need for emotional intelligence training (Figures 4.23 and 4.24). Principals working in elementary schools consistently reported a higher level of need for training in all the emotional intelligence skills than principals working at the middle- and high-school levels.

\section{Figure 4.23}

Perceptions of Need for EI Clusters: By School Level

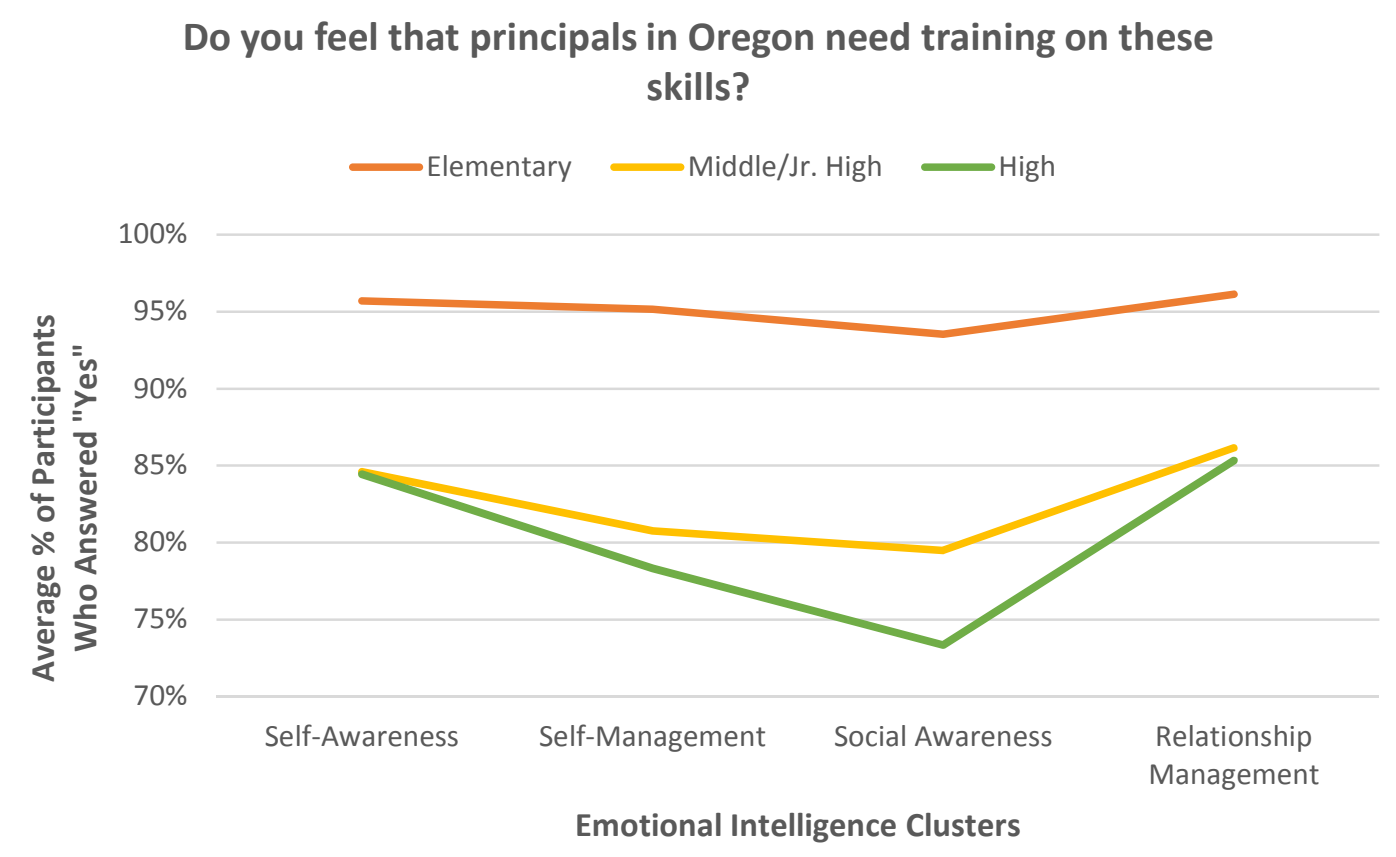

Note. This chart displays principal perceptions of need for the self-awareness, self-management, social awareness, and relationship management clusters (Goleman et al., 2001, 2013) grouped by the level of education offered at the principal's school. Percentages are averaged across all questions for each cluster. 


\section{Figure 4.24}

Perceptions of Need for EI Skills: By School Level

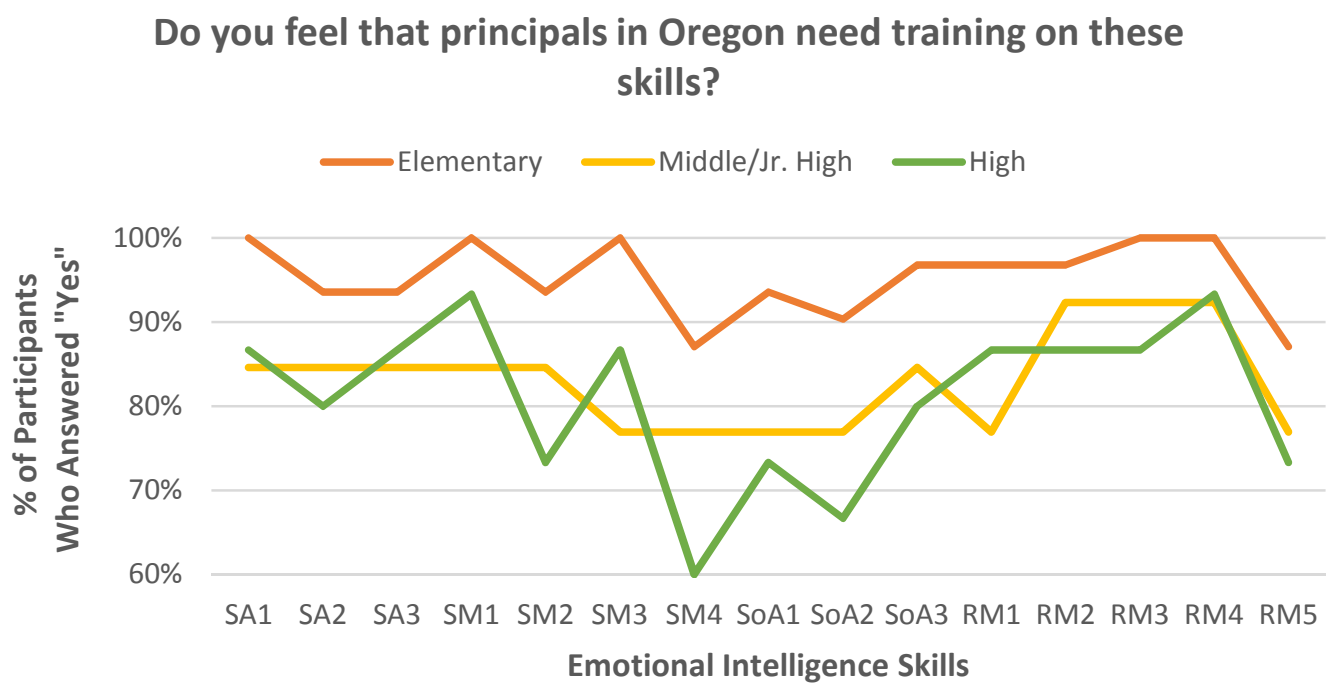

Note. This chart displays principal perceptions of need for training in the 15 emotional intelligence skills when grouped by the level of education offered at the principal's school. The Emotional Intelligence skills include: The emotional intelligence skills include: SA1—Understanding how one reacts to emotions, such as stress; SA2-Understanding how others influence one's emotional state; SA3 - Understanding how emotions affect others; SM1—Adapting to change; SM2— Preventing negative emotions and moods from affecting others; SM3-Managing and coping with stress; SM4-Managing emotional responses to Covid-19; SoA1—Recognizing the unstated feelings and emotions of others; SoA2 - Recognizing the collective mood in a room; SoA3Understanding the political forces at work within groups (social networks, power relationships, etc...); RM1—Supporting the emotional needs of others; RM2—Encouraging trust and collaboration; RM3 - Managing conflict effectively; RM4-Managing change effectively; and RM5-Managing the effects of Covid-19 on staff, students, and families. 
The areas in which their responses indicated the lowest need for training were in managing their emotional responses to Covid-19 (87\%) and managing the effects of Covid-19 on staff, students, and families (87\%); however, their perceptions of need were still considerably higher than middle/junior high (77\%, 77\%) and high-school principals $(60 \%, 73 \%)$. High-school principals reported some of the lowest levels of need overall, and they reported considerably lower need for preventing negative emotions and moods from affecting others (73\%), managing their emotional responses to Covid-19 (60\%), recognizing the collective mood in a room (67\%), and managing the effects of Covid-19 on staff, students, and families (73\%) than the elementary and middle/junior-high-school principals. 


\section{Table 4.11}

Principal Need for EI Skills: By School Level

\begin{tabular}{|c|c|c|c|c|}
\hline \multirow[t]{2}{*}{ Cluster } & \multirow[t]{2}{*}{ Skill } & \multicolumn{3}{|c|}{ Participant Responses by School Level } \\
\hline & & $\begin{array}{l}\text { Elementary } \\
\quad \%(n)\end{array}$ & $\begin{array}{c}\text { Middle/Jr. } \\
\%(n)\end{array}$ & $\begin{array}{l}\text { High } \\
\%(n)\end{array}$ \\
\hline \multirow[t]{3}{*}{ Self-Awareness } & Understanding how one reacts to emotions & $100(31)$ & $85(11)$ & $87(13)$ \\
\hline & $\begin{array}{l}\text { Understanding how others influence } \\
\text { emotions }\end{array}$ & $94(29)$ & $85(11)$ & $80(12)$ \\
\hline & Understanding how emotions affect others & $94(29)$ & $85(11)$ & $87(13)$ \\
\hline$\overline{\text { Self- }}$ & Adapting to change & $100(31)$ & $85(11)$ & $93(14)$ \\
\hline \multirow[t]{3}{*}{ Management } & Preventing emotions from affecting others & $94(29)$ & $85(11)$ & $73(11)$ \\
\hline & Managing and coping with stress & $100(31)$ & $77(10)$ & $87(13)$ \\
\hline & $\begin{array}{l}\text { Managing emotional responses to Covid- } \\
19\end{array}$ & $87(27)$ & $77(10)$ & $60(9)$ \\
\hline \multirow[t]{3}{*}{$\begin{array}{l}\text { Social } \\
\text { Awareness }\end{array}$} & $\begin{array}{l}\text { Recognizing the unstated emotions of } \\
\text { others }\end{array}$ & $94(29)$ & $77(10)$ & $73(11)$ \\
\hline & $\begin{array}{l}\text { Recognizing the collective mood in a } \\
\text { room }\end{array}$ & $90(28)$ & $77(10)$ & $67(10)$ \\
\hline & Understanding the political forces at work & $97(30)$ & $85(11)$ & $80(12)$ \\
\hline Relationship & Supporting the emotional needs of others & $97(30)$ & $77(10)$ & $87(13)$ \\
\hline \multirow[t]{4}{*}{ Management } & Encouraging trust and collaboration & $97(30)$ & $92(12)$ & $87(13)$ \\
\hline & Managing conflict effectively & $100(31)$ & $92(12)$ & $87(13)$ \\
\hline & Managing change effectively & $100(31)$ & $92(12)$ & $93(14)$ \\
\hline & $\begin{array}{l}\text { Managing the effects of Covid-19 on } \\
\text { others }\end{array}$ & $87(27)$ & $77(10)$ & $73(11)$ \\
\hline
\end{tabular}

Note. Participants were asked if they felt principals needed training in the emotional intelligence skills listed. The percentage of the participants who responded with yes at each school level is presented in the columns above.

Principal Context: School Location. Each participant identified the location of their school as either urban $(n=21)$, suburban $(n=21)$, or rural $(n=27)$. I calculated the percentage of participants who indicated that principals in Oregon need training in emotional intelligence for each group (Table 4.12) and visually assessed plots to explore 
how school location was related to principal perceptions of need for emotional intelligence training (Figures 4.25 and 4.26).

\section{Figure 4.25}

Perceptions of Need for EI Clusters: By School Location

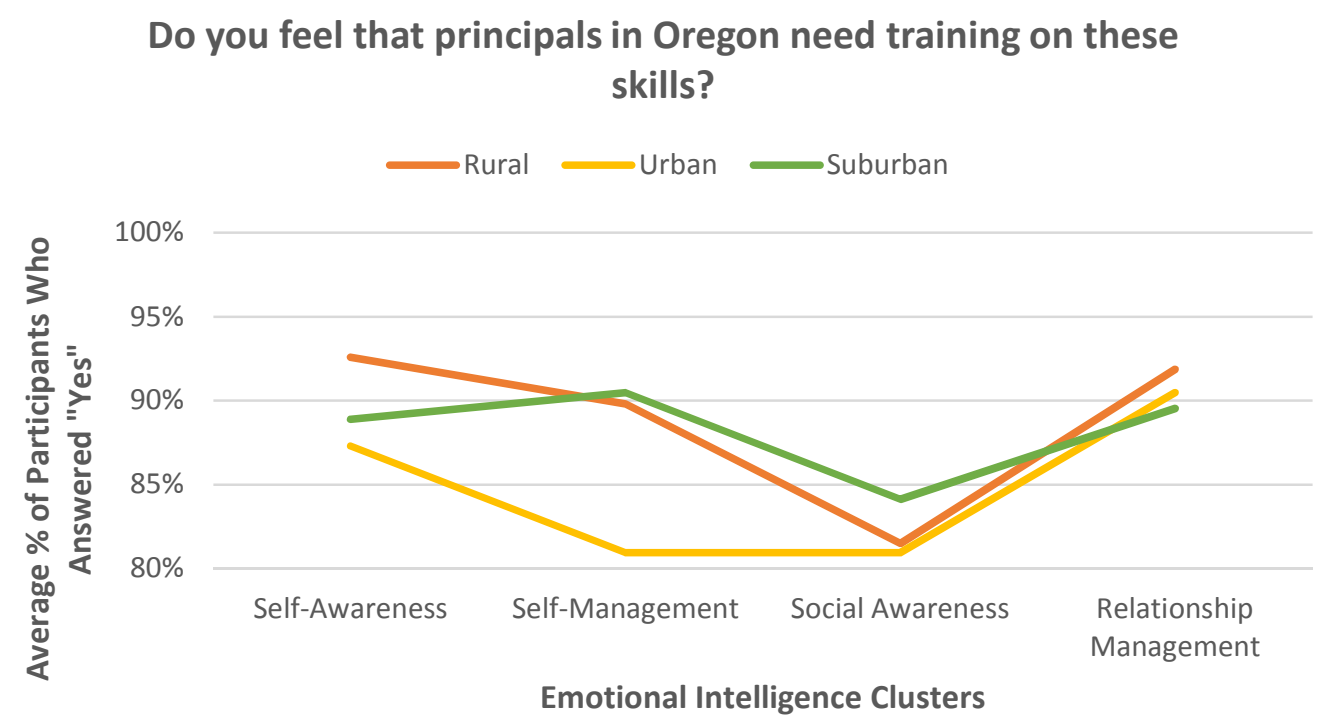

Note. This chart displays principal perceptions of need for self-awareness, self-management, social awareness, and relationship management clusters (Goleman et al., 2001, 2013) grouped by the location of the principal's school. Percentages are averaged across all questions for each cluster. 


\title{
Figure 4.26
}

\author{
Perceptions of Need for EI Skills: By School Location
}

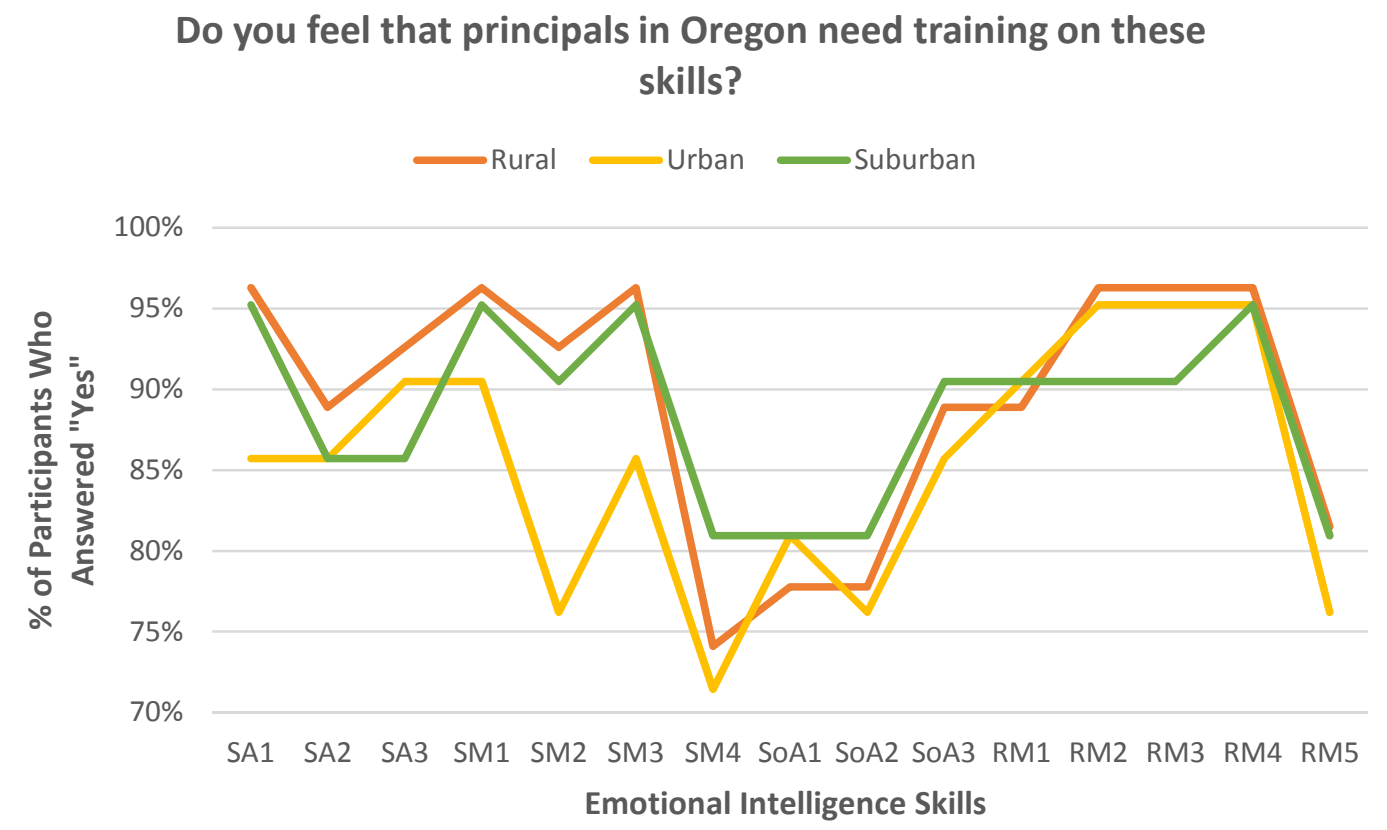

Note. This chart displays principal perceptions of need for training in the 15 emotional intelligence skills when grouped by the location of the principal's school. The emotional intelligence skills include: SA1Understanding how one reacts to emotions, such as stress; SA2-Understanding how others influence one's emotional state; SA3 - Understanding how emotions affect others; SM1—Adapting to change; SM2 - Preventing negative emotions and moods from affecting others; SM3-Managing and coping with stress; SM4-Managing emotional responses to Covid-19; SoA1—Recognizing the unstated feelings and emotions of others; SoA2 - Recognizing the collective mood in a room; SoA3 — Understanding the political forces at work within groups (social networks, power relationships, etc...); RM1—Supporting the emotional needs of others; RM2—Encouraging trust and collaboration; RM3-Managing conflict effectively; RM4-Managing change effectively; and RM5-Managing the effects of Covid-19 on staff, students, and families. 
Urban principals often appeared to perceive the needs for emotional intelligence training to be less than rural and suburban principals did, with the most obvious differences seen in urban principals' indication of a need for training that helps one understand how one reacts to emotions, such as stress (86\%), adapt to change (90\%), prevent negative emotions and moods from affecting others (76\%), and manage and cope with stress $(86 \%)$. Similarly, suburban principals report a slightly lower perception of need than urban and rural principals in training that helps one understand how emotions affect others $(86 \%)$ and how to manage conflict effectively (90\%), whereas they report a higher need for training that helps one manage one's emotional responses to Covid-19 (81\%). 


\section{Table 4.12}

Principal Need for EI Skills: By School Location

\begin{tabular}{llccc}
\hline Cluster & Skill & \multicolumn{3}{c}{ Participant Responses by School } \\
& & \multicolumn{3}{c}{ Location } \\
\cline { 3 - 5 } & & Rural & Urban & Suburban \\
Self-Awareness & Understanding how one reacts to emotions & $96(n)$ & $\%(n)$ & $\%(n)$ \\
& Understanding how others influence & $86(18)$ & $95(20)$ \\
& emotions & $89(24)$ & $86(18)$ & $86(18)$ \\
& Understanding how emotions affect others & $93(25)$ & $90(19)$ & $86(18)$ \\
\hline Self-Management & Adapting to change & $96(26)$ & $90(19)$ & $95(20)$ \\
& Preventing emotions from affecting others & $93(25)$ & $76(16)$ & $90(19)$ \\
& Managing and coping with stress & $96(26)$ & $86(18)$ & $95(20)$ \\
& Managing emotional responses to Covid- & $74(20)$ & $71(15)$ & $81(17)$ \\
& 19 & & & \\
\hline Social Awareness & Recognizing the unstated emotions of & $78(21)$ & $81(17)$ & $81(17)$ \\
& others & & & \\
& Recognizing the collective mood in a & $78(21)$ & $76(16)$ & $81(17)$ \\
& room & & & \\
& Understanding the political forces at work & $89(24)$ & $86(18)$ & $90(19)$ \\
\hline Relationship & Supporting the emotional needs of others & $89(24)$ & $90(19)$ & $90(19)$ \\
Management & Encouraging trust and collaboration & $96(26)$ & $95(20)$ & $90(19)$ \\
& Managing conflict effectively & $96(26)$ & $95(20)$ & $90(19)$ \\
& Managing change effectively & $96(26)$ & $95(20)$ & $95(20)$ \\
& Managing the effects of Covid-19 on & $81(22)$ & $76(16)$ & $81(17)$ \\
& others & & \\
\hline
\end{tabular}

Note. Participants were asked if they felt principals needed training in the emotional intelligence skills listed. The percentage of the participants who responded with yes at each school location is presented in the columns above.

Principal Context: Student Need at the School. Each participant identified the level of student need at the school in which they most recently led as either low need $(n=$ $7)$, average need $(n=20)$, or high need $(n=42)$. I calculated the percentage of participants who indicated that principals in Oregon need training in emotional intelligence for each group (Table 4.13) and visually assessed plots to explore how 
student need affects principal perceptions of need for emotional intelligence training (Figures 4.27 and 4.28). Principals at low need schools reported lower perceptions of need for training in most of the emotional intelligence skills than principals at averageneed and high-need schools, with the exception of the social awareness skills of recognizing the unstated feelings and emotions of others and recognizing the collective mood in a room. Principals working at average-need schools reported slightly lower perceptions of these two skills than principals working at low-need schools. 


\section{Figure 4.27}

Perceptions of Need for EI Clusters: By Level of Need

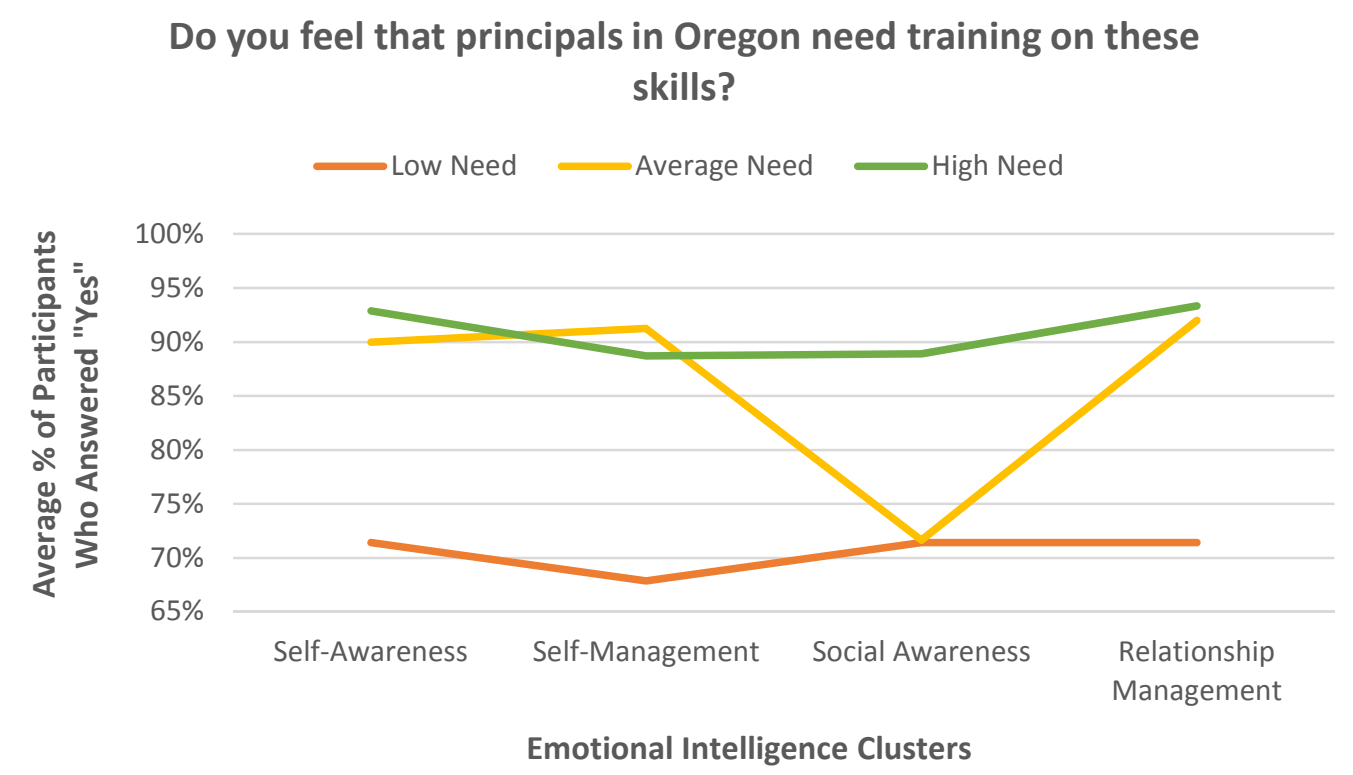

Note. This chart displays principal perceptions of need for self-awareness, self-management, social awareness, and relationship management clusters (Goleman et al., 2001, 2013) grouped by level of student need at the principal's school. Percentages are averaged across all questions for each cluster. 


\section{Figure 4.28}

Perceptions of Need for EI Skills: By Level of Need

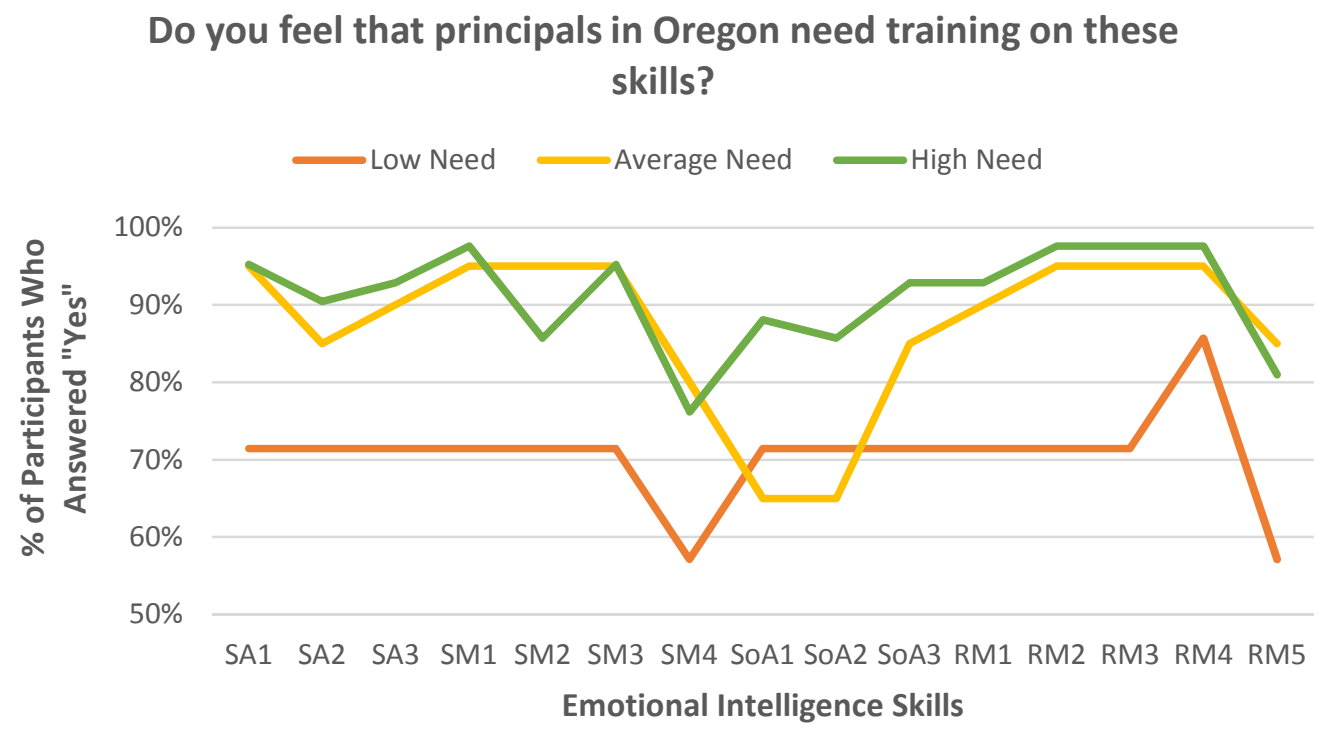

Note. This chart displays principal perceptions of need for training in the 15 emotional intelligence skills when grouped by level of student need at the principal's school. The Emotional Intelligence skills include: The emotional intelligence skills include: SA1—Understanding how one reacts to emotions, such as stress; SA2-Understanding how others influence one's emotional state; SA3Understanding how emotions affect others; SM1—Adapting to change; SM2—Preventing negative emotions and moods from affecting others; SM3-Managing and coping with stress; SM4Managing emotional responses to Covid-19; SoA1—Recognizing the unstated feelings and emotions of others; SoA2-Recognizing the collective mood in a room; SoA3-Understanding the political forces at work within groups (social networks, power relationships, etc...); RM1Supporting the emotional needs of others; RM2-Encouraging trust and collaboration; RM3Managing conflict effectively; RM4—Managing change effectively; and RM5—Managing the effects of Covid-19 on staff, students, and families. 


\section{Table 4.13}

Principal Need for EI Skills: By Level of Student Need

\begin{tabular}{|c|c|c|c|c|}
\hline \multirow[t]{2}{*}{ Cluster } & \multirow[t]{2}{*}{ Skill } & \multicolumn{3}{|c|}{ Participant Responses by Student Need } \\
\hline & & $\begin{array}{l}\text { Low } \\
\%(n)\end{array}$ & $\begin{array}{l}\text { Average } \\
\%(n)\end{array}$ & $\begin{array}{l}\text { High } \\
\%(n)\end{array}$ \\
\hline \multirow[t]{3}{*}{ Self-Awareness } & Understanding how one reacts to emotions & $71(5)$ & $95(19)$ & $95(40)$ \\
\hline & $\begin{array}{l}\text { Understanding how others influence } \\
\text { emotions }\end{array}$ & $71(5)$ & $85(17)$ & $90(38)$ \\
\hline & Understanding how emotions affect others & $71(5)$ & $90(18)$ & $93(39)$ \\
\hline \multirow[t]{4}{*}{ Self-Management } & Adapting to change & $71(5)$ & 95 (19) & $98(41)$ \\
\hline & Preventing emotions from affecting others & $71(5)$ & $95(19)$ & $86(36)$ \\
\hline & Managing and coping with stress & $71(5)$ & 95 (19) & $95(40)$ \\
\hline & $\begin{array}{l}\text { Managing emotional responses to Covid- } \\
19\end{array}$ & $57(4)$ & $80(16)$ & $76(32)$ \\
\hline \multirow[t]{3}{*}{ Social Awareness } & $\begin{array}{l}\text { Recognizing the unstated emotions of } \\
\text { others }\end{array}$ & $71(5)$ & $65(13)$ & $88(37)$ \\
\hline & $\begin{array}{l}\text { Recognizing the collective mood in a } \\
\text { room }\end{array}$ & $71(5)$ & $65(13)$ & $86(36)$ \\
\hline & Understanding the political forces at work & $71(5)$ & $85(17)$ & $93(39)$ \\
\hline Relationship & Supporting the emotional needs of others & $71(5)$ & $90(18)$ & $93(39)$ \\
\hline \multirow[t]{4}{*}{ Management } & Encouraging trust and collaboration & $71(5)$ & 95 (19) & $98(41)$ \\
\hline & Managing conflict effectively & $71(5)$ & 95 (19) & $98(41)$ \\
\hline & Managing change effectively & $86(6)$ & $95(19)$ & $98(41)$ \\
\hline & $\begin{array}{l}\text { Managing the effects of Covid-19 on } \\
\text { others }\end{array}$ & $57(4)$ & $85(17)$ & $81(34)$ \\
\hline
\end{tabular}

Note. Participants were asked if they felt principals needed training in the emotional intelligence skills listed. The percentage of the participants who responded with yes in each age category is presented in the columns above.

Ordinal Logistic Regressions. After analyzing the responses with descriptive statistics, I ran cumulative odds ordinal logistic regressions with proportional odds to determine the relationships of the independent variables - principal age, gender, race/ethnicity, years of experience, school level, school location, and student need at the school—with the principals' perceived need for emotional intelligence training in each of the 13 main emotional intelligence skills. The regressions were not run on the two Covid- 
19-related skills for several reasons: (a) when the descriptive statistics were computed, it became apparent that the inclusion of these skills increased the variability of the data; and (b) each of the Covid-19-related skills include components of other emotional intelligence skills that were already being explored by the regressions—-for example, managing emotional responses to Covid-19 required the ability to adapt to change, prevent one's negative emotions and moods from affecting others, and manage stress well.

Prior to conducting the ordinal logistic regressions, I assessed the data in SPSS to ensure that all assumptions were met and that the ordinal logistic regression method was appropriate for my data. I first used the linear procedure to test the independent variables for multicollinearity. As seen in Table G1, all independent variables produced tolerance values greater than 0.1 , indicating that the independent variables were not highly correlated with one another and there were no problems with collinearity in the data set. PLUM and GENLIN procedures were then used to test the assumptions, provide an omnibus statistical test for each categorical variable, and provide odds ratios. As seen in Table G2, the assumption of proportional odds was met for all dependent variables, except recognizing the collective mood in a room, as assessed by a full likelihood ratio test comparing the fit of the proportional odds model to a model with varying location parameters. Furthermore, the deviance goodness-of-fit test indicated that the ordinal logistic regression model was a good fit for all variables (see Table G3), but most cells were sparse with zero frequencies in $66.7 \%$ of cells, indicating that the goodness-of-fit measures should be treated with suspicion. As seen in Table G4, the Model Fitting 
Information produced by the PLUM procedure revealed that the final model statistically significantly predicted the dependent variables over and above the intercept-only model for seven of the dependent variables but did not statistically significantly predict the dependent variables for six of the dependent variables. In other words, at least one of the eight independent variables tested had a statistically significant effect on seven of the 13 dependent variables.

Next, I analyzed the results of the ordinal logistic regressions to uncover the relationships between the independent variables $(n=8)$ and each dependent variable $(n=$ 13). Appendix $\mathrm{H}$ includes an analysis of the effects of all independent variables on each of the dependent variables. The results that were statistically significant or approaching statistical significance, at an alpha level of .05, are displayed in Table 4.14. Of the eight independent variables, statistically significant differences in perceptions of need for emotional intelligence training were found based only on gender, with the odds of males expressing the need for social awareness training in recognizing unstated feelings at 0.11 $(95 \%$ CI $[0.02,0.59])$ times that of females, a statistically significant result $\left(\chi^{2}(1)=6.60\right.$, $p=.01$; Table 4.14). There were no statistically significant differences found based on race/ethnicity, age, years of experience in education, years of experience as a principal, school level, school location, or student need at the school. 


\section{Table 4.14}

Model Effects of Participant Gender on Perceptions of Need for EI

\begin{tabular}{|c|c|c|c|c|c|c|}
\hline \multirow{2}{*}{$\begin{array}{l}\text { Dependent } \\
\text { Variable }\end{array}$} & \multirow{2}{*}{$\begin{array}{l}\text { Wald } \\
\text { Chi- } \\
\text { Square }\end{array}$} & \multirow[t]{2}{*}{$d f$} & \multirow{2}{*}{$\begin{array}{l}\text { Odds } \\
\text { Ratio }\end{array}$} & \multicolumn{2}{|c|}{$95 \%$ Wald CI } & \multirow[t]{2}{*}{$p$} \\
\hline & & & & Lower & Upper & \\
\hline $\begin{array}{l}\text { Self-Awareness: Understanding How } \\
\text { Others Influence Emotions }\end{array}$ & 3.13 & 1 & 0.13 & 0.01 & 1.25 & .08 \\
\hline $\begin{array}{l}\text { Social Awareness: Recognizing } \\
\text { Unstated Feelings }\end{array}$ & 6.60 & 1 & 0.11 & 0.02 & 0.59 & $.01 *$ \\
\hline $\begin{array}{l}\text { Social Awareness: Recognizing } \\
\text { Collective Mood }\end{array}$ & 3.53 & 1 & 0.14 & 0.02 & 1.09 & .06 \\
\hline $\begin{array}{l}\text { Social Awareness: Understanding } \\
\text { Political Forces }\end{array}$ & 2.92 & 1 & 0.25 & 0.05 & 1.23 & .09 \\
\hline $\begin{array}{l}\text { Relationship Management: Encouraging } \\
\text { Trust }\end{array}$ & 3.01 & 1 & 0.06 & 0.00 & 1.44 & .08 \\
\hline
\end{tabular}

Note. There were no statistically significant differences in the principals' perceptions of need for emotional intelligence training based on race/ethnicity, age, years of experience in education, years of experience as a principal, school level, school location, or student need at the school. $\mathrm{df}=$ degrees of freedom. $\mathrm{CI}=$ confidence interval.

$*=\mathrm{p}<.05$

\section{Qualitative Data}

During the second phase of the study, I collected qualitative data in the form of semi-structured interviews (Appendix F) and a document review process. In interviews, participants were asked to expand upon their answers to the survey questions (see Appendix D), especially regarding the Covid-19 pandemic. Through the document review process, I gathered additional information on specific programs and activities that were mentioned by the participants. 


\section{Response Rates and Participant Demographics}

Of the survey participants, 41 volunteered for Phase 2 of data collection. The volunteers were invited to participate in the interviews based on the degree to which their individual characteristics and the contexts of their schools contributed to maximum variation of the sample. I invited 25 principals to participate, including all the volunteers in groups with low representation, which included all the non-White/Caucasian volunteers $(n=8)$, all volunteers under age $40(n=5)$ and over age $59(n=4)$, all volunteers with less than 10 years $(n=3)$ and more than 29 years $(n=5)$ of experience in education, all volunteers with more than 14 years $(n=4)$ of experience as a principal, all who worked in middle/junior-high schools $(n=5)$, and all volunteers working at lowneed schools $(n=3)$. Although I attempted to achieve equal representation from each of the groups present within the variables studied, it was not possible, but I was able to recruit at least one participant from each group except for principals over age 59. Guest et al. (2006) recommends a minimum of 9 participants to reach data saturation for interviews, so my goal was to interview a minimum of 10 participants, which I achieved.

Twelve individuals responded to my invitations and participated in the interviews, which ranged from 16 to 50 minutes in length. The final sample included seven males and five females; three non-White/Caucasian principals and 9 White/Caucasian principals; one principal under age 40 , seven principals age 40 to 49 , and four principals age 50 to 59; one principal with less than 10 years of experience in education, two principals with 10 to 19 years, seven principals with 20 to 29 years, and two principals with more than 29 years of experience in education; four principals with less than 5 years 
of experience as a principal, five principals with 5 to 9 years, two principals with 10 to 14 years, and one principal with more than 14 years of experience as a principal; five principals who worked at the elementary-school level, five who worked at the highschool level, and two who worked at the middle/junior high-school level; six principals who worked at high-need schools, five who worked at average-need schools, and one who worked at a low-need school; and finally, four principals who worked at urban schools, four who worked at suburban schools, and four who worked at rural schools (Figure 4.29). 


\section{Figure 4.29}

Individual Characteristics and Contexts of the Phase 2 Participants

\section{Gender \\ - Male \\ - Female}

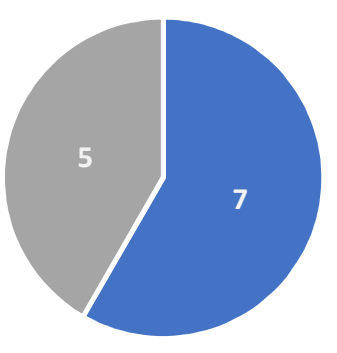

Age
- $<40 \mathrm{yrs}$
$=40-49 \mathrm{yrs}$
$=50-59 \mathrm{yrs}$

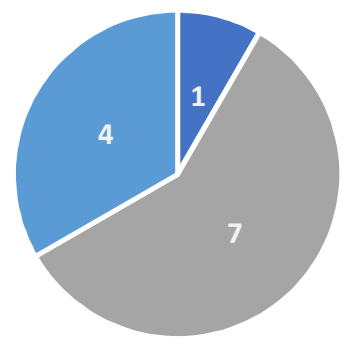 (Principal)
- $<5$ years
- 5-9 years
- 10-14 years
- $>14$ years

Years of Experience

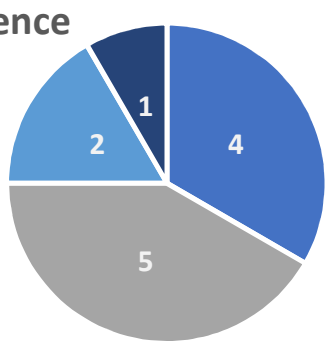

\section{Student Need}

- Low Need

- Average Need

- High Need

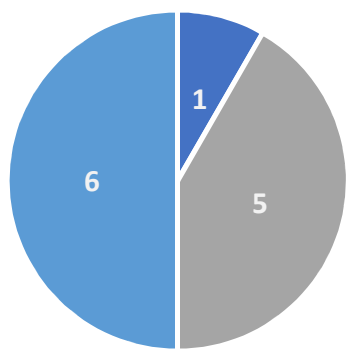

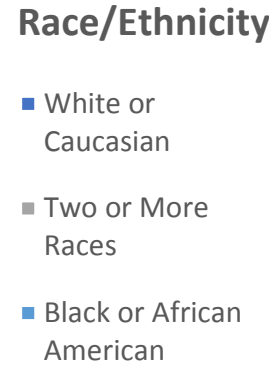
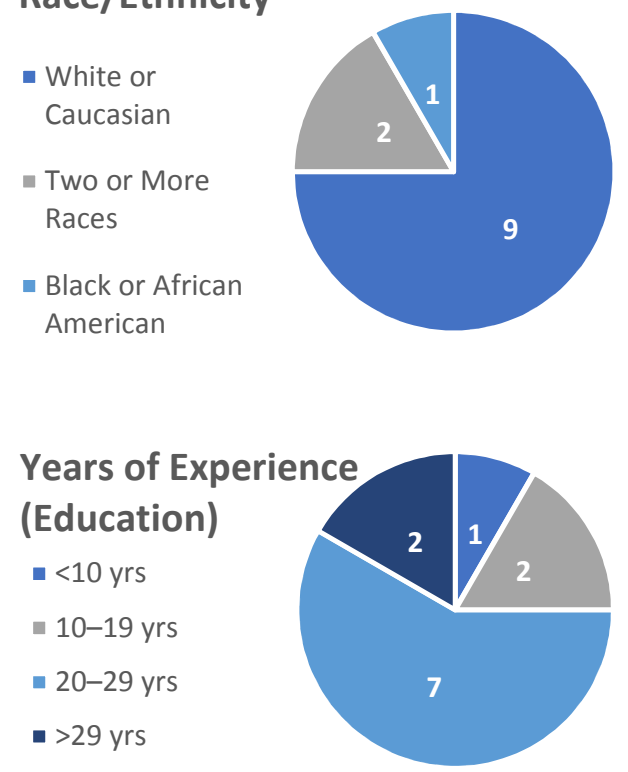

\section{School Level \\ - Elementary \\ - Middle \\ - High}

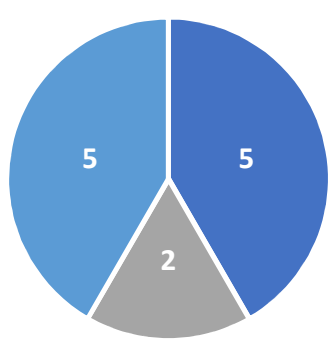

\section{School Location}

- Rural

- Urban

- Suburban

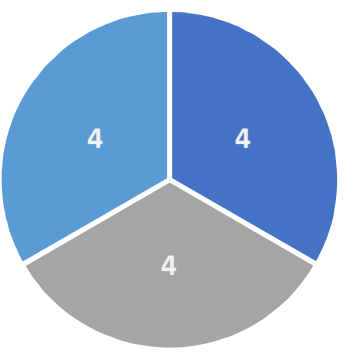

Note. This figure displays the individual characteristics of the 12 principals who participated in the Phase 2 interviews and the contexts of their schools. 


\section{Principal Preparation Programs}

The interviews included three questions regarding the participants' perceptions of their principal preparation programs. The first question asked the participants how their principal preparation program(s) prepared them to manage widespread political and social changes, such as those caused by the Covid-19 pandemic; the second question asked how their principal preparation program(s) prepared them to manage stress and/or build resilience to emotional exhaustion and burnout; and the third question asked the participants how their principal preparation program(s) prepared them to manage the emotional needs of their staff, students, and communities in response to stressful situations. The collected data informed the answers to the second and third research questions:

RQ2. How do $\mathrm{K}-12$ principals in Oregon perceive that their preparation programs have supported the development of emotional intelligence skills?

RQ3. How do $\mathrm{K}-12$ principals in Oregon perceive their preparation programs to have prepared them to manage the stress and emotions caused by Covid19 and other challenges?

Preparation to Manage Widespread Political and Social Changes. Nine (75\%) of the participants stated that they did not feel that their preparation programs prepared them to manage widespread political and social changes, such as those caused by Covid19; however, several of the participants mentioned that their programs had prepared them in indirect ways by facilitating discussions of historical and current events that affected 
the socio-political climate of the time, philosophies of education, and the cultural and societal implications of their work as public educators. One participant stated

I did have courses about social change, certainly not about a pandemic, but having just those conversations about other historical, social changes that have occurred in schools - for example segregation was one of the big topics that we talked about — and you know if that were happening today what would we do? One other area that we talked a lot about was integration of technology from a time when we didn't have technology at all. I feel like those discussions were helpful in being able to organize quickly and think about logistics quickly. (female participant, age 52)

Other participants mentioned specific components of their preparation programs that were helpful, such as a focus on adaptive leadership, flexibility, and perseverance, as well as initiatives regarding meeting the needs of the whole child and ensuring equity. One participant mentioned that her experiences as a principal had prepared her more than any training she had received (female participant, age 47), and another participant pointed out that principals who graduated more recently may have dealt better with the pandemic than those who graduated 7 to 10 years ago because of changes in technology and principal preparation programs over time (female participant, age 49).

\section{Preparation to Manage Stress and/or Build Resilience to Emotional}

Exhaustion and Burnout. Eleven (92\%) of the participants stated that they did not feel that their preparation programs prepared them to manage stress and/or build resilience to emotional exhaustion and burnout, although several said that they had professors who 
mentioned the importance of self-care and strategies to manage stress, such as leaving work at a specific time, not checking email after a certain time, or packing food that could easily be eaten while on the go. One participant stated

I did have one particular professor at the time, who actually was our finance and budget professor, ... and he talked about it kind of offline in the class. You know, he said, you need to look at your day like a budget. If you aren't getting enough sleep, you aren't getting enough exercise, and you are not forcing yourself to eat during the day, you are no good to your kids or your teachers. If you're sick or you have to be out, you know, for four months because you end up with a sinus infection that becomes pneumonia that lays you out, that's not a good budget. (female participant, age 52)

Several participants mentioned that their professors were former administrators who shared a lot of information from their experiences in education; however, the strategies mentioned to manage stress and/or build resilience to emotional exhaustion and burnout were anecdotal and were not formally built into the curriculum.

The participants made some interesting observations about their preparation programs. One participant believed that his preparation program attempted to help principals build resilience by "emulat[ing] some of the workload issues in an effort to replicate some of the potential stressors that might occur on the job" (male participant, age 54); however, he went on to state that "nowhere did we then analyze and discuss what that personal impact and cost is and how to ameliorate or work with it." Another 
principal commented that "people sort of just rise to the top if they can handle it" (male participant, age 37).

Several participants shared their personal experiences with stress and emotional exhaustion. One participant mentioned that although he was prepared to work with students, he was ill prepared for dealing with his adult employees. He described the incredible amount of stress that was involved in his interactions with teachers, stating They don't describe the amount of stress that you go through when you go and have a conversation with someone that went to college for four years, got a master's degree, and then you try to tell them that they're not good at their job ... I dealt with some crazy things with kids that caused a little bit of stress, but they don't prepare you for the amount of stress if you're trying to do what's best for kids and you're trying to get the right people in the building — going through that process with adults and trying to either make the adults better or move them out of the building. (male participant, age 37) Another principal stated, "I don't encourage anybody to go into administration unless they're in a second season of their life" (female participant, age 49), explaining that principals need to have a support network to be successful and should not have young children or elderly parents that they need to care for. One participant stated that it is the system itself that needs to change. He said, "For me personally it's not so much me becoming more resilient or embodying more perseverance within the role, but the system understanding that it's an intolerable amount of pressure that gets put on principals" (male 
participant, age 40). He also shared his concern that "centering self-care looks like neglecting duty at times, so finding that balance is so important."

\section{Preparation to Manage the Emotional Needs of Others in Response to}

Stressful Situations. Six (50\%) of the participants stated that they did not feel that their preparation programs prepared them to manage the emotional needs of their staff, students, and communities in response to stressful situations; however, four (33\%) of the participants felt that their programs did prepare them, and two (17\%) of the participants felt that their programs somewhat prepared them. Those who felt that their programs did prepare them mentioned learning about the importance of collaboration, transparency, empathy, social-emotional learning, and creating a culture of care. Participants also mentioned the value of the instruction they received regarding communication, team building, conflict resolution, and issues of race and equity. One participant mentioned that his program included awareness of the need to manage the emotional needs of others but was missing the practical application component of how to do that work (male participant, age 53). Additionally, several others mentioned not receiving much training about mental health. One principal stated

I think there was a significant amount of opportunities to work with other administrators or aspiring administrators in the discussion of how to address certain volatile or difficult situations and how to address that with the adults and the children with whom you work, but I do think that was a little bit more on the surface and open for discussion, usually pursuant to disciplinary issues or staff conflict issues or a personnel work-related kind of evaluative or directed goal- 
course correction type stuff — not so much the emotional. (male participant, age 54)

Several participants mentioned the emotional needs of their community in response to the pandemic. One principal discussed how the pandemic really highlighted inequities that her preparation program did not prepare her for. She discussed how those who live in high-needs communities often have heart disease, diabetes, mental-health issues, insufficient medical and dental care, and multi-generational families that cannot self-isolate, as well as a limited ability to get masks, check their temperature daily, keep things appropriately clean and disinfected, and feed and care for children that are normally at school all day. She stated

I have a mask. I have a car. I have transportation. At least I can go take a drive somewhere. At least I can work on Zoom, and I still have my job. I see my benefits, and I can afford gas in my car. Whereas, you had other individuals that were literally locked into their homes, without really having the means to seek out other things that they may have needed to aid in their social-emotional wellbeing. (female participant, age 49)

Similarly, another participant mentioned staff members who were living in poverty, some in transitional housing. She discussed the need to have awareness about what is going on in their lives so that she could adequately support them and the rest of her staff. She stated

You have to build that same relationship with your staff members that you would with the kids in your classroom so that you understand their love language, so to 
speak. I have some staff members that they really need those daily affirmations every single day. They need to know that they've done an outstanding job because they're so hard on themselves that they really need that affirmation. I have some staff members that really need little tokens, like they need that little couple of candies on their desk, they need a little bookmark here and there, they need something tangible. I have some staff members that have liked to have scheduled time with me every week, even if it's only 15 or 20 minutes and we're not really talking about anything, they just kind of need a check in. (female participant, age 52)

Although this principal seemed to have a high degree of knowledge regarding how to meet the emotional needs of her staff, she attributed her approach to her background in counseling, rather than anything she learned in her principal preparation program.

\section{Principal Professional Development}

After asking principals about their principal preparation programs, I then asked them four questions about the professional development programs that have been available to them since they obtained their licensure. These questions mirrored the questions that were asked regarding their principal preparation programs. The first question asked if the participants had attended any professional development training prior to the school closures that helped them manage the changes associated with Covid19 and, if so, how the training had helped them. The second question asked if the participants had attended any professional development training prior to the school closures that helped them manage stress and/or build resilience to emotional exhaustion 
and burnout. The third question asked if the participants had attended any professional development training prior to the school closures that had helped them manage the emotional needs of their staff, students, and communities in response to stressful situations. The last question asked if they had attended any professional development training that focused on stress management and/or managing emotions in response to the school closures since the Covid-19 pandemic began. As with the above section, the collected data informed the answers to the second and third research questions.

\section{Pre-Covid Professional Development on Managing Widespread Political and}

Social Changes. Eight (67\%) of the participants stated that they had attended professional development training prior to the school closures that helped them manage the changes associated with Covid-19, whereas three (25\%) participants had not attended any training that had helped, and one (8\%) participant had received training that was not meant to support adults but was helpful in managing the effects of the pandemic and could be applied to adults. Participants found several practices helpful for managing the challenges associated with the pandemic, including collaborative problem solving, deescalation strategies, self-care, care for others, creating a culture where people feel heard and valued, and creating professional networks to share information and get support.

Several participants mentioned that they had received emergency response training, as well as workshops on trauma-informed care and culturally responsive practices, that were particularly helpful during the pandemic. One participant discussed the importance of knowing how to access resources during an emergency. While 
reflecting on how to get food and supplies to families in her high-need community, she stated

[I asked myself] how could I utilize the systems that we have, like our robo call system, our flash alert? I had volunteers from both my school, as well as the church volunteers, helping. I mean it took an hour and a half, and we fed I think 195 families in the school district for that week. . . People will come forward with assistance, but you have to have an organized way of getting the message out there. And then, once you put the message out there, you have to have a plan, where you can put it all [and so on]. (female participant, age 52)

\section{Pre-Covid Professional Development on Managing Stress and/or Building}

Resilience to Emotional Exhaustion and Burnout. Six (50\%) of the participants stated that they had not attended any professional development training prior to the school closures to help them manage stress and/or build resilience to emotional exhaustion and burnout, whereas four (33\%) participants had received training that was helpful, and two $(17 \%)$ had received training that they felt helped them to a degree. Several of the participants who had received helpful training mentioned training in trauma-informed practices and mindful practices.

One participant mentioned having experienced personal trauma that led her to pursue training in trauma-informed care and mindfulness practices to manage her own trauma response (female participant, age 42). She later extended this training to her practices as a principal. Another participant mentioned two mindfulness programs: Mindful Leaders, a service-focused leadership certificate program that cultivates 
compassionate leadership and self-care skills and practices, and Peace in Schools, a mindfulness program for teachers and students based in SEL principles. She discussed how these programs helped her understand how the brain responds during stress and how to use mindfulness strategies to rewire its responses. She stated, "We practiced some kind of physical relaxation strategies. We practiced mindful eating. We did some breathing exercises. So, all of that definitely helped me" (female participant, age 48). Similarly, another participant mentioned having just completed the Mind Flow program, a mindfulness training program for leaders that includes belly breathing and strategies such as taking time to decompress between meetings (male participant, age 40). He felt that the strategies included in the training gave him more balance and allowed him to be more strategic in his approach to stress management. He stated

I thought it was good for me [but] personally, I go back to what the root causes of the stress itself is and it's not my inability to cope with the stress. It's the level of the sheer amount of things that just kind of continue to get piled on your plate... I feel like I'm kind of stuck with, how do I create a balance where I understand the urgency of my job and the need to create meaningful change, while simultaneously understanding I need to bring my best self into this? I can only do that through having these opportunities to decompress and relax. So yeah, I think that mindfulness training was really good. It gave me some tangible things. (male participant, age 40)

Although not all participants had the opportunity to engage in mindfulness training designed for adults, most had experience with social-emotional learning (SEL) 
programs designed for children. One participant mentioned benefiting from such training, stating

The focus was for children, right, but you can't help but begin to, after a period of time of prolonged professional development or immersion in a different way of thinking, begin to translate that over to other environments. Right, so it hasn't been explicit, I'll give you that. I believe that there's a space for explicit training in working with adults and with oneself. (male participant, age 54)

\section{Pre-Covid-19 Professional Development on Managing the Emotional Needs}

of Others in Response to Stressful Situations. Participants were asked if they had attended professional development training prior to the Covid-19 pandemic that helped them manage the emotional needs of their staff, students, and communities. In response, three $(25 \%)$ participants stated that they had not attended training that was helpful in managing the emotional needs of their communities prior to the pandemic and two (17\%) participants did not answer the question directly; however, most (58\%) stated that they had attended training that was helpful. Participants mentioned several programs, such as RULER, a school-wide SEL program, as well as training on trauma-informed care and training that focused on building a positive school culture. One participant mentioned several books he had found helpful, including School Culture by Design by Phil Boyte, Eyes on Culture: Multiply Excellence in Your School by Jimmy Casas, and Lead like a PIRATE: Make School Amazing for Your Students and Staff by Shelley Burgess and Beth Houf. When referring to the benefits he found from reading the latter book, the participant made it clear that he found the training helpful, stating, "I think that 
professional development helped me as much, or more, than anything, going into this year with Covid-19: how to take care of our staff, how to listen to our staff, how to empower staff" (male participant, age 53).

In addition to specific professional development training and resources, some principals referred to overall emotional intelligence skills, which they may have developed directly or indirectly because of training, that contributed to positive outcomes. One principal reflected on her response to recognizing the social-emotional needs of her students, stating

It just was a no brainer to me when the pandemic hit to know that we had to figure out how to get kids food, how to get them devices, and how to really support the loss and trauma that they were experiencing by losing their social connections and by having to become responsible for their younger siblings, [something that] had existed before but was amplified by the pandemic. (female participant, age 47) Likewise, several participants emphasized the importance of relationship building. One principal discussed how she had the support of her teachers, which helped her engage in collaborative decision-making processes that brought her staff together (female participant, age 52). Another principal stated

From the beginning, it has been a team approach, and I think that team approach has been key. . . . I think, because we did it together and we're in it together, that's what made all the difference. There was no program or anything other than we've got each other's backs and we're going to help each other. (female participant, age 48) 
Although it would have been very difficult to predict the effects of the pandemic, and although the principals interviewed felt largely unprepared, it seems that the systems in place pre-Covid-19 that provided opportunities to develop their emotional intelligence skills also proved helpful to several of the participants in managing the emotions and stress of their students and staff during the pandemic.

\section{Post-Covid-19 Professional Development on Managing Stress and Emotions}

in Response to the School Closures. While most participants attended professional development that they found helpful prior to the pandemic, fewer participants (42\%) reported attending professional development that they found helpful after the pandemic began. Five (42\%) of the participants stated that they did not receive any professional development training after the pandemic began. One participant explained that his district supported schools during the pandemic by being responsive to the needs of the community, being transparent with school leaders about what they could and could not accomplish, and giving schools the autonomy to shift their resources as needed to support students and families, but not by providing training opportunities. He stated, "I don't know that [the district has] had the ability to put out PD in this environment. I also know we wouldn't engage in it—just there's so much going on" (male participant, age 42).

Although some districts did not have the ability to provide professional development during the pandemic, several districts and outside agencies did provide training opportunities. Four (33\%) participants reported participating in formal programs, resiliency training, and collaboration spaces that were set up for principals to share best practices and discuss what was going on in their schools during the pandemic. For 
example, the Linn Benton Lincoln Education Service District offered resiliency training that one participant found helpful. She stated "internalizing so much of the stress isn't really moving me to a positive place. That doesn't mean that I'm immune to it. Certainly, there are days where I'm like 'I cannot do this,' but obviously I'm going to get up the next time and do it" (female participant, age 52). As a result, she sought out training to help build resilience both personally and within her staff. She also reported collaborating with colleagues, stating, "we had elementary principal talking hours, where principals could talk through specific issues or concerns." Although her school was the only school providing in-person instruction in the region during that time, and she spent more time providing support than receiving it, she found the talking hours helpful, explaining that "just being able to describe helped me think through how to do things effectively and efficiently."

The participants who reported taking part in formal professional development programs during the pandemic mentioned two specific programs: RULER and Outward Mindset. RULER is a schoolwide SEL program that was created at Yale University's Center for Emotional Intelligence in 2005 to help students, educators, and administrators of all ages experience more success by Recognizing, Understanding, Labeling, Expressing, and Regulating emotions in mindful ways (RULER, 2021). One participant explained that her district's efforts were primarily around healing, around kind of acknowledging the loss that students, and really the world in general, [was] experiencing because of Covid ... [as well as] 
work[ing] on adult SEL as a way to be more present in a more positive way with students. (female participant, age 47)

The Outward Mindset program, initiated by the Arbinger Institute in 1979 (Arbinger

Institute, n.d.), was mentioned by one participant as being very helpful because "it helps you to set your fears and concerns aside and look from a different point of view outside yourself" (female participant, age 48). The program—which uses self-awareness, mindset change, accountability, and collaboration tools to help leaders and their employees develop an outward focus - is based on 45 years of research and has been used globally for more than 35 years to target the needs of a variety of stakeholders (Arbinger Institute, 2016, n.d.).

\section{Principal Need}

The interviews included one question regarding the types of preparation and/or professional development training that principals felt could have helped them prepare better for managing the emotions and stress caused by the political unrest and social changes they experienced during the 2020-2021 school year. All participants related having needs that went unmet and areas for improvement in how they responded to the challenges that they faced. Most of the participants (92\%) mentioned training they felt would have been helpful prior to or during the pandemic, with one (8\%) participant focusing their answer to this question primarily on systems that needed improved but not clarifying whether training would have been helpful. All participants mentioned a variety of activities, programs, and tools that they felt would have been helpful to them as they managed both their own emotions and stress, as well as the emotions and stress of others. 
One theme that emerged was the need to connect with other leaders who were having similar experiences. Several participants discussed the value of partnerships they had formed with other principals during the pandemic and mentioned the need for administrator support groups to get together and talk about their experiences. One participant suggested that mentorship programs would be helpful so that principals could engage in weekly meetings that would allow them to talk about their experiences (male participant, age 37). He discussed struggling significantly with stress management as a new principal and developing ulcers as a result. He stated, somewhat jokingly, that "all the first-year administrators should have a psychologist that they have to go to.... There needs to be something to address the social-emotional stress that administrators go through" (male participant, age 37). Lastly, a participant, who had attended an online principal preparation program, mentioned the value of the cohort model and staying connected to one's classmates, which was something that he felt his program had lacked (male participant, age 42).

The need for skills in strategic communication was another common theme that emerged from the interviews. One principal stated

we can communicate the hell out of everything that we want to do, but not everybody reads what we put out, and there's often too much information put out, and people become desensitized to it, and so we have to be really careful in how we communicate. (male participant, age 56)

Another principal discussed how ill-prepared she felt to deal with the political polarization that she saw in her building, saying 
I would have liked to have had a little more training or preparation, a few sentence stems, so that staff members felt that I heard them. It didn't matter if I agreed or disagreed — that wasn't even the issue — but that they felt more heard. (female participant, age 52)

Opportunities to evaluate case studies and role play were also mentioned specifically as potentially helpful tools for communication. One principal recalled doing role plays and case studies in his preparation program and finding them helpful, although he recognized that it would have been difficult to plan either activity in a way that could prepare anyone for anything "as farfetched and crazy as a global pandemic" (male participant, age 53).

Similarly, several principals mentioned the need for training on basic leadership practices, such as being transparent, being collaborative, empowering others, staying calm, being patient, remaining flexible, and forecasting. On the importance of staying calm, one participant remarked, "If I'm elevated as a principal, I'll have elevated staff. If I'm calm as a principal, I'm able to help calm those around me as well, and I think that was very, very big for this school year" (male participant, age 53). Another participant discussed the importance of developing strong leadership skills:

I've never seen something go terribly wrong because of the content. I've seen things go terribly wrong because of lack of the leadership.... [but] we don't allow for future administrators to sit down and actually process: 'what's my leadership style? What is going to work? How do I fill the gaps?' (male participant, age 42) 
Focusing on how reactive he felt administrators were during the pandemic, another participant said, "there's not a great deal of forecasting that goes on-there's a lot of reacting and, you know, back casting" (male participant, age 56). He suggested creating an inventory of systems and practices so that educators could focus on what was essential to continue doing during the pandemic:

Could we have predicted that students were going to disconnect? Could we have predicted that they were going to struggle emotionally? We predicted that they were going to struggle academically. And then, what were some things that we were absolutely going to do so that we could keep them connected to school and teaching and learning? And then what were some things that we knew we wouldn't be able to continue doing and how were we going to manage those? (male participant, age 56)

Lastly, most principals recognized that the social-emotional needs of both students and staff were elevated. Several participants mentioned the need for training on how to care for oneself and others. One principal stated, "I think there definitely could be more room for professional development specifically around demonstrating grace" (female participant, age 42). Furthermore, several principals had to deal with multiple suicides in their communities. Four (33\%) mentioned that it would have been helpful to have had more training on mental health, such as anxiety, stress, depression, and suicide prevention. One participant mentioned having been fortunate to have had social workers at her school who helped her better understand and manage the mental health needs of her staff, students, and families, a support system that she had not always had in her 
previous schools (female participant, age 47). Another reflected on the time and energy most schools put into active shooter drills, stating, "I believe we could do more by diverting some of the energy, resources, and time that we devote to atrocious acts of violence ... to the day-to-day anxiety and stress and depression that our youth experience" (male participant, age 54).

\section{Document Review}

I used a document review process to gather additional information on how the characteristics of specific programs and activities mentioned by the participants intersect with the emotional intelligence skills explored in this research. I reviewed books and websites that discussed the frameworks mentioned and used a priori coding to identify elements that aligned with the four emotional intelligence clusters (Goleman et al., 2001, 2013). Table 4.15 displays the emotional intelligence clusters that were included in the programs and frameworks mentioned by the Phase 2 participants. All of the frameworks included the social awareness and relationship management clusters in some capacity. In addition, 10 of the 16 frameworks included the self-management cluster along with the social awareness and relationship management clusters, and nine of the frameworks included all four emotional intelligence clusters. Although self-awareness is included in most of the programs and frameworks, the focus is often on others rather than oneself. For instance, many of the programs focus on using self-awareness to improve interpersonal relationships, rather than to engage in self-care practices designed to improve one's personal outlook or to meet inward-facing objectives, such as managing one's own stress and burnout. Only five of the frameworks directly address self-care: 
Building Resilience, Peace in Schools, Mindflow, Mindful Leader, and RULER. Of these five frameworks, Building Resilience, Mindful Leader, and RULER are the only frameworks that include both self-care and all four emotional intelligence clusters, with RULER having the most complete model that addresses emotional intelligence at the student, staff, and administrator levels.

\section{Table 4.15}

EI Included in the Programs \& Frameworks That Emerged in Phase 2

\begin{tabular}{lccccc}
\hline Programs and Activities & Number $^{\mathrm{q}}$ & $\begin{array}{c}\text { Self- } \\
\text { Awareness }\end{array}$ & $\begin{array}{c}\text { Self- } \\
\text { Management }\end{array}$ & $\begin{array}{c}\text { Social } \\
\text { Awareness }\end{array}$ & $\begin{array}{c}\text { Relationship } \\
\text { Management }\end{array}$ \\
\hline Building Resilience $^{\mathrm{a}}$ & 3 & $\mathrm{x}$ & $\mathrm{x}$ & $\mathrm{x}$ & $\mathrm{x}$ \\
Collaborative Problem Solving $^{\mathrm{b}}$ & 1 & & & $\mathrm{x}$ & $\mathrm{x}$ \\
Creating Positive School Cultures $^{\mathrm{c}}$ & 2 & $\mathrm{x}$ & $\mathrm{x}$ & $\mathrm{x}$ & $\mathrm{x}$ \\
Crisis Prevention / De Escalation $^{\mathrm{d}}$ & 1 & $\mathrm{x}$ & $\mathrm{x}$ & $\mathrm{x}$ & $\mathrm{x}$ \\
Culturally Responsive Leadership $^{\mathrm{e}}$ & 2 & $\mathrm{x}$ & $\mathrm{x}$ & $\mathrm{x}$ & $\mathrm{x}$ \\
Emergency Response $^{\mathrm{f}}$ & 1 & & & $\mathrm{x}$ & $\mathrm{x}$ \\
Futures Without Violence $^{\mathrm{g}}$ & 1 & & & $\mathrm{x}$ & $\mathrm{x}$ \\
Having Hard Conversations $^{\mathrm{h}}$ & 1 & & $\mathrm{x}$ & $\mathrm{x}$ & $\mathrm{x}$ \\
Love Languages $^{\mathrm{i}}$ & 1 & & & $\mathrm{x}$ & $\mathrm{x}$ \\
Mindflow $^{\mathrm{j}}$ & 1 & $\mathrm{x}$ & $\mathrm{x}$ & & \\
Mindful Leader $^{\mathrm{k}}$ & 1 & $\mathrm{x}$ & $\mathrm{x}$ & $\mathrm{x}$ & $\mathrm{x}$ \\
Outward Mindset $^{\mathrm{l}}$ & 1 & $\mathrm{x}$ & $\mathrm{x}$ & $\mathrm{x}$ & $\mathrm{x}$ \\
Peace in Schools $^{\mathrm{m}}$ & 1 & $\mathrm{x}$ & $\mathrm{x}$ & & \\
Restorative Practices $^{\mathrm{n}}$ & 1 & & & $\mathrm{x}$ & $\mathrm{x}$ \\
RULER $^{\mathrm{o}}$ & 2 & $\mathrm{x}$ & $\mathrm{x}$ & $\mathrm{x}$ & $\mathrm{x}$ \\
Trauma Informed Care $^{\mathrm{p}}$ & 7 & & & $\mathrm{x}$ & $\mathrm{x}$ \\
\hline
\end{tabular}

Notes. ${ }^{\mathrm{a} N e w m a n ~(2016) ; ~}{ }^{\mathrm{b} O E C D}$ (2017); ${ }^{\mathrm{CP}}$ aschall (2020); ${ }^{\mathrm{d} C r i s i s}$ Prevention Institute (2020);

${ }^{\mathrm{e}}$ Khalifa et al. (2016); ${ }^{\mathrm{f}}$ Multnomah Education Service District (2018); ${ }^{\mathrm{g}}$ Furtures Without Violence (2021); ${ }^{\mathrm{h}}$ Abrams (2009); ${ }^{\mathrm{i}}$ Lawrimore (2021); ${ }^{\mathrm{j} M i n d f l o w ~(2019) ; ~}{ }^{\mathrm{k}}$ Mindful Leader (2019); ${ }^{1}$ Arbinger

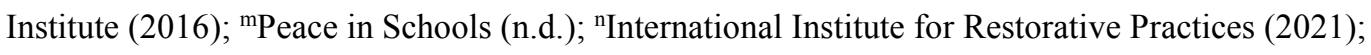
${ }^{\mathrm{o}}$ RULER (2021); ${ }^{\mathrm{p} T r a u m a ~ I n f o r m e d ~ O r e g o n ~(2021) ; ~}{ }^{\mathrm{T}}$ The Number column includes the number of participants who mentioned the program or framework. EI = Emotional Intelligence. 


\section{Limitations of the Study}

There were several limitations to this study discovered during the data collection and analysis phases. First, after piloting my survey with several principals and colleagues, I found that I needed to streamline the original survey to respect the abnormally high stress levels that most principals were experiencing because of the turbulence and challenges of the 2020-2021 school year. I had originally planned to use individual 5-point Likert scale questions to gather information about the emotional intelligence skills that were included in the principal preparation and professional development programs and activities that the participants had experienced; however, this resulted in a 25-minute survey, which I was advised would likely lead to low rates of full participation. Therefore, to provide a survey with an estimated completion time under 10 minutes, I reduced my 5-point scales to 3-point scales and created multi-part questions that were displayed as tables.

These changes significantly reduced the amount of reading for participants and the time required to fill out the survey; however, the changes also created several problems. Given only three options, the answers to the questions were less accurate. For example, instead of asking the participants: Did your preparation program include training in the following self-management skill: adapting to change? with yes, no, and unsure as response options, I had originally planned to ask: To what degree do you agree or disagree with the following statement: my preparation program included training regarding adapting to change with strongly agree, agree, neither agree nor disagree, disagree, and strongly disagree as response options. 
I had also originally planned to use skip logic in the survey, which would skip questions when the participants responded to the first part of the question with strongly disagree, disagree, and neither agree nor disagree. By adding the tables to streamline the reading required to complete the survey, I was not able to skip follow-up questions that did not apply to those participants, which led to incorrect answers by some participants. For example, several participants marked no when asked if their preparation program included training on specific skills but then indicated that the training they had received was helpful in the second part of the question. I corrected these errors manually; however, the potential for mismatched answers added some confusion to my data analysis procedures and may have added noise to the results.

Second, despite my efforts to streamline the survey to recruit more participants, I was unable to recruit the recommended number of participants for survey sample sizes. I had hoped to recruit a minimum of 300 participants, as recommended by Bartlett et al. (2001); however, I was only able to recruit only 117 participants. Unfortunately, the dataset was further reduced by exclusions, resulting in a final dataset of 69 participants for the professional development questions and 77 participants for the principal preparation questions. The small sample size reduced the power of the statistical model chosen, as well as the generalizability of the results.

Third, the two skills that directly addressed stress and emotions related to the Covid-19 pandemic added variability to the data. As I was assessing the descriptive statistics, I noticed that the standard deviations were quite large when I grouped all 15 emotional intelligence skills into the self-awareness, self-management, social awareness, 
and relationship management clusters, particularly when assessing the availability of training and the helpfulness of the training that principals had received. This variability suggests that the Covid-19 questions may have added confusion for the participants. Some participants may have correctly understood the questions to be asking about training that would have helped them manage both their responses and the responses of others to Covid-19, whereas other participants may have misunderstood the questions to be asking if they received training specifically for Covid-19, something that would have been nearly impossible regarding principal preparation training because of the timing of the survey. I had hoped to draw some conclusions about the availability, helpfulness, and need for training in the four emotional intelligence clusters, but I was concerned that the high degree of variability had the potential to obscure the significance of the results. Therefore, because the Covid-19-related skills seemed problematic, and because each of the Covid-19-related skills included components of other emotional intelligence skills that were already being explored, I did not include the two Covid-19-related skills when I ran the ordinal logistic regressions for each emotional intelligence skill. I did, however, continue graphing the results both by the 15 individual emotional intelligence skills and by the four clusters - which I found helpful for noticing trends in the data — but because of the variation, I was unable to make any conclusions based on the data demonstrated by the clusters. Interestingly, when the principals were asked about their needs for training, most principals agreed that there was a need for training in all of the emotional intelligence skills, including the Covid-19-related skills; therefore, when analyzing need, there was considerably less variation in the clusters. 
Finally, the data from the ordinal logistic regressions could not be used reliably to assess the relationship of the independent variables with all dependent variables. The independent variables passed multicollinearity testing, all but one of the dependent variables met the assumption of proportional odds (recognizing the collective mood in a room), and the deviance goodness-of-fit test indicated that the model was a good fit for all the variables. Yet there may have been separation of the data and the final model did not predict the dependent variable over and above the intercept-only model for six of the 13 dependent variables, including three of the five variables that were approaching statistical significance.

\section{Summary}

This study used an explanatory sequential mixed methods design to explore how the principal preparation and professional development programs available to principals in Oregon have supported their needs for the development of emotional intelligence skills. Data were collected in two phases: a quantitative phase and a qualitative phase. The quantitative data collected from the survey instrument were analyzed using differential and inferential statistics. The qualitative data collected from semi-structured interviews and the document review process were then analyzed using a priori coding. Results indicated that emotional intelligence skills are included to some degree in principal preparation and professional development programs and that most principals see a need for the inclusion of emotional intelligence training opportunities; however, there may be some differences in perceptions of need based on the individual characteristics of the principals and the contexts in which they lead. Furthermore, analysis of the results 
indicated that there were several limitations related to the survey design, sample size, and variability in the data. 


\section{Chapter 5: Discussion}

\section{Introduction}

Student success requires strong communities and strong school systems but increasing demands on educators are leading to high rates of burnout and weakening the support structures that provide a foundation for student success (Bottiani et al., 2019; Levin \& Bradley, 2019; Ouellette et al., 2018). Evidence suggests that organizational health is the strongest predictor of reducing teacher stress (Ouellette et al., 2018), indicating that teacher success depends largely on the climate of the school and the leadership of the school's principal (Eddy et al., 2019; Ouellette et al., 2018). However, research also shows that principals experience extremely high levels of stress that often lead to attrition (Bartanen et al., 2019; Grissom \& Bartanen, 2019; Levin \& Bradley, 2019). The high rates of burnout and turnover among principals present an alarming trend because multi-year school improvement initiatives benefit from stable leadership and school districts need to retain effective principals to ensure teacher and student success (Bartanen et al., 2019; Levin \& Bradley, 2019; Levin et al., 2019; Pietsch et al., 2020).

Fortunately, research indicates that the development of emotional intelligence skills can help strengthen resilience against stress and burnout (Anthony-McMann et al., 2017; Haghighi \& Gerber, 2019; Schutte \& Loi, 2014), but very little attention has been devoted to helping K-12 principals develop emotional intelligence (Herman et al., 2020a, 2020b). Student-based social-emotional learning (SEL) programs have been implemented in most K-12 schools (Yettick, 2018), and, recently, programs that target the emotional 
health of teachers have emerged (Jennings et al., 2011; Schonert-Reichl, 2017); however, the needs of educational leaders, such as $\mathrm{K}-12$ principals, have been largely ignored, despite the extreme pressure and chronic stress they often endure (Sanchez et al., 2019; Wallace Foundation, 2016).

This study sought to understand the degree to which the preparation and professional development opportunities available to $\mathrm{K}-12$ principals in Oregon have included emotional intelligence; how the inclusion of emotional intelligence relates to the success of such programs in supporting the needs of practicing principals; and the ways in which the individual characteristics of the principals, and the contexts in which they lead, may influence their need for the development of emotional intelligence. The main purpose of this research was to understand how training in emotional intelligence and resonant leadership practices can be used to develop protective resources that may help principals manage the many stressors they face, especially in light of the challenges they have been experiencing recently due to the Covid-19 pandemic and a heightened social and political environment.

\section{Summary of Key Findings}

No one was prepared for Covid-19; however, there were some support structures in place in the state of Oregon that help principals use emotional intelligence and resonant leadership practices to manage their own and others' emotional needs during crises, such as the pandemic. This section explores how the preparation and professional development opportunities available to $\mathrm{K}-12$ principals in Oregon helped support their 
needs for development of emotional intelligence skills. I discuss the key findings discovered in the data addressing the research questions that were posed in the study.

RQ1: How do the perceptions of K-12 principals in Oregon regarding their needs for the development of emotional intelligence skills vary based on their individual characteristics and the contexts in which they lead?

The survey data indicate that principals in Oregon need training in all of the emotional intelligence skills that were explored to respond to the challenges and uncertainties of their positions. When asked for specific examples regarding the types of training that principals felt could have helped them prepare better for managing the emotions and stress caused by the political unrest and social changes they experienced during the 2020-2021 pandemic, most participants mentioned training that included selfawareness skills that would allow them to recognize their own strengths, weaknesses, and needs; self-management skills that would allow them to use strategies to stay calm, flexible, and patient while managing constant change and stress; social awareness skills that would allow them to recognize the needs of others, including those who have been affected by trauma and those who are suffering from mental health issues; and relationship management skills that would allow them to manage change effectively, build trust, and empower others. These observations are supported by previous research that indicates that emotional intelligence is a necessary component of exceptional leadership (Boyatzis \& McKee, 2005; Bradberry \& Greaves, 2012; Goleman, 1997; Goleman \& Boyatzis, 2008; Goleman et al., 2001, 2013). 
Although the ordinal logistic regressions used to analyze the survey data indicated that the need for the development of emotional intelligence skills did not vary in a statistically significant way based on most of the individual characteristics and contexts in which the principals led, there were several trends observed in the data. First, there appeared to be a relationship between gender and perceptions of need for emotional intelligence training. When male perceptions of need and female perceptions of need were compared, female perceptions of need were $7.0-33.4 \%$ higher in all of the emotional intelligence clusters and skills that were explored, with the most remarkable differences seen in managing one's emotional responses to Covid-19, managing the effects of Covid-19 on others, understanding how emotions affect others, recognizing the unstated feelings and emotions of others, and recognizing the collective mood in a room.

Furthermore, I found through ordinal logistic regression analysis that females were statistically significantly more likely than males to express need for social awareness skills that allow them to recognize the unstated feelings and emotions of others and that females may have been more likely than males to express a need for skills that allow them to recognize the collective mood in a room (results were approaching statistical significance). While there were other results that were approaching statistical significance, the results of the ordinal logistic regression were uncertain for those skill areas (understanding political forces, understanding how others influence one's emotions, and encouraging trust) because the final model did not predict those skill areas at a greater rate than the intercept-only model. 
There could be several reasons for the differences noted between female and male principals. It is possible that the male principals were more confident in their emotional intelligence skills than female principals and, therefore, saw less need for training. It is also possible that male principals saw less value in developing emotional intelligence skills. Current research on the relationship between gender and emotional intelligence is unclear, with some researchers finding that emotional intelligence is influenced by gender (Martínez-Marín et al., 2021) and other researchers finding that it is not (Meshkat \& Nejati, 2017). However, this research examined perceptions of need for emotional intelligence training, which does not appear to have been addressed by previous research, presenting an interesting avenue for future research.

There were no other statistically significant differences in the individual characteristics and contexts of the principals; however, there were several other trends that appeared in the data. In general, younger principals report higher perceptions of need for training than older principals, principals of color report higher perceptions of need for training than White/Caucasian principals, elementary principals report higher perceptions of need than middle/junior-high and high-school principals, and principals working at schools with low levels of student need report lower levels of need for training than principals working at average-need and high-need schools. These differences in perceptions of need indicate that individual characteristics and contexts likely do influence a principal's perceptions of need for emotional intelligence training to some extent, and that the training offered to principals may need to be tailored to meet their specific needs. 
It would be difficult to individualize the training offered by preparation programs; however, it may be possible to tailor professional development programs to the needs of specific populations of principals or the contexts of the schools in which they work, and this is already being done to some extent (e.g. COSA's New Principal Academy). Furthermore, many principals already select the professional development activities they attend based on their individual needs; however, principals may not be aware of all of the available options, and they may not be able to find options to meet their needs.

Regardless, it is clear from the results of this study that Oregon principals see the need for training in all four of the emotional intelligence clusters (Goleman et al., 2001, 2013), yet preparation and professional development programs for school leaders rarely incorporate all four emotional intelligence clusters, as demonstrated by this, and previous, research (Sanchez et al., 2019).

\section{RQ2: How do K-12 principals in Oregon perceive that their preparation and professional development programs have supported the development of emotional intelligence skills?}

Nearly all participants who reported attending professional development that included emotional intelligence training reported higher rates of helpfulness for their professional development programs than they reported for their preparation programs. The interviews showed similar trends. Most participants indicated that their preparation programs did not support the development of emotional intelligence skills that would have prepared them to manage widespread political and social changes, build resilience to stress and burnout, or manage the emotional needs of others in response to stressful 
situations; whereas most participants indicated that the professional development programs and activities that they had participated in did, in fact, help them develop emotional intelligence skills that were helpful in these areas.

The participants had taken part in a wide variety of preparation and professional development programs and activities. Participants reported having the opportunity to attend up to 20 professional development programs and activities per year, and $60 \%$ of the participants had attended both a preliminary and professional administrator licensure program. Participants reported that their preparation programs lacked most of the emotional intelligence skills that were explored in this research but included some emotional skills, such as adapting to change, managing change effectively, managing conflict effectively, and encouraging trust and collaboration. When participants reported that their preparation programs included training on emotional intelligence, most also reported finding that training helpful in all of the skills that were explored, with the exceptions of managing one's own emotional responses to Covid-19 and managing the effects of Covid-19 on others. It is likely that participants reported that the Covid-19related training was unhelpful because Covid-19 presents a wicked problem (Cavins, 2021) that is impossible to prepare for, given its unprecedented and incredibly complex nature.

In most cases, the professional development programs that participants attended included more emotional intelligence skills than the preparation programs they had attended. However, by and large, the professional development programs and activities understandably did not include the two Covid-19 related skills, nor did they include any 
social awareness skills, and very few self-awareness skills. Although lack of access to professional development with an explicit focus on social awareness and self-awareness skills may have been a problem, this does not indicate that programs that target the development of self-awareness and social awareness do not exist. There may be programs available that participants chose not to attend or programs of which the participants were unaware.

The fact that most participants attended training that focused on self-management and relationship management rather than self-awareness and social awareness may reflect an important missing link in emotional intelligence skills. Self-awareness and social awareness are foundational skills that aid in the development of the self-management and relationship management skills (Bradberry \& Greaves, 2012; Goleman et al., 2001, 2013). It is difficult to prevent one's emotions from affecting others if one does not understand how one's emotions affect others, just as it is difficult to support the emotional needs of others without the ability to recognize unstated feelings and emotions. However, it is possible, for example, that some participants may have received training that helped them develop specific relationship management skills, such as encouraging trust and collaboration without understanding how their own and others' emotions factor into the process of building trust. 
RQ3: How do K-12 principals in Oregon perceive their preparation and professional development programs to have prepared them to manage the stress and emotions caused by Covid-19 and other challenges?

In general, principals indicated that their preparation and professional development programs did not adequately prepare them to manage the stress and emotions of their positions during the pandemic; however, there were aspects of the programs that helped them in many ways. Their preparation programs were especially helpful in teaching some participants to adapt to change, to manage change effectively, to encourage trust and collaboration in their organizations, to manage conflict effectively, and to understand the political forces at work, while their professional development programs were especially helpful in teaching some participants to understand how they react to emotions, to manage and cope with stress, and to support the emotional needs of others. Yet, most of the participants reported having received no training in most of the emotional intelligence skills, while seeing a need for training in all of them.

Furthermore, the interviews revealed that stress levels were extreme during the 2020-2021 school year and principals were not adequately prepared to manage the stress and emotions they encountered. One participant stated, "during this time of so much stress and so much uncertainty, I think that for a lot of administrators, there hasn't felt like there is room to breathe." Another stated "the building feels like it's constantly on fire to me." Additionally, several principals mentioned considering leaving their position as a principal and returning to the classroom, resigning, or retiring early. Interestingly, 
self-care was mentioned by close to $60 \%$ of the principals as an area of need to help them manage the stress and burnout many of them were experiencing.

RQ4: How do the principal preparation and professional development themes exposed in the principal interviews and document review process explain the results from the initial quantitative phase of the study?

The strength of the mixed method study design lies in its ability to develop a deep understanding of the issues explored. In the context of this research, the surveys conducted during Phase 1 gathered the general perspectives of principals in Oregon regarding the need for training in 15 emotional intelligence skills, how these skills have been included in principal preparation and professional development programs, and how the individual characteristics and contexts of the principals may have affected their perceived needs. This information provided a framework with which to understand the general needs of principals in Oregon, but very few details regarding the pressures that principals were facing and the programs and activities that were most helpful to them. The principal interviews and document review process allowed me to dig deeper to better understand the needs of principals and the contexts in which they were working, to situate the importance of emotional intelligence training in the larger socio-political context of the 2020-2021 Covid-19 pandemic, to expose specific programs that have been available in Oregon, many of which were not identified during the literature review process, and to understand which aspects of the programs and activities were most helpful to the participants. 


\section{Implications}

Although Covid-19 is a wicked problem that cannot be easily solved, it has provided educational leaders and policy makers with a unique opportunity to look at what has been most helpful to administrators in this heightened context. Research suggests that the development of emotional intelligence and resonant leadership practices fosters protective factors that can help principals manage the many stressors they face (Bakker \& Demerouti, 2014, 2017; Boyatzis \& McKee, 2005; Goleman et al., 2001). As Goleman et al. (2001) explain, resonance is especially important in the face of chaos and turbulence because resonant leaders can

mov[e] people — powerfully, passionately, and purposefully... while managing the inevitable sacrifices inherent in their roles. They give of themselves in the service of the cause, but they also care for themselves, engaging in renewal to ensure they can sustain resonance over time. (Boyatzis \& McKee, 2005, p. 2)

Principals reported untenable amounts of stress both before and during the pandemic. Boyatzis and McKee (2005) explain that when leaders sacrifice too much for too long, they become dissonant and they burn out; therefore, they explain, it is essential for leaders to engage in regular renewal by practicing mindfulness, hope, and compassion. Likewise, Bakker and Demerouti's (2014, 2017) JD-R theory explains that burnout is most likely to occur when job resources are low and job demands are high. Job resources, or protective occupational factors, however, can be used to buffer the negative effects of destructive occupational factors, thereby decreasing stress and increasing job 
satisfaction. Emotional intelligence is a job resource that can be used to improve the ability of principals to cope with and bounce back from stress and burnout.

Overall, principals indicated that the need they see for emotional intelligence training is not being fully addressed by the principal preparation and professional development programs offered in Oregon. When principals had the chance to attend training that supported the development of emotional intelligence skills, they found it helpful, and there were several aspects of some of the programs they attended that helped support their needs during the pandemic. The literature review, interviews, and document review process, however, only found one program that includes all four clusters of emotional intelligence, as well as an emphasis on resonant leadership practices: RULER, which is only used by a handful of school districts post-licensure. Therefore, it is evident that training in emotional intelligence and resonant leadership practices needs to be integrated more consistently in principal preparation programs and made more readily available after licensure. Furthermore, more comprehensive programs that include all four emotional intelligence clusters within a framework of resonant leadership need to be developed and validated by research.

\section{Recommendations for Future Research}

First, I recommend exploring which professional development programs and activities are most effective at reducing stress and burnout in $\mathrm{K}-12$ principals, as there is a continued and growing need at all levels of the $\mathrm{K}-12$ system. Additionally, this research illuminated some trends that should be explored further with larger sample sizes that have the potential to yield more statistically significant results. I recommend exploring if and 
why (a) female principals have higher perceptions of need for training in emotional intelligence than male principals; (b) younger principals have higher perceptions of need than older principals for training in emotional intelligence skills; (c) principals of color have higher perceptions of need than White/Caucasian principals for training in emotional intelligence skills; (d) elementary principals have higher perceptions of need for training in emotional intelligence skills than principals at middle/junior high and high schools; and (e) principals at low-need schools have lower perceptions of need than principals at average-need and high-need schools.

\section{Recommendations for Training}

Prior to this research, it was not clear how principal preparation and professional development programs designed for educational leaders in Oregon, such as $\mathrm{K}-12$ principals, were providing opportunities for the development of emotional intelligence. Nor was it clear which dimensions of emotional intelligence needed to be included in preparation and professional development activities to adequately support principals. The data collected in this study indicate that there are preparation and professional development programs that have been providing training designed to improve the emotional intelligence of principals in Oregon; however, the training that has been available has not consistently targeted all of the emotional intelligence skills required by principals in sufficient depth to meet their needs, nor has the effectiveness of all training programs been determined.

Therefore, I recommend that individuals responsible for the design of principal preparation programs ensure that training in all the dimensions of emotional intelligence 
is integrated into their preparation programs, with an emphasis on including techniques for managing stress, maintaining resonance, and understanding trauma. Additionally, as supported by previous research, I recommend that university decision makers form strong partnerships with school districts (Campanotta et al., 2018; Sanchez et al., 2019; Sutcher et al., 2017; Wallace Foundation, 2016); align principal preparation with the daily work of principals (Wallace Foundation, 2016); use cohort models, mentorship programs, and other methods that include opportunities for principals to discuss their experiences and build professional learning communities (Campanotta et al., 2018; Goode, 2019; Hipp \& Weber, 2008; Sutcher et al., 2017); and include opportunities for experiential learning through role play and clinical experiences (Campanotta et al., 2018; Goode, 2019; Sutcher et al., 2017; Wallace Foundation, 2016).

My recommendations for professional development are similar to those for preparation programs. Although the professional development programs that principals mentioned attending included training in more emotional intelligence skills than their preparation programs, principals indicated that they received little training in most skills, and the training they did receive did not adequately prepare them to manage the stress and emotions of their positions. Therefore, I recommend that decision makers ensure that training in all the dimensions of emotional intelligence is made available, especially training that includes techniques for managing stress and maintaining resonance. Additionally, I recommend using a comprehensive framework, such as the RAND Corporation's professional learning logic model, to design professional development opportunities that align program content and structure with both the needs of individual 
principals — depending on experience level and the context in which they lead—and evidence-based practices. Lastly, it also may be beneficial to include more comprehensive emergency action disaster preparedness training in preparation programs and district-level professional development trainings to prepare for the challenges of traumatic events, such as the Covid-19 pandemic and the wildfires experienced in Oregon during the 2020-2021 school year.

These recommendations have the potential to benefit the $\mathrm{K}-12$ educational system at multiple levels and inform a variety of decision makers, including district-level policy makers; individuals, organizations, and post-secondary institutions involved in the preparation and professional development of principals; researchers interested in the topics of emotional intelligence, leadership, stress, and burnout in $\mathrm{K}-12$ education; as well as $\mathrm{K}-12$ administrators, teachers, students, and communities interested in improving school climate, decreasing turnover, and increasing student achievement.

\section{Summary}

The main purpose of this research was to understand how training in emotional intelligence and resonant leadership practices can be used to develop protective occupational factors that can help principals manage the many stressors they face. Exploring this topic in the context of the challenges and uncertainties $\mathrm{K}-12$ principals have been experiencing recently because of the unprecedented Covid-19 pandemic and a heightened social and political environment provided an opportunity to identify the level to which emotional intelligence skills training has been helpful to principals during the pandemic. Although the pandemic has created unusual demands on leadership, 
understanding the prevalence and perceived effectiveness of emotional intelligence training during a time of extreme stress can, potentially, inform priorities around preparing and developing principals for the high levels of stress they regularly experience, as well as future stress they may experience in periods of heightened social and political tensions. Reducing burnout and turnover in principals will likely help cultivate a positive school climate, improve teacher outcomes, and support the school improvement efforts that will eventually improve student outcomes. I hope the recommendations provided here will catalyze movement toward a stronger focus on the development of emotional intelligence skills through the preparation and professional development opportunities available to $\mathrm{K}-12$ principals in Oregon. 


\section{References}

Abrams, J. (2009). Having hard conversations. Corwin Press. https://us.corwin.com/enus/nam/book/having-hard-conversations\#description

Allred, A., Labat, M. B., Eadens, D., Labat, C. A., \& Eadens, D. M. (2016). The impact of principal emotional intelligence on teacher perceptions of school climate. International Research in Higher Education, 1(2), 127-132. http://dx.doi.org/10.5430/irhe.v1n2p127

Anthony $\square$ McMann, P. E., Ellinger, A. D., Astakhova, M., \& Halbesleben, J. R. (2017). Exploring different operationalizations of employee engagement and their relationships with workplace stress and burnout. Human Resource Development Quarterly, 28(2), 163-195. doi: 10.1002/hrdq.21276

Antonakis, J., \& Dietz, J. (2010). Emotional intelligence: On definitions, neuroscience, and marshmallows. Industrial and Organizational Psychology, 3, 165-170. https://doi. org/10.1111/j.1754-9434.2010.01219.

Arbinger Institute. (n.d.). About Arbinger: How we started. Retrieved from https:// arbinger.com/about.html

Arbinger Institute. (2016). The outward mindset: Seeing beyond ourselves. BerrettKoehler Publishers.

Asma, S. T., \& Gabriel, R. (2019). The emotional mind: The affective roots of culture and cognition. Harvard University Press.

Bakker, A. B., \& Demerouti, E. (2014). Job demands-resources theory. In P. Y. Chen \& C. L. Cooper (Eds.) Wellbeing: A complete reference guide, Volume III (pp. 1-28). 
John Wiley \& Sons. https://www.isonderhouden.nl/doc/pdf/arnoldbakker/articles/ articles_arnold_bakker_344.pdf

Bakker, A. B., \& Demerouti, E. (2017). Job demands-resources theory: taking stock and looking forward. Journal of Occupational Health Psychology, 22(3), 273. http://dx.doi.org/10.1037/ocp0000056

Barnum, T. C., \& Solomon, S. J. (2019). Fight or flight: Integral emotions and violent intentions. Criminology, 57(4), 659-686. https://doi.org/10.1111/17459125.12222

Bar-On, R. (2004). The Bar-On Emotional Quotient Inventory (EQ-i): Rationale, description and summary of psychometric properties. In G. Geher (Ed.), Measuring emotional intelligence: Common ground and controversy (pp. 115145). Nova Science Publishers.

Bar-On, R. (2006). The Bar-On model of emotional-social intelligence (ESI) 1. Psicothema, 18, 13-25. https://reunido.uniovi.es/index.php/PST/article/ view/8415/8279

Bartanen, B., Grissom, J. A., \& Rogers, L. K. (2019). The impacts of principal turnover. Educational Evaluation and Policy Analysis, 41(3), 350-374. https://doi.org/ $10.3102 \% 2 \mathrm{~F} 0162373719855044$

Bartlett, J. E., Kotrlik, J. W., \& Higgins, C. C. (2001). Organizational research: Determining appropriate sample size in survey research. Information Technology, Learning, and Performance Journal, 19(1), 43-50. https://3f89bfc0-a-62cb3alaS- 
sites.googlegroups.com/site/stats4us/docs/samplesizeinsurveyresearch.pdf?attacha uth=ANoY7cqlsyNsIvumeUwxVBRqy6oGm-92QhL7lqjpesT8GLgZyjIhqI4b0D30UQJwrgADVSyjMOXas_F0UIk0nFt3UC5kwVTU2rnofQTkK1xYH7OessRTTNBRdqTXEiT9d4n2szUS4QSnObOfNZwNzYHAgIfb3j gbaK7dIQdkBj4qW5_4CGAhrESmxChtjhcmqmmVWBIHBvms7Bt4TpUybdwP pE-oXtiSVxkWm_FW05QL6gHltduU\%3D\&attredirects $=0$

Bassal, C., Czellar, J., Kaiser, S., \& Dan-Glauser, E. S. (2016). Relationship between emotions, emotion regulation, and well-being of professional caregivers of people with dementia. Research on Aging, 38(4), 477-503. doi:10.1177/01640275155 91629

Baxter, P., \& Jack, S. (2008). Qualitative case study methodology: Study design and implementation for novice researchers. The qualitative report, 13(4), 544-559. http://www.nova.edu/ssss/QR/QR13-4/baxter.pdf

Behera, A. P., \& Pani, P. (2014). Career and emotional self-awareness: Micro initiatives for macro impact. Indian Journal of Positive Psychology, 5(2), 213. http://cupdx. idm.oclc.org/login?url=https://search-proquest-com.cupdx.idm.oclc.org /docview/1614028181?accountid=10248

Bierman, K. L., Coie, J. D., Dodge, K. A., Greenberg, M. T., Lochman, J. E., McMahon, R. J., \& Pinderhughes, E. (2010). The effects of a multiyear universal socialemotional learning program: The role of student and school characteristics. Journal of Consulting and Clinical Psychology, 78(2), 156-168. doi:10.1037/ a0018607 
Blaik Hourani, R., Litz, D., \& Parkman, S. (2020). Emotional intelligence and school leaders: Evidence from Abu Dhabi. Educational Management Administration \& Leadership, 1-25. https://doi.org/10.1177\%2F1741143220913552

Bottiani, J. H., Duran, C. A., Pas, E. T., \& Bradshaw, C. P. (2019). Teacher stress and burnout in urban middle schools: Associations with job demands, resources, and effective classroom practices. Journal of School Psychology, 77, 36-51. https://doi.org/10.1016/j.jsp.2019.10.002

Boyatzis, R. E. (2009). Competencies as a behavioral approach to emotional intelligence. The Journal of Management Development, 28(9), 749-770. https://doi.org/10.1108/02621710910987647

Boyatzis, R. E. (2018). The behavioral level of emotional intelligence and its measurement. Frontiers in Psychology, 9, 1438-1438. https://doi.org/ 10.3389/fpsyg.2018.01438

Boyatzis, R. E., \& McKee, A. (2005). Resonant leadership. Harvard Business Press. Boyum, G. (2008). The Historical and Philosophical Influences on Greenleaf's Concept of Servant Leadership: Setting the Stage for Theory Building. Online Submission.

Bradberry, T., \& Greaves, J. (2009). Emotional Intelligence 2.0. TalentSmart.

Bradberry, T., \& Greaves, J. (2012). Leadership 2.0. TalentSmart.

Campanotta, L., Simpson, P., \& Newton, J. (2018). Program quality in leadership preparation programs: An assessment tool. Education, 138(3), 219-228. 
Carterart. (n.d.). Vector tripod with cameras collection [Clip art]. Vecteezy. https://www.vecteezy.com/vector-art/151554-vector-tripod-with-camerascollection

Castillo, Y., \& Fischer, J. M. (2017). Expressive writing: Enhancing the emotional intelligence of Human Services majors. College Student Journal, 51(2), 183-192.

Cavins, B. (2021). Uncertain times: Emotional-Social Intelligence and relational leadership practices: A conceptual framework. Visions in Leisure and Business, 22(2), 11-31. https://doi.org/10.25035/visions.22.02.04

Chadi, A., Jeworrek, S., \& Mertins, V. (2017). When the meaning of work has disappeared: experimental evidence on employees' performance and emotions. Management Science, 63(6), 1696-1707.

Chalk Board Project. (n.d.). Rural education in Oregon: Overcoming the challenges of income and distance. https://chalkboardproject.org/sites/default/files/Rural\%20 Education\%20Report\%20FINAL_0.pdf

Chaseling, M., Paredes, J. A., \& Boyd, W. E. (2020). Schooling in a time of disruption: the impact of Covid-19 from the perspective of five New South Wales (Australia) secondary principals. Education in the North, 27(2), 152-174. https://doi.org/10.26203/xt08-dx83

Chen, J., \& Guo, W. (2020). Emotional intelligence can make a difference: The impact of principals' emotional intelligence on teaching strategy mediated by instructional leadership. Educational Management Administration \& Leadership, 48(1), 82105. https://doi.org/10.1177\%2F1741143218781066 
Chesak, S. S., Khalsa, T. K., Bhagra, A., Jenkins, S. M., Bauer, B. A., \& Sood, A. (2019). Stress management and resiliency training for public school teachers and staff: a novel intervention to enhance resilience and positively impact student interactions. Complementary Therapies in Clinical Practice, 37, 32-38. https://doi.org/10.1016/j.ctcp.2019.08.001

Cho, M., Bonn, M. A., Han, S. J., \& Lee, K. H. (2016). Workplace incivility and its effect upon restaurant frontline service employee emotions and service performance. International Journal of Contemporary Hospitality Management, 28(12), 28882912. doi: 10.1108/IJCHM-04-2015-0205

Christian-Brandt, A. S., Santacrose, D. E., \& Barnett, M. L. (2020). In the traumainformed care trenches: Teacher compassion satisfaction, secondary traumatic stress, burnout, and intent to leave education within underserved elementary schools. Child Abuse \& Neglect, 110(3), 1-8. https://doi.org/10.1016/ j.chiabu.2020.104437

Clarke, N. (2010). Developing emotional intelligence abilities through team-based learning. Human Resource Development Quarterly, 21(2), 119-138. https://doiorg.cupdx.idm. oclc.org/10.1002/hrdq.20036

Collaborative for Academic, Social, and Emotional Learning. (2005). Safe and sound: An educational leader's guide to evidence-based social and emotional learning programs. Author. 
Collie, R. J. (2021). Covid-19 and teachers' somatic burden, stress, and emotional exhaustion: Examining the roles of principal leadership and workplace buoyancy. AERA Open, 7(1), 1-15. doi:https://doi.org/10.1177/2332858420986187

Comer, J. P. (2020). Commentary: Relationships, developmental contexts, and the school development program. Applied Developmental Science, 24(1), 43-47. https://doi. org/10.1080/10888691.2018.1515296

Côté, S., DeCelles, K. A., McCarthy, J. M., Van Kleef, G. A., \& Hideg, I. (2011). The Jekyll and Hyde of emotional intelligence: Emotion-regulation knowledge facilitates both prosocial and interpersonally deviant behavior. Psychological Science, 22(8), 1073-1080. doi: 10.1177/0956797611416251

Crain, T. L., Schonert-Reichl, K. A., \& Roeser, R. W. (2017). Cultivating teacher mindfulness: Effects of a randomized controlled trial on work, home, and sleep outcomes. Journal of occupational health psychology, 22(2), 138.

https://psycnet.apa.org/doi/10.1037/ocp0000043

CREATE for Education. (2021a). CARE for teachers. https://createforeducation.org/care/ care-program/

CREATE for Education. (2021b). Mission. https://createforeducation.org/about-us/whywe-exist/

CREATE for Education. (2021c). Research findings on CARE. https://createforeducation. org/care/care-research/

Creswell, J. W., \& Creswell, J. D. (2018). Research design: Qualitative, quantitative, and mixed methods approaches ( $5^{\text {th }}$ ed.). Sage. 
Creswell, J. W., \& Plano Clark, V. L. (2018). Designing and conducting mixed methods research ( $3^{\text {rd }}$ ed.). Sage.

Creswell, J. W., \& Poth, C. N. (2018). Qualitative inquiry \& research design: Choosing among five approaches ( $4^{\text {th }}$ ed.). Sage.

Crippen, C. (2010). Greenleaf's servant-leadership and Quakerism: A nexus. The International Journal of Servant-Leadership, 6(1), 199-211.

Crisis Prevention Institute. (2020, October 15). CPI's top 10 de-escalation tips. https://www.crisisprevention.com/Blog/CPI-s-Top-10-De-Escalation-TipsRevisited

Dadehbeigi, M., \& Shirmohammadi, M. (2010). Training employees of a public Iranian bank on emotional intelligence competencies. Journal of European Industrial Training, 34(3), 211-225. https://doi-org.cupdx.idm.oclc.org/10.1108/ 03090591011031728

Daugherty, L., Herman, R., \& Unlu, F. (2017). Logic models for selecting, designing, and implementing evidence-based school leadership interventions. Companion guide to" School leadership interventions under the every student succeeds act." Tool (Research Report No. TL-274-WF). RAND Corporation. https://doi.org/10. 7249/TL274

Doe, R., Ndinguri, E., \& Phipps, S. T. (2015). Emotional intelligence: The link to success and failure of leadership. Academy of Educational Leadership Journal, 19(3), 105. 
Dolev, N., \& Leshem, S. (2017). Developing emotional intelligence competence among teachers. Teacher Development, 21(1), 21-39. doi:10.1080/13664530.2016. 1207093

Doyle, S. L., Jennings, P. A., Brown, J. L., Rasheed, D., DeWeese, A., Frank, J. L., Turksma, C., \& Greenberg, M. T. (2018). Exploring relationships between CARE program fidelity, quality, participant responsiveness, and uptake of mindful practices. Mindfulness, 10(5), 841-853. https://doi.org/10.1007/s12671-018-10349

Drouvelis, M., \& Grosskopf, B. (2016). The effects of induced emotions on pro-social behaviour. Journal of Public Economics, 134, 1-8. https://doi.org/10.1016/ j.jpubeco.2015.12.012

Durlak, J. A., Domitrovich, C. E., Weissberg, R. P., \& Gullotta, T. P. (Eds.). (2015). Handbook of social and emotional learning: Research and Practice. Guilford.

Durlak, J. A., Weissberg, R. P., Dymnicki, A. B., Taylor, R. D., \& Schellinger, K. (2011). The impact of enhancing students' social and emotional learning: A meta-analysis of school-based universal interventions, Child Development, 82(1), 405-432. https://doi.org/10.1111/j.1467-8624.2010.01564.x

Eddy, C. L., Herman, K. C., \& Reinke, W. M. (2019). Single-item teacher stress and coping measures: Concurrent and predictive validity and sensitivity to change. Journal of School Psychology, 76, 17-32. https://doi.org/10.1016/j.jsp.2019. 05.001 
Educator Advancement Council. (2019, July). 2019 Oregon educator equity report. Chief Education Office. https://www.oregon.gov/eac/Documents/57178_CEdO_Ed\% 20Equality\%20Data_2019-Executive\%20Summary-web.pdf

Effrem, K., \& Robbins, J. (2019). Social-emotional learning: K-12 education as new age nanny state [White Paper No. 192]. Pioneer Institute for Public Policy Research. https://files.eric.ed.gov/fulltext/ED593789.pdf

Eklund, K., Kilpatrick, K. D., Kilgus, S. P., \& Haider, A. (2018). Children, research, and public policy: A systematic review of state-level social-emotional learning standards: Implications for practice and research. School Psychology Review, 47(3), 316-326. doi: 10.17105/SPR-2017.0116.V47-3

Elbertson, N. A., Brackett, M. A., \& Weissberg, R. P. (2010). School-based Social and Emotional Learning (SEL) programming: Current perspectives. In A. Hargreaves, A. Lieberman, M. Fullan, \& D. Hopkins (Eds.), Second international handbook of educational change (pp. 1017-1032). Springer. https://www. researchgate.net/ profile/Marc_Brackett/publication/226611736_School-Based_Social_and_ Emotional_Learning_SEL_Programming_Current_Perspectives/links/0fcfd510c3 ae3b4eac000000.pdf

Elias, M. J., Zins, J. E., Weissberg, R. P., Frey, K. S., Greenberg, M. T., Haynes, N. M., Kessler, R., Schwab-Stone, M. E., \& Shriver, T. P. (1997). Promoting social and emotional learning: Guidelines for educators. Association for Supervision and Curriculum Development. https://earlylearningfocus.org/wpcontent/uploads/2019/12/promoting-social-and-emotional-learning-1.pdf 
Embregts, P. J. C. M., Zijlmans, L. J. M., Gerits, L., \& Bosman, A. M. T. (2019).

Evaluating a staff training program on the interaction between staff and people with intellectual disability and challenging behaviour: An observational study. Journal of Intellectual \& Developmental Disability, 44(2), 131-138. doi:10.3109/13668250.2017.1350839

Enachescu, J., Olsen, J., Kogler, C., Zeelenberg, M., Breugelmans, S. M., \& Kirchler, E. (2019). The role of emotions in tax compliance behavior: A mixed methods approach. Journal of Economic Psychology, 74(2019), 1-16. https://doi.org/10. 1016/j.joep.2019.102194

Espelage, D. L., Rose, C. A., \& Polanin, J. R. (2015). Social-emotional learning program to reduce bullying, fighting, and victimization among middle school students with disabilities. Remedial and Special Education, 36(5), 299-311. doi: $10.1177 / 0741932514564564$

Extremera, N. (2020). Coping with the stress caused by the Covid-19 pandemic: Future research agenda based on emotional intelligence [Afrontando el estrés causado por la pandemia Covid-19: futura agenda de investigación desde la inteligencia emocional]. International Journal of Social Psychology, 35(3), 631-638. doi: $10.1080 / 02134748.2020 .1783857$

Farnia, F., \& Nafukho, F. M. (2016). Emotional intelligence research within human resource development scholarship. European Journal of Training and Development, 40(2), 90-110. https://doi.org/10.1108/EJTD-11-2014-0073 
Fernandez, A. A., \& Shaw, G. P. (2020). Academic leadership in a time of crisis: The coronavirus and Covid-19. Journal of Leadership Studies, 14(1), 39-45. doi: $10.1002 / \mathrm{j} 1 \mathrm{~s} .21684$

Fernández-Gámez, M. Á., Rosales-Pérez, A., Molina-Gómez, J., \& Mora-Lucena, L. (2018). The effects of outdoor training on the development of emotional intelligence among undergraduate tourism students. Journal of Hospitality, Leisure, Sport \& Tourism Education (Elsevier Science), 23, 39-49. https://doiorg.cupdx.idm.oclc.org/10.1016/j.jhlste.2018.06.001

Fletcher, R. B., \& Hattie, J. (2011). Intelligence and intelligence testing. Taylor \& Francis.

Fochmann, M., Hechtner, F., Kirchler, E., \& Mohr, P. (2019). When happy people make society unhappy: Incidental emotions affect compliance behavior (Discussion Paper No. 237). Arbeitskreis Quantitative Steuerlehre. https://dx.doi.org/10.2139/ $\operatorname{ssrn} .3259071$

Føllesdal, H., \& Hagtvet, K. (2013). Does emotional intelligence as ability predict transformational leadership? A multilevel approach. The Leadership Quarterly, 24(5), 747-762. https://doi.org/10.1016/j.leaqua.2013.07.004

Ford, T. G., Olsen, J., Khojasteh, J., Ware, J., \& Urick, A. (2019). The effects of leader support for teacher psychological needs on teacher burnout, commitment, and intent to leave. Journal of Educational Administration, 57(6), 615-634. doi: 10.1108/JEA-09-2018-0185 
Fredrickson, B. L. (2004). The broaden-and-build theory of positive emotions.

Philosophical Transactions of the Royal Society of London. Series B: Biological Sciences, 359(1449), 1367-1377. https://www.jstor.org/stable/4142140

Fullan, M. (2011). Change leader: Learning to do what matters most. Jossey-Bass.

Fullan, M., \& Scott, G. (2009). Turnaround leadership for higher education. John Wiley \& Sons.

Fusch, P. I., \& Ness, L. R. (2015). Are we there yet? Data saturation in qualitative research. The Qualitative Report, 20(9), 1408-1416. http://www.nova.edu/ssss/ QR/QR20/9/fusch1.pdf

Futures Without Violence. (2021). Help FUTURES support advocates, survivors and their families in 2021. https://www.futureswithoutviolence.org/

Gardner, H. (1983). Frames of mind: the theory of multiple intelligences. Basic Books.

George, J. M., \& Dane, E. (2016). Affect, emotion, and decision making. Organizational Behavior and Human Decision Processes, 136(1), 47-55. doi: 10.1016/j.obhdp. 2016.06.044

Gignac, G. (2010). Seven-factor model of emotional intelligence as measured by Genos EI: A confirmatory factor analytic investigation based on self- and rater-report data. European Journal of Psychological Assessment: Official Organ of the European Association of Psychological Assessment, 26(4), 309-316. https://doi.org/10.1027/1015-5759/a000041

Gilar-Corbi, R., Pozo-Rico, T., \& Castejón-Costa, J. L. (2019). Desarrollando la inteligencia emocional en educación superior: evaluación de la efectividad de un 
programa en tres países. (Spanish). Educación XX1, 22(1), 161-187.

doi:10.5944/educ XX1.19880

Gloria, C. T., \& Steinhardt, M. A. (2016). Relationships among positive emotions, coping, resilience and mental health. Stress and Health, 32(2), 145-156. https://doi.org/10.1002/smi.2589

Goals 2000: Educate America Act, H. R. 1804, $103^{\text {rd }}$ Cong. (1994). https://www2.ed.gov/ legislation/GOALS2000/TheAct/index.html\#: :text=To\%20improve\%20learning $\% 20$ and $\% 20$ teaching,framework $\% 20$ for $\% 20$ reauthorization $\% 20 \mathrm{of} \% 20$ all

Goleman, D. (1997). Emotional intelligence: Why it can matter more than IQ. Bantam Books.

Goleman, D., \& Boyatzis, R. (2008). Social intelligence and the biology of leadership. Harvard Business Review, 86(9), 74-81. http://files-au.clickdimensions.com/ aisnsweduau-akudz/files/inteligencia-social-y-biologia-de-un-lider.pdf

Goleman, D., Boyatzis, R., \& McKee, A. (2001). Primal leadership: The hidden driver of great performance. Harvard business review, 79(11), 42-53.

Goleman, D., Boyatzis, R., \& McKee, A. (2013). Primal leadership. Harvard Business School Publishing.

Goode, J. L. (2019). Leading for social justice: professional development experiences of K-8 urban principals [Doctoral dissertation, Rutgers University]. Rutgers University Community Repository. https://doi.org/doi:10.7282/t3-nr5x-yw63

Gottfredson, L. S. (1997). Mainstream science on intelligence: An editorial with 52 signatories, history, and bibliography. Intelligence, 24, 13-23. 
Grant, S., Hamilton, L. S., Wrabel, S. L., Gomez, C. J., Whitaker, A., Leschitz, J. T., Unlu, F., Chavez-Herrerias, E. R., Baker, G., Barret, M., Harris, M., \& Ramos, A. (2017). Social and emotional learning interventions under the Every Student Succeeds Act: Evidence review (Report No. RR-2133-WF). RAND Corporation. https://www.shorelineschools.org/cms/lib/WA02217114/Centricity/ Domain/1917/RAND_RR2133z1.summaries.pdf

Grissom, J. A., \& Bartanen, B. (2019). Principal effectiveness and principal turnover. Education Finance and Policy, 14(3), 355-382. https://doi.org/10.1162/ edfp_a_00256

Guest, G., Bunce, A., \& Johnson, L. (2006). How many interviews are enough? An experiment with data saturation and variability. Field methods, 18(1), 59-82. https://doi.org/10.1177\%2F1525822X05279903

Gulliford, L., Morgan, B., Hemming, E., \& Abbott, J. (2019). Gratitude, self-monitoring and social intelligence: A prosocial relationship? Current Psychology, 38(4), 1021-1032. https://doi.org/10.1007/s12144-019-00330-w

Gurdjian, P., Halbeisen, T., \& Lane, K. (2014). Why leadership-development programs fail. McKinsey Quarterly, 1(1), 121-126.

Haghighi, M., \& Gerber, M. (2019). Does mental toughness buffer the relationship between perceived stress, depression, burnout, anxiety, and sleep?. International Journal of Stress Management, 26(3), 297. http://dx.doi.org/10.1037/str0000106 
Hargreaves, A., \& Fullan, M. (2013). The power of professional capital. The Learning Professional, 34(3), 36-39. https://achieve.lausd.net/cms/lib08/CA01000043/ Centricity/Domain/219/JSD-Power-of-Professional-Capital.pdf

Hays, J. M. (2008). Teacher as servant applications of Greenleaf's servant leadership in higher education. Journal of Global Business Issues, 2(1), 113.

Hennink, M. M., Kaiser, B. N., \& Marconi, V. C. (2017). Code saturation versus meaning saturation: How many interviews are enough? Qualitative Health Research, 27(4), 591-608. https://doi-org.cupdx.idm.oclc.org/10.1177/1049732316665344

Herman, K. C., Prewett, S. L., Eddy, C. L., Savala, A., \& Reinke, W. M. (2020a). Profiles of middle school teacher stress and coping: Concurrent and prospective correlates. Journal of School Psychology, 78, 54-68. https://doi.org/10.1016/j.jsp.2019. 11.003

Herman, K. C., Reinke, W. M., \& Eddy, C. L. (2020b). Advances in understanding and intervening in teacher stress and coping: The Coping-Competence-Context Theory. Journal of School Psychology, 78, 69-74. https://doi.org/10.1016/j.jsp. 2020.01 .001

Herman, R., Gates, S. M., Arifkhanova, A., Barrett, M., Bega, A., Chavez-Herrerias, E. R., Han, E., Harris, M., Migacheva, K., Ross, R., Leschitz, J. T., \& Wrabel, S. L. (2017). School leadership interventions under the Every Student Succeeds Act: Evidence review: Updated and expanded (Research Report No. RR-1550-3-WF). RAND Corporation. https://doi.org/10.7249/RR1550-3 
Herrmann, M., Clark, M., James-Burdumy, S., Tuttle, C., Kautz, T., Knechtel, V., Dotter, D., Smither Wulsin, C., \& Deke, J. (2019). The effects of a principal professional development program focused on instructional leadership (Research Report No. 2020-0002). U.S. Department of Education; Institute of Education Sciences; National Center for Education Evaluation and Regional Assistance.

Hesbol, K. A. (2019). Principal self-efficacy and learning organizations: Influencing school improvement. International Journal of Educational Leadership Preparation, 14(1), 33-51. https://files.eric.ed.gov/fulltext/EJ1218932.pdf

Hipp, K. K., \& Weber, P. (2008). Developing a professional learning community among urban school principals. Journal of Urban Learning, Teaching, and Research, 4, $46-56$.

Hofmeyer, A., Sheingold, B. H., Klopper, H. C., \& Warland, J. (2015). Leadership in learning and teaching in higher education: Perspectives of academics in nonformal leadership roles. Contemporary Issues in Education Research, 8(3), 181192. http://hsrc.himmelfarb.gwu.edu/son_nurs_facpubs/175?utm_source=hsrc. himmelfarb.gwu.edu\%2Fson_nurs_facpubs\%2F175\&utm_medium=PDF\&utm_c ampaign $=$ PDFCoverPages

Hord, S. M., \& Roussin, J. L. (2013). Implementing change through learning: Concernsbased concepts, tools, and strategies for guiding change. Corwin Press.

Imenda, S. (2014). Is there a conceptual difference between theoretical and conceptual frameworks? Journal of Social Sciences, 38(2), 185-195. https://doi.org/10.1080/ 09718923.2014.11893249 
International Institute for Restorative Practices. (2021). What is restorative practices? The science of relationships and community. https://www.iirp.edu/restorativepractices/what-is-restorative-practices

Iyi Kon. (n.d.-a). School vector icon [Clip art]. Vecteezy. https://www.vecteezy.com/ vector-art/378701-school-vector-icon

Iyi Kon. (n.d.-b). Vector graduation cap icon [Clip art]. Vecteezy. https://www.vecteezy. com/vector-art/347865-vector-graduation-cap-icon

Jennings, P. A., Brown, J. L., Frank, J. L., Doyle, S., Oh, Y., Davis, R., Rasheed, D., DeWeese, A., DeMauro, A. A., Cham, H., \& Greenberg, M. T. (2017). Impacts of the CARE for Teachers program on teachers' social and emotional competence and classroom interactions. Journal of Educational Psychology, 109(7), 10101028. http://dx.doi.org/10.1037/edu0000187

Jennings, P. A., \& Greenberg, M. T. (2009). The prosocial classroom: Teacher social and emotional competence in relation to student and classroom outcomes. Review of Educational Research, 79(1), 491-525. http://www.jstor.org/stable/40071173? origin=JSTOR-pdf

Jennings, P. A., Jeon, L., \& Roberts, A. M. (2020). Introduction to the Special Issue on Early Care and Education Professionals' Social and Emotional Well-being. Early Education and Development, 31(7), 933-939. https://doi.org/10.1080/10409289. 2020.1809895

Jennings, P. A., Snowberg, K. E., Coccia, M. A., \& Greenberg, M. T. (2011). Improving classroom learning environments by cultivating awareness and resilience in 
education (CARE): Results of two pilot studies. The Journal of Classroom Interaction, 46(1), 37-48. https://www.jstor.org/stable/23870550

Joseph, A., \& George, C. R. (2018). Role of emotional intelligence in teaching and in the development of future teachers: A meta-analysis. Education Sciences \& Psychology, 50(4), 17-25. http://search.ebscohost.com.cupdx.idm.oclc.org/login. aspx $?$ direct $=$ true $\& \mathrm{db}=$ eue $\& \mathrm{AN}=134124302 \&$ site $=$ ehost-live $\&$ scope $=$ site Kaplan, S., Cortina, J., \& Ruark, G. A. (2010). Oops.... We Did It Again: IndustrialOrganizational's Focus on Emotional Intelligence Instead of on Its Relationships to Work Outcomes. Industrial and Organizational Psychology, 3(2), 171-177.

Khalifa, M. A., Gooden, M. A., \& Davis, J. E. (2016). Culturally responsive school leadership: A synthesis of the literature. Review of Educational Research, 86(4), 1272-1311. https://doi.org/10.3102/0034654316630383

Kline, A. M. (2011). Assessing the influence of social and emotional intelligence in effective educational leadership [Doctoral dissertation, Ball State University]. Cardinal Scholar. http://liblink.bsu.edu/catkey/1653348

Klocko, B. A., \& Wells, C. M. (2015). Workload pressures of principals: A focus on renewal, support, and mindfulness. National Association of Secondary School Principals Bulletin, 99(4), 332-355. https://doi.org/10.1177\%2F01926365156 19727

Kunze, F., \& Menges, J. I. (2017). Younger supervisors, older subordinates: An organizational $\square$ level study of age differences, emotions, and performance. 
Journal of Organizational Behavior, 38(4), 461-486.

https://dx.doi.org/10.1002/job.2129

Laerd Statistics (2021). Ordinal logistic regression: SPSS Statistics. https://statistics. laerd.com/premium/spss/olr/ordinal-logistic-regression-in-spss.php

Law, K. S., Wong, C. S., \& Song, L. J. (2004). The construct and criterion validity of emotional intelligence and its potential utility for management studies. Journal of applied Psychology, 89(3), 483. https://psycnet.apa.org/doi/10.1037/00219010.89.3.483

Lawrimore, A. M. (2021). Teacher appreciation: 5 love languages. https://aileengoeson. com/2019/07/31/teacher-appreciation-the-5-love-languages/

Laybourn, S., Frenzel, A. C., \& Fenzl, T. (2019). Teacher Procrastination, Emotions, and Stress: A Qualitative Study. Frontiers in psychology, 10, 2325. https://doi.org/ 10.3389/fpsyg.2019.02325

Leighton, J. P. (2012). Internal validity. In N. Salkind (Ed.), Encyclopedia of research design (pp. 620-622). Sage Publications. https://dx.doi.org/10.4135/97814129 61288

Leiter, M. P., \& Maslach, C. (2016). Latent burnout profiles: A new approach to understanding the burnout experience. Burnout Research, 3(4), 89-100. https://doi.org/10.1016/j.burn.2016.09.001

Leithwood, K., \& Jantzi, D. (1999, April 19-23). The effects of transformational leadership on organizational conditions and student engagement with school [Paper presentation]. Annual Meeting of the American Educational Research 
Association, Montreal, Quebec, Canada. https://files.eric.ed.gov/ fulltext/ED432035.pdf

Leithwood, K., \& Sun, J. (2012). The nature and effects of transformational school leadership: A meta-analytic review of unpublished research. Educational Administration Quarterly, 48(3), 387-423. https://doi.org/10.1177\%2F0013161 X11436268

Lelieveld, G. J., Van Dijk, E., Van Beest, I., \& Van Kleef, G. A. (2012). Why anger and disappointment affect other's bargaining behavior differently: The moderating role of power and the mediating role of reciprocal and complementary emotions. Personality and Social Psychology Bulletin, 38(9), 1209-1221. https://doi.org/ $10.1177 \% 2 \mathrm{~F} 0146167212446938$

Lennard, A. C., Scott, B. A., \& Johnson, R. E. (2019). Turning frowns (and smiles) upside down: A multilevel examination of surface acting positive and negative emotions on well-being. Journal of Applied Psychology, 104(9), 1164-1180. https://psycnet.apa.org/doi/10.1037/ap10000400

Leonard, E. E., \& Maulding Green, W. (2018). Are Leader Behavior and Emotional Intelligence related to Teacher Efficacy? The Journal of Values-Based Leadership,11(2), 1-15. http://dx.doi.org/10.22543/0733.62.1225

Lerner, J. S., Li, Y., Valdesolo, P., \& Kassam, K. S. (2015). Emotion and decision making. Annual Review of Psychology, 66(33), 1-25. doi:10.1146/annurev-psych-010213115043 
Levin, S., \& Bradley, K. (2019). Understanding and addressing principal turnover: A review of the research. National Association of Secondary School Principals; Learning Policy Institute.

Levin, S., Bradley, K., \& Scott, C. (2019). Principal turnover: Insights from current principals. Learning Policy Institute. National Association of Secondary School Principals; Learning Policy Institute.

Lindebaum, D., \& Cartwright, S. (2010). A critical examination of the relationship between emotional intelligence and transformational leadership. Journal of Management Studies, 47(7), 1317-1342. https://doi.org/10.1111/j.14676486.2010.00933.x

Lings, I., Durden, G., Lee, N., \& Cadogan, J. W. (2014). Socio-emotional and operational demands on service employees. Journal of Business Research, 67(10), 21322138. https://doi.org/10.1016/j.jbusres.2014.04.022

Lings, I. N., Durden, G., Lee, N., \& Cadogan, J. W. (2016). The dual impact of socioemotional and operational demands stress and burnout. In C. Campbell \& J. Ma (Eds.) Looking Forward, Looking Back: Drawing on the Past to Shape the Future of Marketing (pp. 403-406). Springer, Cham. https://doi.org/10.1007/978-3-31924184-5_104

Loewenberg, A. (2016). Why elementary school principals matter. New America. https://static.newamerica.org/attachments/13105-principals-corner/5.4 Early-Ed-Principal-1.8d69b7bcac284a57b2dc1 eae4dde54a8.pdf. 
Lovely, S. (2004). Staffing the principalship: Finding, coaching, and mentoring school leaders. ASCD.

Mager, D. (2019, March 22). Mindfulness and emotional intelligence: Mindfulness practices can significantly upgrade your internal operating system. Psychology Today. https://www.psychologytoday.com/us/blog/some-assemblyrequired/201903/mindfulness-and-emotional-intelligence

Mahfouz, J. (2017). Exploring the influence of the Cultivating Awareness and Resilience in Education (CARE) professional development program on school administrators'wellbeing and leadership [Doctoral dissertation, Pennsylvania State University]. Electronic Theses and Dissertations for Graduate School. https://etda.libraries.psu.edu/files/final_submissions/14814

Mahfouz, J. (2018a). Mindfulness training for school administrators: effects on wellbeing and leadership. Journal of Educational Administration, 56(6), 602-619. https://doi.org/10.1108/JEA-12-2017-0171

Mahfouz, J. (2018b). Principals and stress: Few coping strategies for abundant stressors. Educational Management Administration \& Leadership, 1-19. doi: 10.1177/ 1741143218817562

Mahfouz, J., \& Gordon, D. P. (2020). The case for focusing on school principals' socialemotional competencies. Management in Education, 1-5. https://doi.org/10. 1177\%2F0892020620932351

Malterud, K., Siersma, V. D., \& Guassora, A. D. (2016). Sample size in qualitative interview studies: Guided by information power. Qualitative Health 
Research, 26(13), 1753-1760. https://doi-org.cupdx.idm.oclc.org/10.1177/ 1049732315617444

Marques, J. (2015). The changed leadership landscape: What matters today. Journal of Management Development, 34(10), 1310-1322. http://dx.doi.org/10.1108/JMD02-2015-0010

Martin, E., Trigwell, K., Prosser, M., \& Ramsden, P. (2003). Variation in the experience of leadership of teaching in higher education. Studies in Higher Education, 28(3), 247-259. https://doi.org/10.1080/03075070309297

Martinez, L. S. (2018). Variables, operationalization. In M. Allen (Ed.), The Sage encyclopedia of communication research methods (pp.1855-1856). https://dx.doi.org/10.4135/97814 83381411

Martínez-Marín, M. D., Martínez, C., \& Paterna, C. (2021). Gendered self-concept and gender as predictors of emotional intelligence: A comparison through of age. Current Psychology, 40(9), 4205-4218.

Martínez-Monteagudo, M. C., Inglés, C. J., Granados, L., Aparisi, D., \& GarcíaFernández, J. M. (2019). Trait emotional intelligence profiles, burnout, anxiety, depression, and stress in secondary education teachers. Personality and Individual Differences, 142, 53-61. https://doi.org/10.1016/j.paid.2019.01.036

Marx, G. (2006). Future focused leadership: Preparing schools, students, and communities for tomorrow's realities. Association for Supervision and Development. 
Marzano, R. J., Waters, T., \& McNulty, B. A. (2005). School leadership that works: From research to results. Association for Supervision and Curriculum Development; Mid-continent Research for Education and Learning.

Maslach, C., Jackson, S. E., \& Leiter, M. P. (2018). Maslach burnout inventory manual ( $4^{\text {th }}$ ed.). Mind Garden.

Mason, T. L. (2018). Emotionally connected: The role of emotional intelligence in the work of school leaders [Doctoral dissertation, Georgia Southern University]. Digital Commons. https://digitalcommons.georgiasouthern.edu/cgi/viewcontent. cgi?article $=2876 \&$ context $=$ etd

McCleskey, J. (2012). Emotional intelligence and leadership: A review of the progress, controversy, and criticism. International Journal of Organizational Analysis: Bingley, 22(1), 76-93. http://dx.doi.org.cupdx.idm.oclc.org/10.1108/IJOA-032012-0568

McCleskey, J. A. (2014). Situational, transformational, and transactional leadership and leadership development. Journal of Business Studies Quarterly, 5(4), 117-130. https://citeseerx.ist.psu.edu/viewdoc/download?doi=10.1.1.651.8175\&rep=rep1\&t ype $=$ pdf

McGill, C. M., Heikkila, M., \& Lazarowicz, T. (2020). Professional development, performance expectations and academic advisors' perceptions of relational skills: A sequential explanatory mixed methods study. New Horizons in Adult Education \& Human Resource Development, 32(4), 50-69. https://doi-org.proxy.lib.pdx.edu/ 10.1002/nha3.20296 
McGinn, M. K. (2012). Credibility. In A. J. Mills, G. Durepos, \& E. Weibe (Eds.), Encyclopedia of case study research, (pp. 243-244). Sage Publications.

McGinnis, E. J. (2018). Developing the emotional intelligence of undergraduate music education majors: An exploratory study using Bradberry and Greaves' (2009) Emotional Intelligence 2.0. Journal of Music Teacher Education, 27(2), 11-22. https://doi.org/10.1177\%2F1057083717723919

McIntyre, T., McIntyre, S., \& Francis, D. (2017). Educator stress: An occupational health perspective. Springer.

Mehdinezhad, V., \& Mansouri, M. (2016). School principals' leadership behaviours and its relation with teachers' sense of self-efficacy. International Journal of Instruction, 9(2), 51-60. https://doi.org/10.12973/iji.2016.924a

Meneghel, I., Salanova, M., \& Martínez, I. M. (2016). Feeling good makes us stronger: How team resilience mediates the effect of positive emotions on team performance. Journal of Happiness Studies, 17(1), 239-255. doi: $10.1007 / \mathrm{s} 10902-014-9592-6$

Merritt, E. G., Wanless, S. B., Rimm-Kaufman, S. E., Cameron, C., \& Peugh, J. L. (2012). The contribution of teachers' emotional support to children's social behaviors and self-regulatory skills in first grade. School Psychology Review, 41(2), 141-159. https://doi.org/10.1080/02796015.2012.12087517

Meshkat, M., \& Nejati, R. (2017). Does emotional intelligence depend on gender? A study on undergraduate English majors of three Iranian universities. SAGE Open. https://doi.org/10.1177/2158244017725796 
Metcalf, B. (2019). How principals understanding of best practices in professional development impacts teacher pedagogy [Doctoral Dissertation, National Luis University]. Digital Commons. https://digitalcommons.nl.edu/diss/389/

Meyer-Looze, C., Richards, S., Brandell, S., \& Margulus, L. (2019). Implementing the Change Process for Staff and Student Success: An Instructional Module. International Journal of Educational Leadership Preparation, 14(1), 170-187. https://www.icpel.org/uploads/1/5/6/2/15622000/ijelp_volume_14_number_1_sp ring_2019_.pdf\#page=174

Mindflow. (2019). Our programs. https://www.mindflowpdx.com/

Mindful Leader. (2019). Seven steps to mindful leadership. https://www.mindfulleader. org/blog/15158-seven-steps-to-mindful-leadership

Moqbel, M., \& Nah, F. F. H. (2017). Enterprise social media use and impact on performance: The role of workplace integration and positive emotions. AIS Transactions on Human-Computer Interaction, 9(4), 261-280. doi: 10.17705/1thci.00098

Morgan, D. L., \& Ravitch, S. M. (2018). Trustworthiness. In B. B. Frey (Ed.), The SAGE Encyclopedia of Educational Research, Measurement, and Evaluation (pp. 17291731). SAGE Publications. https://dx-doi-org.proxy.lib.pdx.edu/10.4135/ 9781506326139

Multnomah Education Service District. (2018). Emergency operations/resources/plans. https://www.multnomahesd.org/emergency.html 
Nafukho, F. M., Muyia, H. M., Farnia, F., Kacirek, K., \& Lynham, S. A. (2016). Developing emotional intelligence skills among practicing leaders: Reality or myth? Performance Improvement Quarterly, 29(1), 71-87. doi:10.1002/piq.21215

Nagler, U. K., Reiter, K. J., Furtner, M. R., \& Rauthmann, J. F. (2014). Is there a “dark intelligence"? Emotional intelligence is used by dark personalities to emotionally manipulate others. Personality and Individual Differences, 65, 47-52. http://dx.doi.org/10.1016/j.paid.2014.01.025

Newman, K. M. (2016, November 9). Five science-backed strategies to build resilience: When the road gets rocky, what do you do? https://greatergood.berkeley.edu/ article/item/five_science_backed_strategies_to_build_resilience

Nisbett, R. E., Aronson, J., Blair, C., Dickens, W., Flynn, J., Halpern, D. F., \& Turkheimer, E. (2012). Intelligence: New findings and theoretical developments. American Psychologist, 67(2), 130. https://psycnet.apa.org/doi/10.1037/a0026699

Noe, J. (2012). The relationship between principal's emotional intelligence quotient, school culture and student achievement [Doctoral dissertation, Liberty University]. Digital Commons. https://digitalcommons.liberty.edu/doctoral/620

OECD. (2017, November 21). What is collaborative problem solving? In PISA 2015 results (Volume V): Collaborative problem solving (pp. 45-64). OECD Publishing. https://doi.org/10.1787/9789264285521-7-en

Opengart, R. (2005). Emotional intelligence and emotion work: Examining constructs from an interdisciplinary framework. Human Resource Development Review, 4(1), 49-62. https://doi.org/10.1177\%2F1534484304273817 
Oregon Department of Education. (2021, September). Oregon school directory 2020-21. https://www.oregon.gov/ode/about-us/Pages/School-Directory.aspx

Ouellette, R. R., Frazier, S. L., Shernoff, E. S., Cappella, E., Mehta, T. G., Maríñez-Lora, A., Cua, G., \& Atkins, M. S. (2018). Teacher job stress and satisfaction in urban schools: Disentangling individual-, classroom-, and organizational-level influences. Behavior therapy, 49(4), 494-508.

https://doi.org/10.1016/j.beth.2017.11.011

Ozcelik, H., \& Barsade, S. G. (2018). No employee an island: Workplace loneliness and job performance. Academy of Management Journal, 61(6), 2343-2366. https://doi.org/10.5465/amj.2015.1066

Parrish, D. R. (2015). The relevance of emotional intelligence for leadership in a higher education context. Studies in Higher Education, 40(5), 821-837. doi:http://dx.doi.org.cupdx.idm.oclc.org/10.1080/03075079.2013.842225

Paschall, E. (2020). Eyes on culture: Multiply excellence in your school. ConnectEDD. Peace in Schools. (n.d.). About us. https://www.peaceinschools.org/about-us Pearson, A., \& Weinberg, A. (2017). The impact of counsellor training on emotional intelligence. British Journal of Guidance \& Counselling, 45(5), 610-621. doi: 10.1080/03069885.2016.1226496

Pérez-Rodríguez, V., Topa, G., \& Beléndez, M. (2019). Organizational justice and work stress: The mediating role of negative, but not positive, emotions. Personality and Individual Differences, 151, 109392. https://doi.org/10.1016/j.paid.2019.04.047 
Pervez, Z., Dahar, M. A., \& Tahira, R. (2016). Impact of emotional intelligence of principals on school culture at secondary level. Science International, 28(1), 2027-2030.

Petrides, K. V. (2010). Trait emotional intelligence theory. Industrial and Organizational Psychology, 3(2), 136-139.

Petrides, K. V., Sanchez-Ruiz, M. J., Siegling, A. B., Saklofske, D. H., \& Mavroveli, S. (2018). Emotional intelligence as personality: Measurement and role of trait emotional intelligence in educational contexts. In K.V. Keefer, J. D. A. Parker, \& D. H. Saklofske (Eds.) Emotional intelligence in education (pp. 49-81). Springer. https://doi.org/10.1007/978-3-319-90633-1_3

Pietsch, M., Tulowitzki, P., \& Hartig, J. (2020). Examining the effect of principal turnover on teaching quality: A study on organizational change with repeated classroom observations. School Effectiveness and School Improvement, 31(3), 333-355. https://doi.org/10.1080/09243453.2019.1672759

Player, D., Youngs, P., Perrone, F., \& Grogan, E. (2017). How principal leadership and person-job fit are associated with teacher mobility and attrition. Teaching and Teacher Education, 67, 330-339. https://doi.org/10.1016/j.tate.2017.06.017

Pope, D. C. (2017). Increasing validity in qualitative research [Streaming video]. SAGE Research Methods.

Quinlan, D., Vella-Brodrick, D. A., Gray, A., \& Swain, N. (2018). Teachers matter: Student outcomes following a strengths intervention are mediated by teacher 
strengths spotting. Journal of Happiness Studies, 1-17. https://doi.org/10.1007/ s10902-018-0051-7

Ragoonaden, K. (2017). smartEducation: Developing Stress Management and Resiliency Techniques. LEARNing Landscapes, 10(2), 241-255. https://doi.org/10.36510/ learnland.v10i2.813

Raimundo, R., Marques $\square$ Pinto, A., \& Lima, M. L. (2013). The effects of a socialemotional learning program on elementary school children: The role of pupils'characteristics. Psychology in the Schools, 50(2), 165-180. doi: $10.1002 /$ pits. 21667

Rispens, S., \& Demerouti, E. (2016). Conflict at work, negative emotions, and performance: A diary study. Negotiation and Conflict Management Research, 9(2), 103-119.

Rodríguez-Ledo, C., Orejudo, S., Jesús Cardoso, M., Balaguer, Á., \& Zarza-Alzugaray, J. (2018). Emotional intelligence and mindfulness: Relation and enhancement in the classroom with adolescents. Frontiers in Psychology, 9, 1-10. https://doi.org/ 10.3389/fpsyg.2018.02162

Roeser, R. W., Schonert-Reichl, K. A., Jha, A., Cullen, M., Wallace, L., Wilensky, R., Oberle, E., Thomson, K., Taylor, C., \& Harrison, J. (2013). Mindfulness training and reductions in teacher stress and burnout: Results from two randomized, waitlist-control field trials. Journal of Educational Psychology, 105(3), 787-804. https://doi.org/10.1037/a0032093 
Roeser, R. W., Skinner, E., Beers, J., \& Jennings, P. A. (2012). Mindfulness training and teachers' professional development: An emerging area of research and practice. Child development perspectives, 6(2), 167-173. https://doi.org/10.1111/j.17508606.2012.00238.x

RULER. (2021). What is RULER? https://www.rulerapproach.org/about/what-is-ruler/ Rutledge, S. A., Cohen-Vogel, L., Osborne-Lampkin, L. T., \& Roberts, R. L. (2015). Understanding effective high schools: Evidence for personalization for academic and social emotional learning. American Educational Research Journal, 52(6), 1060-1092. https://doi.org/10.3102/0002831215602328

Ryan, S. V., Nathaniel, P., Pendergast, L. L., Saeki, E., Segool, N., \& Schwing, S. (2017). Leaving the teaching profession: The role of teacher stress and educational accountability policies on turnover intent. Teaching and Teacher Education, 66, 1-11. https://doi.org/10.1016/j.tate.2017.03.016

Saldaña, J. (2013). The coding manual for qualitative researchers (2nd ed.). Sage.

Salkind, N. J. (2007). Regression analysis. In Encyclopedia of measurement and statistics (Vol. 1, pp. 830-832). SAGE Publications, Inc., https://www-doiorg.proxy.lib.pdx.edu/10.4135/9781412952644.n379

Salkind, N. J. (2010). Omnibus tests. In Encyclopedia of research design (Vol. 1, pp. 968-969). SAGE Publications, Inc., https://www-doiorg.proxy.lib.pdx.edu/10.4135/9781412961288.n290

Salovey, P., \& Mayer, J. D. (1990). Emotional intelligence. Imagination, Cognition and Personality, 9(3), 185-211. https://doi.org/10.2190/DUGG-P24E-52WK-6CDG 
Sanchez, J. E., Burnham, M. M., \& Zaki, S. (2019). The dynamic transformation of a principal preparation program: A university-district collaborative. International Journal of Educational Leadership Preparation, 14(1), 1-12. https://www.icpel. org/uploads/1/5/6/2/15622000/ijelp_volume_14_number_1_spring_2019_.pdf\#p age $=5$

Sánchez-Núñez, M. T., Patti, J., \& Holzer, A. (2015). Effectiveness of a leadership development program that incorporates social and emotional intelligence for aspiring school leaders. Journal of Educational Issues, (1)1, 65-84. doi:10.5296/jei.v1i1.7443.

Sanz-Vergel, A. I., Rodríguez-Muñoz, A., Bakker, A. B., \& Demerouti, E. (2012). The daily spillover and crossover of emotional labor: Faking emotions at work and at home. Journal of Vocational Behavior, 81(2), 209-217. https://doi.org/10.1016/ j.jvb.2012.07.003

Schonert-Reichl, K. A. (2017). Social and emotional learning and teachers. The Future of Children, 27(1), 137-155. https://www.jstor.org/stable/44219025

Schonert-Reichl, K. A., Hanson-Peterson, J. L., \& Hymel, S. (2015). SEL and preservice teacher education. In J. A. Durlak, C. E. Domitrovich, R. P. Weissberg, \& T. P. Gullotta (Eds.), Handbook of social and emotional learning: Research and practice (pp. 406-421). Guilford Press. https://www.researchgate.net/profile/ Kimberly_Schonert-Reichl/publication/299566575_Social_and_emotional_ learning_and_pre-service_teacher_education/links/56ffc1d508ae650a64f8072c/ Social-and-emotional-learning-and-pre-service-teacher-education.pdf 
Schussler, D. L., DeWeese, A., Rasheed, D., DeMauro, A. A., Doyle, S. L., Brown, J. L., Greenberg, M. T., \& Jennings, P. A. (2019). The relationship between adopting mindfulness practice and reperceiving: A qualitative investigation of CARE for teachers. Mindfulness, 10(12), 2567-2582. https://doi.org/10.1080/10409289. 2020.1809895

Schussler, D. L., Jennings, P. A., Sharp, J. E., \& Frank, J. L. (2016). Improving teacher awareness and well-being through CARE: A qualitative analysis of the underlying mechanisms. Mindfulness, 7(1), 130-142. https://doi.org/10.1007/s12671-0150422-7

Schutte, N. S., \& Loi, N. M. (2014). Connections between emotional intelligence and workplace flourishing. Personality and Individual Differences, 66, 134-139. doi: 10.1016/i.paid.2014.03.031

Schutte, N. S., Malouff, J. M., Hall, L. E., Haggerty, D. J., Cooper, J. T., Golden, C. J., \& Dornheim, L. (1998). Development and validation of a measure of emotional intelligence. Personality and Individual Differences, 25(2), 167-177. https://doi.org/10.1016/S0191-8869(98)00001-4

Sendjaya, S., \& Sarros, J. C. (2002). Servant leadership: Its origin, development, and application in organizations. Journal of Leadership \& Organizational Studies, 9(2), 57-64. https://doi.org/10.1177\%2F107179190200900205

Sharp, J. E., \& Jennings, P. A. (2016). Strengthening teacher presence through mindfulness: What educators say about the cultivating awareness and resilience in 
education (CARE) program. Mindfulness, 7(1), 209-218. https://doi.org/10.1007/ s12671-015-0474-8

Simms, M. (2016). An examination of the relationship between principals' emotional intelligence and teachers' attitudes toward personal and professional development and school culture [Doctoral dissertation, Northcentral University]. ProQuest Dissertations \& Theses Global. http://stats.lib.pdx.edu/proxy.php?url=http:// search.proquest.com/dissertations-theses/examination-relationship-betweenprincipals/docview/1860256273/se-2?accountid=13265

Smith, B. H., \& Low, S. (2013). The role of social-emotional learning in bullying prevention efforts. Theory Into Practice, 52(4), 280-287. https://doi.org/ $10.1080 / 00405841.2013 .829731$

Soleas, E. K. (2015). New teacher perceptions of inclusive practices: An examination of contemporary teacher education programs. Alberta Journal of Educational Research, 61(3), 294-313.

Stake, R. E. (2010). Qualitative research: Studying how things work. Guilford Press. Stephens, J. P., \& Carmeli, A. (2016). The positive effect of expressing negative emotions on knowledge creation capability and performance of project teams. International Journal of Project Management, 34(5), 862-873. http://dx.doi.org/10.1016/ j.ijproman.2016.03.003

Stevenson, H., \& Markowitz, N. L. (2019). Introduction: Social emotional learning and culturally responsive and sustaining teaching practices. Teacher Education Quarterly, 46(4), 3-10. 
Stillman, S. B., Stillman, P., Martinez, L., Freedman, J., Jensen, A. L., \& Leet, C. (2018). Strengthening social emotional learning with student, teacher, and schoolwide assessments. Journal of Applied Developmental Psychology, 55, 71-92. https://doi.org/10.1016/j.appdev.2017.07.010

Stone, A. G., Russell, R. F., \& Patterson, K. (2003). Transformational versus servant leadership: A difference in leader focus. Leadership \& Organization Development Journal, 25(4), 349-361. https://doi.org/10.1108/01437730410538671

Sundem, G. (2014). Beyond IQ: Scientific tools for training problem solving, intuition, emotional intelligence, creativity, and more. Three Rivers Press

Sutcher, L., Podolsky, A., \& Espinoza, D. (2017). Supporting principals' learning: Key features of effective programs. Learning Policy Institute. https://learningpolicy institute.org/product/supporting-principals-learning

Swift, C. L. (2018). The Perceived Emotional Intelligence of Elementary Principals and Teachers' Job Satisfaction: Do They Relate? [Doctoral dissertation, University of North Florida]. Digital Commons. https://digitalcommons.unf.edu/etd/825/

Tai, M. K., \& Kareem, O. A. (2018). The relationship between emotional intelligence of school principals in managing change and teacher attitudes towards change. International Journal of Leadership in Education, 22(4), 469-485. https://doi.org/ $10.1080 / 13603124.2018 .1481535$

Tan, K., Sinha, G., Shin, O. J., \& Wang, Y. (2018). Patterns of social-emotional learning needs among high school freshmen students. Children and Youth Services Review, 86, 217-225. https://doi.org/10.1016/j.childyouth.2018.01.033 
Taner, B., \& Aysen, B. (2013). The role of resonant leadership in organizations. European Scientific Journal, 9(19). http://citeseerx.ist.psu.edu/viewdoc/download? doi $=10.1 .1 .677 .6917 \&$ rep $=$ rep $1 \&$ type $=$ pdf\#page $=604$

Tang, H.-W. V., Yin, M.-S., \& Nelson, D. B. (2010). The relationship between emotional intelligence and leadership practices. Journal of Managerial Psychology, 25(8), 899-926. doi: 10.1108/02683941011089143

Taylor, R. D., Oberle, E., Durlak, J. A., \& Weissberg, R. P. (2017). Promoting positive youth development through school-based social and emotional learning interventions: A meta-analysis of follow-up effects. Child Development, 88(4), 1156-1171. https://doi.org/10.1111/cdev.12864

Thakrar, M. (2019, June 11). How to develop emotional intelligence using mindfulness. Forbes. https://www.forbes.com/sites/forbescoachescouncil/2019/06/11/how-todevelop-emotional-intelligence-using-mindfulness/?sh=61b992213f3a

Thory, K. (2016). Developing meaningfulness at work through emotional intelligence training. International Journal of Training \& Development, 20(1), 58-77. https://doi-org.cupdx. idm.oclc.org/10.1111/ijtd.12069

Trauma Informed Oregon. (2021). Trauma informed care logic model. https://trauma informedoregon.org/roadmap-trauma-informed-care/

Tripses, J. S. (2019). Our future is in our minds and hearts. International Journal of Educational Leadership Preparation, 14(1), 22-32. https://www.icpel.org/ uploads/1/5/6/2/15622000/ijelp_volume_14_number_1_spring_2019_. pdf\#page $=26$ 
Turk, E. W., \& Wolfe, Z. M. (2019). Principal's perceived relationship between emotional intelligence, resilience, and resonant leadership throughout their career. International Journal of Educational Leadership Preparation, 14(1), 147-169. https://www.icpel.org/uploads/1/5/6/2/15622000/ijelp_volume_14_number_1_ spring_2019_.pdf\#page $=151$

Twomey, C., O'Connell, H., Lillis, M., Tarpey, S. L., \& O'Reilly, G. (2018). Utility of an abbreviated version of the Stanford-Binet intelligence scales in estimating 'full scale' IQ for young children with autism spectrum disorder. Autism Research, 11(3), 503-508. https://doi.org/10.1002/aur.1911

Ugoani, J. N., Amu, C. U., \& Kalu, E. O. (2015). Dimensions of emotional intelligence and transformational leadership: A correlation analysis. Independent Journal of Management \& Production, 6(2), 563-584. doi: 10.14807/ijmp.v6i2.278

United States Census Bureau. (n.d.). Quickfacts: Oregon. https://www.census.gov/ quickfacts/OR

Van Dijk, E., Van Kleef, G. A., Steinel, W., \& Van Beest, I. (2008). A social functional approach to emotions in bargaining: When communicating anger pays and when it backfires. Journal of Personality and social Psychology, 94(4), 600. https://psycnet.apa.org/doi/10.1037/0022-3514.94.4.600

Van Kleef, G. A. (2016). The interpersonal dynamics of emotion. Cambridge University Press. 
Volynets, S., Glerean, E., Hietanen, J. K., Hari, R., \& Nummenmaa, L. (2019). Bodily maps of emotions are culturally universal. Emotion, 20(7), 1127-1136. https://psycnet.apa.org/doi/10.1037/emo0000624.

von der Embse, N. P., Pendergast, L. L., Segool, N., Saeki, E., \& Ryan, S. (2016a). The influence of test-based accountability policies on school climate and teacher stress across four states. Teaching and Teacher Education, 59, 492-502. https://doi.org/ 10.1016/j.tate.2016.07.013

von der Embse, N. P., Sandilos, L. E., Pendergast, L., \& Mankin, A. (2016b). Teacher stress, teaching-efficacy, and job satisfaction in response to test-based educational accountability policies. Learning and Individual Differences, 50, 308-317. https://doi.org/10.1016/j.lindif.2016.08.001

Waajid, B., Garner, P. W., \& Owen, J. E. (2013). Infusing social emotional learning into the teacher education curriculum. International Journal of Emotional Education, 5(2), 31-48. http://www.um.edu.mt/cres/ijee

Wallace Foundation. (2016). Improving university principal preparation programs: Five themes from the field. https://eric-ed-gov.cupdx.idm.oclc.org/?id=ED569114 Walters, T. (2019, August 1). Mindfulness and emotional intelligence. Thrive Global. https://thriveglobal.com/stories/mindfulness-and-emotional-intelligence/ Wang, N., Wilhite, S., \& Martino, D. (2016). Understanding the relationship between school leaders' social and emotional competence and their transformational leadership: The importance of self-other agreement. Educational Management 
Administration \& Leadership, 44(3), 467-490. https://doi.org/10.1177\% 2F1741143214558568

Wassif, G. O., Gamal-Eldin, D. A., \& Boulos, D. N. (2019). Stress and Burnout among Medical Students. Journal of High Institute of Public Health, 49(3), 190-198. doi: 10.21608/jhiph.2019.63794

Weissberg, R. P. (2019). Promoting the social and emotional learning of millions of school children. Perspectives on Psychological Science, 14(1), 65-69. https://doi.org/10.1177/ 1745691618817756

Wells, C. M. (2013). Principals responding to constant pressure: Finding a source of stress management. National Association of Secondary School Principals Bulletin, 97(4), 335-349. https://doi.org/10.1177\%2F0192636513504453

Wells, C. M. (2015). Conceptualizing Mindful Leadership in Schools: How the Practice of Mindfulness Informs the Practice of Leading. Education Leadership Review of Doctoral Research, 2(1), 1-23.

Wells, C. M., \& Klocko, B. A. (2018). Principal well-being and resilience: Mindfulness as a means to that end. National Association of Secondary School Principals Bulletin, 102(2), 161-173. https://doi.org/10.1177\%2F0192636518777813

West, D. D. (2018). An analysis of principal burnout and job-person fit among elementary, middle, and high school principals in Alabama [Doctoral dissertation, Liberty University]. Digital Commons. https://digitalcommons.liberty.edu/ doctoral/1853/ 
Whiteside, D. B., \& Barclay, L. J. (2016). The face of fairness: Self-awareness as a means to promote fairness among managers with low empathy. Journal of Business Ethics, 137(4), 721-730. doi: 10.1007/s10551-014-2357-7

Williams, M. (2015). Affect, emotion, and emotion regulation in the workplace: Feelings and attitudinal structuring. Negotiation Journal, 31(4), 425-428. http://cupdx.idm. oclc.org/login?url=https://search-proquest-com.cupdx.idm.oclc.org/docview/ 1765843047 accountid $=10248$

Wubben, M. J., De Cremer, D., \& Van Dijk, E. (2009). How emotion communication guides reciprocity: Establishing cooperation through disappointment and anger. Journal of experimental social psychology, 45(4), 987-990. https://doi.org/ 10.1016/j.jesp.2009.04.010

Yan, R. (2020). The influence of working conditions on principal turnover in $\mathrm{K}-12$ public schools. Educational Administration Quarterly, 56(1), 89-122. https://doi.org/ 10.1177\%2F0013161X19840391

Yang, C., Bear, G. G., \& May, H. (2018). Multilevel associations between school-wide social-emotional learning approach and student engagement across elementary, middle, and high schools. School Psychology Review, 47(1), 45-61. doi: 10.17105/SPR-2017-0003.V47-1

Yettick, H. (2018, September 28). Demand for social-emotional learning products and services is high and expected to grow: Vast majority of $\mathrm{K}-12$ school districts have invested in SEL or will do so over the coming year, survey finds. EdWeek Market Brief. https://marketbrief.edweek.org/exclusive-data/sel/ 
Yin, R. K. (2018). Case study research and applications: Design and methods (6 ${ }^{\text {th }}$ ed.). Sage.

Yip, J. A., \& Côté, S. (2013). The emotionally intelligent decision maker: Emotionunderstanding ability reduces the effect of incidental anxiety on risk taking. Psychological Science, 24(1), 48-55. doi: 10.1177/0956797612450031

Zacher, H., \& Johnson, E. (2015). Leadership and creativity in higher education. Studies in Higher Education, 40(7), 1210-1225. https://doi.org/10.1080/03075079. 2014.881340

Zeidner, M. Z. (2017). Tentative guidelines for the development of an ability-based emotional intelligence intervention program for gifted students. High Ability Studies, 28(1), 29-41. doi:10.1080/13598139.2017.1292895

Zijlmans, L. J. M., Embregts, P. J. C. M., Gerits, L., Bosman, A. M. T., \& Derksen, J. J. L. (2011). Training emotional intelligence related to treatment skills of staff working with clients with intellectual disabilities and challenging behaviour. Journal of Intellectual Disability Research, 55(2), 219-230. doi: http://dx.doi. org.cupdx.idm.oclc.org/10.1111/ j.1365-2788.2010.01367.x

Zijlmans, L. J. M., Embregts, P. J. C. M., Gerits, L., Bosman, A. M. T., \& Derksen, J. J. L. (2015). The effectiveness of staff training focused on increasing emotional intelligence and improving interaction between support staff and clients. Journal of Intellectual Disability Research, 59(7), 599-612. doi: http://dx.doi.org.cupdx. idm.oclc.org/10.1111/ jir.12164 
Zumbrunn, S., Marrs, S., \& Mewborn, C. (2016). Toward a better understanding of student perceptions of writing feedback: A mixed methods study. Reading and Writing: An Interdisciplinary Journal, 29(2), 349-370. doi: 10.1007/s11145-0159599-3 


\section{Appendix A: Recruitment Email Templates}

\section{Principal Email \#1}

Subject: Interested in helping prevent stress and burnout in education?

Dear Principal

Please take this 7-minute survey to provide feedback on how your principal preparation and professional development program(s) have helped you cope with and manage the emotional needs and stress caused by Covid-19 and other challenges.

\section{As an incentive for participation, the first 50 respondents will receive free access to the Maslach Burnout Inventory: Educator's Survey with a detailed individual report and recommendations for managing stress and burnout (a $\$ 15$ value).}

Click on the following link to take the survey:

https://portlandstate.qualtrics.com/ife/form/SV 5A9jWxQGtimnF30

The results of this study have the potential to benefit district-level policy makers interested in improving the quality of professional development programs for school leaders; individuals, organizations, and post-secondary institutions involved in the preparation of principals; and K-12 administrators, teachers, students, and communities interested in the importance of emotional intelligence and stress management for improving school climate, decreasing turnover, and increasing student achievement.

\section{Click here for a brief overview of the research and/or here for more in-depth} information.

Please contact me if you have any questions or concerns.

Sincerely,

\section{Ashlie K. Miller, MEd, MA, EdD Candidate}

Educational Leadership and Policy

College of Education

\section{蛋 Portland State}

For more information about my research, click here

Email: asmiller@pdx.edu

Cell: \#\#\#-\#\#\#-\#\#\#\# 


\section{Principal Email \#2}

Subject: INVITATION REMINDER: Please don't forget to participate!

Dear Principal

If you haven't already taken the survey regarding how your principal preparation and professional development programs have helped you cope with and manage the emotional needs and stress caused by Covid-19 and other challenges, there is still time to participate!

I know that your time is valuable, but your input can make a difference! I would be very grateful for your input.

Please click on the following link to take the survey: [link to consent form and survey here]

The survey will only take 7 minutes of your time. You can find more detailed information about the study in the attached flyer and by going here.

\section{As a reminder, the first 50 respondents get free access to the Maslach Burnout Inventory: Educator's Survey with detailed individual reports and recommendations for managing stress and burnout (a \$15 value).}

Please let me know if you have any questions or concerns.

Sincerely,

Ashlie K. Miller, MEd, MA, EdD Candidate

Educational Leadership and Policy

College of Education

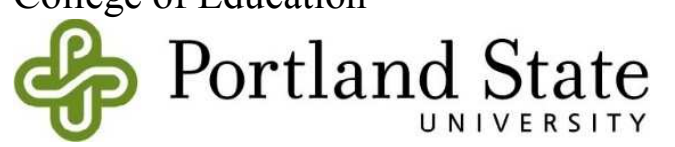

For more information about my research, click here

Email: asmiller@pdx.edu

Cell: \#\#\#-\#\#-\#\#\#\# 


\section{Principal Email \#3}

Subject: LAST CHANCE: Please participate!

Dear Principal

If you haven't already taken the survey regarding how your principal preparation and professional development programs have helped you cope with and manage the emotional needs and stress caused by Covid-19 and other challenges, there is still time to participate!

I know that your time is valuable, but your input can make a difference! I would be very grateful for your input.

Please click on the following link to take the survey: [link to consent form and survey here]

The survey will only take 10-15 minutes of your time. You can find more detailed information about the study in the attached flyer and by going here.

\section{As a reminder, the first 50 respondents get free access to the Maslach Burnout Inventory: Educator's Survey with detailed individual reports and recommendations for managing stress and burnout (a \$15 value).}

Please let me know if you have any questions or concerns.

Sincerely,

Ashlie K. Miller, MEd, MA, EdD Candidate

Educational Leadership and Policy

College of Education

\section{胥 Portland State}

For more information about my research, click here

Email: asmiller@pdx.edu

Cell: \#\#\#-\#\#\#-\#\#\# 


\section{Principal Email \#4}

Subject: Thank You!

Dear Principal

I want to thank you for taking the time to complete the survey regarding how your principal preparation and professional development programs have helped you cope with and manage the emotional needs and stress caused by Covid-19 and other challenges.

Your input is extremely valuable!

If you know any Oregon principals who did not get a chance to take the survey and might like to participate, please forward the survey link to them.

The survey can still be accessed here: [Link to survey].

Those who are interested can find more detailed information about the study here.

Please let me know if you have any questions or concerns.

Sincerely,

Ashlie K. Miller, MEd, MA, EdD Candidate

Educational Leadership and Policy

College of Education

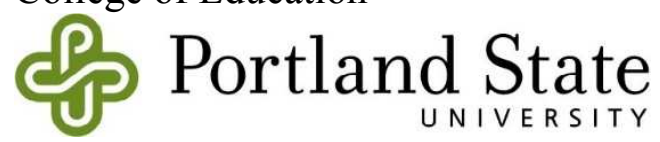

For more information about my research, click here

Email: asmiller@pdx.edu

Cell: \#\#\#-\#\#\#-\#\#\#\# 


\section{Superintendent/District Gatekeeper Email}

Subject: Principal Stress and Covid-19

Dear Superintendent/Gatekeeper

I am a doctoral student researcher at Portland State University, and I am interested in learning more about how we can support K-12 principals during times of stress. I am conducting a study regarding how the principal preparation program(s) and professional development opportunities that have been available to K-12 principals in Oregon have helped them cope with and manage the stress caused by Covid-19 and other challenges.

I would like to ask for your support! Please encourage your principals to participate in my study. The survey will only take 7 minutes to complete. Survey Link:

https://portlandstate.qualtrics.com/ifelform/SV 5A9jWxQGtimnF30

Additionally, as an incentive for participation, the first 50 respondents will receive free access to the Maslach Burnout Inventory with detailed individual reports and recommendations for managing stress and burnout (a \$15 value).

\section{Click on the following link to take the survey: [Link Here]}

The results of this study have the potential to benefit district-level policy makers interested in improving the quality of professional development programs for school leaders; individuals, organizations, and post-secondary institutions involved in the preparation of principals; and K-12 administrators, teachers, students, and communities interested in the importance of emotional intelligence and stress management for improving school climate, decreasing turnover, and increasing student achievement.

Click here for a brief overview of the research and here for more in-depth information.

Please contact me if you have any questions or concerns.

Sincerely,

Ashlie K. Miller, MEd, MA, EdD Candidate

Educational Leadership and Policy

College of Education

Portland State

For more information about my research, click here

Email: asmiller@pdx.edu

Cell: \#\#\#-\#\#-\#\#\#\# 


\section{Appendix B: Recruitment Flyer}

\section{EMOTIONAL INTELLIGENCE \&}

RESONANT LEADERSHIP

Investigating School Principals' Preparation and

Professional Development in Response to Covid-19 and

Other Challenges

A research project by Ashlie K. Miller, Doctoral Candidate

Educational Leadership \& Policy, Portland State University

\section{THE PROBLEM}

The problem is that student success requires strong communities and strong school systems but demands on educators continue to increase, demands such as:

- Rapid change

- Safety concerns

- Racial and economic injustice

- Limited resources

- Increasing accountability

- Lack of support

- And, most recently, Covid-19

This has led to high rates of burnout among teachers and administrators, weakening the support structures that provide a foundation for student success.

\section{THE PURPOSE}

The purpose of this research is to explore whether and to what degree the preparation and professional development opportunities available to K-12 principals in Oregon support their emotional needs, specifically the emotional skills principals need to cope with, manage, and bounce back from stress, such as the stress that has been caused by the Covid19 pandemic. This study also seeks to understand the ways in which the individual characteristics of principals and the contexts in which they lead influence their needs for emotional intelligence skills.

\section{RESEARCH DESIGN: MIXED METHODS}

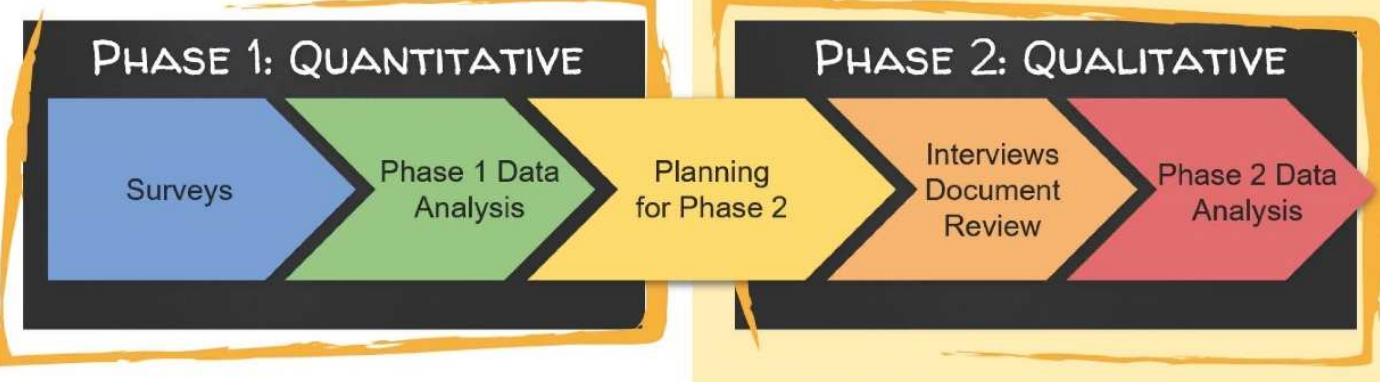

You can find more information about this research, how you can participate, and the incentives that are available for participation here: https://sites.google.com/pdx.edu/ashliekmiller-research/home 
Appendix C: Research Advertisement

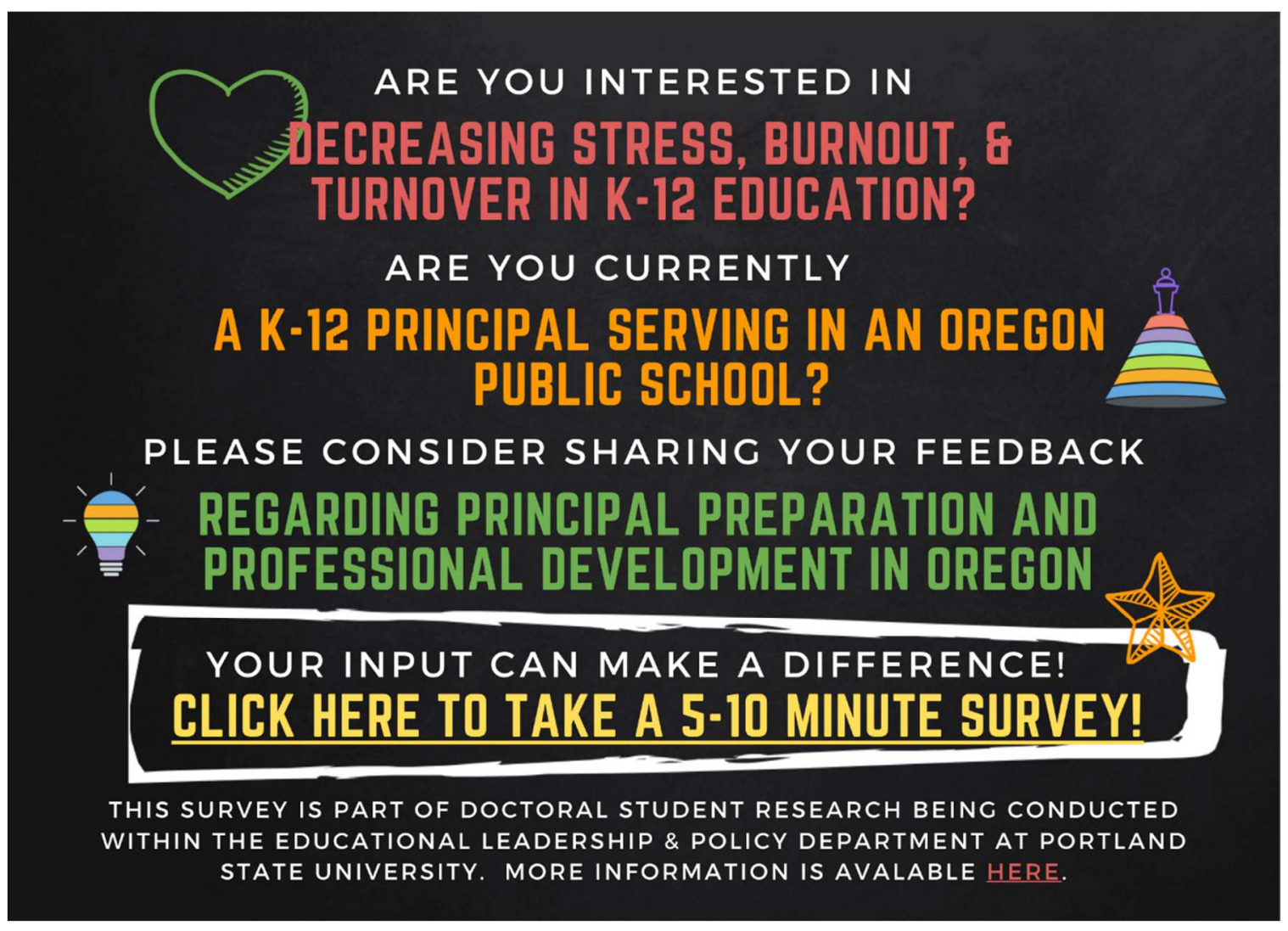




\section{Appendix D: Phase 1 Survey}

\section{$\mathcal{S P o r t l a n d} \underset{\text { UNIVESITY }}{\text { State }}$}

Phase 1 Consent to Participate

You are invited to participate in the following research study:

Project Title: Emotional Intelligence and Resonant Leadership: Investigating School Principals Preparation and Professional Development in Response to Covid-19 and Other Challenges Population: K-12 Principals in Oregon, Online Survey

Researcher: Ashlie Miller, Educational Leadership and Policy, Portland State University

Researcher Contact: asmiller@pdx .edu/541-580-2593

This consent form describes the main facts related to the study. Please reach out to me if you need clarification.

Consent to Participate in Research:

I have had the chance to read and think about the information in the consentform. I have asked any questions I have, and I can make a decision about my participation. I understand that I can ask additional questions anytime while I take part in the research.

O I agree to take part in this study

O I do not agree to take part in this study

\section{Screening}

Select the option that best describes your job title:

O K-12 Principal

O Retired K-12 Principal

O K-12 Vice Principal

K K-12Assistant Principal

O other

Select the option that best describes your most recent school assignment:

Traditional Public School

Public Charter School

O Private school 
Other

From which state did you obtain your initial administrative license (pre-AL)?

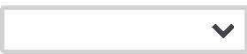

Have you obtained a professional administrative license (pro-AL)?

O Yes

O No

From which state did you initially obtain it?

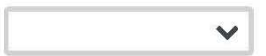

Are you currently working under a reciprocal administrative license?

O Yes

O No

Identification Code

List the following in order to create a code that the researcher will use to keep your survey information anonymous and confidential:

- The first three letters of your birth month (ex: JUL)

- Number of cousins (ex: 0 )

- Number of children (ex: 1)

- First initial of your mother/female guardian's first name (ex A)

- First initial of your father/male guardian's first name (ex: T)

- First initial of your middle name (if none, write $X$ - ex: J)

(Example: JUL01ATJ)

\section{Demographics}




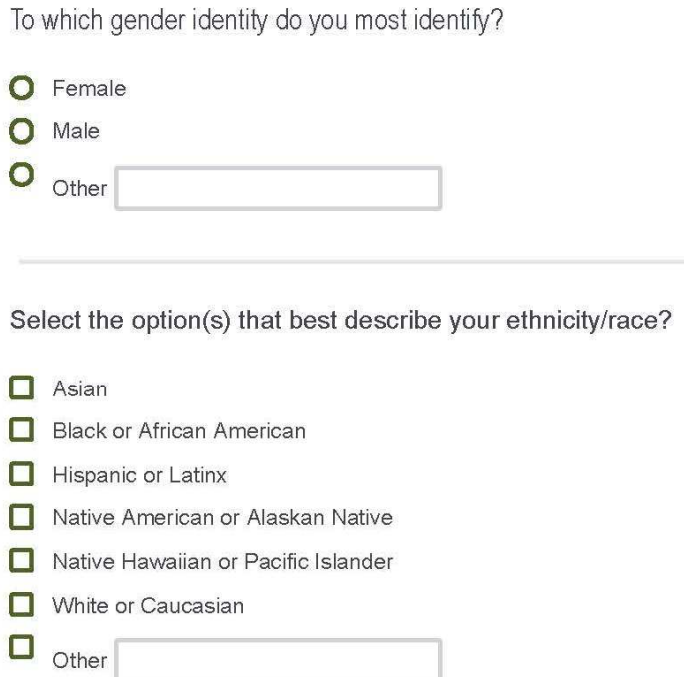


O Suburban

O Rural

How would you describe the level of need at the school in comparison to other schools in the state?

(Student needs are generally higher in communities with higher levels of poverty and students in foster care, who are pregnant or parenting, who are neglected, and who require special education and/or English language development programs)

O Low Need

O Average Need

High Need

\section{Principal Preparation}

The following questions are related to the principal preparation program(s) that you participated in to obtain your Oregon administrative license(s)

Did your preparation program(s) include training on the following self-awareness skills? If yes, how helpful was the training in developing these skills? If no, mark "N/A".

\begin{tabular}{|c|c|c|c|c|c|c|c|}
\hline & \multicolumn{3}{|c|}{$\begin{array}{l}\text { Did your principal preparation program(s) include } \\
\text { training that helped you develop the following skills? }\end{array}$} & \multicolumn{4}{|c|}{$\begin{array}{l}\text { If yes, how helpful was the training in } \\
\text { developing these skills? If no, mark "N/A" }\end{array}$} \\
\hline & Yes & No & Unsure & N/A & Helpful & Not Helpful & Unsure \\
\hline $\begin{array}{l}\text { Understanding how you react } \\
\text { to emotions, such as stress }\end{array}$ & 0 & 0 & 0 & 0 & 0 & 0 & 0 \\
\hline $\begin{array}{l}\text { Understanding how others } \\
\text { influence your emotional state }\end{array}$ & 0 & 0 & 0 & 0 & 0 & 0 & 0 \\
\hline $\begin{array}{l}\text { Understanding how your } \\
\text { emotions affect others }\end{array}$ & 0 & 0 & 0 & 0 & $\mathbf{O}$ & 0 & 0 \\
\hline
\end{tabular}

Did your preparation program(s) include training on the following self-management skills? If yes, how helpful was the training in developing these skills? If no, mark "N/A".

\begin{tabular}{|c|c|c|c|c|c|c|c|}
\hline & \multicolumn{3}{|c|}{$\begin{array}{c}\text { Did your principal preparation program(s) include } \\
\text { training that helped you develop the following } \\
\text { skills? }\end{array}$} & \multicolumn{4}{|c|}{$\begin{array}{c}\text { If yes, how helpful was the training in } \\
\text { developing these skills? If no, mark } \\
\text { "N/A". }\end{array}$} \\
\hline & Yes & No & Unsure & N/A & Helpful & Not Helpful & Unsure \\
\hline Adapting to change & 0 & 0 & 0 & 0 & 0 & 0 & 0 \\
\hline $\begin{array}{l}\text { Preventing your negative } \\
\text { emotions and moods from } \\
\text { affecting others }\end{array}$ & 0 & 0 & 0 & 0 & 0 & 0 & 0 \\
\hline
\end{tabular}




\begin{tabular}{|c|c|c|c|c|c|c|c|}
\hline & \multicolumn{3}{|c|}{$\begin{array}{c}\text { Did your principal preparation program(s) include } \\
\text { training that helped you develop the following } \\
\text { skills? }\end{array}$} & \multicolumn{4}{|c|}{$\begin{array}{c}\text { If yes, how helpful was the training in } \\
\text { developing these skills? If no, mark } \\
\text { "N/A". }\end{array}$} \\
\hline & Yes & No & Unsure & N/A & Helpful & Not Helpful & Unsure \\
\hline Managing and coping with stress & 0 & 0 & 0 & 0 & 0 & $\mathbf{O}$ & 0 \\
\hline $\begin{array}{l}\text { Managing your emotional } \\
\text { responses to Covid-19 }\end{array}$ & 0 & 0 & 0 & 0 & 0 & 0 & 0 \\
\hline
\end{tabular}

Did your preparation program(s) include training on the following social awareness skills? If yes, how helpful was the training in developing these skills? If no, mark "N/A".

\begin{tabular}{|c|c|c|c|c|c|c|c|}
\hline & \multicolumn{3}{|c|}{$\begin{array}{l}\text { Did your principal preparation program(s) } \\
\text { include training that helped you develop the } \\
\text { following skills? }\end{array}$} & \multicolumn{4}{|c|}{$\begin{array}{c}\text { If yes, how helpful was the training } \\
\text { in developing these skills? If no, } \\
\text { mark "N/A". }\end{array}$} \\
\hline & Yes & No & Unsure & N/A & Helpful & Not Helpful & Unsure \\
\hline $\begin{array}{l}\text { Recognizing the unstated feelings and } \\
\text { emotions of others }\end{array}$ & 0 & 0 & 0 & 0 & 0 & 0 & 0 \\
\hline Recognizing the collective mood in a room & O & 0 & 0 & 0 & 0 & 0 & 0 \\
\hline $\begin{array}{l}\text { Understanding the political forces at work } \\
\text { within groups (social networks, power } \\
\text { relationships, etc...) }\end{array}$ & 0 & 0 & 0 & 0 & 0 & 0 & 0 \\
\hline
\end{tabular}

Did your preparation program(s) include training on the following relationship management skills? If yes, how helpful was the training in developing these skills? If no, mark "N/A".

\begin{tabular}{|c|c|c|c|c|c|c|c|}
\hline & \multicolumn{3}{|c|}{$\begin{array}{l}\text { Did your principal preparation program(s) include } \\
\text { training that helped you develop the following skills? }\end{array}$} & \multicolumn{4}{|c|}{$\begin{array}{l}\text { If yes, how helpful was the training in } \\
\text { developing these skills? If no, mark } \\
\text { "N/A". }\end{array}$} \\
\hline & Yes & No & Unsure & N/A & Helpful & Not Helpful & Unsure \\
\hline $\begin{array}{l}\text { Supporting the emotional needs } \\
\text { of others }\end{array}$ & 0 & 0 & 0 & 0 & 0 & 0 & 0 \\
\hline $\begin{array}{l}\text { Encouraging trust and } \\
\text { collaboration }\end{array}$ & 0 & 0 & 0 & 0 & 0 & 0 & 0 \\
\hline Managing conflict & 0 & 0 & 0 & 0 & 0 & 0 & 0 \\
\hline Managing change & 0 & 0 & 0 & 0 & 0 & 0 & 0 \\
\hline $\begin{array}{l}\text { Managing the effects of Covid- } \\
19 \text { on statt, students, and } \\
\text { families }\end{array}$ & 0 & 0 & 0 & 0 & 0 & 0 & 0 \\
\hline
\end{tabular}

Principal Professional Development

The following questions are related to your experiences with professional development trainings during your time as a licensed principal in Oregon 
On average, how many leadership-focused professional development activities do you have the opportunity to participate in each year? Please include all opportunities, even those you have not been able to participate in.

On average, how many leadership-focused professional development activities do you participate in each year?

Have you attended any professional development trainings that have included the following self-awareness skills?

\begin{tabular}{|c|c|c|c|c|c|c|c|c|c|c|}
\hline & \multicolumn{3}{|c|}{$\begin{array}{l}\text { Have you attended any professional } \\
\text { development trainings that helped you } \\
\text { develop the following skills? }\end{array}$} & \multicolumn{4}{|c|}{$\begin{array}{l}\text { If yes, how helpful was the } \\
\text { training in developing these } \\
\text { skills? If no, mark "N/A". }\end{array}$} & \multicolumn{3}{|c|}{$\begin{array}{c}\text { Do you feel that principals in } \\
\text { Oregon need training on these } \\
\text { skills? }\end{array}$} \\
\hline & Yes & No & Unsure & N/A & Helpful & $\begin{array}{l}\text { Not } \\
\text { Helpful }\end{array}$ & Unsure & Yes & No & Unsure \\
\hline $\begin{array}{l}\text { Understanding } \\
\text { how you react to } \\
\text { emotions, such as } \\
\text { stress }\end{array}$ & 0 & 0 & 0 & 0 & 0 & 0 & 0 & 0 & 0 & 0 \\
\hline $\begin{array}{l}\text { Understanding } \\
\text { how others } \\
\text { influence your } \\
\text { emotional state }\end{array}$ & 0 & 0 & 0 & 0 & 0 & 0 & 0 & 0 & 0 & 0 \\
\hline $\begin{array}{l}\text { Understanding } \\
\text { how your emotions } \\
\text { affect others }\end{array}$ & 0 & 0 & 0 & 0 & 0 & 0 & 0 & 0 & 0 & 0 \\
\hline
\end{tabular}

Have you attended any professional development trainings that have in included the following self-management skills?

\begin{tabular}{|c|c|c|c|c|c|c|c|c|c|c|}
\hline & \multicolumn{3}{|c|}{$\begin{array}{l}\text { Have you attended any professional } \\
\text { development trainings that helped you } \\
\text { develop the following skills? }\end{array}$} & \multicolumn{4}{|c|}{$\begin{array}{l}\text { If yes, how helpful was the } \\
\text { training in developing these } \\
\text { skills? If no, mark "N/A". }\end{array}$} & \multicolumn{3}{|c|}{$\begin{array}{c}\text { Do you feel that } \\
\text { principals in Oregon } \\
\text { need training on these } \\
\text { skills? }\end{array}$} \\
\hline & Yes & No & Unsure & N/A & Helpful & $\begin{array}{l}\text { Not } \\
\text { Helpful }\end{array}$ & Unsure & Yes & No & Unsure \\
\hline Adapting to change & 0 & 0 & 0 & 0 & 0 & 0 & 0 & 0 & 0 & 0 \\
\hline $\begin{array}{l}\text { Preventing your negative } \\
\text { emotions and moods from } \\
\text { affecting others }\end{array}$ & 0 & 0 & 0 & 0 & 0 & 0 & 0 & 0 & 0 & 0 \\
\hline $\begin{array}{l}\text { Managing and coping } \\
\text { with stress }\end{array}$ & 0 & 0 & 0 & 0 & 0 & 0 & 0 & 0 & 0 & 0 \\
\hline $\begin{array}{l}\text { Managing your emotional } \\
\text { responses to Covid-19 }\end{array}$ & 0 & 0 & 0 & 0 & 0 & 0 & 0 & 0 & 0 & 0 \\
\hline
\end{tabular}


Have you attended any professional development trainings that have in included the following social awareness skills?

\begin{tabular}{|c|c|c|c|c|c|c|c|c|c|c|}
\hline & \multicolumn{3}{|c|}{$\begin{array}{l}\text { Have you attended any professional } \\
\text { development trainings that helped } \\
\text { you develop the following skills? }\end{array}$} & \multicolumn{4}{|c|}{$\begin{array}{l}\text { If yes, how helpful was the } \\
\text { training in developing these } \\
\text { skills? If no, mark "N/A". }\end{array}$} & \multicolumn{3}{|c|}{$\begin{array}{l}\text { Do you feel that } \\
\text { principals in } \\
\text { Oregon need } \\
\text { training on these } \\
\text { skills? }\end{array}$} \\
\hline & Yes & No & Unsure & N/A & Helpful & $\begin{array}{l}\text { Not } \\
\text { Helpful }\end{array}$ & Unsure & Yes & No & Unsure \\
\hline $\begin{array}{l}\text { Recognizing the unstated feelings } \\
\text { and emotions of others }\end{array}$ & 0 & 0 & 0 & 0 & 0 & 0 & 0 & 0 & 0 & 0 \\
\hline $\begin{array}{l}\text { Recognizing the collective mood in } \\
\text { a room }\end{array}$ & 0 & 0 & 0 & 0 & 0 & 0 & 0 & 0 & 0 & 0 \\
\hline $\begin{array}{l}\text { Understanding the political forces } \\
\text { at work within groups (social } \\
\text { networks, power relationships, } \\
\text { etc...) }\end{array}$ & 0 & 0 & 0 & 0 & 0 & 0 & 0 & 0 & 0 & 0 \\
\hline
\end{tabular}

Have you attended any professional development trainings that have in included the following relationship management skills?

\begin{tabular}{|c|c|c|c|c|c|c|c|c|c|c|}
\hline & \multicolumn{3}{|c|}{$\begin{array}{l}\text { Have you attended any } \\
\text { professional develapment } \\
\text { trainings that helped you develop } \\
\text { the following skills? }\end{array}$} & \multicolumn{4}{|c|}{$\begin{array}{l}\text { If yes, how helpful was the } \\
\text { traning in developing these } \\
\text { skills? If no, mark "N/A". }\end{array}$} & \multicolumn{3}{|c|}{$\begin{array}{l}\text { Do you feel that principals in } \\
\text { Uregon need training on these } \\
\text { skills? }\end{array}$} \\
\hline & Yes & No & Unsure & $\mathrm{N} / \mathrm{A}$ & Helpful & $\begin{array}{c}\text { Not } \\
\text { Helpful }\end{array}$ & Unsure & Yes & No & Unsure \\
\hline $\begin{array}{l}\text { Supporting the } \\
\text { emotional needs of } \\
\text { others }\end{array}$ & 0 & 0 & 0 & 0 & 0 & 0 & 0 & 0 & 0 & 0 \\
\hline $\begin{array}{l}\text { Encouraging trust } \\
\text { and collaboration }\end{array}$ & 0 & 0 & 0 & 0 & 0 & 0 & 0 & 0 & 0 & 0 \\
\hline $\begin{array}{l}\text { Managing conflict } \\
\text { effectively }\end{array}$ & 0 & 0 & 0 & 0 & 0 & 0 & 0 & 0 & 0 & 0 \\
\hline $\begin{array}{l}\text { Managing change } \\
\text { effectively }\end{array}$ & 0 & 0 & 0 & 0 & 0 & 0 & 0 & 0 & 0 & 0 \\
\hline $\begin{array}{l}\text { Managing the effects } \\
\text { of Covid- } 19 \text { on staff, } \\
\text { students, and } \\
\text { families }\end{array}$ & 0 & 0 & 0 & 0 & 0 & 0 & 0 & 0 & 0 & 0 \\
\hline
\end{tabular}

Leads for Phase 2

Are you willing to participate in an interview at a convenient time for you to expand on the topics included in this survey?

O Yes 
O No

O Maybe

Please list your first and last name

Please list the name of your school

How would you like the researcher to contact you regarding an interview?

$\square$ Home Phone

$\square$ Work Phone

$\square$ Cell Phone

$\square$ Personal Email

$\square$ Work Email 


\section{Appendix E: Phase 2 Informed Consent}

\section{胥 Portland State}

Phase 2 Consent to Participate

You are invited to participate in the following research study:

Project Title: Emotional Intelligence and Resonant Leadership: Investigating School Principals' Preparation and Professional Development in Response to Covid-19 and Other Challenges Population: K-12 Principals in Oregon, Interviews

Researcher: Ashlie Miller, Educational Leadership and Policy, Portland State University Researcher Contact: asmiller@pdx.edu /541-580-2593

This consent form describes the main facts related to the study. Please reach out to me if you need clarification.

\section{Consent Statement:}

I have had the chance to read and think about the information in the consent form. I have asked any questions I have, and I can make a decision about my participation. I understand that I can ask additional questions anytime while I take part in the research.

I agree to take part in this study

O I do not agree to take part in this study

Identification

Please list your first and last name

Please list the name of your school

Identification Code

List the following in order to link your information to the code you created in the Phase 1 survey and to keep your information secure and confidential: 
- The first three letters of your birth month (ex: JUL)

- Number of cousins (ex: 0 )

- Number of children (ex: 1)

- First initial of your mother/female guardian's first name (ex A)

- First initial of your father/male guardian's first name (ex: T)

- First initial of your middle name (if none, write $X$ - ex: J)

(Example: JUL01ATJ)

Powered by Qualtrics 


\section{Appendix F: Interview Protocol \& Questions}

\begin{tabular}{|c|c|c|}
\hline \multicolumn{3}{|c|}{$\begin{array}{l}\text { Project: Emotional Intelligence and Resonant Leadership: Investigating School Principals' Preparation } \\
\text { and Professional Development in Response to Covid-19 and Other Challenges }\end{array}$} \\
\hline \multicolumn{2}{|c|}{ Date \& Time: } & Place: Online via Zoom \\
\hline \multicolumn{2}{|c|}{ Interviewer: Ashlie Miller } & Interviewee: \\
\hline \multicolumn{3}{|c|}{$\begin{array}{l}\text { Introduction: I want to thank you for being willing to share your insights with me. The purpose of this } \\
\text { interview is to understand your perceptions regarding how the preparation and professional development } \\
\text { opportunities that you have participated in as a principal have prepared you to manage stress and the } \\
\text { emotions caused by uncertainties and unrest related to Covid- } 19 \text { and other challenges. }\end{array}$} \\
\hline \multicolumn{3}{|c|}{ terview Questions } \\
\hline \multicolumn{3}{|c|}{$\begin{array}{l}\text { Part } 1 \text { Instructions: The first three questions are related the principal preparation program(s) that you } \\
\text { participated in to obtain your Oregon administrative license(s). }\end{array}$} \\
\hline 1. & \multicolumn{2}{|c|}{$\begin{array}{l}\text { How did your principal preparation program(s) prepare you to manage widespread political and } \\
\text { social changes, such as those caused by the Covid- } 19 \text { pandemic? }\end{array}$} \\
\hline 2. & \multicolumn{2}{|c|}{$\begin{array}{l}\text { How did your principal preparation program(s) prepare you to manage stress and/or build resilience } \\
\text { to emotional exhaustion and burnout? }\end{array}$} \\
\hline 3. & \multicolumn{2}{|c|}{$\begin{array}{l}\text { How did your principal preparation program(s) prepare you to manage the emotional needs of your } \\
\text { staff, students, and communities in response to stressful situations? }\end{array}$} \\
\hline \multicolumn{3}{|c|}{$\begin{array}{l}\text { Part } 2 \text { Instructions: The next five questions are related to your experiences with professional } \\
\text { development training during your time as a licensed principal in Oregon. }\end{array}$} \\
\hline 5. & \multicolumn{2}{|c|}{$\begin{array}{l}\text { Did you attend any professional development training prior to the school closures that helped you } \\
\text { manage the changes associated with Covid-19? If so, how did the training help you? }\end{array}$} \\
\hline 6. & \multicolumn{2}{|c|}{$\begin{array}{l}\text { Did you attend any professional development training prior to the school closures that helped you } \\
\text { manage stress and/or build resilience to emotional exhaustion and burnout? If so, how did the } \\
\text { training help you? }\end{array}$} \\
\hline 7. & \multicolumn{2}{|c|}{$\begin{array}{l}\text { Did you attend any professional development training prior to the school closures that helped you } \\
\text { manage the emotional needs of your staff, students, and communities in response to stressful } \\
\text { situations? If so, how did the training help you? }\end{array}$} \\
\hline 8. & \multicolumn{2}{|c|}{$\begin{array}{l}\text { Since the Covid-19 pandemic began, have you attended any professional development training } \\
\text { that focused on stress management and/or managing emotions in response to the school } \\
\text { closures? If so, how did the training help you? }\end{array}$} \\
\hline g. & \multicolumn{2}{|c|}{$\begin{array}{l}\text { What type of training do you think could have helped you prepare better for managing the emotions } \\
\text { and stress caused by widespread political unrest and social changes, such as those caused by the } \\
\text { Covid-19 pandemic? }\end{array}$} \\
\hline \multicolumn{3}{|c|}{$\begin{array}{l}\text { Conclusion: That concludes my questions. I want to thank you for participating in this interview. When I } \\
\text { finish transcribing the interview, I will request you to review the transcript for accuracy and let me know if } \\
\text { anything needs edited. After you have accepted the transcript and any revisions that need to be made, } \\
\text { the audio recording will be deleted, and your responses will be kept confidential. }\end{array}$} \\
\hline
\end{tabular}




\section{Appendix G: Preliminary Statistical Analysis Results}

\section{Table G1}

Collinearity Statistics

\begin{tabular}{lcc}
\hline Independent Variables & Tolerance & VIF \\
\hline Age & .40 & 2.49 \\
Years of experience in education & .52 & 1.92 \\
Years of experience as a principal & .59 & 1.69 \\
Gender = Female & .75 & 1.34 \\
Race/Ethnicity = Black or African American & .70 & 1.44 \\
Race/Ethnicity = Hispanic or Latinx & .68 & 1.47 \\
Race/Ethnicity = More than one race/ethnicity & .84 & 1.19 \\
Level = Middle/Jr High School & .73 & 1.37 \\
Level = High School & .73 & 1.37 \\
Location = Rural & .63 & 1.60 \\
Location = Suburban & .43 & 2.32 \\
Need = Low & .59 & 1.68 \\
Need = High & .60 & 1.67 \\
\hline
\end{tabular}

Note. All tolerance values were above 0.1 , indicating that there were no problems with collinearity in the dataset. VIF $=$ Variance Inflation Factor. 


\section{Table G2}

\section{Full Likelihood Ratio Tests}

\begin{tabular}{llccc}
\hline \multicolumn{1}{c}{ Cluster } & \multicolumn{1}{c}{ Dependent Variables (EI Skills) } & Chi-Square & $d f$ & $p$ \\
\hline Self-Awareness & Understanding how one reacts to emotions & 0.00 & 16 & 1.00 \\
& Understanding how others influence & 11.67 & 16 & .77 \\
& emotions & & & \\
& Understanding how emotions affect others & 9.94 & 16 & .87 \\
\hline Self-Management & Adapting to change & 0.00 & 16 & 1.00 \\
& Preventing emotions from affecting others & 6.60 & 16 & .98 \\
& Managing and coping with stress & 0.00 & 16 & 1.00 \\
\hline Social Awareness & Recognizing the unstated emotions of & 25.40 & 16 & .06 \\
& others & & & \\
& Recognizing the collective mood in a & 26.75 & 16 & .04 \\
& room & & & .68 \\
\hline Relationship & Understanding the political forces at work & 12.92 & 16 & .59 \\
Management & Supporting the emotional needs of others & 14.11 & 16 & .92 \\
& Encouraging trust and collaboration & 8.81 & 16 & .64 \\
& Managing conflict effectively & 13.47 & 16 & 1.00 \\
\hline & Managing change effectively & 0.00 & 16 & \\
\hline
\end{tabular}

Note. The assumption of proportional odds was met for all dependent variables, as assessed by 13 full likelihood ratio tests comparing the fit of the proportional odds model to a model with varying location parameters. $\mathrm{EI}=$ emotional intelligence. $d f=$ degrees of freedom. 


\section{Table G3}

Deviance Goodness-of-Fit Tests

\begin{tabular}{llccc}
\hline \multicolumn{1}{c}{ Cluster } & \multicolumn{1}{c}{ Dependent Variables (EI Skills) } & Chi-Square & $d f$ & $p$ \\
\hline Self-Awareness & Understanding how one reacts to emotions & 0.01 & 120 & 1.00 \\
& $\begin{array}{l}\text { Understanding how others influence } \\
\text { emotions }\end{array}$ & 43.51 & 120 & 1.00 \\
& Understanding how emotions affect others & 23.66 & 120 & 1.00 \\
\hline Self-Management & Adapting to change & 0.00 & 120 & 1.00 \\
& Preventing emotions from affecting others & 43.40 & 120 & 1.00 \\
& Managing and coping with stress & 0.02 & 120 & 1.00 \\
\hline Social Awareness & Recognizing the unstated emotions of & 68.61 & 120 & 1.00 \\
& others & & & \\
& Recognizing the collective mood in a & 53.57 & 120 & 1.00 \\
& room & & & \\
& Understanding the political forces at work & 69.84 & 120 & 1.00 \\
\hline Relationship & Supporting the emotional needs of others & 43.55 & 120 & 1.00 \\
Management & Encouraging trust and collaboration & 36.63 & 120 & 1.00 \\
& Managing conflict effectively & 25.33 & 120 & 1.00 \\
& Managing change effectively & 0.00 & 120 & 1.00 \\
\hline
\end{tabular}

Note. The deviance goodness-of-fit tests indicated that the model was a good fit for all variables, but most cells were sparse, with zero frequencies in $66.7 \%$ of cells. $\mathrm{EI}=$ emotional intelligence. $d f=$ degrees of freedom. 


\section{Table G4}

\section{Model Fitting Information}

\begin{tabular}{llccc}
\hline \multicolumn{1}{c}{ Cluster } & \multicolumn{1}{c}{ Dependent Variables (EI Skills) } & Chi-Square & $d f$ & $p$ \\
\hline Self-Awareness & Understanding how one reacts to emotions & 40.88 & 16 & .001 \\
& $\begin{array}{l}\text { Understanding how others influence } \\
\text { emotions }\end{array}$ & 16.20 & 16 & .44 \\
& Understanding how emotions affect others & 27.38 & 16 & .04 \\
\hline Self-Management & Adapting to change & 35.05 & 16 & .004 \\
& Preventing emotions from affecting others & 19.57 & 16 & .24 \\
& Managing and coping with stress & 40.88 & 16 & .001 \\
\hline Social Awareness & Recognizing the unstated emotions of & 29.04 & 16 & .02 \\
& others & & & \\
& Recognizing the collective mood in a & 27.58 & 16 & .04 \\
& room & & & .23 \\
& Understanding the political forces at work & 19.81 & 16 & .53 \\
\hline Relationship & Supporting the emotional needs of others & 14.96 & 16 & .38 \\
Management & Encouraging trust and collaboration & 17.04 & 16 & .82 \\
& Managing conflict effectively & 10.76 & 16 & .004 \\
\hline & Managing change effectively & 35.05 & 16 & \\
\hline
\end{tabular}

Note. The final model statistically significantly predicted the dependent variables over and above the intercept-only model for seven of the dependent variables (at a significance level of alpha $=.05$ ). It did not statistically significantly predict the dependent variables for six of the dependent variables. EI $=$ emotional intelligence. $d f=$ degrees of freedom. 


\section{Appendix H: Ordinal Logistic Regression Results}

\section{Table H1}

\section{Ordinal Logistic Regression Results: Self-Awareness Cluster}

\begin{tabular}{llccc}
\hline \multicolumn{1}{c}{ Dependent Variable } & \multicolumn{1}{c}{ Independent Variable } & $\begin{array}{c}\text { Wald Chi- } \\
\text { Square }\end{array}$ & $d f$ & $p$ \\
\hline Understanding How & Participant Gender & 0.00 & 1 & .10 \\
One Reacts to & Participant Race/Ethnicity & 0.00 & 3 & 1.00 \\
Emotions, Such as & Participant Age & 0.00 & 1 & .10 \\
Stress & Years of Experience in Education & 0.00 & 1 & .10 \\
& Years of Experience as a Principal & 0.00 & 1 & .10 \\
& School Level & 0.00 & 5 & 1.00 \\
& School Location & 0.00 & 2 & 1.00 \\
& Student Need at the School & 0.00 & 2 & 1.00 \\
\hline Understanding How & Participant Gender & 3.13 & 1 & .08 \\
Emers Influence One's & Participant Race/Ethnicity & 1.76 & 3 & .63 \\
& Participant Age & 0.00 & 1 & .97 \\
& Years of Experience in Education & 1.60 & 1 & .21 \\
& Years of Experience as a Principal & 0.67 & 1 & .41 \\
& School Level & 5.07 & 5 & .41 \\
& School Location & 1.27 & 2 & .53 \\
& Student Need at the School & 2.53 & 2 & .28 \\
\hline Understanding How & Participant Gender & 0.00 & 1 & .10 \\
Emotions Affect Others & Participant Race/Ethnicity & 0.60 & 3 & .90 \\
& Participant Age & 0.02 & 1 & .90 \\
& Years of Experience in Education & 1.49 & 1 & .22 \\
& Years of Experience as a Principal & 1.27 & 1 & .26 \\
& School Level & 4.32 & 5 & .50 \\
& School Location & 2.85 & 2 & .24 \\
& Student Need at the School & 1.67 & 2 & .43 \\
\hline
\end{tabular}

Note. There were no statistically significant differences in the principals' perceptions of need for emotional intelligence training for the self-awareness cluster of skills based on gender, race/ethnicity, age, years of experience in education, years of experience as a principal, school level, school location, or student need at the school. However, the odds of males expressing the need for self-awareness training in understanding how others influence one's emotions was 0.13 (95\% CI [0.01, 1.25]) times that of females, nearing statistical significance, $\chi^{2}(1)=3.13, p=.08 . d f=$ degrees of freedom. 


\section{Table H2}

Ordinal Logistic Regression Results: Self-Management Cluster

\begin{tabular}{|c|c|c|c|c|}
\hline Dependent Variable & Independent Variable & $\begin{array}{l}\text { Wald Chi- } \\
\text { Square }\end{array}$ & $d f$ & $p$ \\
\hline \multirow[t]{8}{*}{ Adapting to Change } & Participant Gender & 0.00 & 1 & .10 \\
\hline & Participant Race/Ethnicity & 0.00 & 3 & 1.00 \\
\hline & Participant Age & 0.00 & 1 & .10 \\
\hline & $\begin{array}{l}\text { Years of Experience in } \\
\text { Education }\end{array}$ & 0.00 & 1 & 1.00 \\
\hline & $\begin{array}{l}\text { Years of Experience as a } \\
\text { Principal }\end{array}$ & 0.00 & 1 & .10 \\
\hline & School Level & 0.00 & 5 & 1.00 \\
\hline & School Location & 0.00 & 2 & 1.00 \\
\hline & Student Need at the School & 0.00 & 2 & 1.00 \\
\hline \multirow{8}{*}{$\begin{array}{l}\text { Preventing Emotions } \\
\text { from Affecting Others }\end{array}$} & Participant Gender & 1.36 & 1 & .24 \\
\hline & Participant Race/Ethnicity & 0.43 & 3 & .93 \\
\hline & Participant Age & 2.00 & 1 & .16 \\
\hline & $\begin{array}{l}\text { Years of Experience in } \\
\text { Education }\end{array}$ & 2.43 & 1 & .12 \\
\hline & $\begin{array}{l}\text { Years of Experience as a } \\
\text { Principal }\end{array}$ & 1.37 & 1 & .24 \\
\hline & School Level & 4.70 & 5 & .45 \\
\hline & School Location & 1.27 & 2 & .53 \\
\hline & Student Need at the School & 1.39 & 2 & .50 \\
\hline \multirow{8}{*}{$\begin{array}{l}\text { Managing and Coping } \\
\text { with Stress }\end{array}$} & Participant Gender & 0.00 & 1 & .10 \\
\hline & Participant Race/Ethnicity & 0.00 & 3 & 1.00 \\
\hline & Participant Age & 0.00 & 1 & .98 \\
\hline & $\begin{array}{l}\text { Years of Experience in } \\
\text { Education }\end{array}$ & 0.00 & 1 & .98 \\
\hline & $\begin{array}{l}\text { Years of Experience as a } \\
\text { Principal }\end{array}$ & 0.00 & 1 & .98 \\
\hline & School Level & 0.00 & 5 & 1.00 \\
\hline & School Location & 0.00 & 2 & 1.00 \\
\hline & Student Need at the School & 0.00 & 2 & 1.00 \\
\hline
\end{tabular}

Note. There were no statistically significant differences in the principals' perceptions of need for emotional intelligence training in the self-management cluster of skills based on gender, race/ethnicity, age, years of experience in education, years of experience as a principal, school level, school location, or student need at the school. $d f=$ degrees of freedom. 
Table $\mathbf{H 3}$

Ordinal Logistic Regression Results: Social Awareness Cluster

\begin{tabular}{|c|c|c|c|c|}
\hline Dependent Variables & Independent Variables & $\begin{array}{l}\text { Wald Chi- } \\
\text { Square }\end{array}$ & $d f$ & $p$ \\
\hline \multirow{8}{*}{$\begin{array}{l}\text { Recognizing Unstated } \\
\text { Feelings of Others }\end{array}$} & Participant Gender & 6.60 & 1 & .01 \\
\hline & Participant Race/Ethnicity & 0.01 & 3 & 1.00 \\
\hline & Participant Age & 0.00 & 1 & .10 \\
\hline & $\begin{array}{l}\text { Years of Experience in } \\
\text { Education }\end{array}$ & 1.23 & 1 & .27 \\
\hline & $\begin{array}{l}\text { Years of Experience as a } \\
\text { Principal }\end{array}$ & 2.76 & 1 & .10 \\
\hline & School Level & 3.38 & 2 & .18 \\
\hline & School Location & 0.56 & 2 & .76 \\
\hline & Student Need at the School & 1.70 & 2 & .43 \\
\hline \multirow{8}{*}{$\begin{array}{l}\text { Recognizing the } \\
\text { Collective Mood in a } \\
\text { Room }\end{array}$} & Participant Gender & 3.53 & 1 & .06 \\
\hline & Participant Race/Ethnicity & 0.00 & 3 & 1.00 \\
\hline & Participant Age & 0.74 & 1 & .39 \\
\hline & $\begin{array}{l}\text { Years of Experience in } \\
\text { Education }\end{array}$ & 1.87 & 1 & .17 \\
\hline & $\begin{array}{l}\text { Years of Experience as a } \\
\text { Principal }\end{array}$ & 0.01 & 1 & .94 \\
\hline & School Level & 8.67 & 5 & .12 \\
\hline & School Location & 0.19 & 2 & .91 \\
\hline & Student Need at the School & 0.77 & 2 & .68 \\
\hline \multirow{8}{*}{$\begin{array}{l}\text { Understanding } \\
\text { Political Forces } \\
\text { Within Groups }\end{array}$} & Participant Gender & 2.92 & 1 & .09 \\
\hline & Participant Race/Ethnicity & 0.00 & 3 & 1.00 \\
\hline & Participant Age & 0.01 & 1 & .93 \\
\hline & $\begin{array}{l}\text { Years of Experience in } \\
\text { Education }\end{array}$ & 0.25 & 1 & .62 \\
\hline & $\begin{array}{l}\text { Years of Experience as a } \\
\text { Principal }\end{array}$ & 0.04 & 1 & .85 \\
\hline & School Level & 5.08 & 5 & .41 \\
\hline & School Location & 0.02 & 2 & .99 \\
\hline & Student Need at the School & 0.68 & 2 & .71 \\
\hline
\end{tabular}

Note. There were no statistically significant differences in the principals' perceptions of need for emotional intelligence training in the social awareness cluster of skills based on race/ethnicity, age, years of experience in education, years of experience as a principal, school level, school location, or student need at the school. However, there were statistically significant differences found based on gender. The odds of males expressing the need for social awareness training in recognizing unstated feelings was $0.11(95 \% \mathrm{CI}$ 
$[0.02,0.59])$ times that of females, which is a statistically significant result, $\chi^{2}(1)=6.60, p=.01$. The odds of males expressing the need for social awareness training in recognizing the collective mood in a room was $0.14(95 \% \mathrm{CI}[0.02,1.09])$ times that of females, nearing statistical significance $\chi^{2}(1)=3.53, p=.06$, and the odds of males expressing the need for social awareness training in understanding political forces within groups was $0.25(95 \% \mathrm{CI}[0.05,1.23])$ times that of females, nearing statistical significance, $\chi^{2}(1)=$ 2.92, $p=.09 . d f=$ degrees of freedom. 


\section{Table H4}

Ordinal Logistic Regression Results: Relationship Management Cluster

\begin{tabular}{|c|c|c|c|c|}
\hline Dependent Variables & Independent Variables & $\begin{array}{l}\text { Wald Chi- } \\
\text { Square }\end{array}$ & $d f$ & $p$ \\
\hline \multirow{8}{*}{$\begin{array}{l}\text { Supporting the } \\
\text { Emotional Needs of } \\
\text { Others }\end{array}$} & Participant Gender & 1.28 & 1 & .26 \\
\hline & Participant Race/Ethnicity & 0.00 & 3 & 1.00 \\
\hline & Participant Age & 1.45 & 1 & .23 \\
\hline & $\begin{array}{l}\text { Years of Experience in } \\
\text { Education }\end{array}$ & 0.01 & 1 & .92 \\
\hline & $\begin{array}{l}\text { Years of Experience as a } \\
\text { Principal }\end{array}$ & 0.40 & 1 & .53 \\
\hline & School Level & 5.02 & 5 & .41 \\
\hline & School Location & 0.44 & 2 & .80 \\
\hline & Student Need at the School & 1.67 & 2 & .43 \\
\hline \multirow{8}{*}{$\begin{array}{l}\text { Encouraging Trust } \\
\text { and Collaboration }\end{array}$} & Participant Gender & 3.01 & 1 & .08 \\
\hline & Participant Race/Ethnicity & 0.00 & 3 & 1.00 \\
\hline & Participant Age & 0.06 & 1 & .81 \\
\hline & $\begin{array}{l}\text { Years of Experience in } \\
\text { Education }\end{array}$ & 0.08 & 1 & .78 \\
\hline & $\begin{array}{l}\text { Years of Experience as a } \\
\text { Principal }\end{array}$ & 0.10 & 1 & .75 \\
\hline & School Level & 4.39 & 5 & .49 \\
\hline & School Location & 0.48 & 2 & .80 \\
\hline & Student Need at the School & 0.45 & 2 & .80 \\
\hline \multirow{8}{*}{$\begin{array}{l}\text { Managing Conflict } \\
\text { Effectively }\end{array}$} & Participant Gender & 0.02 & 1 & .88 \\
\hline & Participant Race/Ethnicity & 0.00 & 3 & 1.0 \\
\hline & Participant Age & 0.21 & 1 & .65 \\
\hline & $\begin{array}{l}\text { Years of Experience in } \\
\text { Education }\end{array}$ & 0.04 & 1 & .85 \\
\hline & $\begin{array}{l}\text { Years of Experience as a } \\
\text { Principal }\end{array}$ & 1.29 & 1 & .26 \\
\hline & School Level & 0.83 & 5 & .98 \\
\hline & School Location & 0.39 & 2 & .82 \\
\hline & Student Need at the School & 1.18 & 2 & .55 \\
\hline \multirow{7}{*}{$\begin{array}{l}\text { Managing Change } \\
\text { Effectively }\end{array}$} & Participant Gender & 0.00 & 1 & .99 \\
\hline & Participant Race/Ethnicity & 0.00 & 3 & 1.00 \\
\hline & Participant Age & 0.00 & 1 & .99 \\
\hline & $\begin{array}{l}\text { Years of Experience in } \\
\text { Education }\end{array}$ & 0.00 & 1 & .10 \\
\hline & $\begin{array}{l}\text { Years of Experience as a } \\
\text { Principal }\end{array}$ & 0.00 & 1 & .10 \\
\hline & School Level & 0.00 & 5 & 1.00 \\
\hline & School Location & 0.00 & 2 & 1.00 \\
\hline
\end{tabular}


EMOTIONAL INTELLIGENCE AND K12 PRINCIPALS

\begin{tabular}{ccccc}
\hline Dependent Variables & Independent Variables & $\begin{array}{c}\text { Wald Chi- } \\
\text { Square }\end{array}$ & $d f$ & $p$ \\
\hline & Student Need at the School & 0.00 & 2 & 1.00 \\
\hline
\end{tabular}

Note. There were no statistically significant differences in the principals' perceptions of need for emotional intelligence training in the relationship management cluster of skills based on gender, race/ethnicity, age, years of experience in education, years of experience as a principal, school level, school location, or student need at the school. However, the odds of males expressing the need for relationship management training in encouraging trust and collaboration was .06 (95\% CI $[0.00,1.44])$ times that of females, nearing statistical significance, $\chi^{2}(1)=3.01, p=.08 . d f=$ degrees of freedom. 